Eric Sabourin - Stéphane Guéneau Julianna Colonna - Luiz Raimundo Tadeu da Silva Organizadores

\title{
Construção de Políticas \\ Estaduais de Agroecologia e Produção Orgânica no Brasil: avanços, obstáculos e efeitos das dinâmicas subnacionalis
}
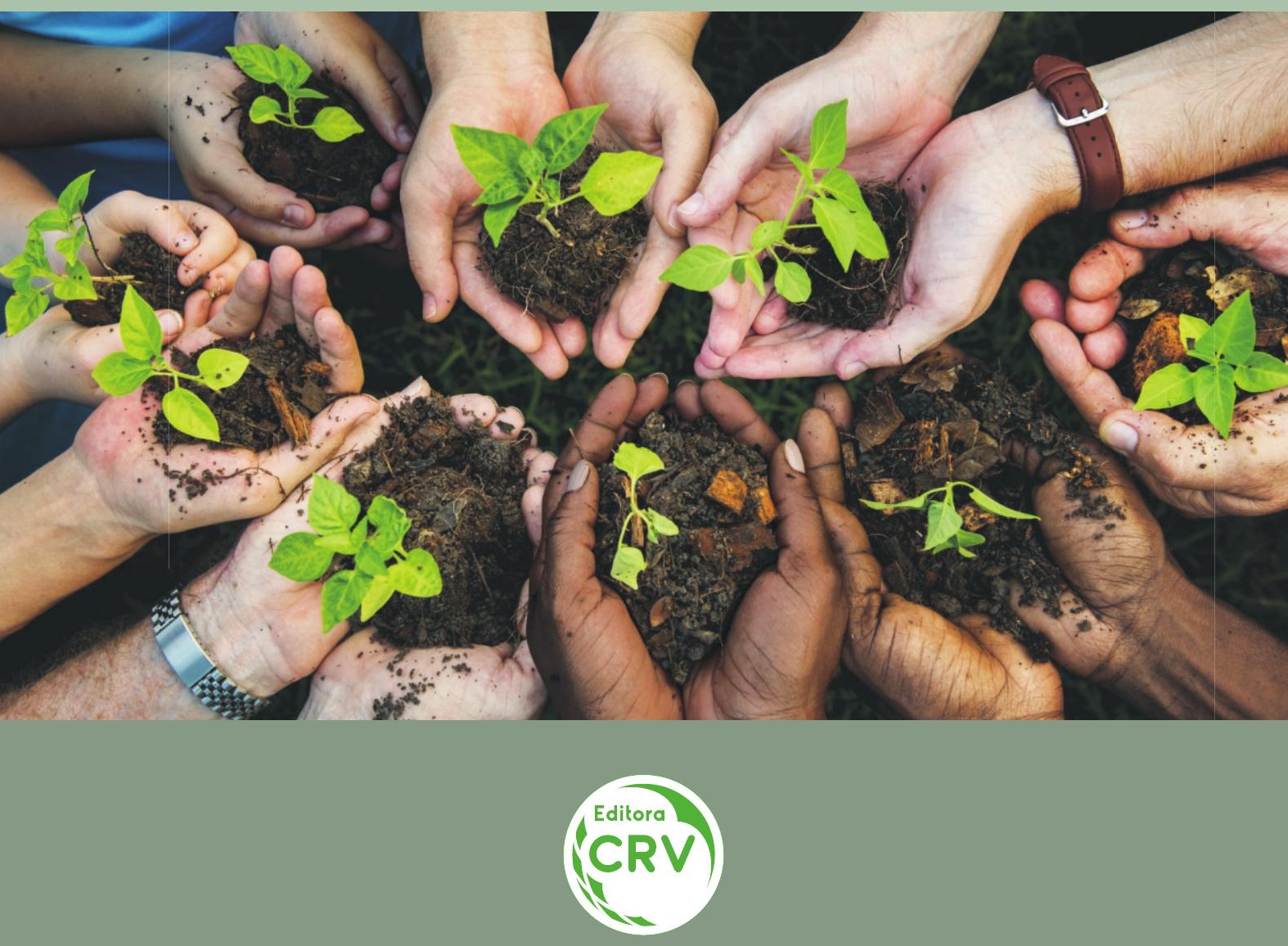


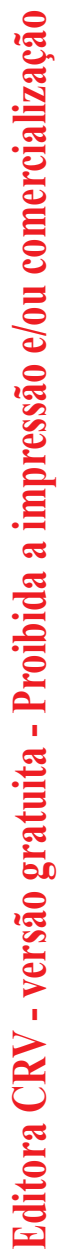




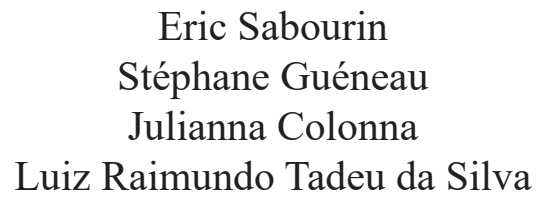

(Organizadores)

\section{CONSTRUÇÃO DE POLÍTICAS ESTADUAIS DE AGROECOLOGIA E PRODUÇÃO ORGÂNICA NO BRASIL: avanços, obstáculos e efeitos das dinâmicas subnacionais}


Copyright (C) da Editora CRV Ltda.

Editor-chefe: Railson Moura

Diagramação e Capa: Editora CRV

Revisão: Os Autores

DADOS INTERNACIONAIS DE CATALOGAÇÃO NA PUBLICAÇÃO (CIP)

CATALOGAÇÃO NA FONTE

S117

Sabourin, Eric.

Construção de Políticas Estaduais de Agroecologia e Produção Orgânica no Brasil: avanços, obstáculos e efeitos das dinâmicas subnacionais / Eric Sabourin, Stéphane Guéneau, Julianna Colonna, Luiz Raimundo Tadeu da Silva (organizadores) - Curitiba : CRV, 2019.

$272 \mathrm{p}$.

Bibliografia

ISBN 978-85-444-3601-1

DOI $10.24824 / 978854443601.1$

1. Agroecologia. 2. Análise de políticas públicas. 3. Agroecologia e produção orgânica. 4. Políticas dos Estados Federados do Brasil. I. Guéneau, Stéphane. org. II. Colonna, Julianna. org. III. Silva, Luiz Raimundo Tadeu da. IV. Título. V. Série.

CDD 631.584

Índice para catálogo sistemático

1. Agroecologia 631.584

ESTA OBRA TAMBÉM ENCONTRA-SE DISPONÍVEL EM FORMATO DIGITAL. CONHEÇA E BAIXE NOSSO APLICATIVO!
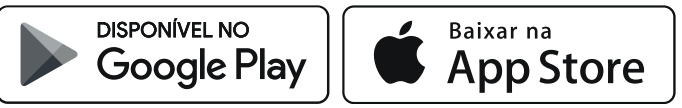

2019

Foi feito o depósito legal conf. Lei 10.994 de 14/12/2004

Proibida a reprodução parcial ou total desta obra sem autorização da Editora CRV

Todos os direitos desta edição reservados pela: Editora CRV

Tel.: (41) 3039-6418 - E-mail: sac@editoracrv.com.br

Conheça os nossos lançamentos: www.editoracrv.com.br 


\section{Conselho Editorial: Comitê Científico:}

Aldira Guimarães Duarte Domínguez (UNB)

Andréia da Silva Quintanilha Sousa (UNIR/UFRN)

Antônio Pereira Gaio Júnior (UFRRJ)

Carlos Alberto Vilar Estêvão (UMINHO - PT)

Carlos Federico Dominguez Avila (Unieuro)

Carmen Tereza Velanga (UNIR)

Celso Conti (UFSCar)

Cesar Gerónimo Tello (Univer. Nacional

Três de Febrero - Argentina)

Eduardo Fernandes Barbosa (UFMG)

Elione Maria Nogueira Diogenes (UFAL)

Élsio José Corá (UFFS)

Elizeu Clementino de Souza (UNEB)

Fernando Antônio Gonçalves Alcoforado (IPB)

Francisco Carlos Duarte (PUC-PR)

Gloria Fariñas León (Universidade de La Havana - Cuba)

Guillermo Arias Beatón (Universidade de La Havana - Cuba)

Jailson Alves dos Santos (UFRJ)

João Adalberto Campato Junior (UNESP) Josania Portela (UFPI)

Leonel Severo Rocha (UNISINOS)

Lídia de Oliveira Xavier (UNIEURO)

Lourdes Helena da Silva (UFV)

Marcelo Paixão (UFRJ e UTexas - US)

Maria de Lourdes Pinto de Almeida (UNOESC)

Maria Lília Imbiriba Sousa Colares (UFOPA)

Maria Cristina dos Santos Bezerra (UFSCar)

Paulo Romualdo Hernandes (UNIFAL-MG)

Renato Francisco dos Santos Paula (UFG)

Rodrigo Pratte-Santos (UFES)

Sérgio Nunes de Jesus (IFR0)

Simone Rodrigues Pinto (UNB)

Solange Helena Ximenes-Rocha (UFOPA)

Sydione Santos (UEPG)

Tadeu Oliver Gonçalves (UFPA)

Tania Suely Azevedo Brasileiro (UFOPA)
Alexsandro Eleotério Pereira de Souza (UEL)

Luciene Alcinda de Medeiros (PUC-RJ)

Maria Regina de Avila Moreira (UFRN)

Patrícia Krieger Grossi (PUC-RS)

Regina Sueli de Sousa (UFG)

Solange Conceição Albuquerque

de Cristo (UNIFESSPA)

Thaísa Teixeira Closs (PUC-RS)

Vinícius Ferreira Baptista (UFRRJ)

Este livro foi avaliado e aprovado por pareceristas ad hoc. 


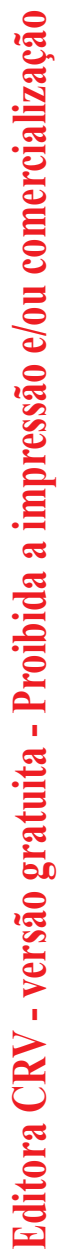




\section{SUMÁRIO}

PREFÁCIO

Mireya E. Valencia Perafán

PRÓLOGO

Romier da Paixão Sousa

CAPÍTULO 1

MARCO TEÓRICO E METODOLÓGICO:

a ação pública para a agroecologia

Eric Sabourin

Stéphane Guéneau

Julianna Colonna

Luiz Raimundo Tadeu da Silva

\section{REGIÃO SUL}

CAPÍTULO 2

A EVOLUÇÃO DA POLÍTICA DE AGROECOLOGIA

NO PARANÁ (2008-2019): avanços e recuos de uma trajetória pioneira ......29

Claire Lamine

Moacir Darolt

Margit Hauer

Alfio Brandenburg

CAPÍTULO 3

CONSTRUÇÃO, INSTITUCIONALIZAÇÃO E IMPLEMENTAÇÃO

DA POLÍTICA ESTADUAL DE AGROECOLOGIA E PRODUÇÃO

ORGÂNICA NO RIO GRANDE DO SUL

Paulo Niederle

José Cleber Dias de Souza

Sabrina Milano Vaz

Gervásio Paulus

Alberto Bracagiolli Neto

\section{REGIÃO SUDESTE}

CAPÍTULO 4

A CONSTRUÇÃO DA POLÍTICA ESTADUAL DE AGROECOLOGIA

E PRODUÇÃO ORGÂNICA EM MINAS GERAIS: interações

Estado-sociedade na institucionalização da agroecologia

Claudia Job Schmitt

Yamira Rodrigues de Souza Barbosa 
CAPÍTULO 5

UMA LEITURA DA TRAJETÓRIA HISTÓRICA DE CONSTRUÇÃO

DA POLÍTICA ESTADUAL DE AGROECOLOGIA E PRODUÇÃO

ORGÂNICA (PEAPO) NO ESTADO DO RIO DE JANEIRO

Guilherme de Freitas Ewald Strauch

Juliano Luís Palm

CAPÍTULO 6

PROCESSO DE CONSTRUÇÃO DA POLÍTICA ESTADUAL DE

AGROECOLOGIA E PRODUÇÃO ORGÂNICA EM SÃO PAULO

Eduardo de Lima Caldas

Julianna Colonna

\section{REGIÃO NORTE}

CAPÍTULO 7

DISSONÂNCIAS NO ESTADO DO PARÁ ENTRE A INEXISTÊNCIA

DA PEAPO E A TRAJETÓRIA RICA DA AGROECOLOGIA

William Santos de Assis

Marc Piraux

Hueliton Pereira Azevedo

\section{REGIÃO NORDESTE}

CAPÍTULO 8

POLÍTICA DE AGROECOLOGIA NA BAHIA:

o diálogo na construção da ação pública

Mario Lucio de Avila

Carlos Eduardo de Souza Leite

CAPÍTULO 9

QUANDO O MOVIMENTO TECE O ESTADO: as ações públicas

em Sergipe na construção de uma agricultura do "plantar, colher

e comer sem agredir a natureza"

Flaviane de Carvalho Canavesi

Edson Diogo Tavares

Mario Lucio de Avila

CAPÍTULO 10

O PROCESSO DE CONSTRUÇÃO DA POLÍTICA DE AGROECOLOGIA E PRODUÇÃO ORGÂNICA DO ESTADO

DO MARANHÃO - PEAPOMA

Stéphane Guéneau

Evaristo José de Lima Neto

Camila Lago Braga 


\section{REGIÃO CENTRO-OESTE}

CAPÍTULO 11

A REDE DE AÇÃO PÚBLICA EM TORNO DA AGROECOLOGIA

E PRODUÇÃO ORGÂNICA NO DISTRITO FEDERAL

Eric Sabourin

Luiz Raimundo Tadeu da Silva

Mario Lucio de Avila

\section{ANÁLISE TRANSVERSAL DOS ESTUDOS DE CASO}

CAPÍTULO 12

RUMOS, ENSINAMENTOS E PERSPECTIVAS PARA

AS POLÍTICAS ESTADUAIS DE AGROECOLOGIA

E PRODUÇÃO ORGÂNICA

Stéphane Guéneau

Eric Sabourin

Julianna Colonna

Luiz Raimundo Tadeu da Silva

Paulo Niederle

Mario Lucio de Avila

Marc Piraux

SOBRE OS AUTORES 


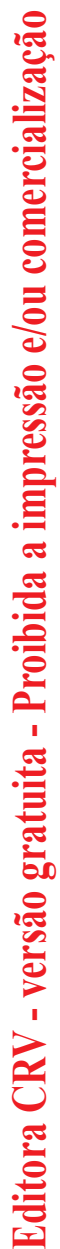




\section{PREFÁCIO}

Mireya E. Valencia Perafán ${ }^{1}$

Este livro é o resultado de uma pesquisa colaborativa entre um número significativo de pessoas que praticam e estudam a agroecologia em 09 estados brasileiros além do Distrito Federal, representativos das cinco macrorregiões do país. Além das análises sobre a construção, institucionalização e implementação das políticas no campo da agroecologia, esta pesquisa traz ensinamentos metodológicos importantes. Em primeiro lugar, mostra que é possível articular grupos de docentes, estudantes, produtoras, produtores e representantes de movimentos sociais, na construção de conhecimento para a ação pública. A capilaridade da Rede Políticas Públicas e Desenvolvimento Rural na América Latina e sua capacidade de articulação facilitaram essa diversa e ampla participação na equipe de pesquisa. Em segundo lugar, o quadro teórico utilizado orientou as categorias de análise para o estudo transversal das políticas estaduais de agroecologia e produção orgânica (PEAPOs) e da relação delas com a política nacional de agroecologia e produção orgânica (PNAPO). Atores, instituições, coalizões e governança são categorias chaves na análise feita. Para os interessados, não só na agroecologia, mas em metodologias para estudo de políticas públicas, este livro indica um caminho teórico-metodológico possível a ser seguido em outros estudos.

1 Professora UnB. Diretora Presidente RETE. 


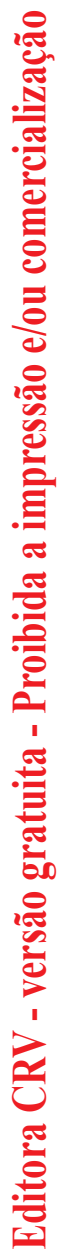




\section{PRÓLOGO}

Romier da Paixão Sousa ${ }^{1}$

Conheci parte da equipe de pesquisadores/as que produziu o livro

\section{Construção de Políticas Estaduais de Agroecologia e Produção Orgânica} no Brasil: avanços, obstáculos e efeitos das dinâmicas subnacionais" em uma reunião de trabalho para a discussão dos resultados trazidos na pesquisa. O frutífero encontro antecedeu o Workshop sobre Perspectivas do Ensino, Pesquisa e Extensão em Agroecologia no Brasil, realizado em março de 2019 pelo Núcleo de Estudos em Agroecologia da Universidade de Brasília (UNB) em parceria com a Associação Brasileira de Agroecologia (ABA-Agroecologia).

Participei de forma entusiasmada do espaço de reflexão sobre o conjunto de informações que haviam sido levantadas sobre as Políticas Públicas Estaduais de Agroecologia em 09 estados brasileiros além do Distrito Federal. Na oportunidade, o professor Eric Sabourin, um dos coordenadores da pesquisa, me convidou gentilmente para prefaciar este livro. Fiquei muito honrado e tive a consciência que deveria fazê-lo a partir da posição que ocupo atualmente, como presidente da Associação Brasileira de Agroecologia, que em quase 15 anos de existência, tem desempenhado papel estratégico na promoção da Agroecologia no âmbito das instituições de ensino, pesquisa e extensão, assim como na disputa de Políticas Públicas que fortaleçam este enfoque a nível nacional.

Inicialmente é importante frisar que a Agroecologia, enquanto conceito científico contemporâneo, nasce como um enfoque mais específico voltado para manejo e desenho dos agroecossistemas, em uma perspectiva ecológicoagronômica (escala local). Nas palavras de Susanna Hecht, "resultado de una decisión de los cientificos de estudiar a los campesinos y sus maneras de hacer agricultura" (1999, p. 17). Logo, Stephen Gliessman a conceitua como " $a$ aplicação dos conceitos e princípios ecológicos para o desenho e manejo dos agroecossistemas sustentáveis", a ciência dos agroecossistemas (GLIESSMAN, 2005, p. 54).

No entanto, com o aprofundamento teórico-conceitual e o crescimento da Agroecologia no país, com a participação ativa de movimentos sociais e organizações da sociedade civil, se percebeu a dificuldade para alcançar a sustentabilidade agrícola, em escala local, a partir das iniciativas dos camponeses e camponesas, de maneira isolada, pois há um conjunto de influências externas desempenhadas por diferentes atores, normativas e instituições. Conforme

1 Educador do Instituto Federal do Pará - Campus Castanhal. Presidente da Associação Brasileira de Agroecologia - ABA. 
ressalta Gonzáles de Molina (2013) "os agroecossistemas são construções socioecológicas e são produzidos a partir de relações de poder". Assim, não é possível avançar em processos de desenvolvimento rural mais sustentáveis apenas com a promoção de inovações meramente tecnológicas, sem pensar em mudanças institucionais, de normativas ou sociais, envolvendo todo o sistema agroalimentar. Neste contexto, houve uma necessidade de compreensão da Agroecologia desde uma perspectiva política.

A dimensão política da Agroecologia pode ser desenvolvida a partir de duas lógicas distintas e complementares. A primeira, por processos de mobilização social e constituição de um corpus organizativo. E, a segunda, pelo estabelecimento de políticas no âmbito do Estado, que promovam a transição agroecológica. No Brasil, a história de mobilização social e construção de políticas em favor da Agroecologia é relativamente recente, se considerarmos os processos de institucionalização efetiva. Obviamente que o conjunto de lutas e reinvindicações realizadas pelos movimentos sociais e sindicais voltadas para da agricultura familiar no país, especialmente pós Regime Militar, tiveram um papel central nas conquistas posteriores.

Petersen et al. (2013) fazem uma reflexão sobre os avanços e desafios da institucionalização das políticas de agroecologia no Brasil, destacando sua inserção nos processos de ensino, pesquisa e extensão, mas deixando claro os obstáculos práticos, teóricos e políticos-ideológicos que dificultam a ruptura com o atual paradigma da modernização da agricultura, incrustado na estrutura das instituições públicas do país. Outros trabalhos têm realizado análises dos processos de institucionalização e seus desafios (MUSSOI, 2011; SOUSA, 2017).

Certamente, a constituição da Política Nacional de Agroecologia e Produção Orgânica (Decreto $n^{\circ} 7.794$, BRASIL, 2012) foi uma das maiores conquistas do movimento agroecológico brasileiro, mesmo havendo muitos pontos de divergência com o documento final publicado. $\mathrm{O}$ fato de termos estabelecido um canal direto de diálogo e negociação em favor da Agroecologia e uma possibilidade de articular e coordenar de maneira intersetorial as ações dedicadas ao tema, por meio da Comissão Interministerial de Agroecologia e Produção Orgânica (CNAPO), foi sem dúvida um momento diferenciado que garantiu diversas conquistas. Uma leitura mais profunda deste debate pode ser encontrada nos bons estudos realizados pela Red de Políticas Públicas y desarrollo rural em America Latina (SABOURIN; NIEDERLE, 2017) e pelo Instituto de Pesquisa Econômica Aplicada - IPEA (SAMBUICHI et al., 2017).

No entanto, a partir de 2016, com as mudanças institucionais ocorridas por ocasião do impeachment da Presidenta Dilma Rousseff, os canais diretos de negociação tiveram a qualidade do diálogo reduzida. E, mais recentemente com a eleição do Presidente Jair Bolsonaro, houve a completa ruptura, com pouca 
ou nenhuma abertura institucional para o debate de uma agenda nacional em favor da Agroecologia no país.

Face ao exposto, este livro possui uma importância estratégica do ponto de vista acadêmico e político. Na esfera acadêmica, é muito potente como uma experiência de pesquisa em Rede, que articula de forma interdisciplinar um conjunto de pesquisadores e pesquisadoras do Brasil e de outros países para encontrar sinergias e articulação teórico-metodológica. Destaca-se ainda a mobilização de uma perspectiva teórica da sociologia da ação pública a partir do quadro de análise conhecido como pentágono da ação pública (LASCOUMES; LE GALÈS, 2012), elemento inovador nas análises das políticas em Agroecologia. Ainda carecemos de instrumentos e métodos efetivos para realizar a avaliação das políticas públicas de Agroecologia, exatamente por suas especificidades e densidades na geração de resultados e impactos nos territórios.

Outro aspecto que merece menção é o esforço de análise comparada das diferentes experiências na implementação de políticas específicas nos Estados, que possuem características e momentos de construção bastante particulares, mas são confrontados a partir de uma matriz de análise única, que oportuniza enxergar ensinamentos coletivos. Além deste olhar de avaliação, a matriz pode nos ajudar na proposição de novas ações e políticas, podendo corrigir os rumos tomados e refletir sobre suas práticas.

No campo político, o livro demonstra o admirável e fundamental papel da sociedade civil organizada na formulação e acompanhamento das políticas públicas no Brasil. Aqui, evidencia-se a atuação das Redes de Agroecologia Regionais, em boa medida ligadas à Articulação Nacional de Agroecologia (ANA), principal campo de confluência das organizações e movimentos sociais ligados a Agroecologia no país. Este aspecto nos parece receber necessário destaque no momento que o novo Governo Federal extinguiu praticamente todos os canais de diálogo e formulação coletiva de políticas de Estado, inclusive a CNAPO.

Cabe ainda destacar a força que esta obra terá no incentivo à continuidade de práticas na constituição de políticas públicas estaduais, onde as mesmas ainda não estão postas. Certamente, dependerá da capacidade de mobilização e articulação institucional para galgar sucesso na investida.

Vivemos um momento de contradições e deveremos buscar aprender com este período histórico, tirando lições e reflexões necessárias para seguirmos acumulando forças políticas direcionadas a promoção da Agroecologia. E, este livro, certamente é mais um instrumento robusto de disseminação de conhecimento, o que nos ajudará nesta tarefa. A Associação Brasileira de Agroecologia recomenda a leitura a seus associados e associadas e a todas as pessoas envolvidas na construção política e institucional da Agroecologia no país. 


\section{REFERÊNCIAS}

DE MOLINA, M. G. Agroecology and politics. How to get sustainability? About the necessity for a political agroecology. Agroecology and sustainable food systems, v. 37, n. 1, p. 45-59, 2013.

GLIESSMAN, S. R. Agroecologia: processos ecológicos em agricultura sustentável. 3. ed. Porto Alegre: Editora da UFRGS, 2005.

HECHT, S. B. et al. La evolución del pensamiento agroecológico. Agroecología y Agricultura Sostenible, p. 38, 1999.

MUSSOI, E. M. Política de Extensión Rural Agroecológica en Brasil: avances y desafíos en la transición en las instituciones oficiales. Investigación de postdoctorado. Universidad de Córdoba/Universidad Internacional de Andalucia, 2011.

PETERSEN, P.; MUSSOI, E. M.; DAL SOGLIO, F. Institucionalización del enfoque agroecológico en Brasil: avances y desafíos. Agroecología, v. 8, n. 2, p. 73-79, 2013.

SABOURIN, E.; NIEDERLE, P. A. Políticas públicas a favor de la agroecología en América Latina y el Caribe. 2017.

SAMBUICHI, R. H. R. Organizadora et al. A Política Nacional de Agroecologia e Produção Orgânica no Brasil: uma trajetória de luta pelo desenvolvimento rural sustentável. 2017.

SOUSA, R. da P. Agroecologia e educação do campo: desafios da institucionalização no Brasil. Educação \& Sociedade, v. 38, n. 140, p. 631648, 2017. 


\section{CAPÍTULO 1 \\ MARCO TEÓRICO E METODOLÓGICO: \\ a ação pública para a agroecologia}

Eric Sabourin

Stéphane Guéneau

Julianna Colonna

Luiz Raimundo Tadeu da Silva

\section{Introdução}

Desde 2012, o Brasil conta com uma Política Nacional de Agroecologia e Produção Orgânica, a PNAPO (BRASIL, 2012), que reúne mais de 120 ações de dez ministérios coordenados na Câmara Interministerial de Agroecologia e Produção Orgânica (CIAPO) em interlocução com a sociedade civil organizada no seio da Comissão Nacional de Agroecologia e Produção orgânica (CNAPO), sob a coordenação da Secretaria da Presidência da República. As ações foram conduzidas a nível federal de acordo com o $1^{\circ}$ Plano Nacional de Agroecologia e Produção Orgânica (PLANAPO I), para o período de 2012 a 2015 (SAMBUICHI et al., 2017). Elas foram redefinidas em 2015 no marco do PLANAPO II (2016-2019) que não chegou a ser implementado, ou foi de maneira muito reduzida e fragmentada, em função da mudança de governo de outubro 2016, após o impeachment da Presidente Dilma Rousseff que tinha, de fato, mostrado um interesse especial em promover essa política (SCHMITT et al., 2017). Entre 2015 e 2016, houve incremento de 133,4\% dos valores de investimento destinados ao Programa Nacional de Fortalecimento da Agricultura Familiar (PRONAF) agroecologia segundo (OLIVEIRA, 2017) e dois editais do programa Ecoforte de fortalecimento das redes de organizações e produtores agroecológicos desde 2014. As avaliações do PLANAPO I indicam como principal elemento positivo o caráter participativo e intersetorial da política, mas deploram a redução dos recursos liberados com relação ao orçamento programado (SAMBUICHI et al., 2016).

Houve, de fato, um salto na institucionalização da agroecologia (NIEDERLE et al., 2019), sendo o Brasil considerado um pioneiro em nível internacional (BAYLE; BEAUVAL, 2013). Em 2018, a PNAPO foi premiada pela Organização das Nações Unidas para Alimentação e Agricultura (FAO), por ser reconhecida como uma das melhores leis de promoção da agroecologia do mundo (prêmio "Future Policy Award"). 
Desde o início do governo Temer (maio de 2016), o país sofreu uma brutal desconstrução de políticas de apoio à agricultura familiar (DE MATTOS, 2017; MATTEI, 2018; SABOURIN, 2018). A ruptura de trajetória foi marcada imediatamente depois dessa data pela extinção do Ministério do Desenvolvimento Agrário (MDA), que era encarregado da implementação da política de agricultura familiar. Os recursos destinados à agricultura familiar foram progressivamente reduzidos, e várias políticas públicas foram paralisadas. Por exemplo, os recursos aplicados na aquisição de produtos do Programa de Aquisição de Alimentos (PAA), um programa que incentiva o manejo agroecológico dos sistemas produtivos, foram reduzidos de $\mathrm{R} \$ 287,5$ milhões em 2015 para $\mathrm{R} \$ 63,3$ milhões em 2018, ou seja, uma diminuição de $79 \%$ no período (CONAB, 2019).

Sendo a PNAPO uma política que tem como protagonista principal a agricultura familiar e camponesa (MOURA, 2017; NIEDERLE et al., 2019), ela não escapou desse movimento de desmantelamento. O atual governo Bolsonaro continua esse desmonte. Ao decidir a extinção do Conselho Nacional de Segurança Alimentar e Nutricional (CONSEA) logo depois da sua posse (CASTRO, 2019), o presidente em exercício começou a desconstruir o quadro institucional que sustenta a agroecologia, já que o CONSEA contribua para fortalecer o diálogo intersetorial entre a agricultura e outras áreas como a saúde, a nutrição e a economia solidaria (NIEDERLE et al., 2019). A assinatura do Decreto $n^{\circ} 9.784$, de 7 maio de 2019, que declarou a revogação da CIAPO e da CNAPO (BRASIL, 2019), completa de maneira efetiva esse desmonte da política federal de agroecologia.

No entanto, as iniciativas anteriores ou posteriores de estruturação de políticas estaduais de agroecologia e produção orgânica nas unidades federativas do Brasil, mantiveram a sua trajetória. Vários estados contam com esse tipo de política construída em paralelo à PNAPO ou antes da PNAPO, em diálogo com a sociedade civil mediante câmaras estaduais de agroecologia e produção orgânica. Algumas já resultaram em leis ou programas como é o caso no estado do Rio Grande do Sul ou no Distrito Federal. Outras estão numa fase de construção como, por exemplo, na Bahia e no Rio de Janeiro.

Embora a trajetória de institucionalização da agroecologia no nível federal já tenha sido objeto de várias análises (PETERSEN et al., 2013; SAMBUICHI et al., 2017; NIEDERLE et al., 2019), poucos estudos examinaram os processos de elaboração das políticas estaduais de agroecologia e de produção orgânica (PEAPOs), em particular em uma perspectiva comparativa.

Em 2017, equipes de pesquisadores reunidos na Rede Políticas Públicas e Desenvolvimento Rural na América Latina (Rede PP-AL. Disponível 
em: <www.pp-al.org.es/>), realizaram um balanço das políticas nacionais a favor da agroecologia em oito países da região (SABOURIN et al., 2017). $\mathrm{Na}$ continuidade desse estudo, pesquisadores de doze instituições membros da Rede PP-AL decidiram aplicar a mesma matriz de análise nas políticas estaduais de agroecologia e produção em 09 estados na União e no Distrito Federal (DF, MG, RJ, SP, RS, PR, MA, SE, BA e PA), examinando também, quais são as interações existentes a nível territorial entre as políticas estaduais e a PNAPO, ou o que sobrou dela.

Este estudo tem como objetivo analisar os processos de construção, institucionalização e implementação das políticas públicas para a agroecologia em vários Estados Federados para identificar, avanços, obstáculos e efeitos das dinâmicas e interações entre atores públicos e sociedade civil. Uma das questões do estudo era, em particular, verificar em que medida as dinâmicas atuais no nível subnacional contrapõem ou, ao contrário, reforçam as rupturas que foram observadas no nível federal.

\section{Referencial teórico mobilizado}

Segundo Leslie Pal, (1992, p. 2) uma política pública constitui "uma série de ações ou inações que autoridades públicas escolhem adotar para regular ou responder a um problema ou um conjunto de problemas interligados". Para Simeon (1976, p. 548), a política pública é "o que os governos fazem e porque o fazem". Para Dye (1984, p.1) ela é também o que os governos "escolhem não fazer".

A abordagem de análise das PEAPOs baseia-se no referencial conceitual e metodológico da sociologia da ação pública. Lagroye et al. (2002, p. 501) definem a ação pública como o "conjunto de efeitos, não necessariamente previsíveis e coerentes, resultantes de interações entre instituições interdependentes, entre os agentes dessas instituições e uma quantidade de atores sociais interessados pelas decisões políticas". Apesar da natureza multidisciplinar da análise de políticas públicas, que envolve disciplinas como a economia, as ciências da administração ou as ciências políticas, a escolha de uma abordagem sociológica para o estudo comparativo das políticas de agroecologia no nível subnacional refere-se à sua capacidade de analisar o papel dos atores privados e públicos, bem como suas interações no desenvolvimento e na implementação de políticas públicas (HASSENTEUFEL, 2011).

A ação pública, no recorte proposto nesse estudo, é materializada e, portanto, analisada, a partir da construção das PEAPOs. Para entender por que e como a ação pública foi construída e quais são seus efeitos, optou-se por adaptar um quadro de análise conhecido como o pentágono da ação pública 
(LASCOUMES; LE GALÈS, 2012a), que inclui cinco variáveis: atores, instituições, ideias, processos e resultados.

Os atores podem ser individuais ou coletivos, são dotados de recursos, têm certa autonomia, estratégias e são capazes de fazer escolhas, são mais ou menos guiados por seus interesses materiais e/ou simbólicos. As representações são os quadros cognitivos e normativos que dão sentido às ações, as condicionam e as refletem. As instituições são as normas, regras, rotinas, procedimentos que governam as interações. Os processos são as formas de interação e sua recomposição no tempo [...]. Os resultados, (outputs) são as consequências, os efeitos da ação pública (LASCOUMES; LE GALES, 2012, p. 45-46).

Embora a primeira representação gráfica desse quadro apresente a forma geométrica de um pentágono com as variáveis interligadas, os autores modificaram essa figura na segunda edição de sua obra, para destacar a dimensão menos simétrica e mais dinâmica das relações entre essas variáveis (Figura 1).

Figura 1 - O "pentágono" da ação pública

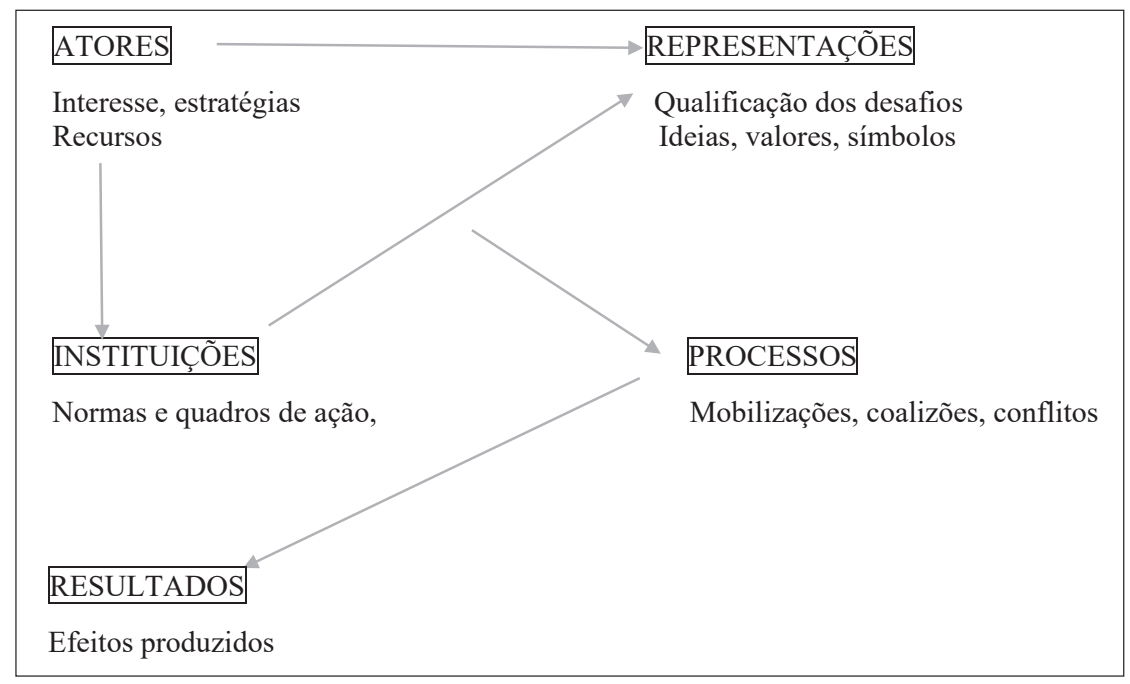

Fonte: Lascoumes e Le Galès (2012b).

A institucionalização da ação pública, aqui da agroecologia, não necessariamente está sancionada por uma lei ou uma política estadual. A sociologia da ação pública examina os processos relevantes que permitem a colocação da questão agroecológica na agenda pública. Ela se interessa pelas propostas e controvérsias entre as concepções da agroecologia que se estabilizam como referências para a ação, e analisa através qual tipo de dispositivos institucionais elas se estabilizam. 
Quais são os obstáculos para essa institucionalização? E quais são os efeitos dessa dinâmica de institucionalização sobre os instrumentos e as práticas de agroecologia (práticas de transição/transformação ou pelo contrário, "convencionalização"?).

Alguns capítulos têm mobilizado algum referencial teórico complementar em particular em torno do conceito de rede de atores (RHODES, 2008) ou de redes de ação pública (LE GALÈS; THATCHER, 1995). A noção de rede foi mobilizada nos casos de estados onde não existe ainda (ou não existe mais) um movimento social da agroecologia estruturado e estabilizado. Mobilizamos esse conceito, porque se adequa melhor a realidade institucional fragmentada da agroecologia em alguns estados que ainda não constituíram um verdadeiro movimento social estruturado e estabilizado. Segundo Rhodes (2008) "as redes de políticas públicas são conjuntos de ligações institucionais formais e informais entre agentes governamentais e outros atores estruturados em torno de crenças e interesses compartilhados, negociados de forma permanente, na formulação e implementação de políticas públicas" (RHODES, 2008, p. 426).

Le Galès e Thatcher (1995) as definem como: "o resultado de cooperação não hierárquica mais ou menos estável entre organizações que se conhecem e se reconhecem, negociam, trocam recursos e podem compartilhar normas e interesses. Essas redes desempenham um papel decisivo na definição da agenda, da decisão e da implementação da ação pública" (LE GALES E THATCHER, 1995, p. 15).

Os autores do capítulo sobre o DF mobilizam a noção de comunidade epistêmica para caracterizar à influência de redes de peritos e acadêmicos. Haas as define como "redes de profissionais com experiência e perícia reconhecidas em um campo particular que possam demonstrar conhecimento relevante sobre políticas públicas nesse campo" (HAAS, 1992, p. 3).

Finalmente, não é possível analisar a construção das PEAPOs sem examinar o nível federal com a criação, o sucesso inicial e o desmantelamento rápido da PNAPO. Bedjar (2014) mostra todo o interesse do princípio de subsidiariedade numa administração federal para implementar ações e decisões públicas no nível mais local ou territorializado. No entanto, no caso do federalismo Brasileiro associado a um presidencialismo de coalizão não programático, mas oportunista no parlamento, a subsidiariedade é pouco operacionalizada. De fato, segundo Arretche (2013), não é necessário obter supermaiorias em inúmeras arenas de veto para aprovar legislação em nível nacional e as minorias regionais têm poucas oportunidades de vetar. O poder central é fortalecido, não enfraquecido.

\section{Metodologia}

Do ponto de vista metodológico, inicialmente, foi elaborada uma primeira matriz de análise inspirada em uma pesquisa anterior conduzida no âmbito da rede "Políticas Públicas e Desenvolvimento Rural na América Latina" (PP-AL. Disponível em: <www.pp-al.org/es>), cujo objetivo era realizar um 
estudo comparativo das políticas nacionais de promoção da Agroecologia nos países da América Latina. Posteriormente, essa matriz foi adaptada ao objeto de estudo - a análise comparativa das políticas agroecológicas no nível subnacional - com base no arcabouço teórico acima apresentado (ver Quadro 1). Essa matriz foi aplicada em nove estados federados e no Distrito Federal (Pará, Maranhão, Distrito Federal, Bahia, Sergipe, Rio Grande do Sul, Paraná, Minas Gerais, Rio de Janeiro e São Paulo) e na cidade de São Paulo. Ela serviu de grade de leitura para diferentes fontes e técnicas de coleta de informação: a análise da bibliografia, documentos oficiais e arquivos, observações participantes em reuniões e fóruns e, finalmente entrevistas dos atores chaves dessas políticas em cada estado. Por fim, foi realizada uma oficina coletiva de análise comparativa em 11 de março de 2019 na Universidade de Brasília para harmonizar e estruturar os resultados dos estudos de caso.

\section{Quadro 1 - Grade de análise das políticas de promoção da ecologia aplicadas no nível subnacional}

\begin{tabular}{|c|}
\hline 1 Atores \\
\hline Atores-chave (individuais e coletivos) da construção da PEAPO \\
\hline Funções dos atores e forma de relação entre o Estado e a Sociedade civil \\
\hline Recursos e interesses dos atores \\
\hline 2 Representações \\
\hline Ideias e concepções de agroecologia prevalecentes na PEAPO \\
\hline Tensões entre atores (no sentido da confrontação das ideias) \\
\hline Principais problemas públicos (sociais) que se destacam nos debates e/ou na agenda política \\
\hline 3 Instituições \\
\hline Trajetória institucional (inclusive "dependência de caminho") e situação atual da PEAPO (em construção, \\
aprovada, implementada) \\
\hline Contexto político estadual e contexto político post-eleições \\
\hline Nivel de institucionalização \\
\hline 4 Processos \\
\hline Coalizões políticas a favor e a contra a PEAPO \\
\hline Espaços de debate e arenas \\
\hline Pontos de tensões e conflitos entre atores e coalizões \\
\hline $\mathbf{5}$ Resultados \\
\hline Modelo de governança da PEAPO \\
\hline Instrumentos da PEAPO \\
\hline Instrumentos que dialogam com a PNAPO e com outras políticas (estaduais ou federais) \\
\hline
\end{tabular}

Fonte: Autores. 


\section{Apresentação dos capítulos do livro}

Além desse capítulo teórico metodológico, o livro é composto por dez capítulos com análises dos processos de elaboração das PEAPOs e dos seus antecedentes em dez estados federados que integram as cinco grandes regiões do Brasil (Figura 2).

\section{Figura 2 - Situação da institucionalização das PEAPOs nos dez estados estudados}

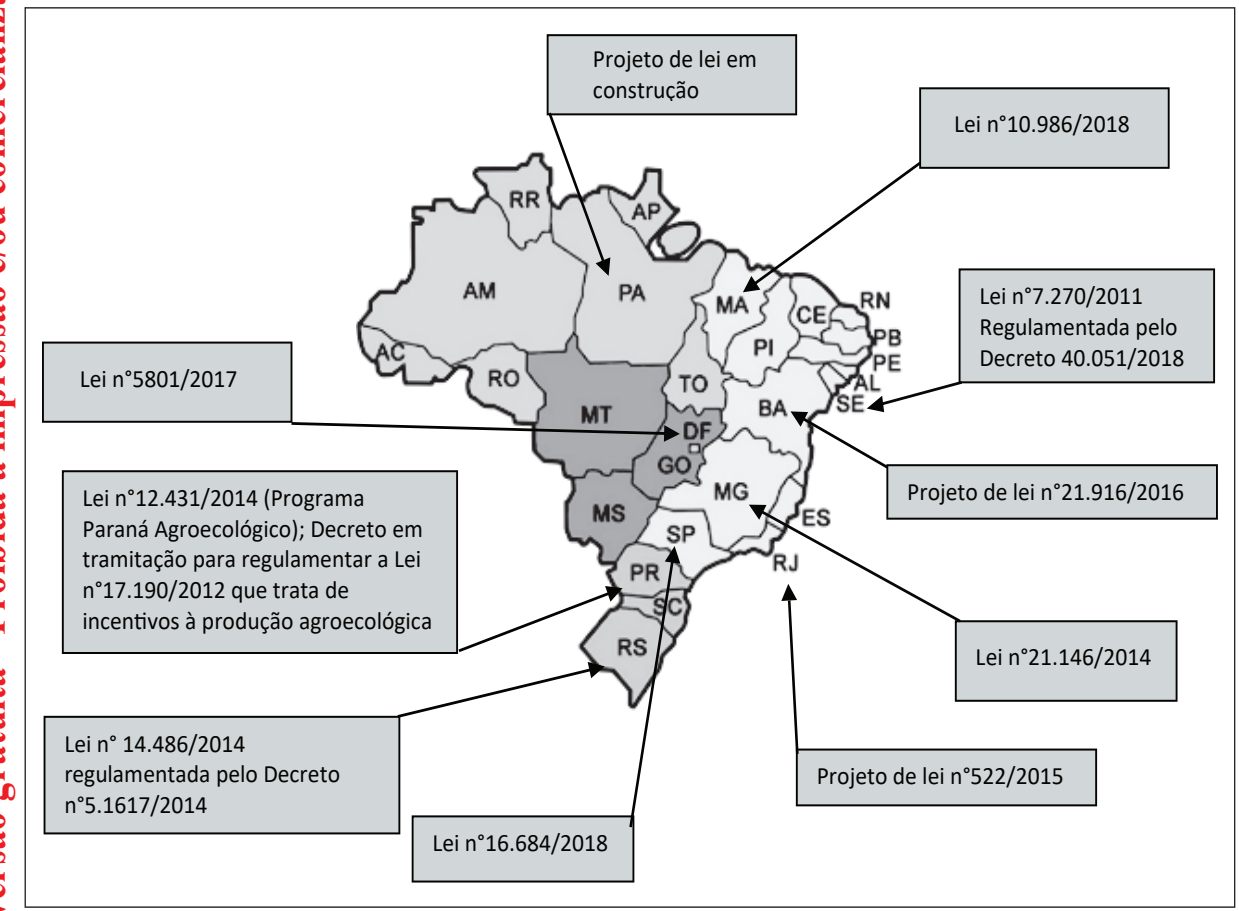

Fonte: Autores.

O capítulo final sintetiza os resultados e os analisa transversalmente a título de considerações finais. Na região Norte/Amazônia se trata dos estudos no estado do Pará; no Nordeste são os casos da Bahia, Maranhão e Sergipe; no Centro-oeste os casos do DF; no Sudeste os casos de Minas Gerais Rio de Janeiro e São Paulo e no Sul os casos dos estados do Paraná e do Rio Grande do Sul. 


\section{REFERÊNCIAS}

ARRETCHE, M. Demos-Constraining or Demos-Enabling Federalism? Political Institutions and Policy Change in Brazil. In: Journal of Politics in Latin America, v. 5, n. 2, p. 133-150. 2013.

BAYLE, E.; BEAUVAL, V. Le Brésil, un pionnier de l'agro écologie. Expériences d'AVSF et de ses partenaires. AVSF. Lyon, 2013.

BEDNAR, J. Subsidiarity and Robustness: Building the Adaptive Efficiency of Federal System. In: NOMOS L. V. Federalism and Subsidiarity. New York: NYU Press, 2014.

BRASIL. Decreto no 7.794, de 20 de agosto de 2012. Institui a Política Nacional de Agroecologia e Produção Orgânica. Diário Oficial da União, seção 1, p. 4, 21 ago. 2012.

. Decreto $\mathrm{n}^{\circ}$ 9.784, de 7 de maio de 2019. Diário Oficial da União, seção 1, p. 3, 8 maio 2019 .

CASTRO, I. R. R. D. A extinção do Conselho Nacional de Segurança Alimentar e Nutricional e a agenda de alimentação e nutrição. Cadernos de Saúde Pública, v. 35, 2019.

CONAB. Agricultura Familiar. Programa de Aquisição de Alimentos - PAA: Resultados das ações da Conab em 2018. Compêndio de Estudos Conab/ Companhia Nacional de Abastecimento, n. 20, p. 24, 2019.

DE MATTOS, L. M. Austeridade fiscal e desestruturação das políticas públicas voltadas à agricultura familiar brasileira. Friedrich-Ebert-Stiftung (FES) Brasil, n. 39, 2017.

DOS SANTOS, A. D. S. et al. Trajetória e desdobramentos da construção da Caravana Agroecológica e Cultural de Sergipe. Cadernos de Agroecologia, v. 10, n. 3, 2016.

EMBRAPA. Marco referencial em agroecologia. Brasília, DF: Embrapa (Empresa Brasileira de Pesquisa Agropecuária), 2006. 
HAAS, P.M. Introduction: Epistemic Communities and International Policy Coordination. International Organization, v. 46, n. 1, p. 1-35, 1992.

HASSENTEUFEL, P. Sociologie politique: 1'action publique. Paris: Armand Colin, 2011.

KALIL, L. M.; MARRA, C. A. As contribuições da Marcha das Margaridas para o avanço da pauta agroecológica no Brasil. Cadernos de Agroecologia, v. 10, n. 3, 2016.

LASCOUMES, P.; LE GALÈS, P. Sociologia da Ação Pública. Maceió: EDUFAL, 2012a.

LASCOUMES, P.; LE GALÈS, P. Sociologie de l'action publique. Paris: Armand Colin, 2012.

LE GALÈS, P. ; THATCHER, M. (Orgs.). Les réseaux de politique publique. Debat autor des policy networks. Paris: Ed. L'Harmattan, 1995.

MATTEI, L. A política agrária e os retrocessos do governo Temer. OKARA: Geografia em debate, v. 12, n. 2, p. 293-307, 2018.

NIEDERLE, P. A. et al. A trajetória brasileira de construção de políticas públicas para a agroecologia. Redes, v. 24, n. 1, p. 270-291, 2019.

NORDER, L.A.; LAMINE, C.; BELLON, S.; BRANDENBURG, A. Agroecologia: polissemia, pluralismo e controvérsias. Ambiente \& Sociedade, v. 19, n. 3, p. 1-20, 2016.

OLIVEIRA, E.; SILVA J.; GOMES, T.; JOSEPH, D.; MONTEBELLO, A.; MARJOTTA-MAISTRO, M. Análise do Pronaf Agroecologia numa perspectiva de desenvolvimento rural sustentável. In: X CONGRESSO BRASILIERO DE AGROECOLOGIA, Brasilia, Setembro de 2017.

PAL, L. Public Policy Analysis: An Introduction. Toront: Nelson, 1992.

PETERSEN, P.; MUSSOI, E. M.; DAL SOGLIO, F. Institutionalization of the agroecological approach in Brazil: advances and challenges. Agroecology and Sustainable Food Systems, v. 37, n. 1, p. 103-114, 2013. 
RHODES, R. Policy network analysis, In: MORAN, M.; REIN, M.; GOODIN, R. E. (Eds), The Oxford handbook of public policy. Oxford: University Press. p. 425 - 443, 2008.

SABATIER, P. A. An advocacy coalition framework of policy change and the role of policy-oriented learning therein. Policy Sciences, v. 21, n. 2-3, p. 129-168, 1988.

SABOURIN, E. Erosão, crise e desmonte de políticas para a agricultura familiar e agroecologia na América Latina. In: SEMINARIO POLÍTICAS PÚBLICAS PARA O MEIO RURAL BRASILEIRO NO PERIODO RECENTE: MUDANÇAS, CONTINUIDADES E RUPTURAS, Rio de Janeiro. Anais... Rio de Janeiro: UFRRJ/CPDA/OPPA, 2018.

SABOURIN, E. et al. (Orgs.). Políticas públicas a favor de la agroecología en América Latina y El Caribe. Porto Alegre: Criação Humana; Red PP-AL; FAO, 2017.

SAMBUICHI, R. H. R. et al. Análise da construção da política nacional de agroecologia e produção orgânica no Brasil. Brasília: IPEA, 2017.

SAMBUICHI, R. H. R. et al. Avaliação do Plano Nacional de Agroecologia e Produção Orgânica: primeiros resultados In: $54^{\circ}$ CONGRESSO DA SOCIEDADE BRASILEIRA DE ECONOMIA, ADMINISTRAÇÃO E SOCIOLOGIA RURAL (SOBER), 2016. Disponível em: <http://icongresso.itarget.com. br/useradm/anais/?clt=ser.6\&lng=P $>$. Acesso em: 15 jun. 2019.

SCHMITT, C. et al. La experiencia brasileña de construcción de políticas públicas en favor de la agroecología. In: POLÍTICAS públicas a favor de la agroecología en América Latina y El Caribe. Porto Alegre: Criação Humana/ Red PP-AL/FAO, 2017. p. 73-122.

SIMEON R. Studying Public Policy. Canadian journal of political science, v. 9 , n. 4 , p. 548-580, 1976. 


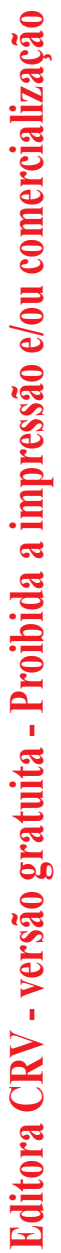

\section{REGIÃO SUL}




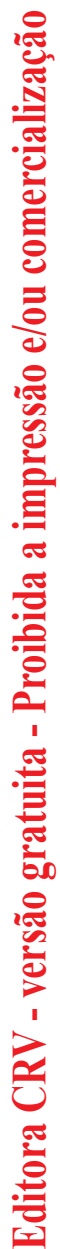




\section{CAPÍTULO 2 \\ A EVOLUÇÃO DA POLÍTICA DE AGROECOLOGIA NO PARANÁ \\ (2008-2019): avanços e recuos de uma trajetória pioneira}

Claire Lamine Moacir Darolt Margit Hauer Alfio Brandenburg

\section{Introdução}

O estado do Paraná apresenta algumas particularidades e paradoxos que o diferencia do contexto nacional em relação ao desenvolvimento da agroecologia. De um lado, os movimentos ecológicos são historicamente atuantes (é o estado com maior número de propriedades agroecológicas/orgânicas certificadas) com uma presença marcante da agricultura familiar (81,6\% dos 371 mil estabelecimentos do Paraná são familiares) (VILELA et al., 2019). De outro lado, existe uma agricultura industrial intensiva com uma das mais altas produtividades agropecuárias do país, focada na exportação de commodities (IPARDES, 2017). Tudo isso é marcado por fortes alternâncias políticas que influenciaram momentos de avanços e de recuos da institucionalização da agroecologia.

A questão que tratamos nesse capítulo está ligada especificamente ao seguinte paradoxo: Por que o Paraná, um dos estados pioneiros em políticas voltadas à agroecologia, teve na década de 2010 , tanta dificuldade para institucionalizar e concretizar sua Peapo? Nossa hipótese é que muitas razões que explicam a força e o pioneirismo da dinâmica institucional no Paraná, nos anos de 2002 a 2011, explicam também sua fragilidade nos períodos posteriores. Para demonstrar tal paradoxo, reconstituímos a trajetória de institucionalização da agroecologia no Paraná a partir dos anos de 1980 até o período mais recente, a fim de contextualizar a formalização da Política Estadual, dentro desse processo histórico. Mostraremos quais atores no processo de mobilização política se destacaram nos movimentos sociais, no meio acadêmico e institucional, quais alianças e parcerias foram formadas (ou não), que narrativas circularam e como se transformaram ao longo do tempo. Finalmente, examinaremos 
quais instrumentos de ação pública foram construídos ao longo das diferentes etapas. Para tanto, apoiamo-nos no arcabouço de análise de políticas públicas que estrutura o conjunto desse trabalho coletivo, articulando-o com uma abordagem sociológica pragmatista centrada nas dinâmicas de reconfiguração das redes de atores que se mobilizam e interagem, e de controvérsias que se opõem ou aproximam essas redes.

Este capítulo está estruturado em quatro partes principais. A primeira introduz o referencial teórico, os métodos e a coleta de dados. A segunda parte mostra a trajetória de emergência e formulação da Política Estadual de Agroecologia (PEAPO-PR), a qual dividimos em três períodos: fatos antecedentes (anos de 1980 a 2002); em seguida a institucionalização pioneira (2002-2011) que se inicia com a formação de um Programa Estadual de Agroecologia de forma voluntária (2008 a 2011); e a fragilização e tentativas de reavivar uma Política Estadual de Agroecologia (2010 a 2018), destacadamente no período seguinte ao lançamento da Política Nacional de Agroecologia e Produção Orgânica (PNAPO), instituída pelo Decreto nº 7.794, de 20/08/2012. Na terceira parte, analisamos a evolução das redes de atores, suas participações nas instâncias estaduais referentes à agroecologia e as parcerias entre essas redes. A quarta parte aborda as concepções de agroecologia em uso por essas redes e suas instâncias, e as controvérsias. Finalmente, a conclusão discute os fatores que podem explicar a força, a precocidade e a fragilidade da dinâmica institucional das políticas de agroecologia no Paraná.

\section{Referencial teórico e metodológico}

Vários estudos sobre a política de agroecologia no Brasil e na América Latina destacaram o papel decisivo dos movimentos sociais da agricultura familiar e camponesa (CAPORAL; COSTABEBER, 2004; PETERSEN et al., 2013; SCHMITT et al., 2017) buscando ampliar e orientar suas narrativas de uma agricultura alternativa em direção à agroecologia como modelo ideal para a agricultura familiar. Essa orientação emerge a partir dos anos de 1970, num contexto de crítica ao padrão técnico e econômico implementado pelas políticas agrícolas de modernização (BRANDENBURG, 2012). A partir da era Lula, nos anos de 2000, houve uma presença marcante de profissionais e representantes de movimentos ecológicos sensíveis à causa agroecológica em cargos chaves no governo federal e nos estados, além de pesquisadores, professores e técnicos nas universidades, órgãos de pesquisa e extensão, que apoiaram o movimento de institucionalização da agroecologia, o que se traduziu na implementação de diversas políticas públicas (Política Nacional de Assistência Técnica e Extensão Rural - PNATER; PNAPO, entre outras) (ALTIERI; TOLEDO, 2011). 
De fato, as iniciativas de agroecologia formaram um tecido social denso e foram articuladas por vários atores que assumiram papéis complementares na estruturação de sistemas agroalimentares agroecológicos. Enquanto os autores supracitados sugerem uma visão positiva dos processos de interações e alianças entre os movimentos sociais, o meio acadêmico, o mundo rural e as políticas públicas, mostrando a "revolução agroecológica" como uma história de sucesso (success story), nosso trabalho procura destacar não somente as alianças, mas também as controvérsias e correlações de força reveladas por esses processos de interação. É o que sugerem trabalhos relacionados à análise cognitiva de políticas públicas (MULLER, 2000), analisando o papel dos atores da agroecologia no processo de construção de políticas públicas para a agricultura familiar e mais recentemente para a agroecologia (NIEDERLE; GRISA, 2013; FLEXOR; GRISA, 2016; SCHMITT et al., 2017).

Dessa forma, nesse capítulo, analisaremos o processo de construção da Política Estadual de Agroecologia no Paraná (PEAPO-PR) numa perspectiva de análise temporal mais longa. Nesse sentido, nosso foco não se limita ao processo de consolidação de um referencial de ação pública (MULLER, 2000), ou seja, de uma estrutura cognitiva, normativa e instrumental única, mas na análise dos debates e controvérsias que precedem e acompanham os processos de construção das políticas públicas (FOUILLEUX; JOBERT, 2017). A criação de uma política pública específica para a agroecologia extrapola a questão apenas de construção de políticas públicas, até porque elas são o resultado de um processo de alianças e controvérsias (LAMINE; NIEDERLE; OLLIVIER, 2019). Controvérsias essas que incluem questões sobre o tipo de agricultura e de agricultores beneficiados por essas políticas e outras relacionadas à reconexão entre agricultura e alimentação. Assim, nossa análise emprestará do referencial teórico do pentágono da ação pública (LASCOUME; LE GALÈS, 2012) a orientação de estudar os atores, instituições, ideias, processos e resultados (através das categorias que mobilizamos), e da sociologia pragmatista, o princípio de estudar ao longo do tempo as controvérsias entre diferentes atores e suas reconfigurações.

As análises desse capítulo baseiam-se numa série de documentos (textos, projetos de lei e decretos, relatórios públicos, atas de reuniões do Conselho Estadual de Desenvolvimento Rural e Agricultura Familiar - CEDRAF e da Câmara Setorial de Agroecologia e Agricultura Orgânica (CSAO - Atas entre 2008 e 2018), além de 20 entrevistas aprofundadas com atores engajados na execução da política de agroecologia no Paraná, conduzidas entre 2012 e 2016 (C. Lamine). Paralelamente, houve a observação etnográfica de uma dúzia de reuniões desses fóruns entre 2012 e 2018 (C. Lamine), bem como a participação dos autores nessas instâncias (M. Hauer e M. Darolt) e mais recentemente no grupo de trabalho encarregado de preparar uma minuta do decreto de aplicação da Política Estadual de Agroecologia (M. Hauer). 


\section{Trajetórias de institucionalização da Agroecologia no Paraná: uma história iniciada na década de 1980}

\section{Antecedentes: iniciativas pioneiras (1983-2002)}

Se o Paraná foi um dos pioneiros na construção de políticas agroecológicas, na vanguarda do que ocorria em nível nacional, isso se deve à sua trajetória histórica (Figura 1). No fim dos anos de 1970, a então Associação dos Engenheiros Agrônomos do Paraná (assim como a Federação das Associações dos Engenheiros Agrônomos do Brasil - FAEAB) desempenhou forte papel na luta pela reforma agrária e na crítica ao modelo de agricultura imposto pela Revolução Verde, discutindo a questão de sementes e de empresas multinacionais, promovendo eventos como o Encontro Brasileiro de Agricultura Alternativa (EBAA) de 1981 em Curitiba e apoiando a criação da primeira Lei Estadual sobre Agrotóxicos (1983) e a Lei Estadual de Uso do Solo Agrícola (1984).

Figura 1 - Cronologia da Agroecologia no Estado do Paraná:

Fases 1 e 2 (antecedentes e institucionalização)

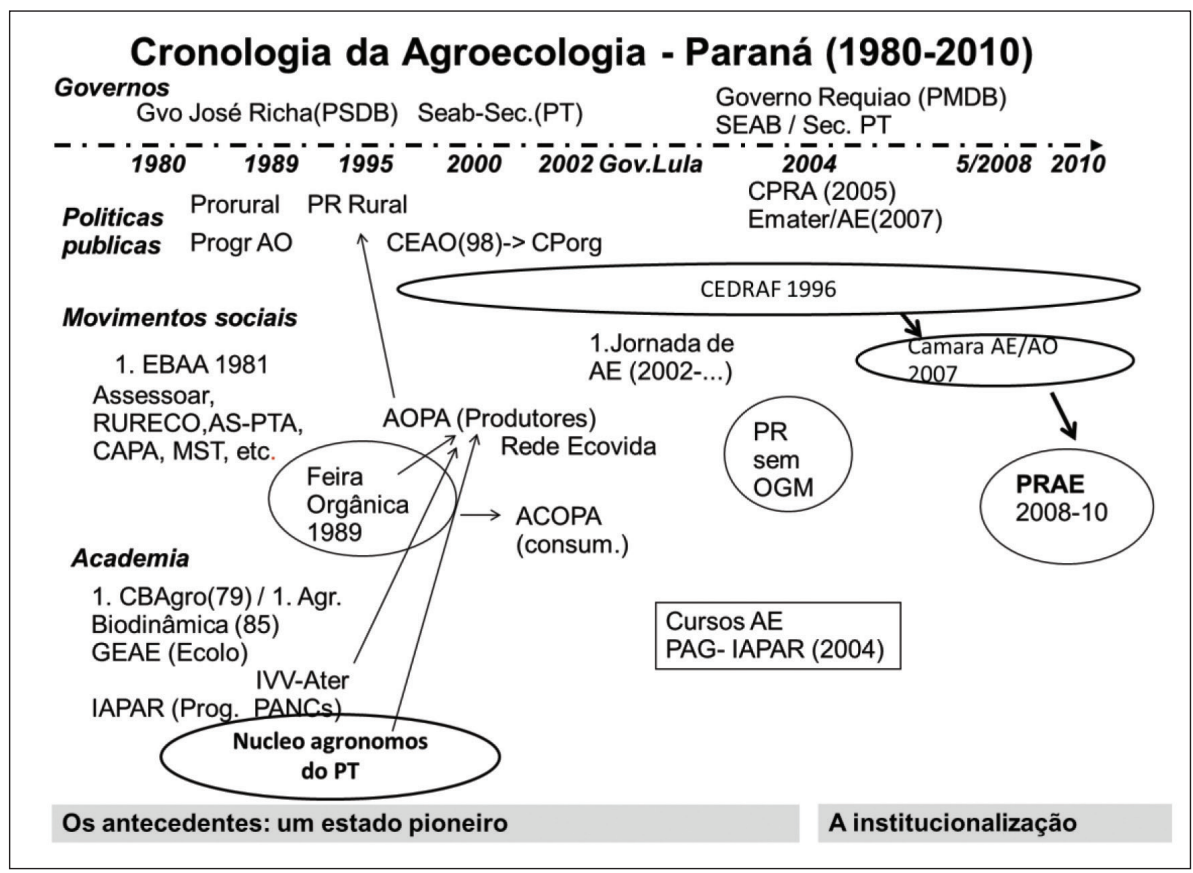

Ainda no início dos anos de 1980, estudantes de Agronomia, da Universidade Federal do Paraná (UFPR), criaram o Grupo de Estudos de Agricultura Ecológica (GEAE), hoje renomeado Grupo de Estudos de Agroecologia. Esse 
grupo realizou diversas atividades, desde hortas no campus da universidade, criação de uma propriedade agroecológica modelo até a organização de eventos e cursos, culminando com o $1^{\circ}$ Curso de Aprofundamento em Agricultura Ecológica, em 1985, de caráter nacional. Dois fundadores do GEAE, ao se formarem, trabalharam no Hospital Oásis Paranaense (na Região Metropolitana), instituição que abriu portas para as hortas agroecológicas e, por isso, era palco de treinamentos. Em 1985, foi organizado o primeiro Congresso Brasileiro de Agricultura Biodinâmica também em Curitiba, que influenciou agricultores a trabalharem nessa linha.

Em 1989, produtores e técnicos procuraram a Prefeitura Municipal de Curitiba para fundar a primeira feira de produtos orgânicos ${ }^{1}$. Em 1991, parte desses atores sociais, notadamente produtores e técnicos (maioria agrônomos), envolvidos com a agricultura orgânica colaboraram para a fundação do IVV - Instituto Verde Vida de Desenvolvimento Rural (já extinto), com objetivo de prestar assistência técnica e extensão rural em projetos de agricultura orgânica, inicialmente na região metropolitana de Curitiba, além de estimular o Estado a desenvolver políticas públicas para esse segmento. Com o aumento do número de produtores, começou a surgir a necessidade de organizar a produção e a comercialização. Esse foi o embrião e o principal motivo para criação da Associação de Agricultura Orgânica do Paraná - AOPA em 1995 (atualmente, renomeada Associação para o Desenvolvimento da Agroecologia), o que permitiu obter apoio oficial do governo estadual.

Cabe destacar que entre os anos de 1980 e 1990, algumas ONGs foram pioneiras no movimento por uma agricultura ecológica em outras regiões do interior do Paraná, como a Associação de Estudos, Orientação e Assistência Rural-ASSESOAR, no sudoeste do Paraná; a Fundação para o Desenvolvimento Econômico Rural da região centro do Paraná - RURECO; o Centro de Apoio e Promoção da Agroecologia - CAPA da região oeste; e a Assessoria e Serviços a Projetos em Agricultura Alternativa - AS-PTA, que atuou na região centro-sul do Paraná (BRANDENBURG, 2002).

É interessante notar que os mesmos profissionais, na maioria agrônomos atuantes na pesquisa, ensino, extensão e produtores rurais ativos no movimento da agricultura ecológica dos anos de 1980 e 1990, foram também os catalizadores e divulgadores da agroecologia no Paraná nos anos seguintes. Parte dessa geração de agrônomos foi trabalhar em instituições de pesquisa, ensino, extensão e fomento do estado e do governo federal, além de participar na concepção e fundação da AOPA. Assim, é com a ação de atores sociais urbanos,

1 Inaugurada em Curitiba em 1989 com três barracas junto à feira de artesanato no Largo da Ordem, a Feira Verde foi transferida para o Passeio Público em 1993. Em 2005, a Portaria n 30/2005 alterou seu nome para Feira Orgânica. 
pesquisadores e estudantes de agronomia, técnicos de instituições governamentais e de entidades não governamentais e outros profissionais engajados na busca de outros paradigmas societários, que incluíam formas de produção sustentáveis e equidade social na agricultura, que se vê a gestação de um projeto social focado na agricultura orgânica/agroecologia (KARAM, 2000).

O movimento de estruturação da sociedade civil em torno das agriculturas de base ecológica (alternativa, natural, orgânica, biodinâmica, permacultura e agroecológica) prosseguiu ao longo dos anos 2000. Outros atores chaves da sociedade civil criaram no ano de 2000 a Associação de Consumidores de Produtos Orgânicos do Paraná - ACOPA, trazendo a voz dos consumidores para o debate. Em 2002, uma coalizão de atores sociais organizou um grande evento: a "Jornada Paranaense de Agroecologia", em Ponta Grossa. Essa coalizão animada pelos movimentos sociais ligados à luta pela reforma agrária (Movimento Nacional dos Trabalhadores Sem Terra - MST e Via Campesina), continua organizando eventos anuais que atrai aproximadamente de 3 a 4 mil participantes. Sua edição de 2018 contou com uma grande feira agroecológica, no centro de Curitiba, para mostrar à sociedade a ligação da agroecologia com a produção de alimentos saudáveis.

No que tange às políticas públicas, no Governo José Richa (1983-1986) a Secretaria da Agricultura criou um programa de agricultura alternativa, que incluiu, no âmbito do Iapar (Instituto Agronômico do Paraná), projetos como o de plantas potenciais (hoje, plantas alimentícias não convencionais ou PANCs) e de difusão de tecnologias. Ainda em meados da década de 1980, a mesma Secretaria criou programas relacionados à agricultura conservacionista, como o Programa de Manejo Integrado de Solos e Água (PMISA) e o Programa de Desenvolvimento Rural (Prorural), que já trazia alguns princípios de práticas da agroecologia. Entre 1990 e 2004, programas como Paraná Rural (19891997)², Paraná 12 Meses e Modelo Paraná de Extensão Rural haviam incluído em sua pauta a Agricultura Orgânica (SEPULCRI; DE PAULA, 2006).

Um marco importante foi a criação, em 1998, do Conselho Estadual de Agricultura Orgânica do Paraná (CEAO), primeiro órgão normativo, deliberativo e regulador da política agrícola estadual para a agricultura orgânica, integrante da estrutura organizacional da Secretaria da Agricultura e do Abastecimento - SEAB/PR, antecipando a Lei ${ }^{\circ} 10.831 / 2003$, que previa a criação de Comissões de Produção Orgânica (CPOrg) nos estados. A iniciativa da criação do CEAO partiu de atores da sociedade civil e do Poder Público e sua composição era paritária.

2 O Paraná Rural foi implementado entre 1989 e 1997, como resultado de um empréstimo formalizado entre o governo do Estado do Paraná e o Banco Internacional para a Reconstrução e Desenvolvimento (BIRD). 


\section{Fase de institucionalização da agroecologia no Paraná num contexto favorável nacionalmente (2002-2011)}

Embora se possa considerar que, nas décadas de 1980 e 1990, a agricultura ecológica permaneceu restrita a algumas redes militantes em espaços circunscritos como a Feira Orgânica do Passeio Público de Curitiba e alguns programas de políticas públicas estaduais, pode-se dizer que a visibilidade da agroecologia em diferentes espaços começou a se consolidar como um marco unificador no início dos anos de 2000, tanto em nível estadual como nacional. Testemunha disso é, por exemplo, o direcionamento político do MST para fomentar a agroecologia como modelo para produção de alimentos, como visto a partir da $1^{\text {a }}$ Jornada Paranaense de Agroecologia em 2002.

Cabe destacar que a eleição de Lula (2002) ensejou a entrada nas instituições federais e estaduais de ensino, de militantes e de atores engajados na defesa da agroecologia, como mostra a análise da trajetória de alguns desses atores (LAMINE; ABREU, 2009). A aliança já estabelecida entre os movimentos sociais camponeses (e, em menor grau, ambientalistas e de consumidores) com o meio acadêmico se estende para os gestores públicos que trabalham na construção e implementação de políticas públicas voltadas à agricultura familiar, o que levou a incorporação da agroecologia nessas políticas (GRISA, 2017; LAMINE; NIEDERLE; OLLIVIER, 2019). Em particular, podemos destacar resultados nas políticas de pesquisa, ensino e extensão (ver abaixo), mas também no desenvolvimento de sistemas de certificação (reconhecimento da certificação participativa e Organização de Controle Social - OCS) e programas de compras públicas (Programa de Aquisição de Alimentos - PAA e Programa Nacional de Alimentação Escolar - PNAE).

É fato que entre os anos de 2002 e 2011 se desenvolveram várias ações em nível nacional e estadual nas universidades, centros de pesquisa e extensão, reflexo da reorientação das políticas públicas em prol da agroecologia. Essas ações compreendem os programas de formação e pesquisa, incentivos à formação de Núcleos de Estudo em Agroecologia (NEAs), redes de pesquisa e desenvolvimento em agroecologia (Rede Paranaense de Pesquisa em Agroecologia - REPAGRO, formada em 2014, identificou 49 organizações trabalhando com pesquisa em Agroecologia no Paraná), reunindo pesquisadores, estudantes, técnicos e agricultores (MIRANDA, 2014). A partir de 2003 se intensificam as formações em agroecologia, como o treinamento de Técnicos em Agroecologia feito pela Universidade Federal do Paraná (UFPR) em parceria com os movimentos sociais do campo, como a AOPA, ASSESOAR, MST e Via Campesina. Em 2004 foi criado o Núcleo de Agroecologia da 
Escola Técnica da UFPR que coordenou a formação dos primeiros técnicos e tecnólogos em agroecologia do país em parceria com as escolas dos movimentos em várias cidades do interior do Paraná, numa iniciativa de formação descentralizada, fora da região metropolitana de Curitiba.

Ainda de forma pioneira foi criado em 2005, pela UFPR no litoral do Paraná, o primeiro curso superior de Tecnólogo em Agroecologia. Também em 2005 foi criada a Escola Latino Americana de Agroecologia (ELAA), em parceria com o Instituto Federal do Paraná (IFPR) por iniciativa da Via Campesina e MST. A ELAA recebe estudantes da América Latina e Caribe e localiza-se no Assentamento Contestado, no município da Lapa. Várias iniciativas se sucederam no ensino da agroecologia como a formação de Núcleos de Estudo em Agroecologia (14 NEAS, em 2017) ofertando treinamentos em 7 Universidades Estaduais e cursos de "Técnico em Agroecologia" oferecidos pelos Colégios Agrícolas e Casas Familiares Rurais do estado. No final de 2011, existiam 12 cursos no Paraná, com formação específica em agroecologia (técnicos, tecnólogos, bacharelado e mestrado), além de outros 18 cursos com ênfase em agroecologia (MELÃO, 2011), que são mantidos até o momento. Em 2009 foi lançado o Programa Paranaense de Certificação de Produtos Orgânicos (PPCPO), que em 10 anos colaborou para que o Paraná atingisse o maior número de propriedades certificadas.

Ainda em 2003 a Itaipu Binacional lança o Programa Cultivando Água Boa que atuou em várias frentes de Pesquisa, ATER, Comercialização e Marketing para impulsionar a agricultura orgânica até 2017. Em 2004, o IAPAR criou o Programa de Pesquisa em Agroecologia (PAG), com a finalidade coordenar ações de pesquisa, desenvolvimento e difusão, com foco em treinamentos de técnicos e agricultores. Paralelamente a Empresa Brasileira de Pesquisa Agropecuária (Embrapa) de Londrina redirecionava pesquisas com destaque para controle biológico e inoculação de sementes.

Outro marco importante foi a criação, em 2005, do Centro Paranaense de Referência em Agroecologia (CPRA) pela Lei Estadual $n^{\circ} 14.980$, de 28/12/2005 (PARANÁ, 2019) instituição única no Brasil (ao lado da fazendinha orgânica da Embrapa Agrobiologia do Rio de Janeiro) criada para divulgar, apoiar e promover ações de ensino, pesquisa, extensão e comercialização baseados nos preceitos da agroecologia e comércio solidário. Essas instituições foram as responsáveis pela organização de vários eventos no período com destaque para o VI Congresso Brasileiro de Agroecologia e II Congresso Latino Americano de Agroecologia, realizados em Curitiba em 2009. Ainda em fevereiro de 2009, com apoio da Prefeitura Municipal de Curitiba e do Ministério do Desenvolvimento Agrário (MDA) foi inaugurado o primeiro Mercado Orgânico do Brasil.

Do lado da extensão rural oficial, a EMATER iniciou um trabalho em prol da agroecologia em 2005, resultando em 2007 na criação de um grupo 
de trabalho em agroecologia, composto por 17 técnicos com a finalidade de difundir as práticas de agroecologia, identificar necessidades de treinamentos, oportunidades e áreas de atuação, visando tornar a agroecologia a "nova matriz tecnológica" da extensão, em consonância com a política nacional de ATER - PNATER de 2003. Em 2011 a instituição contabilizava 50 técnicos capacitados em agroecologia apoiando cerca de 3 mil agricultores, organizados em 71 grupos.

Face às várias iniciativas em curso, em 2007, emergiu a necessidade de congregar os diversos órgãos governamentais e a sociedade civil, de forma paritária, sendo apresentada uma proposta junto ao Conselho de Desenvolvimento Rural e Agricultura Familiar - CEDRAF para a criação da Câmara Setorial de Agroecologia e Agricultura Orgânica, cujo objetivo foi propor ações voltadas para o desenvolvimento da agroecologia e da rede de produção orgânica, constituindo-se num espaço de caráter multissetorial, voltado aos debates acerca das questões mais relevantes para o setor no estado do Paraná.

A primeira demanda para a Câmara foi elaborar o Programa Paraná Agroecológico (PRAE), que mobilizou mais de 30 especialistas de diversas instituições governamentais e da sociedade civil para construir de forma participativa, entre 2008 e 2011, um programa visando promover e apoiar ações para implantação, consolidação e ampliação de sistemas de produção e consumo agroecológicos. O programa, aprovado pelo CEDRAF em outubro de 2010 e publicado em 2011 define sua atuação em cinco grandes eixos: produção, pesquisa, extensão rural, comercialização e legislação. $O$ programa ofereceu subsídios para montagem de planos de ação regionais, ocorrido em oficinas do Programa Paraná Agroecológico em 2017 e 2018.

\section{Fragilização e tentativas de reavivar a política estadual de agroecologia (2011-2018)}

Apesar do pioneirismo em nível nacional e do grande número de parceiros mobilizados na construção de políticas públicas para a agroecologia do Paraná, as mudanças políticas sucessivas criaram descontinuidade e morosidade no processo. Conforme relato de um dos protagonistas desse debate, o governo sob o comando de Roberto Requião até 2010 "viu a mudança de modelo agrícola como uma fonte de inovação, e desejava apoiar a agroecologia/agricultura orgânica mesmo dentro de setores mais clássicos (commodities, cooperativas, setor agroalimentar)" (entrevista ACOPA, nov. 2012). Tratava-se de um período em que o Estado do Paraná permanecia pioneiro em vários setores da agroecologia (Figura 2). 
Figura 2 - Cronologia da Agroecologia no Estado do Paraná, período de fragilização (2010-2018)

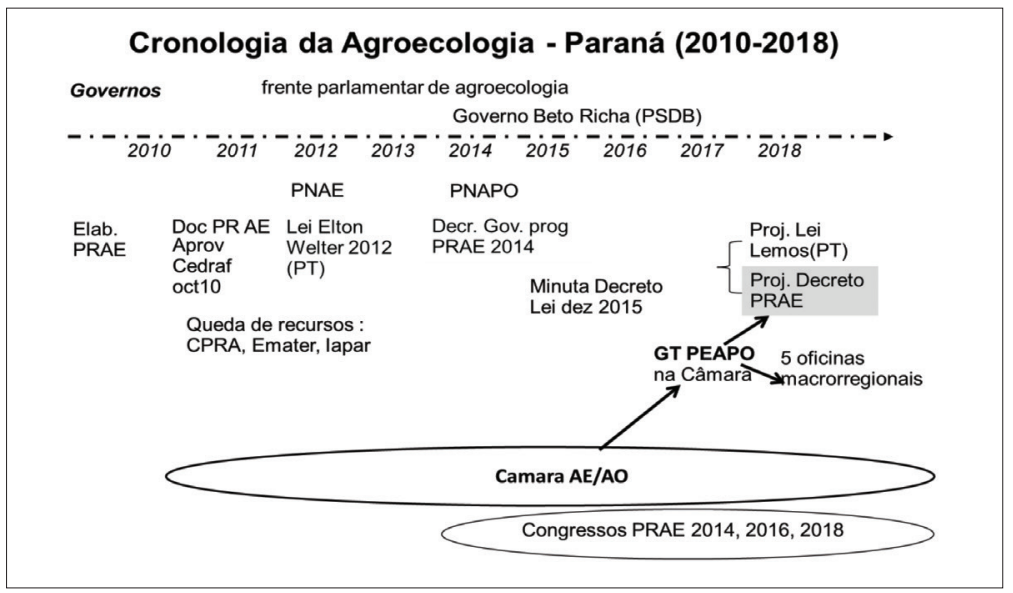

Os governos seguintes após 2010 mostraram-se bem mais reservados no apoio à temática. Com as mudanças governamentais os principais dirigentes do CPRA foram exonerados e retornaram a suas instituições de origem (IAPAR, SEAB, EMATER) e as contratações previstas para formar um quadro próprio de funcionários não foram efetuadas. Nesse período o CPRA correu o risco de fechar suas portas, sob o argumento de que o trabalho era redundante com o que já faziam EMATER e IAPAR, mas foi mantido graças à mobilização de diversos atores da agroecologia, e de uma nova proposição de reestruturação proposto pela sua equipe. Um novo diretor foi nomeado, reagrupando profissionais ligados à agroecologia, remanejados de instituições como SEAB, IAPAR, EMATER e Instituto Paranaense de Desenvolvimento Econômico e Social (IPARDES). Com apoio da Secretaria de Ciência, Tecnologia e Ensino Superior (SETI), foram liberados recursos para contratação de novos profissionais, o que permitiu manter a missão do CPRA.

Cabe destacar que apesar da demora na sua instrumentalização legal, muitas das ações previstas no Programa Paraná Agroecológico foram se desenvolvendo. Nesse meio tempo, foi apresentado, na Assembleia Legislativa do Paraná (ALEP), um projeto de lei para incentivos à produção agroecológica para os agricultores familiares. Tal projeto não foi fruto de um debate profundo na Câmara Setorial, visto que foi discutido apenas uma vez, o que dificultou inclusões ou alterações. Mesmo assim, a Câmara, bem como todo o movimento agroecológico, apoiou o projeto de lei e quando houve veto do Governador, em maio de 2012, todos mobilizaram-se favoravelmente. Enfim, a ALEP derrubou o veto e aprovou a Lei n ${ }^{\circ} 17.190$, de 18/06/2012 (PARANÁ, 2017), que incentiva 
sistemas de produção agroecológicos. Não obstante, como é comum no Brasil, a aprovação da lei não acarretou ações concretas.

A despeito da falta de apoio do novo governo e da falta de visibilidade dessa política, os membros do CEDRAF e da Câmara Setorial tentaram implementar uma regulamentação para o Programa PR Agroecológico, a fim de garantir a continuidade das propostas e de recursos para ações concretas, independente de mudanças governamentais. Finalmente, a Câmara comemorou a publicação do Decreto no 12.431, de 23/10/2014 (PARANÁ, 2017) que institui o Programa Paraná Agroecológico elaborado em 2011.

Em 2015, a Câmara percebe a necessidade de instituir uma Política Estadual de Agroecologia, originariamente, pensada como lei estadual. Na ocasião da $70^{a}$ reunião do CEDRAF, na qual se comemoraram os 10 anos do CPRA, a Câmara solicitou ao Secretário da Agricultura (SEAB) apoio à criação de uma Política Estadual de Agroecologia ${ }^{3}$. A disposição para apresentação do futuro projeto de lei foi manifestada por um deputado presente. Para a elaboração do projeto, a Câmara havia criado um grupo de trabalho (GT Política de Agroecologia), formado pela AOPA, CPRA, IAP (Instituto Ambiental do Paraná) e Secretaria de Estado da Saúde (SESA) e ao qual, posteriormente, juntou-se o INCRA (Instituto Nacional de Colonização e Reforma Agrária). Esse GT discutiu versões sucessivas de uma minuta de projeto de lei, de forma participativa com os membros da Câmara Setorial. Esse processo de discussão apesar de lento, reflete a preocupação em validar as decisões coletivamente, dedicando um tempo maior para pontos que geram dúvidas e conflitos. Por exemplo, numa reunião de março de 2018 que observamos, as regras de condução estabelecidas para as discussões levaram a uma abordagem em duas etapas, primeiro com uma identificação das principais sugestões, observações e destaques, e em seguida uma revisão sistemática dessas sugestões e inclusões. Depois dessa reunião o GT resgatou mais sugestões enviadas pelos demais membros.

Posteriormente, a assessoria jurídica da Secretaria da Agricultura (SEAB), recomendou que a instituição de tal política se desse por meio de um decreto, que regulamentaria a Lei no 17.190/2012. Assim, o processo de construção foi retomado para adequações. Em uma última reunião do GT, em dezembro de 2018, já com assessoria jurídica da ONG Terra de Direitos, o setor jurídico da SEAB, indicou que a minuta proposta pela Câmara extrapolava o disposto na lei que o decreto regulamentaria.

Paralelamente, outro deputado protocola, na ALEP, um projeto de lei (PL) 823/2017 (PARANÁ, 2018), propondo a instituição de uma Política Estadual de Agroecologia e Produção Orgânica. Ao saber do PL, a Câmara mobiliza-se, 
em caráter de emergência, e consegue apresentar algumas contribuições. No entanto, diante da conjuntura desfavorável de correlação de forças na ALEP, a tramitação de tal PL fez-se de maneira lenta e cuidadosa, não tendo sido levado à votação.

Apesar da Lei $n^{\circ}$ 16.751/2010 que instituiu a merenda orgânica nas escolas, apenas em 2017, foi solicitado um estudo de viabilização da merenda orgânica para as escolas do Paraná, realizado por profissionais do governo (CPRA, IAPAR, EMATER e SEAB). Em 2018, por pressão do Ministério Público do Paraná (MP-PR), foi instituído o Grupo de Trabalho Intersetorial Estadual - GTI-E, formado por 10 representantes do Poder Público (Educação, Saúde, Agricultura, Meio Ambiente, Ciência e Tecnologia, CPRA, MP-PR) e 7 representantes da sociedade civil (produtores, consumidores, empresas e certificadores). Sob coordenação do Instituto Paranaense de Desenvolvimento Educacional (FUNDEPAR), responsável pela alimentação escolar, foi elaborada a minuta de um decreto e um Plano de introdução progressiva de alimentos orgânicos na merenda escolar até 2030 .

Com a entrada do novo governo em 2019, foi dada publicidade à intenção de assinatura desse decreto da alimentação escolar, mas a incerteza de continuidade e a perda de força da agroecologia no terreno das instituições governamentais é notória, com a possível extinção e fusão de instituições que foram chaves no processo de condução do Programa Paraná Agroecológico como a EMATER (63 anos), IAPAR (47 anos) e CPRA (14 anos). Essas instituições devem ser incorporadas formando um novo Instituto de Desenvolvimento Rural do Paraná, sem garantias de tratamento diferenciado para a agroecologia e aprovação da PEAPO.

\section{Ações implementadas a partir do Programa Paraná Agroecológico (PRAE)}

Entre as prioridades elencadas no documento PRAE de 2011, e considerando a falta de recursos humanos e apoio financeiro destinados à agroecologia, cabe destacar as ações que foram executadas. Por iniciativa de profissionais ligados as universidades, foram criados 14 Núcleos de Estudo em Agroecologia, além de cursos de formação superior em Tecnologia em Agroecologia, Agronomia com ênfase em Agroecologia, Mestrado em Agroecologia, Doutorado em Meio Ambiente e Desenvolvimento (eixo do Rural com várias teses na linha agroecológica) em sete universidades estaduais e quatro universidades federais (UFPR Curitiba, UFPR Litoral, IFPR Ivaiporã e UFFS Laranjeiras do Sul). 
Foram realizados investimentos em processos de certificação através do Programa Paranaense de Certificação de Produtos Orgânicos (PPCPO) executado pelas universidades estaduais, TECPAR (Instituto de Tecnologia do Paraná) e CPRA, via SETI-PR para desenvolver ações de extensão, pesquisa e capacitação em áreas estratégicas, entre elas a agroecologia e agricultura familiar. O Programa que passou a se chamar "Paraná + Orgânico" completou 10

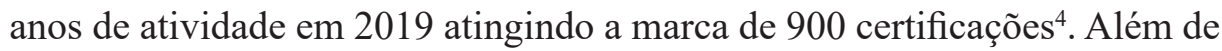
apoiar a organização dos agricultores familiares em processos de certificação e comercialização da produção orgânica, o programa apoia também a formação de profissionais qualificados em produção e certificação de orgânicos.

Um ponto forte dos atores agroecológicos no Paraná tem sido a organização do multievento Paraná Agroecológico, organizado pelos atores chaves do Comitê Gestor do Programa PRAE, para compartilhamento de experiências e conhecimentos entre os atores que atuam com agroecologia. Foram realizadas três edições (I PRAE, Curitiba, 2014; II PRAE Maringá, 2016 e III PRAE Foz do Iguaçu, 2018). Na oportunidade são organizados vários subeventos temáticos que envolvem pesquisa e ensino, extensão, certificação e consumo. Outros eventos que contribuem são as Jornadas de Agroecologia capitaneadas pelos movimentos sociais do campo trazendo uma discussão crítica dos modelos de agricultura e alimentação.

Um dos movimentos que tomaram força a partir de 2014 foram as "festas e feiras de sementes crioulas" realizadas de forma articulada, através do coletivo Rede Sementes da Agroecologia (ReSA) que reúne atores de diferentes regiões do Paraná para fortalecer iniciativas agroecológicas, com destaque para associações de produtores e ONGs agroecológicas. Em 2018, foram mapeadas 14 Feiras de Sementes da agricultura familiar no Paraná. Na seara dos mercados locais, venda direta e mercados institucionais, que corresponde a um dos eixos do PRAE, nota-se um avanço dos circuitos curtos de comercialização de produtos agroecológicos/orgânicos, a partir de iniciativas de atores públicos e privados (DAROLT et al., 2016). Finalmente, uma ação importante foi o trabalho sobre a merenda escolar orgânica ${ }^{5}$, conforme visto anteriormente, com o Programa Estadual de Alimentação Escolar (PEAE), ampliando e equilibrando a participação de atores de diferentes áreas (educação, saúde, agricultura, meio ambiente, alimentação e consumo), e com

4 Disponível em: 〈https://paranaportal.uol.com.br/agronegocio/parana-mais-organico-alcanca-a-marca-de-900-certificacoes〉.

5 A oferta de produtos orgânicos para a alimentação escolar no Paraná vem aumentando desde 0 ano de 2011 e, em 2018, representava 13\% das entregas da Agricultura Familiar e 5\% do volume total de aquisições da alimentação escolar em cerca de 90 municípios. O Paraná é o estado que adquire a maior porcentagem de produtos da agricultura familiar (64\% em 2018) (convencional e orgânico), superando o mínimo estabelecido por lei de $30 \%$ de produtos da AF (Fundepar,2018). 
objetivo de atingir 100\% de alimentos orgânicos nas escolas do estado no ano de 2030.

\section{Atores chaves, alianças e governança}

\section{Atores envolvidos na elaboração do Programa Paraná Agroecológico (PRAE)}

Entre 2008 e 2011 uma equipe técnica e de colaboradores foi mobilizada para trabalhar na elaboração do PRAE, envolvendo instituições de diferentes setores do governo e da sociedade civil, permitindo a participação de representantes da pesquisa, do ensino, da extensão rural, dos movimentos sociais, de associações e redes de agricultores e consumidores, além de funcionários de diferentes secretarias de governo. Nota-se que as instituições pioneiras da agroecologia do Paraná descritas nas seções anteriores fizeram parte dessa construção participativa. A Figura 3, mostra o peso percentual dos quatro tipos de instituições no documento oficial publicado (pesquisa e ensino, movimentos sociais, assistência técnica, várias administrações da agricultura, educação e meio ambiente), totalizando 38 profissionais de 21 instituições.

Figura 3 - Participação de atores na elaboração do PRAE (2011)

\begin{tabular}{|c|c|}
\hline Instituições participantes na elaboração do Programa \\
Paraná Agroecológico
\end{tabular}

Apesar da construção do programa PRAE ser um processo participativo e consultivo, com muitas reuniões realizadas entre setembro de 2009 e setembro de 2010, envolvendo reuniões de trabalho e grupos temáticos na capital e eventos para atores do interior, observou-se que as instituições que representam a sociedade civil permaneceram minoritárias no painel de colaboradores. Isso se explica, em parte, pelos custos de viagem, menor número de funcionários, 
acúmulo de trabalho e desmotivação pela não aprovação de políticas voltadas aos movimentos. Por outro lado, os funcionários governamentais atuantes são na maioria agrônomos engajados com o movimento da agricultura ecológica, pioneiros desde a década de 1980, seja na academia, ensino, pesquisa, extensão ou movimentos sociais. Em termos de equilíbrio multidisciplinar, notava-se no início do processo e no documento PRAE de 2011, um peso maior de profissionais das ciências agrárias, destacadamente engenheiros agrônomos e biólogos e um peso menor das ciências sociais e humanas (sociologia, geografia, economia). Atualmente, percebe-se uma participação ativa das Ciências da Saúde, sobretudo nutricionistas e profissionais ligados ao Programa de Análise de Resíduos de Agrotóxicos (PARA).

Em síntese, pode-se notar a ausência de alguns movimentos sociais importantes da história da agroecologia no Paraná nas contribuições finais ao documento do PRAE, como o MST e Via Campesina, Escola Latino Americana de Agroecologia, ACOPA, AS-PTA, ASESSOAR, RURECO, CAPA, mesmo que estivessem associados e presentes em algumas reuniões, e um peso maior de instituições governamentais.

\section{Evolução da participação de atores na Câmara Setorial de Agroecologia após 2008}

A análise das Atas das reuniões da Câmara Setorial de Agroecologia entre 2008 e 2018 permitem identificar os atores chave que participaram desse processo: EMATER, AOPA, IAPAR, CPRA, EMBRAPA, Universidades (Federal e Estaduais), SEAB, SETI, SEED e outras Secretarias de estado, MST, Rede Ecovida, sindicatos, ASSESOAR, outras ONGs e Associação de Consumidores (ACOPA). No período mais recente (após 2015), alguns atores são incluídos no processo como o IAP e o INCRA, do lado das instituições públicas, assim como alguns operadores comerciais.

De fato, observa-se uma participação regular e continua, desde os anos de 1980, de uma dezena de atores chaves, resultado do engajamento de "agrônomos chave" que atuaram no processo. Percebe-se também na linha do tempo dificuldades crescentes de participação da sociedade civil (sobretudo, ONGs do interior do estado). A nossa análise da participação de entidades da sociedade civil em reuniões da Câmara Setorial mostra que ela foi numa proporção média de $21 \%$, ou seja, em média 1 membro de ONG para cada 5 membros do governo.

Cabe destacar que o princípio de paridade foi mantido como regra geral desde o início, ainda que na Câmara Setorial exista certa flexibilidade, diferentemente do CEDRAF. Outro princípio importante mantido desde 2008 é o da 
coliderança entre atores públicos e ONGs, tendo um secretário e coordenador vindo de cada lado.

Ao longo dos anos, tem havido debates sobre a abertura da lista de participantes para novos integrantes e ajustes na composição da Câmara Setorial. Como exemplo, durante uma das primeiras reuniões em 2009, o então Presidente da Câmara, questionado sobre a inclusão de outras entidades, garantiu que "a lista não é fechada, e a participação ocorre através de ofício enviado à Câmara solicitando inclusão de um novo membro, que será posteriormente analisado pela Câmara" (Ata CSA 24/09/2009).

A maior parte dos membros que participam da Câmara Setorial de Agroecologia (Coordenada pelo CEDRAF) também faz parte da CPOrg-PR, coordenada pelo MAPA. Para otimizar essas reuniões e deslocamentos, a partir de 2015, foi decidido que as reuniões seriam unificadas numa mesma data e local (alternando capital e interior do Paraná), sendo dividida a pauta de reunião, conforme as demandas de cada fórum, incluindo visitas a experiências locais e dividindo responsabilidades na sua organização. Essa estratégia foi positiva e tem proporcionado a participação mais ativa dos membros.

\section{A gestão do Programa Paraná Agroecológico}

O decreto de 2014 prevê duas instâncias de gestão do Programa Paraná Agroecológico:

A Câmara Setorial de Agroecologia e Agricultura Orgânica, a qual compete propor as diretrizes, os objetivos, os instrumentos e as prioridades do PRAE; facilitar a interação entre instâncias governamentais e não governamentais relacionadas à agroecologia; e acompanhar a execução das ações do PRAE.

O Comitê Gestor do PRAE, ao qual compete a responsabilidade técnica pela coordenação, mobilização e monitoramento das ações e processos que contribuam ao cumprimento dos objetivos do Programa Paraná Agroecológico.

O Comitê Gestor é composto por 15 representantes titulares e 15 suplentes dos seguintes órgãos: Secretarias de Estado (Agricultura - SEAB, Ciência Tecnologia e Ensino Superior - SETI, Educação - SEED), CPRA, EMATER, IAPAR, IAP, IPARDES e representantes das Universidades Estaduais.

Ainda é destacada no decreto a necessidade de um Plano de Ação, conduzido pelo Comitê Gestor e aprovado pela Câmara Setorial. Ademais, o decreto acrescenta que o PRAE será realizado com recursos financeiros de dotações consignadas nos orçamentos dos órgãos integrantes do Comitê Gestor, de outras instituições públicas ou privadas que aderirem ao Programa e outras fontes, sem detalhar e especificar valores. Na maioria das instituições 
os orçamentos para a agroecologia estão diluídos no conjunto dos projetos de cada instituição.

\section{Um funcionamento centralizado}

Um funcionamento demasiadamente centralizado nas instâncias governamentais (que geralmente se reúnem em Curitiba) explica a falta de mobilização tanto da sociedade civil (movimentos de agricultores familiares e camponeses), como de apoio político (de representantes eleitos de outras regiões). Isto tem sido enfatizado desde o início da formação da Câmara Setorial e do processo de elaboração do PRAE. Um dos representantes da sociedade civil relatou a importância dos atores do meio rural nas discussões das políticas públicas (Ata CSA 24/09/2009). A questão do formato das reuniões, seja estadual ou regional, e a rotatividade das reuniões, indo para o interior do estado, foi um aspecto destacado como positivo ainda no começo do processo.

Essa dinâmica de descentralização levou o Comitê Gestor a organizar cinco oficinas nas principais macrorregiões do estado em 2017 e 2018, visando divulgar o programa, organizar um diagnóstico atualizado, levantar problemas e potencialidades de forma hierarquizada e montar planos de ação com o apoio de comitês regionais. Esse procedimento permitiu descentralizar as ações, repassar responsabilidades aos atores do território e construir de forma participativa os planos com representantes de organizações ligadas à agroecologia de cada região, com resultados refletindo as especificidades territoriais. Algumas regiões como no litoral e região metropolitana de Curitiba desenvolvem atualmente ações frutos das oficinas regionais e da formação dos Comitês Gestores regionais, as quais facilitaram uma nova articulação entre os atores.

De fato, o exercício de montar Planos de Ação regionais com a participação de agricultores, da sociedade civil e de atores que mobilizam a agroecologia em seus territórios foi potencializada. Esse processo ajudou a retomar a dinâmica de institucionalização da agroecologia e representa uma dinâmica mais ampla de "territorialização" das políticas públicas (Ata CEDRAF 15/12/15).

\section{Conceitos e controvérsias sobre agroecologia}

\section{Definições de agroecologia e transição agroecológica}

Como mostra a comparação abaixo entre temas e conceitos propostos no Programa PRAE (2011) e na minuta de decreto da PEAPO (2018), da Câmara Setorial, o conceito de agroecologia no início continha mais 
fortemente princípios agroecológicos da "dimensão técnica", apesar de citar princípios da "dimensão sociocultural", como conhecimento e cultura local; autoconsumo; segurança alimentar e nutricional; relações equilibradas de gênero e justiça social. O que se vê posteriormente na comparação textual é a busca por uma articulação maior e equilíbrio entre as dimensões "técnicas", "sociais", "econômicas" e "ecológicas" (quadro 1). A transição agroecológica também aparece como prioridade nas ações a conduzir em ambos documentos, aparecendo entre os "termos conceituados" na minuta do Decreto de 2018, como instrumentos da PEAPO, a garantia de renda compensatória na fase de transição agroecológica e de conversão orgânica. Outro novo termo em 2018, que reflete a evolução recente dos debates nas redes de agroecologia brasileiras, são os "produtos da agrobiodiversidade", voltados à formação de cadeias produtivas de interesse dos povos e comunidades tradicionais e de agricultores familiares, que promovam a manutenção e valorização de suas práticas e saberes.

Quadro 1 - Comparação e evolução do conceito de agroecologia e transição agroecológica no documento base do Programa Paraná Agroecológica (2011) e Proposta de Decreto da PEAPO (2018)

\begin{tabular}{|c|c|c|}
\hline Definições & Programa PRAE *(2011) & Minuta de Decreto PEAPO 2018)** \\
\hline $\begin{array}{l}\text { Conceito de } \\
\text { Agroecologia }\end{array}$ & $\begin{array}{l}\text { Agroecologia baseada em } \\
\text { princípios agroecológicos "téc- } \\
\text { nicos" (equilíbrio ecológico, } \\
\text { métodos culturais biológicos, } \\
\text { manutenção do solo, baixa de- } \\
\text { pendência de insumos, etc.); e } \\
\text { princípios "socioculturais" (in- } \\
\text { corporação do conhecimento } \\
\text { e da cultura local, autoconsu- } \\
\text { mo, segurança alimentar e nu- } \\
\text { tricional; relações equilibradas } \\
\text { de gênero e respeito às dife- } \\
\text { renças), participação política } \\
\text { e empoderamento dos atores. }\end{array}$ & $\begin{array}{l}\text { Agroecologia definida como uma agricultu- } \\
\text { ra fruto da articulação entre conhecimento } \\
\text { técnico-científico, saberes e fazeres ances- } \\
\text { trais e culturas populares e tradicionais, } \\
\text { que seja socialmente justa, economica- } \\
\text { mente viável, ecologicamente sustentável, } \\
\text { que busque otimizar a integração entre } \\
\text { capacidade produtiva, uso e conservação } \\
\text { da biodiversidade e dos demais recursos } \\
\text { naturais, englobando formas de produção } \\
\text { orgânica, biodinâmica ou outros estilos de } \\
\text { base ecológica". }\end{array}$ \\
\hline $\begin{array}{l}\text { Transição } \\
\text { Agroecológica } \\
\text { (lugar e con- } \\
\text { ceito) }\end{array}$ & $\begin{array}{l}\text { O apoio e fortalecimento de } \\
\text { iniciativas que visem à trans- } \\
\text { formação de sistemas produ- } \\
\text { tivos agrícolas convencionais, } \\
\text { baseados no uso intensivo de } \\
\text { agroquímicos (adubos, agrotó- } \\
\text { xicos e outros insumos indus- } \\
\text { triais), em estilos de produção } \\
\text { familiar que incorporem prin- } \\
\text { cípios agroecológicos. }\end{array}$ & $\begin{array}{l}\text { Processo gradual e multilinear de mudan- } \\
\text { ça de modelos de produção, de manejo } \\
\text { de agroecossistemas e de sistemas ex- } \\
\text { trativistas, tradicionais ou convencionais, } \\
\text { por meio da transformação das bases } \\
\text { produtivas e sociais do uso da terra e dos } \\
\text { bens naturais, incorporando conceitos, } \\
\text { princípios, metodologias e tecnologias de } \\
\text { base ecológica. }\end{array}$ \\
\hline
\end{tabular}




\section{Controvérsias e discussões sobre o perfil dos agricultores a serem incluídos nas políticas de agroecologia}

A questão do público "alvo" da agricultura familiar nas políticas de agroecologia foi debatida ao longo dos anos. No documento do Programa PRAE (2011) e no Decreto que institui o Programa (2014), as ações do Programa PRAE são dirigidas aos produtores rurais, preferencialmente agricultores familiares e empreendedores familiares rurais e suas organizações. Paralelamente aos produtores, incluem-se uma rede de apoiadores que abrange técnicos da assistência técnica e extensão rural, pesquisadores, professores, estudantes e organizações do setor público e da sociedade civil organizada; os consumidores e suas organizações.

No projeto de decreto da PEAPO (2018), é redefinido o público alvo "produtores rurais, preferencialmente agricultores familiares e empreendedores familiares rurais" sendo acrescentado "povos e comunidades tradicionais". Um parágrafo único foi acrescentado, mencionando que as ações da PEAPO poderão atender também os demais agricultores que demonstrem interesse em participar dessa política. A nuance é significativa, pois expressa em poucas palavras os resultados de muitos debates, ao longo dos anos, em que alguns participantes da Câmara desejam estender as ações a produtores (neorurais), que não se encaixam nas definições de "agricultor familiar" e não conseguem obter financiamentos de políticas, como o Programa Nacional de Fortalecimento da Agricultura Familiar (PRONAF), por exemplo. Em uma das reuniões do CEDRAF (08/12/2015), foi comentado que o Secretário tem compromisso com a agricultura familiar orgânica, mas que é preciso incluir também o público das grandes cooperativas. Esses debates trazem à tona uma problemática de fronteira entre a agricultura familiar/empresarial e a agroecologia, mas também entre uma orientação técnico-produtiva e uma orientação político-social de agroecologia que podem ser vistos amplamente depois de uma década (LAMINE; ABREU, 2009). Um consenso construído em 2018 é a necessidade de ampliar o público alvo da agricultura familiar, sobretudo, para priorizar os povos e comunidades tradicionais.

Os debates se acentuam também no público dos agricultores "em transição". Um consenso dos membros da Câmara de Agroecologia na elaboração da minuta do decreto da PEAPO foi apoiar fortemente os agricultores na fase de transição e os que adotam as práticas orgânicas e agroecológicas, mesmo não tendo certificação, mas com definição de prazos para a conclusão do processo de transição. A proposta é o pagamento de preços diferenciados (prêmio) para os agricultores em transição (entre orgânico e convencional), priorizando aqueles que entregam para programas de alimentação escolar. 


\section{O lugar das questões alimentares e da escala territorial nos debates}

No Programa Paraná Agroecológico e mais amplamente nos debates das instâncias que foram acompanhadas, a narrativa continua centrada nas questões agronômicas e técnicas (tipos de práticas, propriedades e agricultores), sendo a participação de agrônomos e agricultores majoritária nas diferentes instâncias (Câmara, CPORg e CEDRAF), e as questões alimentares tratadas por nutricionistas (ciências da saúde), por exemplo, sendo minoritárias.

A questão alimentar tem sido abordada sobretudo por meio de mercados institucionais, como o programa de alimentação escolar. Não obstante, o PRAE em seus cinco eixos levou em consideração os diferentes elos do sistema alimentar, desde a produção, processamento e distribuição, comercialização e consumo, considerando apoios para pesquisa, ensino, extensão e legislação. Cabe destacar que por um longo tempo alguns Programas da EMATER, como a "Fábrica do Agricultor", permitiram apoiar diretamente o processamento e transformação por meio de pequenas agroindústrias. No entanto, questões de interdependência no sistema alimentar (que favorecem e promovem mudanças de práticas alimentares) e a conexão necessária entre agricultura, meio ambiente, alimentação e saúde não foram aprofundadas.

Na última fase de desenvolvimento da minuta de decreto (2018), a questão alimentar parece encontrar um lugar de destaque nas diretrizes da PEAPO, aparecendo inicialmente como "a promoção da soberania e segurança alimentar e nutricional e do direito humano à alimentação adequada e saudável, conforme prevê a Lei $\mathrm{n}^{0} 11.346$, de 15/09/2006, por meio da oferta de produtos orgânicos e de base agroecológica, garantindo o acesso da população a esses produtos", e em seguida como "o uso sustentável dos recursos naturais e conservação dos ecossistemas". Em outra minuta de decreto complementar à PEAPO, que trata da Política Estadual de Alimentação Escolar (supracitado), fica evidente a ligação com a questão alimentar e nutricional.

Em termos de intersetorialidade, cabe destacar que o Paraná criou também um Plano Estadual de Segurança Alimentar e Nutricional (PESAN) e, como em outros estados, um Conselho Estadual de Segurança Alimentar e Nutricional (CONSEA-PR). Porém, as articulações entre as duas instâncias (CONSEA-PR e Câmara de Agroecologia) não foram muito sinérgicas. A agroecologia aparece mais valorizada como um modelo agrícola no PESAN do que a SAN no documento do Programa PRAE: "modelos agroecológicos de produção podem contribuir para reduzir as desigualdades sociais, uma vez que permitem a inclusão social dos produtores e consumidores excluídos do modelo convencional de produção, que leva a concentração de riquezas" 
(PESAN-PR, 2013, p. 13). O desafio de uma visão sistêmica é integrar não apenas diferentes aspectos dos sistemas agrícolas, mas também o acesso à alimentação, como citado no documento, que enfatiza também a necessidade de considerar uma visão sistêmica das relações entre pobreza, produção de alimentos e segurança alimentar (PESAN-PR, 2013, p.25).

Finalmente, como no nível nacional (LAMINE; NIEDERLE; OLLIVIER, 2019), a escala territorial também aparece nos debates. Em algumas reuniões observou-se que alguns atores destacam "a necessidade de enfatizar a abordagem territorial. Em relação à agricultura de pequena escala, um participante acredita que o plano deveria propor uma conexão do público consumidor com o espaço rural e sua produção, que não é somente alimentos, mas água, ambiente, paisagem e uma série de coisas que o meio urbano desfruta e nem percebe. O rural precisa entrar na agenda política da educação, da saúde e em todos os setores" (Ata, CEDRAF, 15/12/2015). De fato, a ligação entre o nível estadual e o nível municipal é facilitada pela presença de vários agentes nos escritórios locais (EMATER, em particular), bem como a mobilidade e forte presença nos municípios de alguns agentes de serviços de estado (caso da Secretaria de Educação - SEED, com o Programa Estadual de Alimentação Escolar, que atende todos os municípios do estado).

Pode-se notar também que, além do recente debate sobre os riscos de redução de áreas de proteção ambiental e discussões sobre o uso abusivo de agrotóxicos, as questões ambientais mais amplas - relacionadas com a agricultura (equilíbrio entre as formas de agricultura, questões de paisagem, manutenção de ecossistemas, entre outros) - parecem menos apoiadas pela sociedade civil. Isto pode ser explicado pelo fato de que os representantes da sociedade civil estão principalmente ligados as associações de agricultores e mobilizados pelas questões de acesso e uso da terra, além de uma associação de consumidores que apoia a agroecologia como modelo de produção alimentar, pois sabe que "a inclusão do tema saúde e agrotóxicos na política agroecológica mobiliza o mundo urbano", como destaca um dos membros da Câmara (reunião CEDRAF, novembro de 2012).

\section{Conclusão}

As dificuldades de implantar uma política estadual de agroecologia e a justificativa do Paraná como estado pioneiro na agroecologia começam, com o passar dos anos, a perder força, mesmo se o Centro Paranaense de Referência em Agroecologia (CPRA) foi considerado uma inovação em termos de instituição totalmente dedicada a agroecologia: "o Paraná é o único 
estado brasileiro que possui uma instituição estatal voltada exclusivamente à agroecologia" (CEDRAF, 15/12/2015). Uma instituição original hoje em risco de extinção.

O governo eleito em 2010 não apoiou significativamente a agroecologia. Mesmo com duas leis e dois decretos aprovados (Leis da Merenda Escolar Orgânica de 2010 e Lei sobre incentivos a implantação de sistemas de produção agroecológica e orgânica de 2012; além do Decreto que institui o Programa Paraná Orgânico de 2014 e o Decreto que institui o Grupo de Trabalho intersetorial para regulamentar a alimentação escolar orgânica), os recursos financeiros para implementar as ações previstas foram muito pontuais. Com o novo governo (2019-2022), a situação é ainda mais preocupante, sinalizando uma tendência clara de desinstitucionalização da agroecologia. Além desses fatores políticos evidentemente decisivos para implementação de uma política de agroecologia permanente, esse trabalho mostrou que alguns fatores que explicam a dinâmica pioneira do Paraná, também apontam para "retrocessos" que mostram as dificuldades atuais de institucionalização da agroecologia:

A dinâmica pioneira da agroecologia foi impulsionada por funcionários altamente comprometidos, tanto em instituições de pesquisa, como de ensino e extensão (a geração de agrônomos "antirrevolução verde", formados, em sua maioria, a partir da década de 1980). Atualmente boa parte das instituições encontra-se fragilizada em recursos humanos, com a aposentadoria de pessoas-chave, associadas ao declínio de recursos e investimentos nessas instituições enfraquecendo a "portfólio institucional";

O estado que apresentava boa capacidade de pesquisa e desenvolvimento de ações de extensão rural, mas, desde 2011, registrou reduções significativas de investimentos em recursos humanos e materiais;

Em meados dos anos 2000, o Paraná estava em uma fase de debate e luta contra os transgênicos (na época o governo Requião queria declarar o Paraná livre de transgênicos), ao lado da pressão do agronegócio para colocar o Paraná como um dos maiores produtores de grãos (soja e milho) para exportação. Note-se que no período recente, os debates voltam a esta questão, estimulando "o fomento à criação de territórios livres de transgênicos e de agrotóxicos" (minuta de decreto da PEAPO-PR, 2018).

Finalmente, outros fatores emergem de uma comparação com outros estados (GUÉNEAU et al., 2019). A pouca participação dos atores (nas instâncias), que podemos notar graças à abordagem longitudinal desse estudo, também explica uma certa falta de renovação. O enfraquecimento da participação da sociedade civil nessas instâncias enfraquece as alianças e os processos de legitimação da agroecologia. Isso parece ocorrer por um conjunto de fatores 
como a falta recursos financeiros para participar das reuniões, falta de motivação pela demora na implementação dessas políticas, por não contemplarem suas demandas, e pelos movimentos priorizarem outros eventos e projetos (feiras de sementes e jornada de agroecologia, por exemplo). No entanto, também em comparação com outros estados, o recente ressurgimento do processo de institucionalização mostra a renovação (através dos Núcleos de Estudo em Agroecologia - NEAs ligados as universidades), a remobilização de alguns atores (embora ainda poucos da sociedade civil) e uma maturidade nos processos de debates democrático e participativo, enquanto em alguns estados o desenvolvimento do PEAPO parece ter sido feito de uma maneira mais tecnocrática. 


\section{REFERÊNCIAS}

ALTIERI, M. A.; TOLEDO V. M. The agroecological revolution in Latin America: rescuing nature, ensuring food sovereignty and empowering peasants. The Journal of Peasant Studies, v. 38, n. 3, p. 587-612, 2011.

BRANDENBURG, A. Movimento agroecológico: trajetória, contradições e perspectivas. Desenvolvimento e Meio Ambiente, n. 6, p. 11-28, 2002.

BRASIL. Lei 10831, de 23/12/2003. Dispõe sobre agricultura orgânica e dá outras providências. Disponível em: $<\mathrm{http}: / / w w w . p l a n a l t o . g o v . b r>$. Acesso em: 31 ago. 2018.

CAPORAL, F. R.; COSTABEBER, J. A. (Orgs.). Agroecologia e extensão rural sustentável: contribuições para a promoção do desenvolvimento rural sustentável. Brasília: MDA/SAF/DATER/IICA, 2004.

DAROLT, M. R.; LAMINE, C. L.; BRANDENBURG, A.; ALENCAR, M. C. F.; ABREU, L. S. Redes alimentares alternativas e novas relações produção-consumo na França e no Brasil. Ambiente \& Sociedade, São Paulo, v. 19, n. 2, p. 1-22, 2016.

FLEXOR G.; GRISA C. Contention, ideas, and rules: the institutionalization of family farm policy in Brazil. Canadian Journal of Latin American and Caribbean Studies, v. 41, n. 1, p. 23-37, 2016.

FOUILLEUX, E.; JOBERT, B. Le cheminement des controverses dans la globalisation néo-libérale: pour une approche agonistique des politiques publiques. Gouvernement et action publique, v. 3, n. 3, p. 9-36, 2017.

FUNDEPAR. Plano de introdução progressiva de produtos orgânicos na alimentação escolar do Estado do Paraná. Relatório interno (não public.). Curitiba: Instituto Paranaense de Desenvolvimento Educacional/Fundepar, 2018.

GRISA, C. A agricultura familiar nas políticas para a agricultura familiar. In: DELGADO, G. C.; BERGAMASCO, S. M. P. P. Agricultura familiar brasileira: desafios e perspectivas de futuro. Brasília: SEAD, 2017. p. 292-313. 
GUÉNEAU, S. et al. A construção das políticas públicas estaduais de agroecologia e produção orgânica no Brasil. Revista Brasileira de Agroecologia, v. 14, n. 1, p. 9-23, 2019.

IPARDES. As espacialidades socioeconômico-institucionais no período 20032015. Instituto Paranaense de Desenvolvimento Econômico e Social. Curitiba: IPARDES, 2017.

KARAM, K. F. Agricultura orgânica: estratégia para uma nova ruralidade. 2001. Tese (Doutorado em Meio Ambiente e Desenvolvimento) - Universidade Federal do Paraná, Curitiba, 2001.

LAMINE C.; ABREU L. S. Compared trajectories of agro-ecology in Brazil and France: the role of scientists and social movements. XXIII ESRS Congress, Vaasa, Finland, aug. 2009.

LAMINE C.; NIEDERLE P.; OLLIVIER, G. Alliances et controverses dans la mise en politique de l'agroécologie au Brésil et en France. Natures, Sciences et Sociétés, v. 27, n. 1, p. 6-19, 2019.

LASCOUME, P.; LE GALÈS, P. Sociologia da Ação Pública. Maceió: EDUFAL, 2012.

MALUF, R. Prefacio. In: NIEDERLE, P. A. et al. (Orgs.). Agroecologia: práticas, mercados e políticas para uma nova agricultura. Curitiba: Kairós Edições, 2013.

MELÃO, I. B. Programa Paraná Agroecológico: o processo participativo para construção de uma política pública. Cad. IPARDES, v. 1, n. 2, p. 36-44, 2011.

MIRANDA, M. Lançamento da Rede Paranaense de Pesquisa em Agroecologia - REPAGRO. Cadernos de Agroecologia, v. 9, n. 1, 2014.

MULLER, P. L'analyse cognitive des politiques publiques: vers une sociologie politique de l'action publique. Revue française de science politique, v. 50, n. 2, p. 189-207, 2000.

NIEDERLE, P.; GRISA, C. Ideias e valores: a análise da ação pública a partir das interfaces entre a abordagem cognitiva e a economia das convenções. Política \& Sociedade, v. 12, p. 97-136, 2013.

PARANÁ. Decreto 12.431, de 23/10/2014. Institui o Programa Paraná Agroecológico. Disponível em: <https://www.legislacao.pr.gov.br>. Acesso em: 23 out. 2017. 
PARANÁ. Lei 16.751, de 29/12/2010. Institui, no âmbito do sistema estadual de ensino fundamental e médio, a merenda escolar orgânica. Disponível em: $<\mathrm{http} / / /$ portal.assembleia.pr.leg.br>. Acesso em: 31 ago. 2018.

Lei 17.190, de 18/06/2012. Dispõe sobre os incentivos à implantação de sistemas de produção agroecológica e orgânica pelos agricultores familiares no Estado do Paraná. Disponível em: <http://portal.assembleia.pr.leg.br>. Acesso em: 23 out. 2017.

. Lei Estadual 14.980, de 28/12/2005. Institui o Centro Paranaense de Referência em Agroecologia - CPRA, entidade autárquica vinculada à Secretaria de Estado da Agricultura e do Abastecimento. Disponível em: $<$ https://www. legislacao.pr.gov.br>. Acesso em: 10 jun. 2019.

Projeto de Lei 823/2017. Dispõe sobre política estadual de agroecologia e produção orgânica. Disponível em: $<$ http://portal.alep.pr.gov.br/index.php/ pesquisa-legislativa/proposicao $>$. Acesso em: 21 fev. 2018.

PESAN-PR. Plano Estadual de Segurança Alimentar e Nutricional. Curitiba: CAISAN - Câmara Governamental Intersetorial de Segurança Alimentar e Nutricional. 2012. Disponível em: $<$ http://www.consea.pr.gov.br/arquivos/File/ ANEXOIPlanoEstadualIIregina.pdf $>$. Acesso em: 24 jun. 2019.

PETERSEN, P.; MUSSOI, E.; DAL SOGLIO, F. Institutionalization of the agroecological approach in Brazil: advances and challenges, Agroecology and Sustainable Food Systems, v. 37, n. 1, p. 103-114, 2013.

SCHMITT, C. et al. La experiencia brasileña de construccion de políticas públicas en favor de la Agroecologia. In: SABOURIN, E. et al. (Eds.). Políticas Públicas en favor de la agroecología en América Latina y el Caribe. Porto Alegre: Red PP-AL, FAO, 2017. p. 73-122.

SEPULCRI, O.; DE PAULA, N. A EMATER e seu Papel na Difusão de Tecnologia nos seus 50 Anos. Prêmio Extensão Rural, n. 2, 2006.

VILELA, G. F. et al. Agricultura orgânica no Brasil: um estudo sobre o Cadastro Nacional de Produtores Orgânicos. Campinas: Embrapa Territorial, 2019. 


\title{
CAPÍTULO 3
}

\section{CONSTRUÇÃO, INSTITUCIONALIZAÇÃO E IMPLEMENTAÇÃO DA POLÍTICA ESTADUAL DE AGROECOLOGIA E PRODUÇÃO ORGÂNICA NO RIO GRANDE DO SUL}

\author{
Paulo Niederle \\ José Cleber Dias de Souza \\ Sabrina Milano Vaz \\ Gervásio Paulus \\ Alberto Bracagiolli Neto
}

\section{Introdução}

Este capítulo analisa a trajetória de construção, institucionalização e implementação da Política Estadual de Agroecologia e Produção Orgânica do Rio Grande do Sul (PEAPO-RS)1. Desde os anos 1990, este estado tem demonstrado importante protagonismo nas discussões sobre a incorporação de um referencial de agroecologia como orientador da ação pública, principalmente no que tange às políticas para a agricultura familiar e o desenvolvimento rural (SCHMITT, 2016). Com efeito, trata-se de um dos poucos estados brasileiros que, atualmente, possui um Plano Estadual de Apoio à Agroecologia e à Produção Orgânica (PLEAPO) em implementação - com algumas ações já concluídas -, e cujos resultados parciais também serão brevemente discutidos neste capítulo.

Em grande medida, o protagonismo do Rio Grande do Sul na construção de políticas para a agroecologia e produção orgânica está associado à capacidade de articulação da sociedade civil organizada, a qual, desde o final dos anos 1970, vem produzindo experiências de "agricultura alternativa"2. No entanto, foi principalmente com a reorientação política no governo estadual durante o mandato de Olívio Dutra (1999-2003) - no qual organizações da sociedade civil participaram ativamente -, que o tema da agroecologia

1 Os autores agradecem os comentários e sugestões de Agda Regina Yatsuda Ikuta e Marli Guimarães.

2 Termo utilizado sobretudo nos anos 1980 para se contrapor ao modelo de agricultura da Revolução Verde (LUZZI, 2007). 
adentrou na esfera estatal. Naquele momento produziu-se um primeiro esforço de ecologização da agricultura gaúcha por meio, principalmente, da extensão rural (CAPORAL; COSTABEBER, 2000)3. . Apesar de parcialmente interrompida em gestões posteriores, esta experiência tem contribuído, desde 2003, para a construção tanto da nova Política Nacional de Assistência Técnica e Extensão Rural (PNATER, em 2010), quanto da Política e do Plano Nacional de Agroecologia e Produção Orgânica (PNAPO, em 2012 e PLANAPO, em 2013).

Antes mesmo da criação da PNAPO, a incorporação do referencial da agroecologia pelo Estado brasileiro já havia implicado em alterações em um amplo conjunto de instrumentos de políticas públicas, com destaque para os programas de compras públicas de alimentos da agricultura familiar, de extensão rural, de uso e conservação dos recursos naturais e de crédito rural (NIEDERLE et al., 2018; SCHMITT; GRISA, 2013). A maioria destes instrumentos foi incorporada pelo PLANAPO (SAMBUICHI et al., 2017), o que resultou em um plano intersetorial formado a partir da "oferta" de 185 ações sob responsabilidade de diferentes ministérios, em especial dos Ministérios do Desenvolvimento Agrário (MDA), do Meio Ambiente (MMA) e da Agricultura (MAPA). O fortalecimento da PNAPO deu novo impulso à discussão no RS, que ganhou relevância durante o governo Tarso Genro (2011-2014), ao final do qual foi aprovada a PEAPO (Lei Estadual $n^{\circ} 14.486 / 2014$ ) e regulamentado o PLEAPO (Decreto Estadual n 5.1617/2014).

Com vista a analisar esta trajetória, e seguindo a orientação metodológica do projeto que deu origem a nossa pesquisa (ver introdução do livro), em 2018 iniciamos um esforço coletivo de sistematização e análise dos principais elementos estruturantes da PEAPO-RS (atores, referenciais, instituições, instrumentos). Este trabalho partiu da formulação de uma matriz qualitativa que foi preenchida por atores que participaram da construção da PEAPO-RS e do PLEAPO. Embora todos representem alguma organização pública ou privada com assento no Comitê Gestor da política estadual, demandou-se que as avaliações fossem de caráter pessoal. Em seguida, as informações obtidas foram sintetizadas em uma única matriz, a qual foi encaminhada para todos os informantes. Estes reagiram aos comentários dos demais e uma nova versão da matriz foi produzida, a qual foi então discutida presencialmente. O conteúdo deste capítulo refere-se à síntese deste processo e, é importante ratificar, não expressa a posição das entidades às quais os autores estão vinculados.

3 Isto consolidou um processo que se iniciou ainda na década de 1980, quando a EMATER-RS passou a rediscutir suas diretrizes e objetivos institucionais. Em 1987, o Programa Estadual de Assistência Técnica e Extensão Rural já previa diretrizes e premissas favoráveis à ampliação e valorização de novas frentes de ação, entre elas o atendimento prioritário ao pequeno produtor (ver DIESEL; NEUMANN; SÁ, 2012). 
Seguindo a proposta de análise da ação pública apresentada por Lascoumes e Le Galès (2012), inicialmente identificamos os atores que participaram de maneira mais ativa do processo de construção da PEAPO-RS. Em seguida, analisamos brevemente os principais referenciais de agroecologia que orientam suas ações. Busca-se aqui interpretar como diferentes representações acerca do tema convergem para uma definição comum capaz de orientar a ação pública. A seção subsequente trata especificamente do processo de institucionalização da política estadual, compreendendo, neste sentido, a incorporação pelo estado de ideias produzidas em diferentes fóruns ou mundos sociais (dos movimentos sociais, dos gestores públicos, dos pesquisadores).

Outra seção trata especificamente dos processos políticos, com destaque para as relações entre as diferentes coalizões que disputaram a tradução da política no PLEAPO. A penúltima seção analisa os aspectos relativos à implementação deste plano, destacando o modelo de governança, os instrumentos de política pública e os resultados da sua aplicação. Finalmente, as considerações finais apresentam reflexões sobre os limites e desafios das políticas estaduais para a promoção da agroecologia e produção orgânica.

\section{Os atores na construção da política}

Como afirmamos acima, a construção da PEAPO-RS repercute uma longa trajetória de articulação entre atores estatais e da sociedade civil (EHLERS, 1994; ALMEIDA; NAVARRO, 1997; LUZZI, 2007). No entanto, se considerarmos apenas as discussões mais atuais referentes ao desenho desta política pública, esta trajetória pode ser dividida em três momentos. $\mathrm{O}$ primeiro refere-se ao período do processo legislativo (2013-2014), ou seja, de elaboração e aprovação da lei estadual que instituiu a PEAPO-RS. Neste momento destacou-se o protagonismo das organizações da sociedade civil, com destaque para representantes da Federação dos Trabalhadores na Agricultura Familiar (FETRAF), do Centro de Tecnologias Alternativas Populares (CETAP) e da Rede Ecovida de Agroecologia. Estas organizações estiveram à frente da articulação com deputados estaduais identificados com a agroecologia e com a agricultura familiar para a elaboração e aprovação da PEAPO-RS. Na Assembleia Legislativa coube ao deputado Altemir Tortelli (antigo dirigente sindical vinculado à FETRAF), protocolar o Projeto de Lei, o qual, durante sua discussão, também passou a contar com importantes aportes de técnicos da Secretaria de Desenvolvimento Rural, Pesca e Cooperativismo (SDR), embora este órgão não estivesse, naquele momento, institucionalmente engajado na proposta. 
Em nossa análise, não se perceberam movimentos públicos contrários à aprovação da lei, de modo que a PEAPO-RS foi aprovada por unanimidade. A partir daí tornou-se necessário regulamentá-la. Com efeito, o segundo momento (ao longo de 2014) refere-se ao processo de elaboração do Decreto Estadual $n^{\circ} 5.1617 / 2014$, para o que, em virtude das próprias características do trabalho demandado, assumiram maior protagonismo os atores ligados ao poder executivo estadual, com destaque para os técnicos da SDR. Estes elaboraram uma primeira versão do decreto, a qual foi, em seguida, apresentada e discutida na Câmara Técnica de Agroecologia (CTAGRO) do Conselho Estadual de Desenvolvimento Rural Sustentável (CEDRS). A partir deste momento ampliou-se a colaboração de outros órgãos como a EMATER-RS, o Instituto Rio Grandense do Arroz (IRGA), a Fundação Estadual de Pesquisa Agropecuária (FEPAGRO), a Secretaria Estadual do meio Ambiente (SEMA) e a Universidade Federal do Rio Grande do Sul (UFRGS). Por sua vez, com relação à sociedade civil, houve a inclusão de novos interlocutores nesta etapa, tais como a Associação dos Guardiões de Sementes Crioulas. Além disso, este período também foi marcado por uma participação mais ativa da representação estadual de órgãos do governo federal, especialmente da Superintendência Federal da Agricultura no RS (SFA/RS/MAPA).

O terceiro período (2015-2016) envolve a elaboração e coordenação do plano (PLEAPO), o que foi atribuído ao Comitê Gestor instituído pelo Decreto Estadual n ${ }^{\circ} 5.1617 / 2014$ e cuja composição é paritária entre representantes da sociedade civil e do estado. Enquanto a definição das entidades governamentais do Comitê Gestor se deu no âmbito da CTAGRO, as organizações da sociedade civil foram selecionadas por meio de um edital lançado em 2014, o qual definiu como critério de participação a inclusão de diferentes segmentos sociais: representações da agricultura familiar, entidades de prestação de serviços de ATER, representação de consumidores e empresas do setor de insumos orgânicos. Na prática, para além do arranjo de atores já estabelecido na segunda fase, destaca-se nesta fase a ampliação da participação da Embrapa e das universidades federais e estadual.

Também é importante notar os principais ausentes nesta trajetória. Neste sentido se destacam como ausentes, por um lado, as entidades representativas do setor da agricultura empresarial e, por outro, determinados movimentos sociais e sindicais agrários. A ausência destes atores está associada a razões distintas. $\mathrm{O}$ apoio à produção orgânica por grandes fazendas ou empresas agroindustriais nunca foi o foco prioritário das políticas nacional e estadual de agroecologia, inclusive porque este tipo de produção ainda está amplamente concentrado nas unidades familiares de produção agrícola e processamento alimentar. Além disso, apesar do crescente interesse das grandes empresas na 
expansão do mercado de orgânicos, suas vias de acesso a recursos públicos geralmente não envolvem os mesmos canais utilizados pelos agricultores familiares e, muito menos, o engajamento em espaços de participação social que demandam tempo e compromissos políticos. No entanto, estes atores também não apresentaram resistência direta à aprovação das políticas nacional e estadual de agroecologia, apesar de muitas vezes criticarem a incorporação do conceito de "agroecologia" como referencial das políticas públicas de desenvolvimento rural.

Por outro lado, dentre os movimentos sociais da agricultura familiar e camponesa, destacam-se as ausências da FETAG-RS e da Via Campesina ${ }^{4}$. No primeiro caso, isto se explica basicamente pela menor aderência da agroecologia à pauta de reivindicações e à base social da FETAG-RS. Apenas mais recentemente este tema começou a ganhar espaço nas discussões do movimento sindical. De outro modo, a Via Campesina tem na agroecologia uma das suas principais bandeiras de luta (MARTINS, 2017), de modo que sua ausência está associada a outros dois fatores. Primeiro, ao fato de que este movimento sempre foi reticente a ingressar em fóruns participativos de construção de políticas públicas, o que inclusive não se restringe apenas à gestão das políticas para agroecologia. Esta decisão abarca quase todo o conjunto de políticas que foram produzidas para a agricultura familiar nas duas últimas décadas (GRISA; SCHNEIDER, 2015).

Segundo, porque estes movimentos historicamente também preferiram criar seus próprios canais de interlocução com o Estado. No caso do Rio Grande do Sul, isto se expressou principalmente na negociação do Plano Camponês com o governo Tarso Genro, o qual consistia em um conjunto específico de instrumentos e recursos (oriundos do Banco Nacional de Desenvolvimento Econômico e Social - BNDES) que, mesmo incorporando o apoio à agroecologia e tendo sido incluído como ação do PLEAPO, não era gerido no âmbito do Comitê Gestor do mesmo (LEAL; GÖRGEN, 2015).

Existem outros atores ausentes ou com participação limitada neste processo. É o caso, por exemplo, dos consumidores e das comunidades tradicionais e indígenas. No entanto, estas ausências estão muito mais associadas às dificuldades de articulação, visibilização e aproximação destes atores do que de uma escolha deliberada dos mesmos por se ausentar, como ocorreu com a Via Campesina e as entidades do setor empresarial. Por outro lado, podem-se citar os esforços para diálogo com fóruns e entidades que, em alguma medida, incorporam estes e outros atores ou, ao menos, suas demandas. Este é o caso do Fórum Fome Zero, da Comissão de Direito Ambiental da Ordem dos

4 Na verdade, no caso da própria FETRAF, a mesma estava formalmente vinculada ao Comitê Gestor, mas teve pouca participação no mesmo. 
Advogados do Brasil (OAB-RS), do Conselho Estadual de Nutricionistas e do Centro Estadual de Vigilância em Saúde. A aproximação destes atores se tornou central para a efetividade das políticas de apoio à agroecologia, o que tem sido discutido não apenas no âmbito do Comitê Gestor do PLEAPO, mas que toca o conjunto das organizações e movimentos em prol da agroecologia.

Cabe ainda destacar a aproximação com o Conselho Nacional de Segurança Alimentar e Nutricional - CONSEA. Apesar da PEAPO-RS não mencionar diretamente a Segurança Alimentar e Nutricional, o Comitê Gestor incorporou a temática na $1^{a}$ Diretriz do PLEAPO. Além disso, a SDR participou ativamente do CONSEA-RS, inclusive indicando ações do PLEAPO para compor o Plano Estadual de Segurança Alimentar. Além disso, a própria justificativa anexada ao Projeto de Lei que deu origem à PEAPO já acentuava o objetivo de articular, por meio dela, "um instrumento para o fomento de sistemas agrícolas sustentáveis, reforçando as estratégias de segurança alimentar, com inclusão social e preservação ecológica [...]", de modo a "contribuir para o desenvolvimento local e regional, mas também, na promoção da saúde, tanto de agricultores(as), como de consumidores(as)" (TORTELLI, 2012). Com efeito, além de agricultura familiar e sustentabilidade, termos como saúde, alimentação saudável e segurança alimentar também são recorrentes na justificativa que embasa o projeto de lei e, atualmente, na prática das entidades envolvidas.

\section{Os referenciais de agroecologia}

O conceito de agroecologia incorporado pela PEAPO-RS seguiu aquele estabelecido na PNAPO. De modo geral, ele destaca uma concepção acadêmica de agroecologia, a qual aponta para o uso dos conhecimentos da ecologia para o manejo de agroecossistemas, incluindo seus componentes socioculturais, econômicos, técnicos e ecológicos. Como outros autores já identificaram (SABOURIN et al., 2017), este tipo de definição tem sido mais facilmente incorporado pelo Estado na medida em que ele carrega um argumento de autoridade que é praticamente indiscutível. Afinal, quem seria contra utilizar os conhecimentos da ecologia para fazer agricultura? O problema, contudo, é que sua generalidade abre espaço para inúmeras discussões acerca de quais conhecimentos são mais relevantes, afinal, a ecologia não é uma disciplina isenta de conflitos. Além disso, como estes conhecimentos devem ser incorporados e, sobretudo, quem se beneficiará dos mesmos são outras questões centrais ao debate. Como destacam Guéneau et al. (2019), é na tentativa de encontrar resposta para estas questões que a agroecologia "científica" se encontra com a agroecologia "política" defendida pelos movimentos sociais, o que gera inúmeras tensões que se expressam no desenho das políticas públicas. 
Uma das tensões mais conhecidas e analisadas pela literatura diz respeito à contraposição entre o referencial tecnológico da agricultura orgânica e o referencial sociopolítico da agroecologia (PETERSEN et al., 2013; ROSSET; ALTIERI, 1997). Apesar de frequentemente retornar ao debate, esta oposição foi menos presente ao longo da construção da PEAPO-RS - pelo menos em comparação à relevância que ela teve nas discussões sobre a regulamentação dos orgânicos no Brasil (FONSECA, 2005; NIEDERLE; ALMEIDA, 2013). Isto se deve, por um lado, ao próprio público prioritário da política, o qual, como destacamos acima, não abarca os segmentos empresariais que, em geral, são aqueles que mais tencionam por um processo de "convencionalização dos alimentos orgânicos" (GUTHMAN, 2004). Por outro lado, a política estadual também se beneficiou do conhecimento acumulado nas discussões para a implementação da política nacional, o que favoreceu a construção de sinergias entre as dimensões técnicas e sociopolíticas.

Uma das questões mais relevantes - e que também esteve presente na construção da política nacional - diz respeito à incorporação de agricultores "não ecologistas" como público beneficiário da política de agroecologia. O PLEAPO-RS incorpora instrumentos de suporte a práticas "não convencionais" de agricultura, tais como redução do uso de agrotóxicos, técnicas de adubação verde, produção e conservação de sementes crioulas e terapias não convencionais como homeopatia e fitoterapia. Esta concepção ampla de agroecologia contempla as demandas de organizações sociais que possuem em sua base agricultores que não são estritamente "ecologistas", mas que estão (ou podem estar) abertos ao desenvolvimento de "práticas e métodos de base ecológica". Com isso, visa-se não apenas apoiar estritamente a produção orgânica, mas também promover processos mais graduais de transição agroecológica. Com efeito, são focos principais do PLEAPO-RS:

(1) Ampliar o número de agricultores envolvidos na produção agroecológica e, para tanto, desenvolver e facilitar o acesso a tecnologias de produção de base ecológica.

(2) Melhorar as práticas para uso e conservação da agrosociobiodiversidade por meio do apoio à implantação de sistemas biodiversos, incentivo ao uso de espécies nativas e crioulas.

(3) Ampliar os espaços de comercialização de alimentos orgânicos, e aumentar a inserção de alimentos orgânicos nos mercados institucionais.

(4) Qualificar a ação de ATER e levar aos agricultores familiares tecnologias apropriadas aos sistemas orgânicos de produção (SDR, 2014).

Esta concepção também facilitou a resolução de um problema de ordem operacional, qual seja, a impossibilidade de, por meio dos sistemas de planejamento e monitoramento utilizados pela EMATER-RS, realizar uma distinção 
precisa entre os sistemas de produção orgânico, em transição agroecológica e convencional. São recorrentes as situações em que os agricultores familiares que adotam alguma prática conservacionista ou de controle biológico são considerados como agricultores em transição agroecológica, embora eles mesmos não se reconheçam deste modo e sequer tenham realmente a intenção em migrar para a produção orgânica. Assim, ao apoiar o desenvolvimento de práticas agroecológicas - e não focalizar em um tipo específico de unidade familiar - o plano não apenas contentou diferentes atores políticos, como também se tornou factível do ponto de vista operacional.

\section{A trajetória institucional}

Comparativamente a outros estados brasileiros, a criação da Política Estadual de Agroecologia e Produção Orgânica foi facilitada pelo alinhamento político existente entre os governos estadual e federal no período de 2011 a 2014 (GUÉNEAU et al., 2019). Não obstante, além da influência das discussões e políticas nacionais, a trajetória da PEAPO-RS é fortemente marcada por eventos específicos à dinâmica político-institucional gaúcha. Neste sentido, cabe notar a existência de instrumentos de apoio à agroecologia anteriores não apenas à própria $\mathrm{PEAPO}-\mathrm{RS}$, mas também à política nacional.

No final de 2011, ou seja, antes da criação da PNAPO (em agosto de 2012), o governo gaúcho já havia instituído o Programa Estadual de Agricultura de Base Ecológica (PABE). Lançado pela SDR, o PABE era principal instrumento de incentivo à agroecologia do governo gaúcho. Até 2014 - antes da criação da PEAPO-RS - este programa já havia capacitado 8 mil agricultores e fornecido assistência técnica e extensão rural para a transição agroecológica para outros 15 mil agricultores. Além disso, financiou 57 projetos de sistemas agroflorestais e cerca de 200 projetos para transição de base ecológica por meio do Fundo Estadual de Apoio ao Desenvolvimento dos Pequenos Estabelecimentos Rurais (FEAPER-RS). Posteriormente, o PABE foi incorporado como um dos principais instrumentos do PLEAPO.

A elaboração do PLEAPO pelo Comitê Gestor ocupou todo ano de 2015, já durante o governo de José Ivo Sartori. No entanto, após seu lançamento, em março de 2016, se tornou cada vez mais evidente a mudança de prioridades do governo gaúcho com relação ao tema da agroecologia. Entre 2016 e 2018 não houve financiamentos do PABE porque, anualmente, o novo governador emitiu decretos limitando a utilização de recursos do Tesouro do Estado para a modalidade "custeio", o que inviabilizou o uso dos recursos do FEAPER para concessão de financiamento aos pequenos empreendimentos rurais, incluindo aqueles destinados ao PABE. Na prática, portanto, o principal instrumento de financiamento que é específico ao estado do RS deixou de ser utilizado durante 
a implementação do PLEAPO, limitando consideravelmente a efetividade do mesmo no cumprimento das metas previamente estabelecidas. Em virtude disso, já durante a fase de elaboração do plano, a SDR (gestora do PABE) decidiu apostar na consolidação de parcerias com a EMATER-RS, sobretudo no que tange às ações de ATER e capacitação. Considerava-se na época que esta seria uma alternativa mais segura tendo em vista que os recursos para a EMATER-RS vinham sendo historicamente assegurados.

No que diz respeito ao acesso aos recursos orçamentários do estado, destaca-se ainda as limitações relativas ao financiamento das organizações não governamentais que atuam com assistência técnica e extensão rural, as quais são essenciais para a viabilização das metas e ações do PLEAPO. Em 2014, o Decreto Estadual n 51.565 criou e estabeleceu diretrizes para a Política Estadual de Assistência Técnica e Extensão Rural e Social no Estado do Rio Grande do Sul (PEATERS) e para o Fundo Estadual de Assistência Técnica e Extensão Rural e Social (FUNDATERS). O mesmo estabeleceu que a "Administração Pública Estadual por meio da SDR formalizará convênios com outras entidades públicas ou privadas, ou realizará contratos de financiamentos com outras entidades privadas, desde que previamente credenciadas no PROATERS, para a realização de serviços específicos e complementares de Assistência Técnica e Extensão Rural e Social, visando à execução de seus objetivos". Esta regra refletia o entendimento de que as organizações da sociedade civil deveriam ser fortes aliados nos processos de transição agroecológica, colaborando para a implementação das políticas públicas, o que também é condizente com as diretrizes da PNAPO e da PNATER.

$\mathrm{O}$ mesmo decreto, no seu art. $32 \S 1^{\circ}$, estabeleceu que "os recursos anuais destinados ao serviço permanente e continuado não serão inferiores a 90\% (noventa por cento) da dotação anual do FUNDATERS, e só poderão ser superiores a este percentual caso outras entidades, previamente credenciadas no PROATERS, não utilizarem os recursos disponíveis". Na prática isso significa a reserva de até $10 \%$ dos recursos anuais destinados aos serviços específicos e complementares da dotação anual inicial do FUNDATERS para as organizações da sociedade civil. No entanto, esta disposição nunca foi cumprida pelo governo estadual, de modo que a totalidade dos recursos se destinou à EMATER-RS. Esta decisão se tornou um dos principais pontos de tensão nas discussões internas ao Comitê Gestor e, em face da irredutibilidade do governo estadual em alterar sua decisão, resultou na gradativa redução do engajamento de muitas organizações não governamentais.

De acordo com o art. $8^{\circ}$ da PEAPO, podem constituir fontes de financiamento da mesma: I - recursos do Tesouro do Estado do Rio Grande do Sul; II - recursos oriundos de convênios com outros entes da Federação; III - Fundo Estadual de Apoio ao Desenvolvimento dos Pequenos Estabelecimentos Rurais - FEAPER; IV - Fundo Estadual do Meio Ambiente - FEMA; 
IV - recursos de empresas e instituições financeiras, organismos multilaterais e organizações não governamentais; e VI - recursos oriundos de operações de crédito. No entanto, em virtude da restrição de recursos para construir instrumentos específicos de políticas, o PLEAPO depende da mobilização dos recursos próprios das organizações parceiras, sobretudo de Ministérios, Secretarias Estaduais, Embrapa, Universidades, Institutos Federais, entre outros.

As mudanças ocorridas em 2016 no Governo Federal em decorrência do impeachment da Presidente Dilma Rousseff restringiram a capacidade de ação e a disponibilidade de recursos dos órgãos federais, sobretudo no que tange ao apoio à agroecologia e agricultura familiar. Em suma, o contexto de instabilidade política, associada à redução significativa do aporte de recursos limitou sensivelmente a implementação do PLEAPO. Exemplo disso é o modo como o fim do programa de Assessoria Técnica, Social e Ambiental à Reforma Agrária - ATES afeta o suporte dos extensionistas rurais para a produção agroecológica nos assentamentos rurais e, em virtude disso, acaba indiretamente limitando os resultados das ações desenvolvidas a partir do plano estadual.

Mais recentemente, com vistas a ampliar o apoio à PEAPO-RS e, ao mesmo tempo, viabilizar ações que demandam menor aporte de recursos, no final de 2018 o Comitê Gestor do PLEAPO e a CPOrg-RS (Comissão de Produção Orgânica do Rio Grande do Sul) começaram a realizar reuniões conjuntas. Cabe notar que, no Rio Grande do Sul, a CPOrg não teve participação ativa no processo de elaboração do PLEAPO, ainda que sua implementação envolva a atuação de entidades do Comitê Gestor que, frequentemente, também compõem a CPOrg. A título de exemplo desta nova articulação, destaca-se o tema da reduzida oferta de sementes orgânicas para potencializar o aumento da produção. Como houve dificuldades na implementação da ação "Ater para a produção de Sementes Orgânicas", avaliou-se que as discussões e levantamentos realizados pela CPOrg-RS poderiam contribuir na efetivação desta ação.

\section{A governança da política pública}

Formado por 24 representantes de órgãos públicos estaduais e federais e outros 24 representantes da sociedade civil, o Comitê Gestor do PLEAPO-RS é o principal ator da elaboração, monitoramento e avaliação da política estadual de agroecologia. Como se trata de um ator coletivo, sua ação depende da mediação de distintos interesses e representações. O primeiro tipo de mediação é justamente entre as demandas da sociedade civil e dos órgãos do poder executivo estadual e federal. Como destacamos acima, as mudanças político-institucionais decorrentes da emergência de um novo referencial de ação pública a partir de 2015 (no âmbito estadual) e 2016 (no âmbito federal), o qual é muito menos 
aberto aos processos participativos e à gestão compartilhada dos recursos públicos com a sociedade civil, reduziram a capacidade de ação do Comitê Gestor e, por conseguinte, à efetividade das ações inicialmente previstas pelo PLEAPO.

Outra mediação importante diz respeito à articulação entre atores e políticas de diferentes escalas federativas (federal, estadual e municipal). Para a construção do $\mathrm{PLEAPO}^{5}$, o Comitê Gestor tomou como referência a estrutura do PLANAPO. Contudo, não houve uma interlocução direta entre órgãos estaduais e federais com vistas a criação de uma gestão compartilhada dos instrumentos de políticas, ainda que praticamente todos os instrumentos previstos no PLEAPO também dialoguem com o PLANAPO, com destaque para os programas de ATER; Desenvolvimento Territorial, Análise de Resíduos de Agrotóxicos em Alimentos (PARA), crédito rural (PRONAF) e compras públicas (PAA e PNAE). Ademais, os próprios eixos de ação do PLEAPO e do PLANAPO são similares, com a diferença de que este possui metas mais abrangentes. Outra diferença substancial é o fato de que o PLANAPO possui uma correspondência mais forte com as metas do PPA (Plano Plurianual) federal, com vinculação a possíveis fontes e rubricas orçamentárias para a implantação das metas, o que não ocorre entre o PLEAPO e o PPA estadual.

Na medida em que, apesar de incorporar instrumentos do PLANAPO, o PLEAPO não tinha nenhuma ingerência direta na gestão dos mesmos, a maioria dos editais públicos lançados pelo governo federal para ações de apoio à agroecologia e produção orgânica eram acessados diretamente pelas organizações sociais e entes públicos sem qualquer mediação da escala estadual. Isso criou diversos tipos de tensão. Um dos mais evidentes se dá com relação à ATER, haja vista que, por exemplo, as mesmas organizações não governamentais que não conseguiam acessar recursos do FUNDATERS, captavam recursos de editais nacionais de ATER. Assim, elas atuavam nos municípios gaúchos com a promoção da agroecologia, mas, a rigor, sua ação não estava diretamente articulada àquelas definidas pelo PLEAPO. Quando havia alguma correspondência entre o trabalho destas ONGs e os objetivos do PLEAPO isto se devia muito mais ao comprometimento das mesmas com a política de agroecologia do que em virtude da estrutura de gestão do plano ${ }^{6}$.

Ao adotar uma estrutura similar àquela do PLANAPO, o programa estadual também trouxe para a escala estadual alguns dos principais dilemas vivenciados em âmbito nacional. O primeiro deles diz respeito às ambições, à generalidade e à amplitude das metas e ações propostas. Ao invés de um programa com um número limitado de instrumentos de ação específicos como era o PABE,

5 Em 2015 foram realizadas 10 reuniões do Comitê Gestor para elaboração do PLEAPO.

6 Cabe notar também que o Ministério do Desenvolvimento Agrário elaborou diversos editais para ATER em agroecologia. No entanto, não houve um diálogo com o Comitê Gestor estadual para delineamento de estratégias de ação. Este problema foi agravado pela reduzida participação deste ministério no espaço de gestão da política estadual. 
o PLEAPO se tornou um guarda-chuva para ações ofertadas por diferentes órgãos. Isto levou à dispersão das ações e criou dificuldades no estabelecimento de prioridades e hierarquias, haja vista, inclusive, que os diferentes atores sociais envolvidos não convergem na defesa das mesmas ações. Associado a isso encontra-se a questão da (falta de) transversalidade na gestão das políticas públicas. Para alguns atores o PLEAPO era visto como um plano dentro de um departamento da antiga SDR (que atualmente passou ao status Departamento da Secretaria da Agricultura, Pecuária e Desenvolvimento Rural - SEAPDR) e não como uma política pública transversal e intersetorial. ${ }^{7}$

No entanto, alguns atores mais diretamente engajados com a implementação do plano destacam um processo de construção gradual da transversalidade e da governança intergovernamental. $\mathrm{O}$ acompanhamento dos resultados alcançados é obtido a partir das informações lançadas pelos órgãos estaduais no Sistema de Planejamento e Gestão (SPG) controlado pelo Departamento de Planejamento (DEPLAN) da Secretaria de Planejamento, Governança e Gestão e responsável por avaliar a execução do Plano Plurianual. Este gera um relatório anual e as reuniões de monitoramento são realizadas quadrimestralmente. A partir disso esperam-se avanços gradativos na integração das políticas oriundas dos diversos órgãos públicos. ${ }^{8}$

\section{PLEAPO: dos instrumentos aos resultados limitados}

O PLEAPO é formado por quatro diretrizes, 11 objetivos e 49 estratégias e ações, as quais abarcam 24 órgãos estaduais e federais. Existem quatro formas de implementação das ações do PLEAPO. A primeira envolve diretamente os órgãos do governo estadual por meio de recursos do tesouro. Além da SDR, aqui também se destacam as ações diretas de órgãos como MAPA, INCRA, Embrapa, Universidades e Institutos Federais. Ademais, assim como o PLANAPO, o PLEAPO busca adequar programas executados por diferentes órgãos do Governo Estadual à uma estratégia de promoção da agroecologia, tais como Programa Leite Gaúcho; Programa de Pecuária Familiar; PROATERS; e o Programa Estadual de Agroindústria Familiar (PEAF).

A segunda forma de ação refere-se aos convênios estabelecidos entre o governo do estado e outros órgãos como a EMATER-RS e as prefeituras municipais. O foco dos convênios com os municípios volta-se, por exemplo, à

$7 \quad 0$ argumento da falta de transversalidade associa-se às limitações institucionais da governança do PLEAPO. Cabe notar que, no caso da Câmara Interministerial de Agroecologia e Produção Orgânica (Ciapo), responsável por executar o PLANAPO, a coordenação é responsabilidade da Casa Civil, estrutura que, pelo menos em tese, poderia articular a ação dos diferentes ministérios envolvidos (NIEDERLE et al., 2018). Além disso, o plano de gestão do PLEAPO-RS prevê sua avaliação a cada dois anos por meio de seminários de avaliação. O primeiro foi realizado em 29 de junho de 2018. 
assistência técnica, realização de oficinas de capacitação, e ampliação do acesso a insumos para produção orgânica a agricultores familiares. A terceira forma de ação abarca os Termos de Cooperação Técnica firmados com órgãos federais. A última possibilidade são as parcerias com entidades da sociedade civil, mas esta forma de ação foi reduzida em virtude do não cumprimento do disposto no art. 20 da Lei $n^{\circ} 14.245 / 2013$, relativa aos recursos do FUNDATERS (ver supra).

Dentre as ações com resultados mais expressivos até o momento, destacam-se aquelas relativas à capacitação e organização de agricultores por meio de cursos, seminários e palestras com vistas à adequação das propriedades rurais à legislação de produtos orgânicos. Esta iniciativa já envolveu 115 grupos organizados e mais de 1.100 famílias em todo o estado. No entanto, estas atividades de capacitação deveriam se articular a um conjunto mais amplo de ações de assistência técnica e extensão rural, o que foi dificultado pelos inúmeros problemas orçamentários e institucionais encontrados pela EMATER-RS para a execução de suas ações. Por conta disso, após o lançamento do PLEAPO, em 2016, realizaram-se três reuniões entre a SDR, a DEPLAN/SPGG e a EMATER-RS com vistas a ampliar a participação desta entidade.

Na medida em que a ATER é uma ação estruturante do apoio à agroecologia, as demais ações do PLEAPO também passaram a ter resultados mais limitados do que inicialmente se projetava. Mas não é apenas a ATER. Soma-se a ela todo o contexto de incertezas institucionais e restrições orçamentárias. A redução drástica dos recursos do Programa de Aquisição de Alimentos (PAA), por exemplo, se tornou um fator de desestímulo e retrocesso do ponto de vista da articulação e consolidação de iniciativas para atender a demanda dos mercados institucionais com produtos oriundos da agricultura familiar e de base ecológica. As políticas de ajuste fiscal também implicaram na redução dos recursos para pesquisa, capacitação e extensão universitária, ou seja, para as principais ações ofertadas pelas universidades e institutos federais. Por sua vez, a desestruturação dos espaços de participação social para a produção, implementação e monitoramento das políticas públicas também se tornou um fator crítico em face da estrutura de gestão do PLEAPO.

\section{Considerações finais}

Ancorado em uma longa trajetória de organização de movimentos sociais que pressionam pela inovação nas políticas para a agricultura familiar e pela incorporação de um enfoque agroecológico como referencial de ação pública, o estado do Rio Grande do Sul foi pioneiro na construção de políticas públicas de apoio à agroecologia. Estas políticas projetaram o estado como um dos principais produtores de alimentos orgânicos do país e, mais do que isso, como centro de inovação tecnológica, organizacional e institucional nesta área. Exemplo disso são os quatro Organismos Participativos de Avaliação 
da Conformidade Orgânica que operam no estado, os quais o tornaram uma referência nas discussões nacionais e internacionais sobre certificação participativa (MEIRELES, 2004; NIEDERLE; DORVILLE; LEMEILLEUR, 2019). Outro exemplo refere-se à intensa contribuição de representantes das organizações estatais e dos movimentos sociais gaúchos na estruturação das políticas nacionais para a agroecologia.

Mesmo assim, apesar de todo este protagonismo e do pioneirismo, a situação da PEAPO-RS se tornou mais problemática do que se poderia imaginar quando da sua criação. Mesmo sendo o único estado com um PLEAPO em execução, grande parte das ações tem sido limitada por bloqueios institucionais ou orçamentários. Assim como no restante do país, o principal fator de instabilidade parece ser a descontinuidade institucional decorrente das mudanças mais ou menos abruptas nos referenciais de ação pública (MULLER, 2005). Independentemente da coalizão política no poder, todos os novos governos têm-se mostrado reticentes a manter programas, projetos e estruturas institucionais criados por seus antecessores. Outro problema está associado às incertezas que cercam o contexto político nacional. Além do fim das várias políticas para a agricultura familiar e dos espaços de governança participativa, este cenário limita a capacidade dos governos estaduais em projetar suas ações porque, em grande medida, elas dependem do orçamento da União.

Seja como for, parece cada vez mais urgente que os estados federados, e talvez os próprios municípios, tomem a dianteira na construção de programas de apoio à agroecologia e produção orgânica. Para tanto, além de maior disponibilidade de recursos (descentralização orçamentária), é necessário o entendimento de que esta não é apenas uma medida de suporte a movimentos e organizações sociais - o que geralmente incorre em críticas por parte das coalizões políticas contrárias aos mesmos -, mas uma ação urgente para dar conta da crescente demanda por produtos orgânicos. Isto se expressa, por um lado, no mercado doméstico, para o que é preciso ampliar e qualificar os espaços de comercialização. Hoje se observa um vácuo de espaços de oferta de alimentos orgânicos, especialmente nas periferias das grandes cidades e, também, nos municípios pequenos e médios. Por outro lado, também implica em atender à crescente demanda internacional, inclusive de importantes compradores de produtos brasileiros como a China, a qual tem vivenciado uma pressão crescente para a promoção de dietas saudáveis, incluindo o consumo de alimentos orgânicos. 


\section{REFERÊNCIAS}

ALMEIDA, J.; NAVARRO, Z. (Orgs.). Reconstruindo a agricultura: ideias e ideais nas perspectivas do desenvolvimento rural sustentável. Porto Alegre: UFRGS, 1997.

CAPORAL, F. R.; COSTABEBER, J. Agroecologia e desenvolvimento rural sustentável: perspectivas para uma Nova Extensão Rural. Agroecologia e Desenvolvimento Rural Sustentável, v. 1, n. 1, p. 16-37, 2000.

DIESEL, V.; NEUMANN, P. S.; CLAUDINO DE SÁ, V. (Orgs.). Extensão Rural no Contexto do Pluralismo Institucional: Reflexões a partir dos serviços de ATES aos assentamentos da reforma agrária no RS. Ijuí: UNIJUÍ, 2012.

EHLERS, E. A agricultura alternativa: uma visão histórica. Estudos Econômicos, v. 24, n. esp., p. 231-262, 1994.

FONSECA, M. F. A institucionalização dos mercados de orgânicos no mundo e no Brasil: uma interpretação. 2005. Tese (Doutorado em Desenvolvimento, Agricultura e Sociedade) - Rio de Janeiro: UFRRJ, 2005.

GRISA, C.; SCHNEIDER. S. (Eds.). Políticas de Desenvolvimento Rural no Brasil. Porto Alegre: UFRGS, 2015.

GUÉNEAU, S. et al. A construção das políticas estaduais de agroecologia e produção orgânica no Brasil. Revista Brasileira de Agroecologia, 2019. (no prelo).

GUTHMAN J. The trouble with 'organic lite' in California: a rejoinder to the 'conventionalisation' debate. Sociologia Ruralis, v. 44, p. 301316, 2004.

LASCOUMES, P.; LE GALÈS, P. Sociologia da Ação Pública. Maceió: EDUFAL, 2012.

LEAL, M.; GORGEN, S. A Hora e a Vez de um Programa Camponês. 2015. Disponível em: <http://www.mst.org.br/2015/03/23/a-hora-e-a-vez-de-um-programa-campones.html>. Acesso em: 2 mar. 2018. 
LUZZI, N. O debate agroecológico no Brasil: uma construção a partir de diferentes atores sociais. 2007. Tese (Doutorado em Ciências Sociais) - Rio de Janeiro: UFRRJ, 2007.

MARTINS, A. A Produção Ecológica de arroz nos assentamentos da região metropolitana de Porto Alegre: territórios de resistência ativa e emancipação. 2017. Tese (Doutorado em Geografia) - Porto Alegre: UFRGS, 2017.

MEIRELLES, L. A certificação de produtos orgânicos: caminhos e descaminhos. 2004. Disponível em: <http://www.centroecologico.org.br/artigo $>$. Acesso em: 18 maio 2018.

MULLER, P. Esquisse d'une théorie du changement dans l'action publique : structures, acteurs e cadres cognitifs. Revue Française de Science Politique, v. 55, n. 1, p. 155-187, 2005.

NIEDERLE, P. et al. A trajetória brasileira de construção de políticas públicas para a agroecologia. Redes, v. 24, p. 270-291, 2019.

NIEDERLE, P. A.; ALMEIDA, L. A nova arquitetura dos mercados para produtos orgânicos: o debate da convencionalização. In: NIEDERLE, P. A.; ALMEIDA, L.; VEZZANI, F. (Orgs.). Agroecologia: práticas, mercados e políticas para uma nova agricultura. Curitiba: Kayrós, 2013. p. 23-67.

NIEDERLE, P. A.; DORVILLE, C.; LEMEILLEUR, S. Estrutura e Funcionamento dos Organismos Participativos de Avaliação da Conformidade Orgânica (OPACs) no Rio Grande do Sul. Porto Alegre, 2019.

PETERSEN, P.; MUSSOI, E. e DAL SOGLIO, F. Institutionalization of the agroecological approach in Brazil: advances and challenges. Agroecology and Sustainable Food Systems, v. 37, n. 1, p. 103-114, 2013.

ROSSET, P.; ALTIERI, M. Agroecology versus input substitution: a fundamental contradiction of sustainable agriculture. Society and Natural Resources, v. 10, n. 3, p. 283-295, 1997.

SABOURIN, E. et al. Análisis comparativo en escala regional. In: SABOURIN, E. et al. (Orgs.). Políticas públicas a favor de la agroecología en América Latina y El Caribe. Porto Alegre: Red PP-AL, FAO, 2017. p. 351-396. 
SAMBUICHI, R. H. R. et al. (Eds.). A política nacional de agroecologia e produção orgânica no Brasil. Uma trajetória de luta pelo desenvolvimento rural sustentável. Brasília: IPEA. 2017.

SCHMITT, C. A transformação das 'ideias agroecológicas' em instrumentos de políticas públicas: dinâmicas de contestação e institucionalização de novas ideias nas políticas públicas para a agricultura familiar. Revista Política e Sociedade, v. 15, p. 16-48, 2016.

SCHMITT, C.; GRISA, C. Agroecologia, mercados e políticas públicas: uma análise a partir dos instrumentos de ação governamental. In: NIEDERLE, P.; ALMEIDA, L.; VEZZANI, F. (Orgs.). Agroecologia: práticas, mercados e políticas para uma nova agricultura. Curitiba: Kairós, 2013. p. 215-265.

SECRETARIA DE DESENVOLVIMENTO RURAL, PESCA E COOPERATIVISMO. Plano Estadual de Agroecologia e Produção Orgânica. Porto Alegre, 2014

TORTELLI, A. Justificativa ao Projeto de Lei que institui a Política Estadual de Agroecologia e Produção Orgânica do Rio Grande do Sul. Porto Alegre: ALERGS, 2012. 


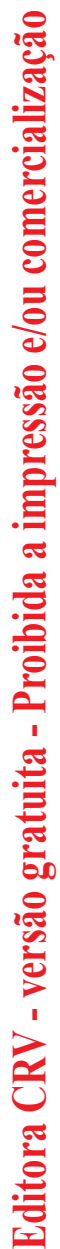




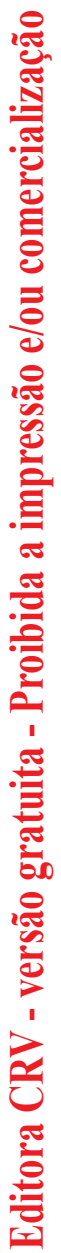

\section{REGIÃO SUDESTE}




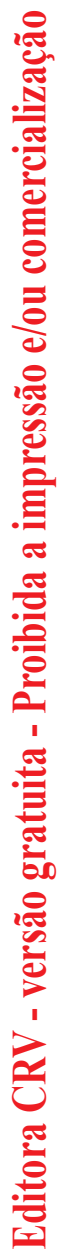




\section{CAPÍTULO 4 \\ A CONSTRUÇÃO DA POLÍTICA ESTADUAL DE AGROECOLOGIA E PRODUÇÃO ORGÂNICA EM MINAS \\ GERAIS: interações Estado-sociedade na institucionalização da agroecologia}

Claudia Job Schmitt

Yamira Rodrigues de Souza Barbosa

\section{Introdução}

Este capítulo busca reconstituir os processos sociais que possibilitaram a construção da Política Estadual de Agroecologia e Produção Orgânica (PEAPO) no estado de Minas Gerais. Como procuraremos demonstrar ao longo do texto, a estruturação deste instrumento de política pública emerge como resultado de múltiplas influências, mobilizando um conjunto diversificado de atores e campos de relações, envolvendo toda uma série de dinâmicas de coprodução entre agentes estatais e redes e organizações da sociedade civil.

Minas Gerais manteve, historicamente, um papel de destaque na produção agrícola e agroindustrial brasileira, contribuindo de forma expressiva para a produção nacional de milho, feijão, bovinos de corte e cana-de-açúcar, e assumindo nacionalmente uma posição de liderança, tanto na produção de café como no setor leiteiro (BRASIL, 2018).

De acordo com os dados do Censo Agropecuário, Minas Gerais contava, em 2006, com 437.320 estabelecimentos agrícolas enquadrados como pertencentes à agricultura familiar, figurando, depois da Bahia, como o segundo maior espaço de concentração de unidades produtivas de base familiar no país ${ }^{1}$. Segundo estimativas divulgadas pela Empresa de Assistência Técnica e Extensão Rural do Estado de Minas Gerais (EMATER-MG), 50\% do café e $70 \%$ da produção mineira de leite provinham, em 2015, da agricultura familiar (GOVERNO DO ESTADO DE MINAS GERAIS, 2015).

1 IBGE. Ver: <https://sidra.ibge.gov.br/tabela/2727>. Acesso em: 22 jun. 2019. Infelizmente, os dados preliminares do Censo Agropecuário 2017, divulgados pelo Instituto Brasileiro de Geografia e Estatística (IBGE), não possibilitam a identificação dos estabelecimentos de base familiar. 
A importância historicamente assumida pela agricultura na economia do estado repercute, também, na presença de instituições públicas vinculadas ao governo estadual, com relevante atuação no espaço rural, em que cabe mencionar: (i) a Empresa de Pesquisa Agropecuária de Minas Gerais (EPAMIG); (ii) a EMATER-MG; (iii) o Instituto Mineiro de Agropecuária (IMA), responsável por atividades relacionadas à defesa sanitária animal e vegetal, inspeção e certificação de produtos.

A exemplo do que ocorreu em outros estados e, também, em nível federal, os processos que possibilitaram a legitimação da agroecologia como uma referência na formulação de políticas públicas em Minas Gerais, contaram com a participação de uma coalização de atores envolvendo movimentos sociais, organizações da sociedade civil, gestores públicos, pesquisadores e outros profissionais engajados, que passam a atuar, nas arenas públicas, em defesa da agricultura familiar, da promoção da Segurança Alimentar e Nutricional (SAN) e de um novo modelo de agricultura, capaz de conciliar justiça social e sustentabilidade ambiental.

O trabalho aqui apresentado procurou reconstruir as dinâmicas que possibilitaram, na esfera estadual, esse alinhamento de atores, ideias e instituições em torno da agroecologia, tomando como foco a PEAPO-MG. O estudo envolveu um esforço de pesquisa bibliográfica e documental, bem como a realização de entrevistas semiestruturadas com gestores públicos e representantes de organizações da sociedade civil, direta ou indiretamente envolvidos na construção da PEAPO-MG ${ }^{2}$. Foram entrevistados, no total, oito gestores públicos e nove representantes de organizações da sociedade civil, em conversas realizadas entre o segundo semestre de 2018 e o primeiro semestre de 2019.

O texto, a seguir, encontra-se dividido em quatro seções. A primeira delas buscou organizar uma reflexão acerca dos contextos e cenários que possibilitaram a construção das PEAPOs, nos diferentes estados, tomando como referência o caso de Minas Gerais. Resgatamos, a seguir, as relações estabelecidas, desde os anos 1990, entre as organizações da sociedade civil vinculadas ao "campo agroecológico" e o poder público estadual, buscando apreender, em suas múltiplas dimensões, os processos que possibilitaram a implantação, no estado de Minas Gerais, de programas e ações voltados à promoção da agroecologia e da agricultura orgânica. A terceira seção tem como foco o processo de institucionalização da PEAPO, considerando seus

Nossos sinceros agradecimentos a todas as pessoas e instituições que contribuíram para a realização do trabalho: Articulação Mineira de Agroecologia (AMA); Cáritas-MG; EMATER-MG; EPAMIG; Federação das Comunidades Quilombolas de Minas Gerais; Federação dos Trabalhadores na Agricultura do Estados de Minas Gerais (FETAEMG); Graal; GT Mulheres da Articulação Nacional de Agroecologia (ANA); Secretaria de Assistência Social, Segurança Alimentar e Cidadania da Prefeitura de Belo Horizonte (SMASAC); SEDA; Rede de Intercâmbio de Tecnologias Alternativas (REDE). 
diferentes espaços de formulação e legitimação, as concepções de agroecologia que orientaram sua construção, o desenho de implementação adotado pela política e os esforços dispendidos por diferentes atores no sentido mobilizar instrumentos capazes de possibilitar a sua efetiva implementação. Buscamos, por fim, organizar algumas reflexões acerca dos efeitos gerados pela construção da PEAPO, indicando alguns dos desafios que se apresentam para sua

efetivação no cenário atual.

\section{A construção das políticas de apoio à agroecologia e à produção orgânica em nível estadual: contextos e cenários a partir da PEAPO-MG}

A institucionalização da PEAPO-MG encontra-se vinculada à trajetória brasileira recente de implantação de diferentes políticas públicas voltadas ao fortalecimento da agricultura familiar, ao reconhecimento dos direitos dos povos e comunidades tradicionais, à garantia da SAN das populações urbanas e rurais e à promoção de um desenvolvimento rural sustentável. Em um ciclo histórico marcado pelo processo de redemocratização política do país e pela aprovação da Constituição de 1988, experiências diferenciadas de exclusão e subalternização vivenciadas pelas populações do campo ganharam expressão nas arenas públicas, sendo problematizadas e publicizadas por meio da ação dos movimentos sociais, setores da academia e organizações da sociedade civil, estabelecendo, ao longo desse processo, conexões práticas e discursivas com temas de largo alcance como o combate à fome e a preservação do meio ambiente.

A construção de políticas de promoção da agroecologia aparece como um capítulo relativamente recente nesse percurso, tendo como marco nacional a aprovação, em 2012, da Política Nacional de Agroecologia e Produção Orgânica (PNAPO) e, na sequência, do Plano Nacional de Agroecologia e Produção Orgânica (PLANAPO), publicado em 2013 e revisado e atualizado em 2016. As mediações políticas que possibilitaram a construção da PNAPO têm sido debatidas por diferentes autores (KALIL, 2016; SAMBUICHI et al., 2017; SCHMITT et al., 2017), que chamam atenção para o papel de destaque assumido pelos movimentos sociais e organizações da sociedade civil na construção desta política pública e para o forte enraizamento das redes de agroecologia envolvidas nesta construção, em uma pluralidade de iniciativas social e ecologicamente situadas de organização da produção, acesso à mercados e organização social nas diferentes regiões do país.

O Decreto $n^{0} 7.794 / 2012$ que instituiu a PNAPO estruturou dois órgãos distintos que deveriam atuar, de forma coordenada, na gestão da Política: a Câmara Nacional de Agroecologia e Produção Orgânica (CNAPO), um espaço 
colegiado constituído por representantes do poder público e da sociedade civil, e a Câmara Interministerial de Agroecologia e Produção Orgânica (CIAPO), que reúne representações dos diferentes ministérios.

Os marcos regulatórios que orientam a PNAPO não trazem uma definição mais precisa acerca das relações a serem estabelecidas entre o governo federal e os governos estaduais e municipais na implementação desta política. Os instrumentos de apoio à agroecologia e à produção orgânica articulados por meio do PLANAPO $^{3}$ possuem, por sua vez, trajetórias e arquiteturas institucionais muito distintas no que diz respeito à participação dos entes federados, bem como das organizações da sociedade civil em sua implementação. Não existe, por exemplo, no âmbito da PNAPO, um mecanismo formal de adesão pelos governos estaduais e municipais, e nem um dispositivo que viabilize o repasse de recursos direcionados especificamente a sua implementação. A construção das PEAPOs não pode ser compreendida, portanto, como um desdobramento "natural" da estruturação de uma política nacional.

As relações existentes entre a estrutura federativa do Estado brasileiro e a implementação de políticas públicas nos vários períodos históricos têm se constituído como objeto de discussão, sobretudo no campo da ciência política e das análise de políticas públicas (ARRETCHE, 2004; ABRUCIO, 2005; FRANZESE, 2010; LASSANCE, 2012; LOTTA; GONÇALVES; BITELMAN, 2014). De modo geral essas análises convergem no sentido de identificar, a partir da aprovação da Constituição de 1988, um movimento de descentralização das políticas públicas, associado, no caso das políticas sociais, a uma agenda orientada por princípios de universalização, igualdade de acesso e garantia de direitos. Amplia-se, a partir da década de 1980, o protagonismo político de prefeitos e governadores, sendo possível identificar, além disso, um fortalecimento das capacidades dos governos estaduais e municipais na implantação de instrumentos de ação governamental (ABRUCIO, 2005; LASSANCE, 2012). Verifica-se posteriormente, sobretudo a partir dos anos 1990, um reforço da atuação do governo federal na coordenação de programas e ações desenvolvidos em parceria com os demais entes federados, por meio da constituição e regulamentação de sistemas únicos (como o Sistema Único de Saúde - SUS), da estruturação de políticas e planos nacionais, e da institucionalização de diferentes instrumentos normativos, orçamentários e fiscais.

O lugar assumido pelos governos estaduais nesse federalismo cooperativo, (FRANZESE, 2010) tem sido interpretado de diferentes maneiras. Lotta, Gonçalves e Bitelman (2014, p. 16) chamam atenção para o fato de que nos

O primeiro PLANAPO (2013-2015) conseguiu congregar 125 iniciativas, distribuídas em 10 ministérios. O segundo PLANAPO, contemplando 194 iniciativas ancoradas em diferentes órgãos federais, foi lançado em maio de 2016, em um período marcado por forte instabilidade política, em meio ao processo de impeachment da Presidenta Dilma Rousseff, encontrando, portanto, uma série de desafios em sua implementação (BRASIL, 2016). 
nove arranjos de políticas analisados em seu trabalho, "os governos estaduais aparecem como apenas mais um ente federativo, em graus similares aos dos municípios, com poucas responsabilidades diferenciadas", o que sinalizaria um relativo enfraquecimento ou indefinição do papel do poder público estadual nestes sistemas de políticas. Outros autores destacam, no entanto, o peso político das elites estaduais na estruturação das dinâmicas partidárias e eleitorais em todos os níveis (BORGES, 2010). Observam, também, que "o declínio dos estados não foi absoluto", sendo que os governos estaduais continuam se constituindo como atores-chave na organização política brasileira, tendo em vista sua influência na organização dos partidos, na relação com as bancadas estaduais no Congresso e seu papel de destaque nas eleições presidenciais (LASSANCE, 2012, p. 28).

No caso da PNAPO, a capacidade de intervenção das instâncias responsáveis pela coordenação da Política Nacional no sentido de estimular os governos estaduais a contribuir de uma forma mais efetiva em sua implantação foi bastante reduzida. Isso se explica, por um lado, pela própria complexidade inerente ao desenho institucional da Política, que buscava, com suas instâncias de coordenação, orientar e articular um amplo e diversificado conjunto de instrumentos de intervenção governamental, dispersos em diferentes órgãos da administração pública federal, garantindo que os mesmos pudessem ser ajustados e direcionados na promoção da agroecologia. A superação dos obstáculos políticos, institucionais e operacionais existentes no que diz respeito ao alinhamento destes diversos instrumentos de acordo com as diretrizes estabelecidas pela PNAPO, na esfera federal, já se configurava, por si só, como uma tarefa de grande envergadura.

Cabe reforçar, além disso, que o mix de políticas agregado pelo PLANAPO em suas duas edições ${ }^{4}$ (2013-2015 e 2016-2019), contemplava programas e ações embasados em marcos regulatórios, desenhos institucionais e lógicas de operacionalização muito distintos no que diz respeito às relações estabelecidas entre os entes federados, incorporando, cada um deles, uma trajetória própria de negociações e pactuações no que diz respeito à divisão de recursos, responsabilidades e competências entre o governo federal e as entidades subnacionais.

Em que pesem as dificuldades enfrentadas pela Política Nacional no sentido de coordenar a implantação de programas e ações de promoção da agroecologia e da agricultura orgânica em nível estadual, não há dúvida de que a mobilização social desencadeada em torno da construção da PNAPO contribuiu para a criação, em diferentes unidades da federação, de PEAPOs,

4 Cabe mencionar, a título de ilustração: o Programa Nacional de Fortalecimento da Agricultura Familiar (PRONAF), o Programa de Aquisição de Alimentos (PAA), a Política Nacional de Assistência Técnica e Extensão Rural (PNATER), o Programa Cisternas, a Política Nacional de Desenvolvimento Sustentável de Povos e Comunidades Tradicionais (PNDSPCTs), entre outros. 
inspiradas, em boa medida, na experiência desenvolvida na esfera federal. Verificamos, ao mesmo tempo, ao analisar o caso de Minas Gerais, que a trajetória da PEAPO-MG foi fortemente influenciada por todo um histórico de relação das redes e organizações da sociedade civil com os poderes executivo e legislativo estadual e, no plano municipal, com a Prefeitura de Belo Horizonte, colocando em prática os dispositivos de participação institucionalizados pela Constituição de 1988.

Refletindo acerca dos avanços e recuos do Estado brasileiro na construção de políticas de bem-estar social universalistas e redistributivas, Kerstenetzky (2012) chama atenção para a ocorrência, no período posterior à aprovação da Constituição de 1988, de ciclos alternados, marcados pela expansão e pela contração do gasto social. Os dois mandatos presidenciais liderados por Luís Inácio Lula da Silva (2003-2006; 2007-2010) são qualificados pela autora como momentos de recuperação econômica, ampliação dos investimentos públicos e implementação de políticas sociais (KERSTENETZKY, 2012, p. 234). No que diz respeito às políticas de desenvolvimento rural e promoção da SAN, este período histórico foi marcado pela implementação do Programa Fome Zero, a recriação do Conselho Nacional de Segurança Alimentar e Nutricional (CONSEA) e pela estruturação de um amplo conjunto de instrumentos de políticas públicas voltados ao fortalecimento da agricultura familiar.

A criação da PNAPO (2012) e, posteriormente, das diversas PEAPOs, possui uma forte conexão com essa trajetória política e institucional de construção da políticas, mas tem como pano de fundo uma cenário marcado pela crise global de 2008, pela queda do preço internacional das commodities e por um processo de desaceleração da economia brasileira que se inicia a partir de 2011 (CARVALHO, 2018).

Analisando a trajetória recente de evolução da dívida estadual no Brasil, Mora (2016), chama atenção para emergência, entre 2008 e 2013, de um novo ciclo de endividamento dos governos estaduais, sendo que o estado de Minas Gerais ganha destaque em sua análise como um dos principais devedores.

Nesse mesmo período, os resultados decorrentes da implantação pelo governo do estado de Minas Gerais do chamado Choque de Gestão, política adotada pelo governo estadual sobretudo na gestão Aécio Neves (2003-2006 e 2007-2010), orientada pelo ideário da Nova Gestão Pública (New Public Management), de inspiração neoliberal, já evidenciavam os limites desta estratégia como um instrumento de recuperação das finanças estaduais (SILVEIRA; FONSECA; OLIVEIRA, 2012).

Este novo modelo de administração buscava ampliar as receitas públicas através de melhorias na efetividade da arrecadação e da redução de despesas, reestruturando o processo de gestão a partir de "projetos estruturadores", centralizando as compras públicas e adotando um conjunto diversificado de ferramentas gerenciais semelhantes às utilizadas pelo setor privado. Os efeitos 
iniciais gerados pelo Choque de Gestão no que se refere à redução de despesas e melhoria da capacidade de arrecadação foram se erodindo ao longo da década, com fragilização das receitas, redução das taxas de investimento público e ampliação dos níveis de endividamento por parte do estado (SILVEIRA; FONSECA; OLIVEIRA, 2012).

Mas como veremos a seguir, as projeções de um cenário pouco promissor no que diz respeito às possibilidades de ampliação dos investimentos públicos em programas sociais, e os desafios de uma estrutura institucional historicamente marcada pelo peso político do agronegócio e permeada por lógicas administrativas de cunho neoliberal, não impediram que as redes e organizações da sociedade civil buscassem ampliar sua capacidade de influência na relação com o poder público estadual.

\section{Agroecologia e políticas públicas no estado de Minas Gerais: atores, dinâmicas e instituições}

Refletindo acerca das dinâmicas sociais e políticas envolvidas na criação de uma rede de legitimidade em torno da agroecologia, Wit e Iles (2016) chamam atenção para o fato de que o reconhecimento deste enfoque implica na mobilização de diferentes arenas e testes de credibilidade, que não estão amparados exclusivamente em provas de natureza científica, mas que envolvem considerações de ordem política, legal, prática, cívica, entre outras. As dinâmicas de coprodução que se estabelecem entre essas diferentes linhas de legitimidade podem contribuir para reforçar, ou não, determinadas concepções ou formas de produção conhecimento. O caminho percorrido pelas redes de agroecologia no estado de Minas Gerais na relação com as instituições públicas, em nível estadual, nos parece ilustrativo deste processo multinível de construção de vínculos e bases de legitimidade em diferentes arenas.

Em Minas Gerais, organizações da sociedade civil com atuação em diferentes regiões do estado participaram ativamente no processo de redemocratização do país, influenciando, nas décadas de 1980 e 1990, uma série de iniciativas importantes de articulação política em âmbito nacional. A fundação da Central Única dos Trabalhadores (CUT) em 1983, a criação do Conselho Nacional de Segurança Alimentar e Nutricional (CONSEA) em 1993, as mobilizações dos trabalhadores do campo pela efetiva implantação dos direitos sociais garantidos pela Constituição de 1988 (ocorridas sobretudo na primeira metade da década de 1990), a criação do Programa Nacional de Fortalecimento da Agricultura Familiar (Pronaf, 1996), contaram com a participação de organizações sociais mineiras com atuação em diferentes campos temáticos.

Ainda nos anos 1980, sindicatos de trabalhadores rurais, Comunidades Eclesiais de Base (CEBs), técnicos ligados aos movimentos sociais e profissionais com atuação no campo das ciências agrárias, contando em alguns casos com o 
apoio da Federação dos Trabalhadores na Agricultura do Estado de Minas Gerais (FETAEMG), participaram da criação dos chamados Centros de Tecnologias Alternativas (CTAs), ligados, em boa parte, à Rede Projeto de Tecnologia Alternativas (Rede PTA) ${ }^{5}$. Estas organizações, com atuação em diferentes regiões do estado (Norte de Minas, Zona da Mata, Leste de Minas, Vale do Rio Doce, Vale do Jequitinhonha e Sul de Minas), engajaram-se na organização do I Encontro Nacional de Agroecologia (ENA), em 2002, e, na sequência, na criação da Articulação Nacional de Agroecologia (ANA). Em 2003, a experiência de atuação em rede vivenciada por estas entidades deu origem à constituição da Articulação Mineira de Agroecologia (AMA).

No campo das políticas públicas, a experiência desenvolvida pela Prefeitura de Belo Horizonte a partir de 1993, sob a administração de Patrus Ananias, do Partido dos Trabalhadores (PT), voltada à construção de políticas de abastecimento e de promoção da SAN, tornou-se também uma referência em nível nacional e internacional. Algumas das políticas implantadas nesse período, continuaram a ser implementadas com maior ou menor disponibilidade de recursos pelas administrações municipais subsequentes, merecendo destaque a própria continuidade, ao longo do tempo, da Secretaria Municipal de Abastecimento e Segurança Alimentar (SMAB).

As relações existentes entre as políticas de abastecimento agroalimentar de Belo Horizonte e as ideias agroecológicas, que começavam a circular no Brasil naquele período, mereceriam um esforço mais cuidadoso de investigação. É visível, no entanto, que as iniciativas implementadas durante a administração de Patrus Ananias - incluindo, o abastecimento do Restaurante Popular e dos programas de alimentação escolar com produtos fornecidos por agricultores da Região Metropolitana de Belo Horizonte, as diversas iniciativas de venda direta ao consumidor (Direto da Roça, Campanha de Safra, Feira de Orgânicos, Bolsa Verde, entre outros) e o estímulo à criação de hortas comunitárias - afirmaram-se como referências importantes, tanto no campo da SAN como para a comunidade de práticas organizada em torno da agroecologia (MAFRA, 2004). O esforço por integrar agricultura, abastecimento e assistência alimentar em uma cidade do porte de Belo Horizonte, fortaleceu, também, o debate em torno da agricultura urbana.

Em 1993 foram criados os Centros de Vivência Agroecológica (CEVAEs), por meio de parceria da Prefeitura de Belo Horizonte com a organização não governamental Rede de Intercâmbio de Tecnologias Alternativas (REDE) e moradores locais, constituídos como um espaço de formação e troca de conhecimentos, com protagonismo das comunidades. Foram criados nesse período quatro CEVAEs, que continuam funcionando enquanto equipamentos públicos até hoje

5 Rede não governamental de geração e intercâmbio de tecnologias alternativas, estruturada no início dos anos 1980, com atuação sobretudo nas regiões Sul, Sudeste e Nordeste do país. 
(junho de 2019). Um trabalho de incidência desenvolvido por organizações da sociedade civil em parceria com diferentes atores, permitiu que esta iniciativa se transformasse em política pública, por meio de uma deliberação normativa do Conselho Municipal de Meio Ambiente.

$\mathrm{Na}$ esfera estadual, as relações das organizações da sociedade civil com o governo do estado de Minas Gerais tornam-se mais estreitas sobretudo a partir do foi convidado pelo governador para participar da estruturação do Conselho de Segurança Alimentar e Nutricional Sustentável de Minas Gerais (CONSEA-MG). A ida de Dom Mauro Morelli para Minas Gerais e a criação do CONSEA-MG em $1999^{6}$, abriram uma janela de oportunidades para o processo de articulação de políticas públicas voltadas ao fortalecimento da SAN, da agricultura familiar e da agroecologia. A respeitabilidade alcançada pelo Bispo em função de sua atuação como presidente do CONSEA, contribuiu para que ele se tornasse um importante mediador político na interlocução das redes da sociedade civil com diferentes setores da política mineira.

No que se refere especificamente à construção de marcos regulatórios e políticas públicas de âmbito estadual, cabe mencionar ainda a construção, nos anos 2000, de algumas políticas de interesse da agricultura familiar, povos e comunidades e das redes mobilizadas em torno da agroecologia e da SAN. Entre elas, cabe destacar: o Programa Mineiro de Incentivo ao Cultivo, à Extração, ao Consumo, à Comercialização e à Transformação do Pequi e Demais Frutos e Produtos Nativos do Cerrado - Pró-Pequi (2001), o Programa Estadual de Apoio Financeiro à Escola Família Agrícola (2003), a Política Estadual de Apoio à Agricultura Urbana (2006), a Lei no 16.680/2007 - que buscou dar suporte ao processamento da produção familiar e à comercialização direta entre agricultores e consumidores, a Política Estadual de Incentivo à Formação de Bancos Comunitários de Cultivares Locais, Tradicionais ou Crioulas (Lei n $\left.{ }^{\circ} 18.374 / 2009\right)$. Os projetos que deram origem a estes regulamentos foram apresentados, em boa parte, por deputados ligados ao PT (Partido dos Trabalhadores), que têm desempenhado, ao longo das últimas décadas, um papel importante na representação das demandas das organizações sociais ligadas à agricultura familiar, agroecologia, agricultura urbana e povos e comunidades tradicionais no legislativo estadual, em articulação com outros partidos.

Em 2004, como um desdobramento da aprovação da Lei $n^{\circ} 10.831 / 2003$, que regulamentou a agricultura orgânica no Brasil, foi criada a Comissão de

6 O CONSEA-MG, criado em 1999 pelo Decreto n 40.324, delibera, propõe e monitora ações e políticas de segurança alimentar e nutricional sustentável no âmbito do estado de Minas Gerais. Atualmente o CONSEA-MG é regido pela Lei $n^{0} 22.806 / 2017$, que dispõe sobre a Política Estadual de Segurança Alimentar e Nutricional. Disponível em: <http://conseaminas.blogspot.com/p/institucional_6.html>. Acesso em: 22 maio 2019. 
Agricultura Orgânica de Minas Gerais (CPOrg), por meio de uma portaria publicada pelo governo federal. Em 2005, o IMA, que já atuava na certificação de produtos agropecuários como o café e a cachaça, passou a dispor de um regulamento técnico voltado à certificação de produtos orgânicos.

A construção da PEAPO-MG insere-se, por sua vez, em um ciclo mais recente de interações entre agentes públicos com atuação na esfera estadual e organizações sociais do campo, tendo como marco temporal importante a criação, em 2011, de uma Subsecretaria da Agricultura Familiar pelo Governo Anastasia (2010-2014). Com a extinção do Instituto de Terras do estado de Minas Gerais, em 2013, esta Subsecretaria passou a incorporar atribuições relacionadas à regularização fundiária. Registra-se em 2015, já no Governo Pimentel (2015-2018), a criação da Secretaria de Estado de Desenvolvimento Agrário (SEDA), responsável por coordenar as políticas de desenvolvimento rural, acesso à terra, fortalecimento da agricultura familiar e SAN, abrigando, também, em novas bases, a Subsecretaria de Agricultura Familiar.

Segundo depoimentos colhidos durante o trabalho de campo, a criação da Subsecretaria da Agricultura Familiar, em 2011, foi influenciada por atores ligados às organizações da agricultura familiar, ao campo da SAN e às redes de agroecologia. $\mathrm{O}$ gestor que se tornou responsável por esta subsecretaria possuía uma longa trajetória de atuação, tanto no movimento agroecológico (desde os anos 1980), como no Fórum Brasileiro de Soberania e Segurança Alimentar (FBSSAN), tendo sido conselheiro do CONSEA Nacional.

Ainda durante o Governo Anastasia, mas, sobretudo, no Governo Pimentel, uma série de outros profissionais e quadros políticos, historicamente vinculados às dinâmicas de organização da sociedade civil, também passaram a ocupar cargos comissionados no governo estadual. Esta rede foi também fortalecida por funcionários de carreira, identificados com a proposta da agroecologia e a produção orgânica, vinculados a organizações governamentais como a EPAMIG, a EMATER, o IMA, entre outras. Algumas delas já desenvolviam algum tipo de trabalho relacionado à agroecologia e à produção orgânica. É importante destacar, no entanto, que estas três instituições, de grande relevância para a promoção do desenvolvimento rural, mantiveram sua vinculação à Secretaria de Estado de Agricultura, Pecuária e Abastecimento (SEAPA).

As interfaces estabelecidas entre os atores sociais articulados em torno da Subsecretaria da Agricultura Familiar (e posteriormente da SEDA) e do CEDRAF (Conselho Estadual de Desenvolvimento Rural Sustentável), envolvendo movimentos sociais, organizações da sociedade civil, parlamentares e assessores legislativos na Assembleia Legislativa do Estado de Minas Gerais (ALMG), possibilitaram a aprovação, entre 2011 e 2014, além da PEAPO $\left(\right.$ Lei $\left.^{\circ}{ }^{\circ} 21.146 / 2014\right)$, de uma série de outras legislações, que aparecem referenciadas no Quadro 1. Buscamos sistematizar no Quadro, ainda que de forma não exaustiva, os marcos regulatórios instituídos no estado de Minas 
Gerais relacionados à agroecologia e à produção orgânica a partir do final dos anos 1990. Como se pode perceber, a estruturação da PEAPO encontra-se inserida em um esforço mais amplo de construção política e institucional, sendo importante chamar atenção para as conexões estabelecidas entre iniciativas de parlamentares e a atuação do Poder Executivo, sobretudo a partir do Governo Anastasia. Os nexos existentes entre estas diferentes iniciativas e a construção da PEAPO serão desenvolvidos na próxima seção.

\section{Quadro 1 - Marcos regulatórios relacionados à agroecologia e à produção orgâ-} nica instituídos a partir do final da década de $1990 \mathrm{em}$ Minas Gerais ${ }^{7}$

\section{Governo Itamar Franco PMDB (1999-2002) \\ Lei 13.965/2001 - Pró-Pequi \\ Governo Aécio Neves PSDB (2003-2006) (2007-2010) \\ Lei 14.614/2003 - Programa Estadual de Apoio Financeiro à Escola Família Agrícola \\ Lei 15.973/2006 - Política Estadual de Agricultura Urbana \\ Lei 16.680/2007 - Apoio à Transformação e ao Processamento da Produção Familiar e à Comercialização Direta entre Agricultores Familiares e Consumidores \\ Lei 18.374/2009 - Dispõe sobre a política estadual de incentivo à formação de bancos comunitários de sementes de cultivares locais, tradicionais ou crioulas}

Governo Antonio Anastasia PSDB (março de 2010 a dezembro de 2010) (2011-2014)*

Decreto 45.962/2012 - Nova estruturação do Conselho Estadual de Desenvolvimento Rural Sustentável - CEDRAF-MG

Lei 20.608/2013 - Política Estadual de Aquisição de Alimentos da Agricultura Familiar Lei 21.146/2014 - Política Estadual de Agroecologia e Produção Orgânica - PEAPO-MG

Lei 21.147/2014 - Política Estadual de Desenvolvimento Sustentável dos Povos e Comunidades Tradicionais

Lei 21.156/2014 - Política Estadual de Desenvolvimento Rural Sustentável da Agricultura Familiar

\section{Governo Fernando Pimentel PT (2015-2018)}

Decreto com Numeração Especial 481/2018 - Plano de Ação da Estratégia Intersetorial de Redução do Uso de Agrotóxicos e Apoio à Agroecologia e à Produção Orgânica em Minas Gerais 2018-2022

Lei 23.207/2018 - Institui o Polo Agroecológico e de Produção Orgânica da Zona da Mata

* Entre abril de 2014 e $1^{\circ}$ de janeiro de 2015 o Vice-Governador, Alberto Pinto Coelho Jr., do

Partido Progressista (PP), assumiu o cargo de Governador, após renúncia do titular.

Fonte: elaborado pelas autoras, a partir de informações obtidas no site da Assembleia Legislativa de Minas Gerais - ALMG.

7 Siglas dos partidos políticos indicados na tabela: Partido do Movimento Democrático Brasileiro (PMDB); Partido da Social Democracia Brasileira (PSDB); Partido dos Trabalhadores (PT). 


\section{O processo de construção e implementação da PEAPO-MG e os desafios da institucionalização}

A PEAPO-MG foi instituída por meio da Lei n ${ }^{\circ} 21.146 / 2014$, tendo como referência original em sua formulação o Projeto de Lei no 2.547/2011, apresentado à ALMG pelo Deputado Estadual Adelmo Leão, do PT. O CEDRAF-MG, vinculado até recentemente à SEDA, participou ativamente desta construção, apresentando, em comum acordo com o autor do projeto, um substitutivo à proposta original, que foi debatido e, posteriormente, aprovado pelo Legislativo Estadual. Uma das principais arenas de discussão envolvidas na formulação da PEAPO no estado de Minas Gerais foi o CEDRAF-MG. O Conselho contava, no momento em que foi elaborada a política, com um Grupo Temático de Agroecologia e Produção Orgânica, que passaria, posteriormente, à condição de Câmara Técnica.

O CEDRAF-MG tem sua origem no Conselho Estadual Sustentável (CEDRS) do Estado de Minas Gerais, criado pelo Decreto $n^{\circ} 41.557 / 2001$, tendo passado, conforme já mencionado anteriormente, por um processo de reestruturação e ampliação durante o Governo Anastasia. Destacam-se, entre suas atribuições, o monitoramento e avaliação das políticas de desenvolvimento rural, a elaboração do Plano Estadual de Desenvolvimento Rural (PEDRS) e a articulação com os programas implementados pelo Governo Federal.

Figuram formalmente como membros natos do CEDRAF-MG, representando o governo estadual, seis Secretários de Estado e quatro representantes de empresas estatais. Órgãos federais ligados à agricultura também têm assento como convidados, assim como os presidentes da ALMG e da Associação Mineira de Municípios. Participam também do Conselho pela sociedade civil, nesta mesma categoria de membros convidados, representantes da FETAEMG, da Federação das Comunidades Quilombolas do Estado de Minas Gerais, do Conselho de Povos Indígenas de Minas Gerais, da AMA, da Articulação do Semiárido (ASA), da Via Campesina MG, da Associação Mineira das Escolas Família Agrícola (AMEFA), da União das Cooperativas do Estado de Minas Gerais (UNICAFES), da Federação dos Trabalhadores na Agricultura Familiar do Estado de Minas Gerais (FETRAF-MG), da Federação das Comunidades Quilombolas de Minas Gerais (N'Golo), da Rede Estadual de Colegiados Territoriais, do Movimento dos Atingidos por Barragens (MAB), da Federação de Pescadores Artesanais e Aquicultores do Estado de Minas Gerais, do Movimento dos Pequenos Agricultores (MPA) e da Articulação das Mulheres do Campo de Minas Gerais. No que diz respeito à participação das organizações da sociedade civil, chama atenção a forte presença dos movimentos sociais 
e de organizações do chamado "campo agroecológico", que se mostraram bastante ativas em todo o processo de construção da PEAPO.

Para além do CEDRAF-MG, cabe destacar a importância da ALMG como espaço de debates relacionado à construção da Política. O projeto que deu origem à PEAPO foi debatido na Comissão de Constituição e Justiça $(\mathrm{CCJ})$ e na Comissão de Política Agropecuária e Agroindustrial. Entre as justificativas apresentadas às Comissões em favor da proposta cabem ser destacadas o potencial de disseminação da agroecologia e da produção orgânica "nas atividades da agricultura familiar", bem como os benefícios desta prática, não apenas para os agricultores, "como também para os beneficiários da produção agrícola”. A existência de marcos regulatórios relacionados ao tema na esfera federal, contribuiu, também, para reforçar a aprovação do projeto. A Comissão que deu parecer favorável à redação final do projeto era composta por deputados do Partido Republicano Brasileiro (PRB) e do Partido Verde (PV).

Segundo os depoimentos obtidos, a CPOrg-MG não teve uma participação direta na formulação da PEAPO. Analisando o perfil dos produtores orgânicos certificados pelo MAPA (Ministério de Agricultura, Pecuária e Abastecimento) em Minas Gerais, identificamos uma forte presença, tanto de agricultores familiares, como de Sistemas Participativos de Garantia (SPGs) de alcance local ou regional. A CPOrg possui uma composição paritária envolvendo representantes do setor público e entidades da sociedade civil. Algumas das entidades que estiveram à frente da construção da PEAPO, como a AMA e a FETAEMG, participam também da CPOrg, mas a comissão é composta, também, por organizações não governamentais ambientalistas, associações e cooperativas de produtores que trabalham com agricultura orgânica, entre outras organizações.

Não foi possível identificar movimentos abertamente contrários à institucionalização da PEAPO-MG. As avaliações parecem convergir no sentido de que a PEAPO não colocava em questão, pelo menos de uma forma aberta, temas delicados da política estadual, relacionados, por exemplo, aos interesses do agronegócio e da mineração, setores que têm um peso econômico e político importante em Minas Gerais. A participação relevante da produção familiar na economia agrícola mineira parece contribuir para que as demandas da agricultura familiar tenham algum nível de visibilidade, tanto na ALMG, como nos diferentes órgãos que integram o poder executivo estadual. Observa-se, ao mesmo tempo, que a coalizão construída em torno da PEAPO e demais legislações acima mencionadas, enfrentou grandes dificuldades no sentido de 
influenciar o quadro geral de distribuição dos recursos públicos, assegurando a efetiva implementação da Política.

São bastante visíveis as conexões entre os instrumentos de suporte à agroecologia e à produção orgânica institucionalizados nos últimos anos no estado de Minas Gerais e os programas e ações previstos no âmbito dos PLANAPOs. Cabe observar que atores sociais relevantes para a implantação da PEAPO-MG estiveram diretamente envolvidos na construção da PNAPO, participando, posteriormente, dos debates desenvolvidos no âmbito da CNAPO.

\section{A concepção de Agroecologia incorporada à PEAPO-MG}

\section{A PEAPO-MG define agroecologia como o}

campo do conhecimento transdisciplinar que estuda os agroecossistemas, visando ao desenvolvimento equilibrado das relações entre capacidade produtiva, equilíbrio ecológico, eficiência econômica, equidade social e uso e conservação da biodiversidade e dos demais bens naturais, por meio da articulação entre conhecimento técnico-científico, práticas sociais diversas e saberes e culturas populares e tradicionais (GOVERNO DO ESTADO DE MINAS GERAIS, 2014) ${ }^{8}$.

É interessante observar que esta definição amplia, em certa medida, o conceito adotado pela PNAPO, que utiliza palavras semelhantes para caracterizar a Produção de Base Agroecológica e não a Agroecologia, entendida nos termos da PEAPO-MG como um campo de conhecimento e não como uma forma de produção.

No que se refere especificamente ao conceito de "transição agroecológica", tanto a PNAPO como a PEAPO-MG empregam uma definição que tem como foco principal a "transformação dos agroecossistemas convencionais". Ou seja, ainda que a agroecologia seja referenciada de forma bastante abrangente, a transição agroecológica parece ser compreendida de modo mais restrito, como uma transformação nas práticas e formas de manejo associadas especificamente aos agroecossistemas. Ganham centralidade, portanto, nesse conceito, sobretudo, os aspectos relacionados à produção e à superação do "sistema convencional".

Os grupos prioritários a serem atendidos pela PEAPO-MG são os agricultores familiares, agricultores urbanos e povos e comunidades tradicionais. O protagonismo destes segmentos "na construção e socialização de

8 Lei no 21.146/2014. Disponível em: <https://www.almg.gov.br/consulte/legislacao/completa/completa. html?ano=2014\&num = 21146\&tipo=LEl>. Acesso em: 20 jun. 2019. 
conhecimento" e "na gestão, na organização social e nas atividades produtivas da agroecologia, da produção orgânica e da transição agroecológica" é também valorizado na definição das diretrizes da política. De forma mais ampla, a participação da sociedade civil "na elaboração e na gestão de programas e projetos de pesquisa, ensino e Assistência Técnica e Extensão Rural (ATER) em agroecologia, produção orgânica e transição agroecológica" é reforçada pelos objetivos da PEAPO.

Cabe chamar atenção para o fato de que as falas dos atores entrevistados dialogam, em boa medida, com os quadros de referência construídos nas últimas décadas no espaço das redes de agroecologia, particularmente no âmbito da Articulação Nacional de Agroecologia (ANA) e da Associação Brasileira de Agroecologia (ABA), como associação científica. A agroecologia foi mencionada, várias vezes, nas entrevistas como "ciência, movimento e prática", como um "campo transdisciplinar", como campo do conhecimento que articula "ensino, pesquisa e extensão". Merecem destaque, também, no caso de Minas Gerais, as fortes relações estabelecidas entre "agroecologia e agricultura urbana", "agroecologia e povos e comunidades tradicionais" e "agroecologia e feminismo".

Quanto a essa última conexão, é importante destacar o envolvimento, na construção da política, das organizações de mulheres, particularmente por meio da Articulação das Mulheres do Campo de Minas Gerais, com representação no CEDRAF-MG. Segundo entrevistas realizadas com mulheres que participam direta ou indiretamente desta Articulação, ainda que exista um esforço na incorporação de uma abordagem de gênero às políticas de desenvolvimento rural, permanece o desafio de compreender a agroecologia sob uma perspectiva mais ampla. De acordo com nossas interlocutoras, a tendência é olhar a agroecologia de um ponto de vista técnico-produtivista, sendo que esta visão não contribui no processo de articulação com outros programas e ações de interesse público, como as políticas de enfrentamento à violência contra as mulheres e de apoio a empreendimentos econômicos sob uma perspectiva feminista.

A múltiplas dimensões da agroecologia aparecem, também, na fala do representante das comunidades quilombolas, que chamou atenção para o fato de que "a agroecologia é o modo de fazer de sempre das comunidades", práticas que são "passadas de pai para filho", "passadas por geração". Refletindo sobre o papel das lideranças nessa tarefa de tradução dos conceitos utilizados no âmbito das políticas públicas no diálogo com as comunidades comentou:

9 Segundo fala de um líder quilombola, a agroecologia é modo de fazer de sempre das comunidades indígenas e quilombolas, sendo o termo agroecologia compreendido como uma nomenclatura que a legislação abarca. O papel das lideranças é fazer esse trabalho de "tradução", já que nas comunidades os termos utilizados são "tradicional", "passado de pai pra filho", "passado por geração". 
A gente prefere não confrontar muito essa linguagem que a gente tem nas comunidades com a linguagem que a gente tem com os técnicos, os parceiros, governos, até pra gente também não perder o que é nosso, nosso linguajar. Então a gente tem o maior cuidado de saber do que se fala, aonde, mas sabendo que muitas vezes é a mesma coisa, é o mesmo termo. O que a legislação traz pra gente é segurança naquilo que a gente sempre fez. Deixa de ser visto como atrasado aquilo que a gente fazia, né? Eu acho que a primeira coisa é isso. Eu acho que a legislação como um todo, se a gente analisar ela traz a segurança que o que a gente faz não é atrasado.... (Entrevista, 2019)

\section{A implementação da PEAPO: o esforço por superar obstáculos na articulação entre marcos referenciais, instrumentos e recursos}

Analisando os objetivos gerais da PEAPO-MG é possível identificar quatro grandes problemas públicos sobre os quais a Política Estadual buscou incidir (i) a ampliação da oferta de produtos agroecológicos, orgânicos e em transição; (ii) a garantia do acesso, uso e conservação dos bens naturais (terra, água e biodiversidade) pelos agricultores e agricultoras; (iii) a construção e consolidação de instrumentos de políticas públicas voltados à promoção da agroecologia e da agricultura orgânica e, (iv) a ampliação da capacidade de geração e socialização de conhecimentos relacionados à agroecologia e à produção orgânica, não apenas no âmbito do setor público, mas considerando, também, as instituições da sociedade civil.

São considerados instrumentos da PEAPO:

I - o Plano Estadual de Agroecologia e Produção Orgânica (Pleapo); II - a Ater especializada em agroecologia; III - a pesquisa e a inovação científica e tecnológica com foco na agroecologia; IV - a formação profissional e a educação do campo; $\mathrm{V}$ - as compras governamentais de gêneros alimentícios agroecológicos ou orgânicos, nos termos da Política Estadual de Aquisição de Alimentos da Agricultura Familiar; VI - medidas fiscais e tributárias que favoreçam a produção agroecológica, orgânica e em transição agroecológica ${ }^{10}$.

O modelo de governança institucionalizado pela PEAPO confere ao CEDRAF-MG a responsabilidade pelo acompanhamento e promoção da participação social no âmbito da política. O CEDRAF-MG é responsável também pelo monitoramento da Política Estadual de Desenvolvimento Rural 
Sustentável da Agricultura Familiar (PEDRAF) ${ }^{11}$ e, de modo geral, dos programas e ações voltados à agricultura familiar e ao desenvolvimento rural. Existiu em Minas Gerais, portanto, ao longo dos últimos anos, um esforço por integrar as ações voltadas ao desenvolvimento rural e à agricultura familiar implementadas por diferentes órgãos do governo estadual, estabelecendo algum nível de conexão com as políticas voltadas à agroecologia, particularmente com a PNAPO, na esfera federal.

A estratégia desenvolvida pela coalizão de atores engajada na construção da PEAPO-MG envolvia, portanto, a construção de marcos regulatórios que pudessem viabilizar não apenas a criação de uma estrutura de coordenação, capaz de direcionar programas e ações já existentes na perspectiva da agroecologia, mas, também, de impulsionar a criação de novos instrumentos. Isso explica, por exemplo, a regulamentação, praticamente no período em que foi instituída a PNAPO, de uma série de outros instrumentos de políticas públicas. Gestores públicos e organizações da sociedade civil tinham presentes as limitações a serem enfrentadas no que diz respeito à obtenção dos recursos necessários para o desenvolvimento destas ações. O caminho percorrido pela equipe que assumiu a Subsecretaria da Agricultura Familiar no Governo Anastasia buscou dar visibilidade à agricultura familiar e à agroecologia, criar marcos legais e fortalecer espaços de controle social, ao mesmo tempo em que os diferentes atores continuavam, insistentemente, lutando por recursos capazes de alavancar a implementação dessas políticas.

A implantação da PEAPO ocorreu em um período marcado pela crise fiscal do estado e por uma forte instabilidade política tanto em nível federal como no plano estadual, sendo que as disputas entre diferentes setores da política mineira, durante o Governo Pimentel, chegaram a colocar na agenda a própria possibilidade de impeachment do governador. Para além das restrições orçamentárias, a saúde das finanças do governo estadual não estimulava as agências de cooperação internacional a construir parcerias na implementação de políticas públicas. As tentativas de estabelecer uma parceria com o Fundo Internacional de Desenvolvimento Agrícola (FIDA) das Nações Unidas não foram adiante.

O reforço à atuação no espaço legislativo foi visto, então, como uma alternativa viável. Movimentos sociais e organizações da sociedade civil mineira buscaram incidir sobre o governo estadual, através da ALMG, de forma a

11 O Plano Estadual de Desenvolvimento Rural Sustentável da Agricultura Familiar (PEDRS) foi aprovado em 2014. Por meio dele é possível visualizar, de uma forma mais abrangente, o contexto político e institucional em que estão situadas as políticas de desenvolvimento rural no estado de Minas Gerais, considerando suas possíveis interfaces com as políticas de promoção da agroecologia a serem articuladas por meio do PLEAPO. 
ampliar os recursos disponíveis, tanto no que diz respeito à implementação da PEAPO, como das demais legislações acima mencionadas. Cabe destacar, nesse sentido, a participação na Comissão de Participação Popular (CPP) da ALMG, institucionalizada desde 2003 e atualmente coordenada pelo Deputado André Quintão (PT). A CPP recebe e encaminha propostas de ação legislativa, dentre outras funções, e por meio desse mecanismo, sindicatos, associações, conselhos e ONGs têm conseguido interagir com a ALMG em torno de um conjunto diversificado de demandas, ampliando sua capacidade de influência sobre o orçamento estadual.

Um dos principais obstáculos para que a PEAPO se materializasse em um Plano Estadual de Agroecologia e Produção Orgânica estava associado, justamente, a essa questão orçamentária. As normas estabelecidas pela Secretaria de Estado de Planejamento e Gestão de Minas Gerais (SEPLAG), não permitiam a criação de um plano sem ações orçamentárias. Em 2014, em meio a uma série de desafios, a SEDA conseguiu finalizar a elaboração do PEDRS. Mas o Plano Estadual que deveria dar concretude à PEAPO, teve dificuldades para "sair do papel". Nas palavras de um dos gestores envolvidos no processo:

o Plano Estadual de Desenvolvimento Rural Sustentável nós fizemos na cara e na coragem. Nós mesmos. Não teve nem dinheiro para pagar consultoria e fazendo as articulações conseguimos aprovar um plano minimamente aí, concebível. Esse da agroecologia nós não conseguimos. Embora a gente perseguia sempre (Entrevista, 2018).

A alternativa encontrada foi tentar avançar na implantação dos diversos instrumentos previstos na PEAPO: "a gente resolveu né, ao invés de como diz, fazer do limão uma limonada. Articular. Começar a construir as bases desse plano que está previsto na Política Estadual de Agroecologia" (Entrevista, 2018). Cabe observar que os principais atores engajados na construção da PEAPO, continuavam organizados em torno do CEDRAF. Refletindo sobre esse processo, uma de nossas entrevistadas, com atuação nas redes da sociedade civil observou:

[O Governo] cedeu a Secretaria do Desenvolvimento Agrário, com pouquíssima força, sem efetivo, sem orçamento, as principais agências EMATER, EPAMIG, não estavam dentro da SEDA (...) mas pelo menos tinha o CEDRAF, o Conselho de Desenvolvimento Rural Sustentável que estava dentro da SEDA, foi nosso principal meio de incidência, foi no âmbito do CEDRAF, com muitas conquistas (Entrevista, 2018). 
De acordo com os depoimentos, colhidos durante o trabalho de campo, estas conquistas estiveram vinculadas a todo um esforço de articulação política e coordenação de instrumentos que possibilitou, por exemplo, a criação de um Programa Estadual de Pesquisa em Agroecologia no âmbito da EPAMIG, construído em diálogo com as organizações da sociedade civil. Em 2017 realizou-se o seminário "Dialogar para Transformar", que buscou fortalecer uma interlocução com a Fundação de Amparo à Pesquisa do Estado de Minas Gerais (FAPEMIG), através da construção de um conjunto de diretrizes de apoio à pesquisa em "Agroecologia, Agricultura Familiar e Urbana e Povos e Comunidades Tradicionais". Este seminário não chegou a resultar, no entanto, em iniciativas concretas de financiamento de projetos nessa área.

No caso da EMATER, a empresa monitorou os atendimentos feitos pelos técnicos com foco na agroecologia (incluindo cursos, encontros, palestras, visitas, entre outros), considerando o número de agricultores envolvidos. No ano de 2018, foram realizados 29.564 atendimentos diretamente relacionados à agroecologia (havendo a possibilidade de repetição dos agricultores). A título de comparação cabe mencionar os 350.137 atendimentos direcionados, de forma mais geral, à agricultura familiar, e os 10.548 atendimentos destinados a cadeias de valor (café, bovinocultura e olericultura).

A empresa buscou implementar uma agenda baseada em três eixos: "construção do conhecimento", "construção social de mercados" e "apoio ao crédito e fomento". No primeiro eixo foram realizados investimentos na qualificação dos quadros técnicos em todas as regiões de atuação da EMATER, fomentando-se também a criação de redes regionais de produção de conhecimento agroecológico, articulando diferentes parcerias. No eixo "construção social dos mercados", houve fomento ao circuito de feiras agroecológicas, sendo que esta iniciativa se encontra articulada à construção de uma rede sociotécnica de certificação participativa, contando também com a parceria da Prefeitura de Belo Horizonte. Por fim, o terceiro eixo contemplou duas iniciativas centrais: a organização de uma rede de insumos de apoio à transição agroecológica e a produção de coeficientes técnicos para viabilizar a operacionalização do Pronaf Agroecologia no Banco do Brasil. Foi criado também, na EMATER, um espaço de interlocução com as organizações da sociedade civil, mantendo-se uma agenda regular de reuniões.

Avanços foram obtidos, também, nas aquisições de alimentos oriundos da agricultura familiar no âmbito da administração pública estadual direta e indireta. De acordo com os depoimentos, resultados positivos foram registrados na interlocução com a Fundação Hospitalar do Estado de Minas Gerais (FHEMIG), responsável pela administração de 20 unidades assistenciais e um Centro de Atenção Psicossocial, sendo todas essas unidades ligadas ao SUS. 
Chamadas Públicas foram lançadas, também, em 2018, visando abastecer escolas estaduais localizadas em diferentes municípios ${ }^{12}$.

Um novo esforço de construção de dispositivos capazes de assegurar a coordenação de políticas públicas em favor da agroecologia e da produção orgânica foi a institucionalização, em 2018, do Plano de Ação da Estratégia Intersetorial de Redução do Uso de Agrotóxicos e Apoio à Agroecologia e à Produção Orgânica em Minas Gerais 2018-2022 (PLANERA). O plano faz referência ao Projeto de Lei (PL n ${ }^{\circ}$ 6.670/2016) que tem por objetivo institucionalizar a Política Nacional de Redução de Agrotóxicos (PNARA), existindo muito claramente uma vinculação entre o PLANERA e as propostas incorporadas ao PNARA. O Decreto ${ }^{\circ} 47.223$, de 26/07/2017 criou o Grupo Executivo Permanente (GEP) da Estratégia Intersetorial de Redução do Uso de Agrotóxicos e Apoio à Agroecologia e Produção Orgânica em Minas Gerais, sendo que a versão final do PLANERA foi publicada em setembro de 2018. Trata-se, neste caso, de uma estratégia intersetorial, descrita no documento intitulado Plano Estratégico (PLANERA) 2018-2022 “como um instrumento de natureza estratégica, estabelecido com a finalidade de orientar a implementação da Política Estadual de Agroecologia e produção Orgânica PEAPO” (GOVERNO DO ESTADO DE MINAS GERAIS, 2018). A redução do consumo de agrotóxicos figura como eixo principal do documento, que contempla, também, todo um capítulo voltado ao apoio à agroecologia e à produção orgânica. Participam do controle social do PLANERA, oito diferentes conselhos, incluindo aí o CEDRAF. A exemplo da PEAPO, o PLANERA não conseguiu se estruturar com base em um orçamento próprio.

\section{Breves observações sobre o cenário atual}

O principal elemento de desestabilização da coalizão que liderou a construção da PEAPO e das políticas voltadas à agricultura familiar e ao desenvolvimento rural em Minas Gerais, tanto no campo governamental como no contexto da sociedade civil, diz respeito à derrota eleitoral da candidatura Pimentel nas eleições de 2018. Não cabe aqui discutir os motivos que levaram a esse resultado, mas não há dúvida de que as correlações de forças estabelecidas em nível nacional com o processo de impeachment da Presidenta Dilma Rousseff, a ascensão de novas forças políticas e a desestruturação, em nível

Uma notícia publicada pelo Diário do Comércio, reproduzida no site do Sistema OCEMG de cooperativismo, noticiava o lançamento de editais coletivos para a compra de alimentos da agricultura familiar visando abastecer 253 escolas estaduais em 27 municípios. Disponível em: <http://www.minasgerais. coop.br/pagina/10121/produtos-da-agricultura-familiar-ve-227-o-suprir-merenda-em-minas-gerais.aspx>. Acesso em: 25 jun. 2019. 
federal, das políticas de desenvolvimento rural e de diversos conselhos de políticas públicas influenciaram esse processo.

No início de 2019, com posse do empresário Romeu Zema, vinculado ao Partido Novo, eleito em 2018 para o Governo do Estado de Minas Gerais (sem coligação), o novo governador apresentou à ALMG o PL nº 367/2019, propondo a extinção da SEDA. Neste projeto, parte das atribuições da SEDA desapareceram e parte foi incorporada à Secretaria de Estado de Agricultura e Abastecimento do Estado de Minas Gerais (SEAPA). Alguns órgãos colegiados foram extintos, mas o CEDRAF-MG foi, em princípio, mantido.

Ainda é cedo para avaliar os impactos gerados pela nova correlação de forças que passa a se estabelecer no governo estadual com ascensão ao Poder Executivo do Partido Novo. O espaço político conquistado por gestores identificados com a agricultura familiar e, mais especificamente, com as propostas historicamente construídas pelas organizações da sociedade civil com atuação no campo da agroecologia, possibilitou avanços importantes na construção de marcos regulatórios, na dinamização de espaços de participação social e na incorporação da agroecologia à agenda de instituições como a EMATER-MG e a EPAMIG. Em que pese as limitações existentes do ponto de vista dos recursos financeiros, foram implementados programas de grande relevância como o PAA-Familiar. O que se verifica no presente momento é um fechamento de espaços institucionais voltados à implantação das políticas em favor da agricultura familiar, da agroecologia e da SAN em nível estadual e federal.

Porém, cabe chamar atenção para a existência, em diferentes regiões do estado de Minas Gerais, de um conjunto de movimentos sociais e organizações da sociedade civil com atuação no campo da agroecologia que têm conseguido intervir, em diferentes momentos, na relação com o governo estadual, de forma articulada e relativamente coesa. A existência da AMA, criada no início dos anos 2000, expressa em boa medida esta capacidade de articulação em rede. Além disso, vale mencionar a existência, no âmbito da ALMG, de deputados sensíveis ao tema da agroecologia e que têm apresentado, recorrentemente, propostas nessa área.

A experiência acumulada pelos diferentes atores na formulação e implantação de políticas públicas de agroecologia e produção orgânica em nível estadual trouxe ganhos importantes no que diz respeito ao reconhecimento de direitos e ao amadurecimento do enfoque agroecológico como uma referência de ação pública. A coordenação horizontal e vertical entre diferentes instrumentos, o exercício da intersetorialidade e os significados da participação social na construção de políticas públicas permanecem como temas de aprofundamento. 


\section{REFERÊNCIAS}

ABRUCIO, F. L. A coordenação federativa no Brasil: e experiência do período FHC e os desafios do Governo Lula. Revista de Sociologia Política, Curitiba, n. 24, p. 41-67, 2005.

ARRETCHE, M. Federalismo e políticas sociais no Brasil: problemas de coordenação e autonomia. São Paulo em Perspectiva, São Paulo, v. 18, n. 2, p. 17-26, 2004.

BORGES, A. Federalismo, dinâmica eleitoral e políticas públicas no Brasil. Uma tipologia e algumas hipóteses. Sociologias, Porto Alegre, v. 12, n. 24, p. 120-157, 2010.

BRASIL, MINISTÉRIO DA AGRICULTURA, PECUÁRIA E ABASTECIMENTO. Projeções do Agronegócio: Brasil 2017-2018 a 2017 a 2028. Projeções de Longo Prazo. Brasília, DF: MAPA/ACE, 2018.

CARVALHO, L. A valsa brasileira: do boom ao caos econômico. São Paulo: Todavia, 2018.

FRANZESE, C. Federalismo cooperativo no Brasil: da Constituição de 1988 aos sistemas de políticas públicas. 2010. Tese (Doutorado em Administração Pública e Governo) - Escola de Administração de Empresas de São Paulo, FGV, 2010.

GOVERNO DO ESTADO DE MINAS GERAIS. Lei 21.146 de 14/01/2014. Disponível em: $<$ http://extwprlegs1.fao.org/docs/pdf/bra168956.pdf $>$. Acesso em: 21 jun. 2019.

GOVERNO DO ESTADO DE MINAS GERAIS, SEAPA/EMATER-MG. Balanço Social 2015. Belo Horizonte: SEAPA/EMATER-MG, 2015.

KALIL, L. Une construction collective de l'action publique: la Politique Nationale d'agroécologie et de production biologique au Brésil. Mémoire (Master 2) - IHEAL, Sorbonne Nouvelle Paris III, 2016.

KERSTENETZKY, C. L. O Estado do Bem-Estar Social na Idade da Razão: a reinvenção do Estado Social no mundo contemporâneo. Rio de Janeiro: Elsevier, 2012. 
LASSANCE, A. Federalismo no Brasil: trajetória institucional e alternativas para um novo patamar de construção do Estado. In: LINHARES, Paulo de Tarso F.; MENDES, Constantino C.; LASSANCE, A. Federalismo à brasileira: questões para discussão. Brasília: IPEA, 2012. p. 23-35.

LOTTA, G. S.; GONÇALVES, R.; BITELMAN, M. A coordenação federativa de políticas públicas: uma análise das políticas brasileiras nas últimas décadas. Cadernos Gestão Pública e Cidadania, São Paulo, v. 19, n. 64, p. 2-18, 2014.

MAFRA, L. A. S. O município na gestão de políticas locais de Segurança Alimentar: regulação de mercado e assistência alimentar em Belo Horizonte. 2004. Dissertação (Mestrado em Ciências) - Programa de Pós-Graduação em Desenvolvimento, Agricultura e Sociedade, 2004.

SAMBUICHI, R. H. R. et al. (Orgs.). A Política Nacional de Agroecologia e Produção Orgânica no Brasil: uma trajetória de luta pelo desenvolvimento rural sustentável. Brasília: IPEA, 2017.

SCHMITT, C. J. et al. La experiencia brasileña de construcción de políticas públicas en favor de la agroecología. In: SABOURIN, E. et al. (Orgs.). Políticas públicas a favor de la agroecología en América Latina y el Caribe. Porto Alegre: Evangraf/ Criação Humana, Red PP-AL: FAO, 2017. p. 73-122.

SILVEIRA, M. C.; FONSECA, G. P. S.; OLIVEIRA, K. P. de. Os limites fiscais e orçamentários da reforma gerencial nos estados: o exemplo de Minas Gerais. Revista Contabilidade Vista \& Revista, Belo Horizonte, v. 23, n. 1, p. 127-163, 2012.

WIT, M. M. de; ILES, A. Toward thick legitimacy: creating a web of legitimacy for agroecology. Elementa: Science of the Anthropocene, v. 4-000115, p. 1-24, 2016. doi: 10.12952/journal. elementa.000115 


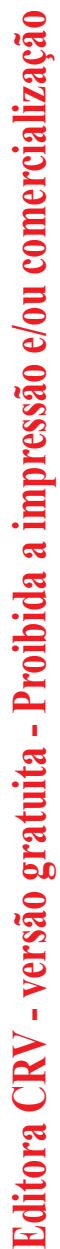




\section{CAPÍTULO 5}

\section{UMA LEITURA DA TRAJETÓRIA HISTÓRICA DE CONSTRUÇÃO DA POLÍTICA ESTADUAL DE AGROECOLOGIA E PRODUÇÃO ORGÂNICA (PEAPO) NO ESTADO DO RIO DE JANEIRO}

Guilherme de Freitas Ewald Strauch Juliano Luís Palm

\section{Introdução}

Esse capítulo contextualiza a trajetória histórica e a situação atual do processo de construção da Política Estadual de Agroecologia e Produção Orgânica no estado do Rio de Janeiro - PEAPO-RJ. Consideramos que a análise da trajetória dos atores e a identificação de distintos contextos sejam relevantes para a compreensão do processo de construção de políticas públicas de promoção do desenvolvimento rural no estado e, em especial, aquelas de apoio à agroecologia e produção orgânica. Conforme buscamos demonstrar nas páginas subsequentes, o processo histórico analisado é destacado pela dificuldade de articulação dos movimentos sociais com o poder público, especialmente em nível estadual, em um contexto marcado pela invisibilidade da agricultura familiar no estado, utilizada como justificativa e reforçada pela fragilidade política e institucional em ações públicas de desenvolvimento rural.

O estado do Rio de Janeiro é o mais urbanizado do país, com $95 \%$ de sua população vivendo em centros urbanos (SILVA; MARAFON, 2005). Com base em dados do Instituto Brasileiro de Geografia e Estatística (IBGE) e do Instituto Nacional de Colonização e Reforma Agrária (Incra), Alentejano $(2012$, p. 8) chama a atenção para a continuidade, nos últimos anos, "do processo de esvaziamento do meio rural, a ampliação da concentração fundiária e a redução da importância da agricultura, seja em relação à produção, à área e, principalmente ao emprego" no Rio de Janeiro. Este processo tem promovido, historicamente, dinâmicas de exclusão social e política dos espaços e das populações rurais no estado (MOREIRA, 2001). 
É em relação a este contexto que buscamos examinar as interações dos atores inseridos em experiências de promoção de agriculturas de base ecológica com o poder público e o processo de construção de políticas públicas de promoção do desenvolvimento rural, especialmente de apoio à agroecologia e produção orgânica, no Rio de Janeiro. Nossa leitura parte, neste sentido, do conjunto de atores que se articulam neste campo temático no estado, na qual não se pode perder de vista o processo mais amplo de fragilização de políticas públicas de desenvolvimento rural e voltadas para a agricultura familiar no contexto estadual.

Identificamos três contextos distintos em relação a problemática que buscamos analisar, que correspondem às seções em que subdividimos o texto: i) emergência de diversas experiências de agriculturas de base ecológica, de fins da década de 1970 ao início da década de 2000, com interações pontuais com o poder público, principalmente municipais; ii) articulação em torno de políticas e arranjos institucionais específicos, em um contexto de maior abertura para a participação da sociedade civil nos processos de construção e operacionalização de políticas públicas em escala federal, a partir de princípios da década de 2000; iii) esforços que visam a criação de políticas públicas estaduais de fortalecimento da agricultura orgânica e agroecologia, em um contexto de fragilização das políticas públicas em escala federal, especialmente a partir de 2016. Salientamos, no entanto, que essa subdivisão em três contextos deve ser lida como um esforço que visa auxiliar na compreensão de diferentes configurações que integram o processo analisado, o qual realizamos a partir dos focos de atuação dos atores inseridos na construção de experiências em agricultura de base ecológica no estado.

Ressaltamos, no entanto, que o processo histórico analisado é apresentado de forma muito resumida, focando na análise de atores que participaram desde o seu início e que, em maior ou menor grau, têm contribuído com a recente de construção da PEAPO-RJ. O foco dessa pesquisa também se restringe a identificar algumas das diferentes dinâmicas desses atores, nos diferentes contextos, ao longo dessa trajetória. Os recortes feitos, portanto, se baseiam em nossa compreensão de que não seria possível, no espaço desse capítulo, listar todos os atores e sistematizar os múltiplos eventos e as dinâmicas de constituição do rico e diversificado movimento da agroecologia e agricultura orgânica no estado do Rio de Janeiro.

\section{Emergência de experiências de agriculturas em base ecológica no Rio de Janeiro (fins dos anos 1970 ao início da década de 2000)}

Essa seção apresenta o contexto a partir do qual emergiram diferentes iniciativas de agricultura de base ecológica no estado do RJ, à época denominada 
de agricultura alternativa. Trata-se de um momento importante politicamente no país, no início dos anos 1980, de redemocratização e retomada das funções das instituições públicas, de organização e manifestação da sociedade civil e, portanto, da possibilidade de se rediscutir os modelos hegemônicos de desenvolvimento e as políticas de apoio à agricultura.

Essas iniciativas ocorrem no RJ em variados âmbitos, como da produção, comercialização e consumo, além da pesquisa, ensino e Assistência Técnica e Extensão Rural - Ater, mobilizando referenciais de agricultura em base ecológica também distintos, mas que criaram sinergias em alguns momentos e promoveram interações pontuais com as políticas públicas.

Em fins da década de 1970 afloram duas iniciativas que se constituem em referências fundamentais na construção e consolidação desse processo no estado. Em 1978, é fundado o Grupo de Agricultura Ecológica - GAE, formado por estudantes, predominantemente das ciências agrárias, na Universidade Federal Rural do Rio de Janeiro - UFRRJ ${ }^{1}$. Sua atuação em diversos espaços e momentos de construção de uma agricultura alternativa no estado do RJ é significativo não só na formação de gerações de estudantes, mas também na execução de projetos de assessoria e na construção do conhecimento agroecológico a partir das experiências desenvolvidas com agricultores familiares em atividades de extensão universitária.

Outra referência importante foi a fundação da Cooperativa de Produtores e Consumidores de Ideias, Produtos e Soluções Naturais - Coonatura. A partir de um encontro de consumidores da cidade do Rio de Janeiro, interessados em uma alimentação isenta de agrotóxicos, foi formada a Coonatura, que passou a promover um conjunto de ações de militância ecológica, antinuclear e pacifista. No início de 1980 um dos cooperados da Coonatura deu início a uma experiência de produção no município de Petrópolis, na região serrana do estado, com a adesão de agricultores familiares. Desta forma, foi se constituindo o núcleo rural da Coonatura, a qual, na década de 1990, manteve cerca de dois mil associados-consumidores, com trinta e cinco famílias de agricultores (FERREIRA, 2013).

Um outro marco histórico neste processo foi a realização do II Encontro Brasileiro de Agricultura Alternativa - EBAA, ocorrido em abril de 1984, em Petrópolis. O II EBAA foi organizado pela AEARJ e a Federação dos Engenheiros Agrônomos do Brasil - FAEAB, com apoio de instituições de

1 As origens do GAE, como aponta Felippe (2017), remetem a um grupo de estudantes da UFRRJ que passaram a realizar encontros para estudar e debater formas "alternativas" de praticar agricultura, tendo grande influência sobre as turmas de ciências agrárias dos anos de 1976, 1977 e 1978, das quais participaram diferentes atores que tiveram grande importância na construção dos movimentos em torno da agroecologia e da agricultura orgânica no estado nas décadas de 1980 e 1990. 
ensino, pesquisa e extensão rural, e da prefeitura municipal de Petrópolis. Esse encontro contou com a presença de mais de 1.000 pessoas, inclusive de 24 secretários de Agricultura, Saúde e Meio Ambiente de 11 estados da federação. Como resultado do encontro foi redigido um documento denominado Carta de Petrópolis, na qual os participantes firmavam um compromisso de redirecionar a pesquisa agrícola, realizar um diagnóstico dos diversos problemas ambientais, difundir o uso de tecnologias alternativas na agricultura e implantar uma legislação sobre o uso de agrotóxicos. Neste evento também se encontraram diferentes atores que estavam desenvolvendo experiências de produção em agricultura de base ecológica no estado do RJ, motivando a criação da Associação de Agricultores Biológicos do Estado do Rio de Janeiro - ABIO, em 1985. Além disso, o II EBAA impulsionou as discussões entre pesquisadores da Empresa Brasileira de Pesquisa Agropecuária - Embrapa Agrobiologia acerca da estruturação de uma unidade experimental, que veio a se concretizar na criação da Fazendinha Agroecológica, em 1993.

Desde o início da década de 1980 diversos atores, principalmente jovens de origem urbana da região metropolitana do estado, haviam iniciado experiências de produção de alimentos sem agrotóxicos, adquirindo sítios, especialmente na região serrana do estado. Estas experiências eram motivadas pelo contexto de ampliação dos debates sobre questões ambientais, em que os temas de alimentação e intoxicação por agrotóxicos estavam presentes. Grande parte destes atores participou do II EBAA em Petrópolis e, a partir deste contato, articularam uma reunião para debaterem estratégias de fortalecimento das iniciativas que vinham desenvolvendo, a ser realizada em Nova Friburgo. Esta reunião foi realizada em fins de 1984, na qual decidiram pela realização de uma feira. Um dos participantes tinha contatos com o poder público de Nova Friburgo e ficou responsável por articular a liberação de um espaço para a realização de uma feira semanal. Em março de 1985 inicia-se a Feirinha da Saúde, em uma rua no centro da cidade, e realizada semanalmente.

Com a estruturação da feira, a prefeitura demandou que alguma entidade ficasse responsável pela mesma, o que motivou a criação da ABIO. A estruturação da feira também demandou que fossem estipuladas regras acerca de quais manejos produtivos seriam permitidos ou não aos participantes, levando a ABIO a elaborar, ainda em 1985, um caderno de Normas Técnicas de Certificação da Produção, com base nos parâmetros adotados pela International Federation of Organic Agriculture Movements ${ }^{2}$ - IFOAM (ABIO, 2002).

Em 1988 membros da ABIO também conseguiram articular com a direção da Companhia Brasileira de Alimentos - COBAL um box na unidade de Botafogo, na cidade do Rio de Janeiro, onde passaram a comercializar grande 
parte de sua produção (FONSECA, 2009). O escoamento da produção dos associados da ABIO para este estande na COBAL era realizado por meio de um caminhão, que a $\mathrm{ABIO}$ havia adquirido com recursos captados com a cooperação internacional, a partir de um de seus sócio-fundadores, também professor da faculdade de agronomia da UFRRJ. Este espaço na COBAL tinha uma clientela expressiva, entretanto, a operação logística para escoar a produção dos associados desde suas propriedades até a cidade do Rio de Janeiro era extremamente complexa e exaustiva, sendo um dos motivos para o encerramento desta atividade ainda na primeira metade da década de 1990.

A realização da RIO 92, neste contexto, também fortaleceu significativamente as ações que buscavam dinamizar experiências em agricultura de base ecológica no estado, tendo em vista os debates sobre vários temas relacionados ao desenvolvimento sustentável, como a degradação ambiental (suas causas e consequências) e a necessidade de apoiar os processos de transição agroecológica na agricultura (MOURA, 2017).

Em 1994, a Coonatura e a ABIO conseguiram estruturar uma feira de produtos orgânicos no bairro da Glória, na cidade do Rio de Janeiro. Uma normativa municipal inviabilizava a estruturação de novas feiras de produtos agropecuários na cidade. Assim, a Feira da Glória foi viabilizada enquanto espaço cultural e gastronômico, constituindo-se em importante espaço para comercialização de alimentos orgânicos. Entretanto, após a criação desta feira, a normativa municipal inviabilizou a criação de outras na cidade, o que se manteve até 2010.

O EBAA II impulsionou, ainda, a proposta de estruturação de uma unidade experimental de pesquisa em agricultura orgânica. A partir deste evento, um pequeno grupo de pesquisadores da Embrapa Agrobiologia intensificou as discussões acerca da necessidade de estruturação desta unidade e, a proposta foi rapidamente apoiada por docentes da UFRRJ. Assim, em 1993 é inaugurado o Sistema Integrado de Produção Agroecológica - SIPA, mais conhecido como Fazendinha Agroecológica, em uma área de 70 hectares da Embrapa Agrobiologia, em Seropédica. Fruto de uma parceria entre a própria Embrapa, a Empresa de Pesquisa Agropecuária do Estado do RJ - PESAGRO RIO, UFRRJ e Colégio Técnico da UFRRJ - CTUR, seus objetivos são desenvolver e adaptar tecnologias relacionadas à agroecologia e à produção orgânica, apoiar a formação de recursos humanos nos níveis de graduação e Pós-Graduação para atuar na expansão da agroecologia e da agricultura orgânica, além de contribuir no diálogo e na construção do conhecimento envolvendo pesquisadores, professores, agentes de extensão rural e agricultores.

Ao longo destes anos também merecem destaque iniciativas desenvolvidas no âmbito da assessoria técnica com enfoque agroecológico. Como 
exemplo das experiências promovidas por extensionistas da EMATER-RIO, salientamos o processo de transição agroecológica fomentado em São José do Vale do Rio Preto por um extensionista da empresa ${ }^{3}$, a partir de 1990. Este processo foi de fundamental importância para a criação da associação Horta Orgânica, que buscou aproximar a produção de agricultores familiares de São José e Petrópolis com redes de supermercados, após o encerramento das atividades da Coonatura ${ }^{4}$ (FELIPPE, 2017).

Em 1999, é fundada a Cooperativa CEDRO, por profissionais que, em sua maioria, eram oriundos do Projeto Lumiar/INCRA $(1997 / 2000)^{5}$. A partir deste momento a CEDRO passou a contribuir com a "qualificação da Reforma Agrária e ao fortalecimento de redes institucionais em prol da Agroecologia" no estado (GOLLO, 2014, p. 215). Também em 1999 a Assessoria e Projetos em Agricultura Alternativa (AS-PTA) inaugura o Programa de Agricultura Urbana na zona oeste do município do Rio de Janeiro, passando a estimular o aproveitamento de espaços no centro urbano para o cultivo de alimentos, plantas medicinais e criações de animais, sob um enfoque agroecológico (MATTOS; MONTEIRO, 2014). Este programa teve um papel central no processo organizativo e de dinamização da Articulação de Agroecologia do Rio de Janeiro - AARJ, a partir de 2006. Além disso, ações desenvolvidas no âmbito do programa de agricultura urbana da AS-PTA foram relevantes para a criação da Rede Carioca de Agricultura Urbana - Rede CAU, na década de 2000. Ainda no final dos anos 1990, teve início, na região sul do estado, mais especificamente em Paraty, um trabalho de assessoria técnica (com integrantes do GAE UFRRJ) que incluiu ações de intercambio de conhecimento com agricultores em locais de referência em manejo de sistemas agroflorestais.

Em 1998, têm início as ações da Rede Agroecologia-Rio, coordenada pela Embrapa Agrobiologia e apoiada com recursos da FINEP e da FAPERJ. A Rede tinha o objetivo de promover o movimento agroecológico no estado do Rio de Janeiro, atuando em comunidades de agricultores familiares nas regiões metropolitana e serrana do estado. Constituída pela AS-PTA, PESAGRO-Rio,

O qual também teve sua formação acadêmica marcada pela participação nos grupos de estudos que deram origem ao GAE.

4 A Coonatura encerrou suas atividades devido as dificuldades impostas pela comercialização com grandes redes de supermercados na região metropolitana do estado, iniciativa que passou a desenvolver a partir da segunda metade dos anos 1990. A Horta Orgânica deu sequência a esta iniciativa, entretanto, pelos mesmos motivos, encerrou as atividades ainda no início dos anos 2000 (FERREIRA, 2013).

O Projeto Lumiar/INCRA se constitui na primeira política de ATER específica para os assentamentos de reforma agrária, com amplitude nacional, criado pelo Instituto Nacional de Colonização e Reforma Agrária (INCRA), em 1997 e extinto em 2000. Este projeto promoveu a terceirização e descentralização da assistência técnica nos assentamentos rurais, de tal modo que as organizações dos agricultores assentados pudessem contratar os serviços de ATER junto às organizações públicas e privadas, credenciadas para tal (DA ROS e PICCIN, 2012). 
EMATER-Rio, UFRRJ, ABIO e a empresa Agrinatura, a Rede é considerada a primeira experiência de instituições públicas do Brasil a articular todos os elos da cadeia produtiva da agricultura (NEVES et al., 2000 apud MOURA, 2017). Entretanto, um dos principais entraves para o avanço da Rede foi a não liberação de extensionistas da EMATER RIO para que esses pudessem dar maior atenção as ações previstas, o que foi solicitado ao governo estadual, mas sem êxito (WEID, 2001).

Como podemos observar, a partir de fins da década de 1970, emergiram diversas iniciativas e experiências de promoção de agriculturas em base ecológica no estado do Rio de Janeiro, mobilizando diferentes referenciais e sendo dinamizadas em múltiplos âmbitos: produção, comercialização, consumo, pesquisa, ensino e ATER. Em um contexto marcado pelo processo de redemocratização do país, estas iniciativas promoveram ações sinérgicas, em alguns momentos, buscando interagir pontualmente com o poder público, principalmente municipal. Esta dinâmica passou por transformações expressivas a partir do início da década de 2000, em um contexto de maior abertura para participação da sociedade civil nos processos de formulação e implementação de políticas públicas, especialmente na esfera federal, como analisaremos na próxima seção deste capítulo.

\section{Articulações em torno de políticas e arranjos institucionais em escala federal (princípios da década de 2000 a 2016)}

Em um contexto de ampliação dos espaços de participação da sociedade civil nos processos de formulação e operacionalização de políticas públicas em escala federal, a partir de 2003, em que as temáticas da agroecologia e produção orgânica passam a ser incorporadas em diferentes instrumentos de ação pública ${ }^{6}$, atores inseridos no movimento agroecológico e da agricultura orgânica no estado do Rio de Janeiro passaram a se articular em torno de determinadas políticas públicas e participar mais diretamente de arranjos políticos-institucionais específicos. Além dessa ênfase em processos relacionados às dinâmicas de políticas públicas em escala federal, nestes anos observamos alguns avanços em ações públicas em âmbito estadual em determinadas temáticas, conforme salientamos ao final da seção.

Um marco neste processo foi o I Encontro Nacional de Agroecologia - ENA, em que alguns dos núcleos de discussões em que atores estaduais passaram a centrar seus esforços nos anos subsequentes foram desencadeados. Após um período de preparação e encontros em todas as regiões do 
Brasil, é realizado, em 2002, o I ENA, no Rio de Janeiro. Participaram cerca de 1.100 pessoas entre técnicos de assessoria e extensão rural, agricultores/as, representantes de movimentos sociais e de povos e comunidades tradicionais, pesquisadores e estudantes.

Grande parte dos atores envolvidos com a promoção e dinamização de experiências em agriculturas de base ecológica no estado do Rio de Janeiro participam deste encontro, interagindo em diferentes debates. Merecem destaque, neste sentido, a participação de membros da ABIO no grupo de trabalhos sobre comercialização no I ENA, a partir do qual teve início a formação do Grupo de Agricultura Orgânica - GAO, central nas interações entre sociedade civil e estado no processo de conformação da legislação sobre certificação orgânica nos anos posteriores. Um dos principais encaminhamentos do I ENA foi o fortalecimento das redes estaduais e regionais de agroecologia, além da criação da Articulação Nacional de Agroecologia - ANA (MONTEIRO; LONDRES, 2017), em torno das quais passaram a centrar esforços diferentes atores do movimento agroecológico em âmbito estadual, viabilizando a criação e dinamização da Articulação de Agroecologia do Rio de Janeiro - AARJ, em 2006. Outro foco de atuação de atores que compõem o movimento agroecológico no estado foram as políticas de ATER, no contexto de profundas transformações nas políticas públicas federais nesta temática, a partir de 2004.

No I ENA o grupo de trabalho sobre comercialização propôs a retomada de um processo participativo na construção da regulamentação sobre agricultura orgânica no país, com a criação de um coletivo específico para debater o tema ${ }^{7}$. Articula-se, nesta direção, a continuidade das discussões deste grupo de trabalho para uma reunião a ser realizada, ainda em 2002, em Curitiba, da qual participaram 30 pessoas de oito estados. Nesta ocasião, foi criado o Grupo de Agricultura Orgânica - GAO, com o objetivo de dinamizar este conjunto de debates sobre a legislação entre atores da agricultura orgânica de diferentes regiões do país (FONSECA, 2005).

Membros da ABIO participaram ativamente dos processos de criação do GAO e das discussões sobre certificação orgânica, que se seguiram de forma bastante intensa até fins da década de 2000. A participação nestes espaços de

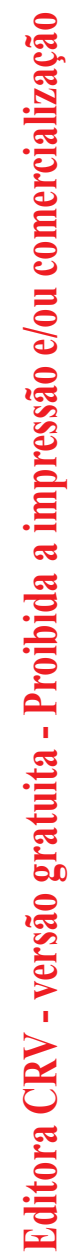

7 Os participantes deste debate consideravam que o processo de construção da Instrução Normativa 007/1999, que versa sobre a regularização da agricultura orgânica no Brasil, havia se dado de forma participativa, com amplos debates, elaborações e re-elaborações do texto. Entretanto, a regulamentação desta normativa, por meio da IN 006/2002, "não passou pelo mesmo processo de interações e adequações às diferentes realidades e condições, além de ter favorecido a concentração de poder na CNPOrg" (Comissão Nacional de Produção Orgânica), onde as representações tinham problemas de comunicação com outros atores da agricultura orgânica e os debates não conseguiam incorporar a complexidade observada nos procedimentos de avaliação da conformidade em diferentes regiões do país e seus arranjos institucionais (FONSECA, 2005, p. 324). 
discussão foi de suma importância para ampliarem as trocas de experiência com iniciativas desenvolvidas em diferentes regiões do país, além de ter sido fundamental para garantir a incorporação do Sistema Participativo de Garantia (SPG) na legislação ${ }^{8}$.

Em abril de 2007, a ABIO decidiu, por meio de assembleia geral, criar um SPG, recebendo do MAPA (Ministério de Agricultura, Pecuária e Abastecimento) seu credenciamento como Organismo Participativo de Avaliação da Conformidade OPAC, em 2010. A certificação participativa, a partir deste contexto, passou a ser de suma importância para viabilizar a certificação orgânica de agricultores no estado do Rio de Janeiro. Esta questão foi crucial no processo de expansão vivenciado, principalmente, a partir de 2009, com a criação do Circuito Carioca de Feiras Orgânicas - CCFO.

Através da participação na Comissão de Produção Orgânica, coordenada pelo MAPA, membros da ABIO passaram a buscar espaços na Prefeitura do Rio de Janeiro que pudessem viabilizar a abertura de novas feiras na cidade, haja vista a normativa municipal que impossibilitava isto. A proposta foi ganhando espaço na Secretaria Especial de Desenvolvimento e Economia Solidária (SEDES), que articulou uma reunião com a Secretaria Especial de Ordem Pública - SEOP para a implementação de um decreto que liberasse a criação de novas feiras na cidade.

O Decreto n. ${ }^{\circ} 35.064$ só foi assinado em 2012, mas as feiras do CCFO passaram a funcionar desde 2010. Em 2018, o CCFO já era composto por 21 feiras na cidade do Rio de Janeiro. Além disso, a criação do Circuito motivou um movimento que vem se estendendo por outras cidades da região metropolitana do estado, como também em municípios do interior do estado. Este processo foi de suma importância para a expressiva ampliação do número de agricultores orgânicos no Rio de Janeiro, certificados, em sua grande maioria, pela $\mathrm{ABIO}^{9}$.

Em 2006, tem início a constituição da Articulação de Agroecologia do Rio de Janeiro - AARJ, como um desdobramento do "Grupo de Articulação pró-Encontro Nacional de Agroecologia no Estado do Rio de Janeiro", formado em julho do ano anterior. Este grupo inicialmente mobilizou diversos movimentos e organizações da sociedade civil do "campo" agroecológico no estado do Rio de Janeiro, para participação nos debates e atividades propostas pela Articulação Nacional de Agroecologia - ANA. Em maio de 2006, como

O SPG passou a ser reconhecido como um dos mecanismos do Sistema Brasileiro de Avaliação da Conformidade Orgânica (SISORG/ MAPA), previsto no Decreto $n^{\circ} 6.323$, de 27 de dezembro de 2007, que regulamenta a Lei $n^{0} 10.831$. 
processo preparatório para a participação de agricultores do estado no II ENA (ocorrido em junho de 2006, em Recife/PE), foi realizado um Encontro Estadual de Agroecologia, que reuniu, em Nova Iguaçu, 106 agricultores/as e técnicos/as de todas as regiões do Rio de Janeiro. Ao final do encontro foram eleitos/as 45 representantes e identificadas e escolhidas 32 experiências, as quais se constituíram numa amostra da diversidade agroecológica existente à época no estado.

Parte desse esforço de sistematização das experiências foi viabilizada, a partir do final de 2007, pelo projeto "Desenvolvimento participativo de metodologias e processos de construção de conhecimento agroecológico no estado do Rio de Janeiro", financiado pelo CNPq/MDA, coordenado pelo departamento de Geografia da Universidade Federal Fluminense - UFF e executado em parceria com a AARJ. Dois produtos gerados pelo projeto foram o vídeo "Caminhos do Rio"10, contendo oito iniciativas agroecológicas do estado do Rio de Janeiro, e a publicação "Caminhos Agroecológicos do Rio de Janeiro: caderno de experiências agroecológicas" (GOLLO et al., 2014), com 21 experiências sistematizadas sobre vários temas e abrangência nas 5 regiões do estado do RJ.

Ao longo das décadas de 2000 e 2010, a AARJ desenvolveu um amplo conjunto de projetos de extensão, em parceria com os atores que a compõem, promovendo a agroecologia nas diferentes regiões do estado. Em sua maioria, estes projetos foram desenvolvidos com apoio de recursos federais, que se ampliaram neste contexto. Destacamos, neste sentido, o projeto Campo e Campus, desenvolvido em 2009 em parceria com a UFRRJ e com recursos do MDA/CNPq, que visou fortalecer o protagonismo de jovens rurais/quilombolas na agricultura familiar e processos de construção do conhecimento agroecológico. Em articulação com o Núcleo Interdisciplinar de Agroecologia - NIA-UFRRJ e Embrapa Agrobiologia a AARJ também passou a contribuir nas ações do projeto Ambientes de interação agroecológica: ensino, pesquisa e expressões da agroecologia no Rio de Janeiro, a partir de 2013. Este projeto, desenvolvido a partir de edital destinado ao fortalecimento e formação dos Núcleos de Estudos em Agroecologia - NEAs ${ }^{11}$, viabilizou avanços nos processos de sistematizações de experiências agroecológicas nas diferentes regiões do estado, a realização de Caravanas Agroecológicas, além da capacitação de agricultores, técnicos e estudantes no método de Análise Econômica Ecológica de Agroecossistemas - LUME ${ }^{12}$.

Vídeo com 26'52", produzido em julho de 2010 pela Cipó Caboclo Vídeos: <www.cipocaboclovideos.blogspot>. Chamada MCTI/MAPA/MDA/MEC/MPA/CNPq N 81/2013.

Com vistas a salientar a fragilidade social e político-institucional da agricultura familiar e agroecológica no estado do Rio de Janeiro, a Caravana Agroecológica e Cultural do estado, realizada entre os dias 24 a 28 de novembro de 2015, foi intitulada Existe Agricultura no Rio de Janeiro: Existe, Resiste e Alimenta! 
Desta forma, os atores articulados em torno da AARJ buscaram avançar, principalmente, nos processos de sistematização de experiências, facilitar intercâmbios e promover encontros regionais e estaduais de agroecologia (realizando seu IV Encontro em Paraty, em 2017). Em interação com as demais articulações de agroecologia que fazem parte da ANA, a AARJ visou contribuir nos processos de discussão e operacionalização de políticas públicas em favor da agricultura familiar e agroecologia, em que merecem destaque os esforços realizados, em âmbito nacional, para a formulação da PNAPO.

Outra consequência da realização do I ENA no estado do RJ foi a criação da gerência técnica de Agroecologia, dentro da estrutura da EMATER RIO, como forma de pautar o tema nas ações de extensão rural governamental. Ao longo do tempo essa gerência teve uma aproximação e colaboração crescentes na agenda dos movimentos e ONGs atuantes no campo agroecológico do estado do RJ, como a AARJ, a AS-PTA e a instituições de ensino coordenadoras de projetos de sistematização de experiências de agroecologia, e de formação dos NEAs. Entretanto, essa gerência foi esvaziada por uma decisão interna da direção da EMATER RIO em abril de 2016.

As mudanças nas políticas públicas federais que orientam os serviços de assessoria técnica à agricultores, a partir de $2004^{13}$, também foram de suma importância para fortalecer ações de organizações que, ao longo de sua trajetória, também estiveram inseridas no processo de promoção da agroecologia no estado e nas dinâmicas da AARJ. No âmbito de operacionalização do programa ATES merecem destaque as ações desenvolvidas pela Cooperativa CEDRO e COOPERAR. As duas chamadas públicas de ATER lançadas pelo MDA para o estado do RJ também foram operadas pela Cooperativa CEDRO.

As políticas públicas federais de ATER motivaram, ademais, processos de construção coletiva no estado do RJ, em que diversos atores da sociedade civil, movimentos sociais e instituições governamentais se reuniram para participar das conferências estaduais de ATER, ocorridas em 2012 e 2015, ainda sob a coordenação do MDA.

A experiência mais específica com a construção coletiva de políticas públicas de desenvolvimento rural no âmbito estadual se deu a partir de meados da década de 2000, com o processo amplo de construção do Plano Estadual de Assistência Técnica e Extensão Rural - PEATER RJ, resultado de um chamamento feito pelo então Ministério do Desenvolvimento Agrário, para

13 Em 2004 foram criados dois programas distintos: um deles voltado ao atendimento exclusivo dos agricultores assentados chamado de Assessoria Técnica, Social e Ambiental à Reforma Agrária (ATES), coordenado e gerido pelo INCRA; 0 outro, voltado às categorias sociais enquadradas sob a designação da agricultura familiar, chamado de Política Nacional de Assistência Técnica e Extensão Rural (PNATER), coordenada e dirigida pela Secretaria da Agricultura Familiar (SAF) do Ministério do Desenvolvimento Agrário (MDA). 
que os estados construíssem seus planos estaduais de ATER, em sequência à efetivação da PNATER em 2004. O processo de construção do PEATER RJ envolveu 3.100 participantes no período de 2004 a 2006, entre encontros municipais, regionais e um estadual, com participação ativa de diversas categorias de agricultores familiares, pescadores artesanais, populações tradicionais, e também representantes de entidades de ensino, pesquisa, extensão, terceiro setor, e outras representações ligadas à agricultura e ao meio ambiente, tanto federais como estaduais e municipais.

O PEATER RJ foi submetido à apreciação do Conselho Estadual de Desenvolvimento Rural Sustentável - CEDRUS, que o homologou em reunião em fevereiro de 2006, sendo posteriormente lavrado como programa oficial do Governo do Estado do Rio de Janeiro. Entretanto, mesmo após o amplo esforço empreendido em sua construção, o PEATER-RJ nunca foi efetivamente colocado em prática como política pública de ATER no estado do Rio de Janeiro.

Outra iniciativa em nível estadual com ampla participação de organizações da sociedade civil e de agricultores, e instituições de apoio à agricultura familiar no estado do RJ foi desencadeada a partir da Conferência Estadual de Desenvolvimento Rural Sustentável e Solidário (2013), a qual apontou para a construção de um Plano Estadual de Desenvolvimento Rural Sustentável e Solidário. O plano foi concluído em 2018, mas ainda não foi homologado.

Também merece destaque, ao longo deste período, a execução do programa Rio Rural, coordenado pela Secretaria de Agricultura do Estado do RJ (atual SEAPPA), executado pela EMATER RIO e PESAGRO RIO e, por diversos parceiros institucionais e grupos de agricultores. O programa iniciou em 2006, a partir de uma doação do Fundo Global Ambiental - GEF para realização de um projeto piloto em 48 microbacias nas regiões norte e noroeste do estado. A partir de 2009 o programa foi ampliado para as demais regiões do Rio de Janeiro, por meio de um empréstimo do Banco Mundial e contrapartida do governo do estado do RJ.

Devido a sua atuação em 373 microbacias hidrográficas do estado do RJ, e em amplas temáticas (ambiental, social, produtiva), o Rio Rural apresenta também resultados variados. Um dos mais significativos é a utilização de ferramentas e processos que apoiaram a autogestão comunitária dos recursos naturais. $\mathrm{O}$ capital social acumulado nos grupos de agricultores familiares promoveu o seu protagonismo em instâncias de decisão e influência nas políticas públicas municipais, em muitos casos. Também é perceptível o aumento do grau de participação dos agricultores em suas organizações, inclusive de jovens, e em alguns grupos se constata o protagonismo das mulheres. 


\section{Contexto de formulação da política estadual (2016-2019)}

Em um contexto de fragilização política em escala federal, aprofundado a partir de 2016, observamos certa rearticulação dos atores inseridos nos debates em torno das noções de agroecologia e agricultura orgânica no estado do Rio de Janeiro. Este conjunto de atores, que havia se organizado em torno de arranjos políticos institucionais específicos ao longo dos anos anteriores, em grande parte impulsionados por políticas públicas federais, passaram a dinamizar um novo processo de sinergia mais direta com vistas a formulação e implementação de políticas em nível estadual, a partir de 2017. Este novo contexto, de aproximação entre os diferentes atores no estado, é marcado, ainda, pela tentativa de construção de um projeto em conjunto para o edital do Programa de Fortalecimento e Ampliação das Redes de Agroecologia, Extrativismo e Produção Orgânica - ECOFORTE, e pelos esforços em se incorporar a temática agroecologia nos debates entre candidatos nas eleições de 2018.

Em agosto de 2017 é realizado o Seminário Regional de Agroecologia e Produção Orgânica - Região Sudeste, em Campinas-SP. A proposta de realização destes seminários nas cinco regiões do país, sob coordenação da Secretaria Nacional de Articulação Social e, por meio da Comissão Nacional de Agroecologia e Produção Orgânica (CNAPO), estava ancorada na compreensão de que: "a Política (Nacional de Agroecologia e Produção Orgânica) e o Plano se concretizam efetivamente nos territórios, que essa efetivação passa pelo comprometimento e interação dos atores governamentais e sociais locais e nas esferas municipais e estaduais" (CNAPO, 2017, p. 6). A partir de um processo coletivo de avaliação da PNAPO, visava-se fortalecer o compromisso político e a formação de sinergias entre os atores envolvidos nos processos de promoção da agroecologia nos diferentes estados. Do Rio de Janeiro estiveram representadas 12 entidades governamentais e da sociedade civil com inserção nas ações de promoção da agroecologia e agricultura orgânica.

Na reunião realizada no segundo dia do seminário, foram recorrentes as falas salientando a necessidade de se avançar nas sinergias entre os diferentes atores presentes e, de se tensionar a formulação de instrumentos de ações públicas em escala estadual para promoção da agroecologia e agricultura orgânica. Neste momento, se divulga a notícia de um Projeto de Lei ( $\mathrm{PL} \mathrm{n}^{\circ}$ 2.746/2017) em tramitação na Assembleia Legislativa do estado do Rio de Janeiro - ALERJ, propondo a criação de uma Política Estadual de Agroecologia e Produção Orgânica. O PL não era de conhecimento dos atores inseridos no movimento agroecológico e da agricultura orgânica do 
estado do Rio de Janeiro, tendo sido elaborado de forma isolada por um deputado do Partido Republicano da Ordem Social - PROS, reproduzindo literalmente o texto que criou a mesma política no estado de SP. Essa constatação reforçou o entendimento de que era estratégico se avançar na articulação entre os diferentes atores envolvidos com os movimentos agroecológico e de agricultura orgânica no estado do Rio de Janeiro para, desta forma, viabilizarem uma maior participação na construção de instrumentos de ação pública em escala estadual, ainda mais em um contexto de forte fragilização político institucional em nível federal.

No final de 2017, um grupo dentro da Comissão da Produção Orgânica do Rio de Janeiro (CPOrg RJ) inicia um processo de aperfeiçoamento do texto desse PL, de forma organizada em dois grupos de trabalho: um para sistematização de contribuições ao texto do PL e redação e o outro focando no diálogo político junto aos parlamentares envolvidos na tramitação do PL dentro da ALERJ, por dentro das comissões temáticas. Ambos grupos dialogam e se organizam, principalmente, dentro do espaço da CPOrg RJ. Ao longo do tempo o processo é ampliado com a participação das assessorias parlamentares de partidos progressistas, como Partido Socialismo e Liberdade - PSOL, principalmente, e Partido dos Trabalhadores - PT.

Já em 2018, uma avaliação vinda das assessorias parlamentares na ALERJ considera que seria difícil prosseguir com a tramitação desse PL, por questões políticas e textuais, assim consideraram melhor prosseguir o processo com outro PL, de 2015, semelhante e com maiores possibilidades de aprovação. Nesse caso, o grupo que estava trabalhando no PL anterior incorpora as contribuições feitas até então no texto do PL 522/2015, que cria então uma Política Estadual de Desenvolvimento Sustentável, Agroecologia e Produção Orgânica, elaborado dentro da ALERJ de forma semelhante ao PL de 2017, ou seja, sem nenhum processo de construção participativa e diálogo com o movimento agroecológico do Rio de Janeiro.

Neste contexto de ampliação dos esforços para inserção dos temas da agroecologia e produção orgânica na agenda política em âmbito estadual, a AARJ promove, em setembro de 2018, o "Encontro com Candidatos e Candidatas que Apoiam a Agroecologia", no qual os candidatos se comprometeram com a Carta-Compromisso que apresentava as pautas da Articulação. O documento foi firmado por 42 candidatos/as a deputado/a estadual e federal, senador/a e governador/a do estado. Desses, 20 participaram do Encontro e, para um público de cerca de 200 pessoas, se comprometeram a levar adiante as reivindicações da articulação, caso fossem eleitos/as ${ }^{14}$. de sua Carta Política, de forma a dar visibilidade as pautas da agroecologia no âmbito político do estado do RJ. 
Em março de 2019 um pequeno grupo de membros da CPOrg RJ faz um trabalho de melhoria na redação desse novo texto do PL 522/2015, principalmente inserindo nos instrumentos e objetivos relacionados à aproximação com as políticas e instâncias estaduais de gestão da SAN no estado do RJ. Esse texto é então apresentado ao colegiado da CPOrg RJ numa reunião no início de junho e, após sua aprovação, o texto seguiu para tramitação dentro da ALERJ.

Os atores chave nesse processo de construção do PL são representantes de movimentos sociais, assessores de ONGs e funcionários de algumas instituições e órgãos governamentais. Por exemplo, estão alguns funcionários da SFA/MAPA no RJ, integrantes da Articulação de Agroecologia do RJ AARJ (Coletivo de AU-Agricultura Urbana), representantes da Associação de Agricultores Biológicos do RJ - ABIO e do IDACO, pesquisadores da Embrapa Agrobiologia, da Empresa de Pesquisa Agropecuária do Estado do Rio de Janeiro - PESAGRO RIO, e funcionários da Superintendência de Desenvolvimento Sustentável da Secretaria Estadual de Agricultura e Pecuária - SEAPPA, todos atuando por dentro da CPOrg RJ. Além disso também tem sido decisivo no processo os mandatos e assessorias de deputados estaduais do PT e do PSOL.

A CPOrg RJ tem sido o principal espaço de diálogo e construção de uma política estadual de agroecologia no RJ, mas em um sentido de aperfeiçoamento de propostas preexistentes em tramitação dentro da ALERJ. Dito de outra forma, o processo não foi uma construção coletiva e em diálogo com a sociedade civil desde o início de sua concepção, mas um movimento de aperfeiçoamento e complementação de um PL preexistente. Os mandatos de dois deputados estaduais, com destaque para suas assessorias parlamentares, têm sido espaços agregadores e de grande importância nas orientações para mobilização em favor da aprovação do PL da PEAPO.

Como movimentos a favor da PEAPO, identificamos o próprio coletivo formado a partir de agosto de 2017 (citado anteriormente), juntamente com as assessorias de alguns mandatos parlamentares do PT e do PSOL. Duas frentes parlamentares dentro da ALERJ se mostram favoráveis e disponíveis para atuar em favor de uma política estadual de Agroecologia: uma delas é aquela relacionada à Economia Solidária, e a outra criada em maio de 2019 é a de Agroecologia. Por outro lado, não identificamos um movimento organizado contrário a PEAPO, salvo os vetos do poder executivo comentados mais adiante, no último parágrafo desse texto.

A concepção de Agroecologia (AE) prevalecente no PL na versão atual do texto é: 
AE - campo do conhecimento científico, movimento político popular e prática social, fundamentada em diversas áreas do conhecimento para compreender o funcionamento dos agrossistemas e suas correlações na construção ou manutenção de sistemas agroalimentares sustentáveis, em todas as suas complexidades, escalas e dimensões, da produção ao consumo, visando a proporcionar qualidade de vida, geração de renda, inclusão social e conservação dos recursos naturais ${ }^{15}$.

Não foram identificados elementos de tensões entre os atores (elementos de desestabilização das coalizões), na verdade, existem mais dúvidas que tensões. Essas dúvidas referem-se principalmente aos aspectos da governança e gestão da PEAPO - onde será construído o Plano Estadual de AE e PO, e por quem? Como será a gestão? Quem coordena o processo? Ficará dentro da estrutura governamental? Em um espaço intersecretarias estaduais (mais ou menos como na gestão da PNAPO)?

Sobre os instrumentos de políticas públicas da PEAPO específicos ao Estado do RJ, necessariamente aparece o próprio Plano Estadual de Agroecologia e Produção Orgânica - PLEAPO (previsto no texto do PL 522/15), mas que necessariamente depende da criação anterior da PEAPO. Outros instrumentos que dialogam com a PEAPO seriam a Política Estadual de Agricultura Urbana (PL 2381/17), a qual foi aprovada na ALERJ em dezembro de 2018, e embora vetada em janeiro de 2019 pelo Executivo atual, teve seu veto derrubado em março de 2019 em nova votação. Outro PL que instituía um percentual de compra de $30 \%$ de produtos orgânicos para hospitais públicos foi aprovado em dezembro de 2018 na ALERJ, também foi vetada pelo Poder Executivo em janeiro de 2019, mas teve o veto derrubado em nova votação no final de março de 2019. Outros instrumentos seriam o Plano Estadual de Desenvolvimento Rural Sustentável e Solidário - PEDRSS, a CAISAN Câmara Intersecretarias de Segurança Alimentar e Nutricional Sustentável, a Política Estadual e o Sistema Estadual de SAN - SISANS (Lei no 5.594/2009), e o I Plano Estadual de SAN Sustentável do ERJ, cuja minuta foi aberta para consulta pública em dezembro de 2018.

Recentemente o CEDRUS foi reestruturado, e sua coordenação ficou à cargo da Secretaria Estadual de Agricultura, Pecuária, Pesca e Abastecimento do estado do RJ. Nessa proposta de reestruturação foram criadas diversas Câmaras Técnicas, dentre elas a de Agroecologia e Agricultura Orgânica. A coordenação dessa CT propõe como uma de suas funções apoiar tanto o processo de construção do (futuro) Plano Estadual de Agroecologia e Agricultura Orgânica - PLEAPO, como a gestão e monitoramento desse PLEAPO.

15 A citação se refere ao texto em sua versão atual, que ainda não está registrado em nenhuma comissão da ALERJ e, portanto, ainda não pode ser acessado como arquivo digital. 
As recentes votações na ALERJ realizadas ao final do mês de março para a derrubada (com sucesso) dos vetos a duas políticas importantes para o movimento agroecológico no estado do RJ, juntamente com o fato da existência de frentes parlamentares de apoio à agroecologia e agricultura orgânica dentro da ALERJ (já comentadas anteriormente), indicam uma sinalização positiva para o avanço na implementação dessa política pelo Legislativo.

\section{Considerações finais}

A análise do processo histórico de construção da PEAPO no estado do RJ aponta para uma longa e diversificada trajetória, em variados contextos, e com múltiplos atores. Uma problemática central ao longo do processo histórico analisado é a dificuldade de articulação dos movimentos sociais com o poder público, especialmente em nível estadual, em um contexto marcado pela invisibilidade da agricultura familiar, reforçada pela fragilidade política e desarticulação institucional em diversas ações públicas de desenvolvimento rural no estado.

O esforço de análise aqui empreendido e as reflexões dele decorrentes salientam, em nossa compreensão, a necessidade de se aprofundar os debates em torno das políticas públicas de apoio à agricultura familiar e desenvolvimento rural em escala estadual, em que buscamos enfatizar aquelas de promoção da agroecologia e agricultura orgânica. Neste sentido, a identificação dos três contextos históricos de interação entre atores inseridos em experiências de agriculturas de base ecológica e poder público, no estado do Rio de Janeiro, é aqui entendida como um esforço para que se avance na compreensão dos processos de convergência observados recentemente na construção de uma PEAPO no estado do RJ.

O primeiro momento observado no texto corresponde a emergência do movimento de agricultura alternativa no estado do RJ, um dos primeiros nesse sentido no Brasil. São identificados, nesse período, o GAE da UFRRJ, a COONATURA, a ABIO e o surgimento de feiras orgânicas em diferentes partes do estado, além da criação da Fazendinha Agroecológica e de organizações de assessoria técnica, como também o trabalho interinstitucional através da Rede de Agroecologia. Vários atores identificados neste contexto permanecem até hoje como de fundamental importância no processo de discussão e construção da PEAPO RJ.

No período seguinte, identificado a partir de princípios da década de 2000, surgem outros atores importantes do movimento agroecológico do estado do RJ, como a AARJ (em 2006), havendo também o envolvimento de instituições de ensino como coordenadoras de editais para sistematização das experiências agroecológicas (caso da UFF) e, também, de implantação dos 
núcleos de agroecologia - NEAs (caso da UFRRJ). Nesse período surgem, ainda, diversas oportunidades de apoio aos movimentos da agricultura orgânica e de agroecologia no estado do RJ, em decorrência do acesso às políticas públicas disponibilizadas com recursos públicos, principalmente federais (Petrobras, MDA, MDS, Banco do Brasil e BNDES são alguns exemplos). Nesse contexto merecem destaque também a AS-PTA e seu trabalho de apoio à consolidação da AARJ nas diferentes regiões do estado do RJ, além de seu apoio à atuação da Rede CAU, ator presente no processo de discussão e construção da PEAPO-RJ.

O período mais recente na trajetória proposta nesse capítulo - de 2016 até hoje - corresponde à intensificação do processo de desmonte das políticas públicas de apoio à agroecologia e agricultura orgânica em nível federal, inclusive com o esvaziamento de instâncias de gestão dessas políticas, como a CNAPO e CIAPO, além do CONDRAF e CONSEA. E é justamente nesse contexto que a CPOrg RJ surge como o espaço de convergência dos atores anteriormente identificados em torno à construção da PEAPO RJ. Esta política aparece como um esforço coletivo para contemplar os vários aspectos e dimensões da agroecologia e da agricultura orgânica no estado do Rio Janeiro, mas também traz um significado bem atual como forma de resistência ao processo de desmonte institucional imposto em nível federal. 


\section{REFERÊNCIAS}

ABIO. Associação de Agricultores Biológicos do Estado do Rio de Janeiro. Normas Técnicas para Certificação de Produtos Orgânicos. Versão 200.

ALENTEJANO, P. Um breve balanço da agricultura e da política agrária no estado do Rio de Janeiro nas últimas décadas. II Caderno de Textos do GT Agrária, AGB Rio, jul. 2012.

CNAPO. Resultados do Seminário Regional de Agroecologia e Produção Orgânica, Região Sudeste, Campinas, 29 a 31 de ago. 2017.

DA ROS, C. A.; PICCIN, M. B. A implantação do programa de assessoria técnica, social e ambiental aos assentamentos de reforma agrária no estado do Rio de Janeiro nos anos de 2002 a 2008: diretrizes, formatos institucionais e dinâmica de execução. Revista NERA, v. 18, n. 27, 2015.

FELIPPE, E. L. D. C. O papel da formação técnica alternativa e da extensão rural pública na construção de redes de apoio à transição agroecológica e à produção orgânica: um estudo no município de São José do Vale do Rio Preto. 2017. Dissertação (Mestrado em Agricultura Orgânica) - UFRRJ, Rio de Janeiro, 2017.

FERREIRA, J. Os agentes da construção política do mercado. Iluminuras. v. 14, n. 33 , p. $87-99,2013$.

FONSECA, M. F. D. A. C. Agricultura orgânica: regulamentos técnicos para acesso aos mercados dos produtos orgânicos no Brasil. Niterói, PESAGRO-RIO, 2009.

. A institucionalização do mercado de orgânicos no mundo e no Brasil: uma interpretação. 2005. Tese (Doutorado em Sociologia, Área de Concentração Desenvolvimento e Agricultura) - UFRRJ, Rio de Janeiro, 2005.

GOLLO, A. Cooperativa CEDRO: 10 anos de ATER pública não estatal no Rio de Janeiro. In: GOLLO, A. et al. (Orgs.). Caminhos agroecológicos do Rio de Janeiro: caderno de experiências agroecológicas. Rio de Janeiro: AS-PTA/PACS, 2014. 
MATTOS, M.; MONTEIRO, D. Semeando agroecologia na cidade - Notas sobre a construção da Rede da Agricultura Urbana do Rio de Janeiro. In: GOLLO, A. et al (Orgs.). Caminhos agroecológicos do Rio de Janeiro: caderno de experiências agroecológicas. Rio de Janeiro: AS-PTA/PACS, 2014.

MONTEIRO, D.; LONDRES, F. Pra que a vida nos dê flor e frutos: notas sobre a trajetória do movimento agroecológico brasileiro. In: SAMBUICHI, R. H. R. et al. (Orgs.). A política nacional de agroecologia e produção orgânica no Brasil: uma trajetória de luta pelo desenvolvimento rural sustentável. Brasília: IPEA, 2017. p. 53-83.

MOREIRA, R. Uma análise crítica do modelo de desenvolvimento do Estado do Rio de Janeiro. In: MOREIRA, R. et al. Anais... Niterói: EDUFF, 2001.

MOURA, I. F. de. Antecedentes e aspectos fundantes da agroecologia e da produção orgânica na agenda das políticas públicas no Brasil. In: SAMBUICHI, R. H. R. et al. (Orgs.). A política nacional de agroecologia e produção orgânica no Brasil: uma trajetória de luta pelo desenvolvimento rural sustentável. Brasília, IPEA, 2017. p. 25-51.

PEGORER, A. P. Apresentação da Associação de Agricultores Biológicos do Estado do Rio de Janeiro: ABIO em números - Atualização. Conselho Técnico ABIO. Seropédica, nov. 2017.

SCHMITT, C. J. et al. La experiencia brasileña de construcción de políticas públicas en favor de la Agroecología. In: SABOURIN, Eric et al. (Orgs.). Políticas públicas a favor de la agroecología en América Latina y EI Caribe. Porto Alegre: Evangraf; Criação Humana; Rede PP-AL; FAO, 2017.

SILVA, E. S. O.; MARAFON, G. J. A agricultura familiar no estado do Rio de Janeiro. In: II SEMINÁRIO INTERNACIONAL SOBRE DESENVOLVIMENTO REGIONAL. Santa Cruz do Sul, RS, 28 setembro a 01 de outubro, 2005. Anais... Santa Cruz do Sul, RS, 28 setembro a 01 de outubro, 2005.

WEID, J. M. V. D. Desenvolvimento Agroecológico: como promovê-lo? In: ENCONTRO INTERNACIONAL SOBRE AGROECOLOGIA E DESENVOLVIMENTO RURAL SUSTENTÁVEL. Anais... Botucatu: FCA/ UNESP, 2001. 


\section{Agradecimentos}

Os autores agradecem a colaboração ao texto feita por Bernadete Montesano, da Rede CAU - Coletivo de Agricultura Urbana e da AARJ, e à Licia Castelo Branco, extensionista rural da EMATER RIO e atualmente assessora parlamentar no gabinete do deputado estadual Flávio Serafini (PSOL). 


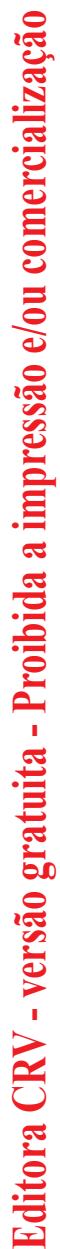




\section{CAPÍTULO 6 \\ PROCESSO DE CONSTRUÇÃO \\ DA POLÍTICA ESTADUAL DE \\ AGROECOLOGIA E PRODUÇÃO \\ ORGÂNICA EM SÃO PAULO}

Eduardo de Lima Caldas Julianna Colonna

\section{Introdução}

Este capítulo analisa o processo de construção da Política Estadual de Agroecologia e Produção Orgânica de São Paulo (PEAPO-SP) e suas interfaces com as diversas ações e práticas de atores políticos e sociais com maior incidência no município de São Paulo, as quais foram centrais para a trajetória da agroecologia e de sua institucionalização.

O objetivo deste trabalho é identificar e analisar o processo de institucionalização da agroecologia e da agricultura orgânica no estado de São Paulo e os principais atores que incidiram e influenciaram a produção da PEAPO como instrumento de ação pública; as representações cognitivas desses atores; os trajetórias de diferentes processos que culminam na produção da política estadual; as instituições envolvidas e, finalmente, os resultados alcançados por esse processo, entre eles a própria promulgação da política como lei estadual.

Os procedimentos adotados para a realização do capítulo foram a leitura de documentos oficiais, a participação em reuniões públicas e conduzidas pelo poder público e a realização de entrevistas semiestruturadas com atores chaves do referido processo ${ }^{1}$.

Ao todo foram realizadas nove entrevistas com atores mapeados por meio da metodologia da bola de neve. Durante as entrevistas, cada ator entrevistado indicava mais pessoas relevantes na construção de políticas estaduais e municipais que se relacionam com a ação pública de agroecologia no nível estadual de São Paulo. As entrevistas não foram exaustivas, mas permitiram obter informações de indivíduos do setor público dos níveis nacional, estadual e municipal e da sociedade civil organizada.

1 As entrevistas foram realizadas entre os meses de março e maio de 2019. Foram entrevistados gestores públicos dos três níveis de governo (federal, estadual e municipal) e representantes da sociedade civil. 
A participação nos eventos se deu entre os meses de abril e maio de 2019 e se referiram à Reunião da Câmara Setorial de Agricultura Ecológica na Secretaria de Agricultura e Abastecimento (SAA) do estado de São Paulo; Reunião do Conselho de Desenvolvimento Rural, Sustentável e Solidário do Município de São Paulo; Seminário sobre a Política Estadual de Agroecologia e Agricultura Orgânica.

Este trabalho está organizado em cinco partes, além dessa introdução e das considerações finais: a trajetória da Agroecologia em São Paulo: os caminhos até a PEAPO; a relevância da Frente Parlamentar; os objetivos da PEAPO; os atores diretamente envolvidos na produção da PEAPO; e finalmente, os referenciais: agricultura, conflito territorial e suas muitas interfaces.

\section{Trajetória da agroecologia em São Paulo: os caminhos até a PEAPO}

A PEAPO do estado de São Paulo foi instituída em 2018, por meio da Lei $\mathrm{n}^{\circ} 16.684$, publicada em 19 de março do referido ano. A lei não é ponto de partida nem de chegada na configuração da ação pública estadual de agroecologia e produção orgânica, mas ponto intermediário, entre as referidas articulações e experiências prévias e as regulamentações demandadas.

Nessa trajetória, alguns acontecimentos que se articulam ao longo do tempo merecem destaque para reconstruir os caminhos percorridos até a instituição da lei em 2018.

Para retomar parte dos elementos que culminaram na PEAPO-SP, a história nos remete aos anos 1970 quando foi fundada em São Paulo a Estância Demétria, em Botucatu, cuja ênfase é a agricultura biodinâmica. Trata-se da primeira fazenda biodinâmica no Brasil (XAVIER; FRANCO, 2015), origem também da Associação Brasileira de Agricultura Biodinâmica que realiza pesquisas, cursos e presta consultorias a centenas de produtores rurais por todo o Brasil e, também, da Associação de Certificação Instituto Biodinâmico (IBD), primeira e maior certificadora brasileira.

Em 1989, foi criada a Associação de Agricultura Orgânica (AAO) em São Paulo, um ator extremamente importante na articulação da pauta no cenário municipal e estadual, e por vezes mesmo o nacional. Até então observa-se que as iniciativas em torno das agriculturas alternativas partem apenas da sociedade civil.

Somente em 2000, seguindo a discussão do governo federal sobre a certificação e formas de incentivo à produção orgânica (ALVES; SANTOS; AZEVEDO, 2012) iniciada nos anos 1990 que culminou na criação da Comissão Nacional de Produção Orgânica (CNPOrg). Em 2010, foi criada em São 
Paulo a Câmara Setorial de Agricultura Ecológica, que tinha entre seus objetivos, o desenvolvimento prioritário da agricultura orgânica principalmente em áreas de mananciais.

A Câmara Setorial de Agricultura Ecológica reúne historicamente os principais atores do estado ligados a agriculturas não convencionais e preocupadas com a degradação ambiental ocasionada pela agricultura convencional. Nesta medida, a referida Câmara Setorial articula preocupações com agricultura alternativa, alimentação saudável, e preservação ambiental. Ela é uma das principais arenas na construção de um ambiente participativo, que envolve a sociedade civil, academia, órgãos governamentais, e foi fundamental para a institucionalização da PEAPO dezoito anos depois.

Uma experiência relevante do setor público com práticas agrícolas sustentáveis, nome mais utilizado dentro do governo na época, foi a elaboração e execução do Projeto Guarapiranga Sustentável, desenvolvido pela agora extinta Secretaria de Meio Ambiente (SMA), que visava, entre outros objetivos, promover uma transição para uma agricultura menos impactante e conter a expansão urbana das áreas do entorno da represa de Guarapiranga, o que engloba sete municípios, dentre eles a cidade de São Paulo. É no município de São Paulo que as ações do Projeto foram de fato executadas com objetivo de modelar e testar uma metodologia original a ser desenvolvida pelo estado para, com os instrumentos disponíveis, promover uma agricultura mais sustentável.

Havia na SMA uma preocupação em garantir apoio às suas ações por meio de uma base legal, por isso, o Projeto Guarapiranga Sustentável se apoiava legalmente na priorização à agricultura orgânica estabelecida pela Lei Estadual n 12.233 de 2006, a Lei Específica da Guarapiranga.

Adotando a mesma estratégia de garantia da base legal, visando também a continuidade da política mesmo com alterações governamentais, foi elaborada a Resolução Conjunta n ${ }^{0} 08$ de 2009 (SÃO PAULO, 2009) entre as SMA e a Secretaria de Agricultura e Abastecimento (SAA) que estabelecia estratégias para desenvolver a agricultura sustentável para Bacia do Alto Tietê, da qual a Guarapiranga também faz parte. Essa resolução conjunta, que já menciona explicitamente a agroecologia como uma das vertentes que compõem a agricultura sustentável, traz muitas inovações ao tema porque, ao "trazer para o jogo" a SAA, pode tratar de questões como desenvolvimento de mercado especializado, cadastramento de produtores e extensionismo agroecológico entre outras.

O Projeto Guarapiranga Sustentável, uma vez finalizado, transformou-se em um grande aprendizado dos atores envolvidos, já que os produtores e Organizações Não Governamentais (ONGs) foram também protagonistas das ações desenvolvidas. O projeto se mostrou um piloto do que poderia ser feito no estado para promoção dessa alternativa à agricultura convencional. Um dos principais aprendizados do Projeto foi a elaboração do Protocolo de 
Boas Práticas Agroambientais, o qual se tornou a base do futuro Protocolo de Transição Agroecológica oferecido a partir de 2016 pela SMA e SAA para agricultores que iniciem o processo de alteração produtiva para tornar sua prática agrícola mais sustentável como o paulatino abandono do uso de agrotóxicos, para citar um exemplo.

Ocorreu também uma série de atividades e construções de instrumentos dentro do chamado Projeto São Paulo Orgânico, dentre as quais, o reconhecimento, em 2013, de um sítio em São Roque como Unidade de Pesquisa e Desenvolvimento (UPD) em Agricultura Ecológica, local onde as formações sobre agroecologia são realizadas para os técnicos de extensão rural do estado de São Paulo.

Ressalta-se que organizações da sociedade civil concomitantemente aos projetos específicos do setor público e na maior parte das vezes em parceria com ele - sobretudo SMA e SAA -, foram realizados importantes movimentos de fortalecimento de comercialização específica, como o apoio às feiras de produtos orgânicos de São Paulo no Parque da Água Branca, e também a introdução de ações de incentivo à produção e comercialização orgânica do estado dentro da Bio Brazil Fair - Biofach América Latina, que passou a realizar, dentre outras atividades, rodadas de negócios entre produtores orgânicos locais e compradores em potencial.

É importante destacar também a construção de mercados institucionais por meio dos quais a venda de alimentos orgânicos foi promovida pelo poder público. Trata-se da criação de demanda por produtos orgânicos pelo poder público. No entanto, a oferta não estava suficientemente organizada e apoiada para suprir a nova demanda, e, portanto, não foi capaz de suprir a demanda institucional.

Para a construção institucional de mercados, muitas oportunidades foram criadas. O primeiro exemplo dessas oportunidades foi o Projeto Copa Orgânica e Sustentável que tinha como um dos objetivos oferecer exclusivamente alimentos orgânicos para os atletas durante os jogos da Copa do Mundo de Futebol Masculino, o que implicaria na necessidade de importação de alimentos orgânicos para atender a demanda. Houve também o Projeto de Lei (PL) $n^{\circ} 447 / 2011$ do Vereador Gilberto Natalini (Partido Verde - PV) que propunha que a Prefeitura de São Paulo destinaria no mínimo 30\% dos recursos orçamentários totais da alimentação escolar para a compra de alimentos orgânicos, contudo, como o PL não previa metas progressivas, era inviável que de um ano para outro o município conseguisse utilizar todo esse recurso orçamentário para a compra de produtos orgânicos, visto que os produtores não estavam prontos para suprir essa demanda. Neste caso específico, o prefeito Fernando Haddad (Partido dos Trabalhadores - PT) vetou integralmente o PL em 2013 e convocou a sociedade civil e os órgãos competentes para 
formularem um novo projeto que levasse em consideração a capacidade de oferta do município e contasse com metas progressivas.

Em 2015, então, é aprovada a Lei n ${ }^{\circ} 16.140$ em 17 de março que torna obrigatória a inclusão de alimentos orgânicos ou de base agroecológica na alimentação escolar municipal a qual é regulamentada pelo Decreto $\mathrm{n}^{\circ} 56.913$, de 5 de abril de 2016, que estabelece metas progressivas que preveem que até $2026100 \%$ da merenda escolar municipal será de produtos orgânicos ou de base agroecológica. Tal lei é implantada gradativamente pelo Plano de Introdução Progressiva de Alimentos Orgânicos ou de Base Agroecológica na Alimentação Escolar elaborado pelo executivo municipal, em conjunto com a sociedade civil organizada que além da introdução de alimentos livres de veneno, também prevê a promoção pedagógica do tema nas escolas. Esta medida municipal possui grande potencial para promover mudanças significativas na produção agroecológica estadual via compras públicas sustentáveis. Aliás, por meio de processos de disseminação de iniciativas de políticas públicas, essa experiência pode, no futuro breve, inspirar outras prefeituras e outros estados.

É também nesse contexto que nasce no âmbito legislativo, a arena responsável pela discussão da futura PEAPO, a Frente Parlamentar do estado de São Paulo em Defesa da Produção Orgânica e Desenvolvimento da Agroecologia, criada em março de 2013, a qual reuniu inicialmente 48 parlamentares e 60 organizações da academia e da sociedade civil para debater caminhos para institucionalizar a referida política estadual. Especificamente no campo da sociedade civil, a AAO emerge e se destaca no exercício de conectar diferentes atores em favor da causa. Outra organização bastante mencionada nos documentos analisados e entrevistas é o Instituto Kairós, Ética e Atuação Responsável, outra organização da sociedade civil que tem como objetivo fomentar novas práticas de produção, distribuição, comercialização e consumo responsáveis (KAIRÓS, 2019) que foi fundada em 2000 e tem atuação focada na Região Metropolitana de São Paulo.

O grupo composto por essa Frente Parlamentar realizou reuniões técnicas no intuito de construir a PEAPO, tendo como inspiração as políticas estaduais já aprovadas de outros estados, realizou uma audiência pública em São Paulo para prefeitos e deputados para angariar apoio e mais sete audiências públicas (Araçoiaba da Serra, Botucatu, Campinas, Registro, Sorocaba, São Roque e São Paulo) para colher contribuições da população e apresentar as alterações periódicas decorrentes da tramitação.

Após cinco anos de trabalho da Frente Parlamentar, a PEAPO de São Paulo é aprovada em março de 2018, a qual em termos conceituais, define agroecologia em seu Art. $1^{\circ}$ como: 
campo do conhecimento transdisciplinar que estuda os agroecossistemas, visando ao desenvolvimento equilibrado das relações entre capacidade produtiva, equilíbrio ecológico, eficiência econômica, equidade social e uso e conservação da biodiversidade e dos demais bens naturais, por meio da articulação entre conhecimento técnico-científico, práticas sociais diversas e saberes e culturas populares e tradicionais (SÃO PAULO, 2018).

Entre os instrumentos que a Política estabelece destacam-se i) o Plano Estadual de Agroecologia e Produção Orgânica - PLEAPO; ii) a ATER (Assistência Técnica e Extensão Rural) especializada em agroecologia; iii) as compras governamentais de produtos agroecológicos e orgânicos; iv) as medidas fiscais e tributárias que favoreçam a agroecologia e a produção orgânica e em transição agroecológica; v) a comercialização e o apoio ao acesso a mercados; vi) a expansão do acesso dos consumidores aos produtos orgânicos ou de base agroecológica; vii) os fundos estaduais, o crédito rural, as linhas de financiamento e subsídios; viii) as instâncias de gestão de controle social; ix) a transição agroecológica.

Na presente Lei, a Câmara Setorial de Agricultura Ecológica da Secretaria da Agricultura e Abastecimento do estado de São Paulo é definida como o primeiro espaço de controle social, gestão e participação da PEAPO e do PLEAPO.

A PEAPO, até o presente momento (junho de 2019), não havia sido regulamentada. O novo governo eleito no último pleito reestruturou os principais órgãos do Executivo que lidavam com a temática (SAA e SMA), entretanto, as discussões sobre o tema ainda permanecem dentro da Câmara Técnica.

\section{A relevância da frente parlamentar}

A PEAPO- SP resulta de um esforço coletivo com grande participação da sociedade civil, mas que dentro do legislativo foi institucionalmente liderada pela Frente Parlamentar, que por sua vez era conduzida pela deputada Ana do Carmo do Partido dos Trabalhadores (PT) e pelo deputado Aldo Demarchi (Democratas - DEM). De acordo com a justificativa do Projeto de Lei n ${ }^{\circ}$ 236/2017, posteriormente, Lei n $16.684 / 2018$, a proposição é da Frente Parlamentar "Em Defesa da Produção Orgânica e Desenvolvimento da Agroecologia". A iniciativa do poder legislativo estruturou seu foco de argumentação em dois eixos: na produção e consumo de alimentos saudáveis e na conservação dos recursos e bens naturais. Esse processo do legislativo configurou-se, portanto, como um esforço de articular dois setores sociais, agricultura e meio ambiente.

Inicialmente, a Frente Parlamentar estava focada nos agricultores orgânicos que já produziam alimentos sem utilização de agrotóxicos, os quais 
também já vislumbravam o potencial da agroecologia como campo de conhecimento e prática interdisciplinar.

A participação e o protagonismo da sociedade civil no processo legislativo podem ser encarados como um dos pontos fortes da Frente Parlamentar e da PEAPO e, também, como um dos seus objetivos principais.

Deste modo, observa-se uma diversidade de atores envolvidos nessa ação pública, dentre os quais os deputados e deputadas, servidores e servidoras públicos especializados, e muitas vezes multiposicionados, e representantes da sociedade civil territorialmente localizados em diversas regiões do estado de São Paulo, mas sobretudo na capital.

O trabalho da Frente Parlamentar consistiu inicialmente na identificação de recursos potenciais a serem alocados nas políticas de promoção da produção orgânica e, também, agroecológica; e na interação com as políticas públicas produzidas e realizadas tanto no governo federal quanto nas experiências estaduais e municipais, como forma de reconhecer o acúmulo de experiências, seus pontos fortes, potenciais e fragilidades.

Assim, a Frente Parlamentar, além de atender demandas emergenciais e específicas por meio da busca de recursos diversos e fundamentalmente orçamentários das emendas parlamentares também promoveu o debate e a disseminação de conhecimento e ideias sobre os temas da agricultura orgânica e da agroecologia, seja para parcela ampliada da sociedade, seja para os parlamentares, por meio de audiências públicas e sessões informativas para o legislativo, por exemplo. O processo de produção da política em forma de lei fez da ALESP um fórum privilegiado para produção e disseminação de ideias sobre agricultura orgânica e agroecologia com ampla participação da sociedade civil, da sociedade política e da burocracia estatal. A ALESP e os deputados diretamente envolvidos no processo de produção da PEAPO demonstram como "pessoas de diferentes ideologias conseguem, muitas vezes, chegar a um acordo sobre uma decisão política concreta" (LINDBLOM, 1959) muito menos pela maximização de seus interesses e predominância de suas ideias; e muito mais pelo ganho marginal que cada um dos atores tem ao garantir a "presença" mínima de suas ideias e de seus interesses no conjunto da política formulada. Em decorrência dessa lógica incremental observam-se objetivos abrangentes e diversos entre si no corpo da referida PEAPO.

\section{Os objetivos da PEAPO}

O processo de construção da PEAPO resultou em uma política abrangente cujos principais objetivos estão organizados no Quadro 01.

No primeiro item citado, fica explícito o interesse de promoção do setor da agroecologia e da agricultura orgânica em todo o processo, desde a 
produção até o consumo passando pelo processamento. No segundo, evidencia-se a interface que se espera sinérgica do setor rural com o setor ambiental.

A ênfase no processo de formação, disseminação, extensão rural, produção e troca de conhecimento nos itens posteriores evidencia por um lado a importância deles para a política; e por outro a força e a organização da extensão rural como um setor, organizada pela articulação de servidores públicos militantes. Nesse aspecto, a valorização e o incentivo à adesão ao protocolo Estadual de Boas Práticas Agroambientais presente em um dos objetivos da política estadual evidencia tanto a valorização do processo histórico de produção do protocolo quanto a participação do grupo de técnicos e burocratas diretamente envolvidos com o tema.

\section{Quadro 01 - Principais objetivos da PEAPO-SP}

\begin{tabular}{|c|c|}
\hline \multirow{10}{*}{$\begin{array}{l}\text { Principais objetivos da } \\
\text { PEAPO-SP }\end{array}$} & $\begin{array}{l}\text { Ampliar e fortalecer a produção, o processamento e o consumo de produtos } \\
\text { agroecológicos e orgânicos, com ênfase nos mercados locais e regionais }\end{array}$ \\
\hline & $\begin{array}{l}\text { Fortalecer o uso e a conservação dos bens naturais pelos agricultores e } \\
\text { agricultoras }\end{array}$ \\
\hline & Promover a troca de mudas e sementes crioulas, orgânicas e variedades \\
\hline & $\begin{array}{l}\text { Promover a pesquisa e facilitar o acesso aos Bancos Ativos de Germoplasma } \\
\text { (BAGs) das instituições públicas }\end{array}$ \\
\hline & $\begin{array}{l}\text { Criar e efetivar instrumentos regulatórios, fiscais, creditícios, de incentivo } \\
\text { para apoiar a transição agroecológica e a produção orgânica }\end{array}$ \\
\hline & Fortalecer a certificação orgânica coletiva \\
\hline & Fortalecer os espaços institucionalizados de participação, como conselhos \\
\hline & $\begin{array}{l}\text { Promover a produção agroecológica de alimentos com objetivos de auto- } \\
\text { consumo, geração de renda e de processos pedagógicos }\end{array}$ \\
\hline & $\begin{array}{l}\text { Estimular a produção e consumo de Plantas Alimentícias Não Convencionais } \\
\text { (PANCs) e plantas medicinais }\end{array}$ \\
\hline & $\begin{array}{l}\text { Apoiar e estimular agricultoras e agricultores em transição agroecológica, } \\
\text { equiparando seus benefícios aos produtos de orgânicos já certificado. }\end{array}$ \\
\hline
\end{tabular}

Os objetivos da política relacionados especificamente com o fortalecimento das hortas urbanas e do autoconsumo, também indicam a participação de setores produtivos urbanos ou periurbanos, não apenas na construção da PEAPO-SP, mas também como atores que querem demarcar seu espaço. Esses pontos também indicam uma permeabilidade da política a representações cognitivas alinhadas com outros paradigmas de consumo que privilegiam ciclos mais curtos.

Finalmente, permanece presente o reconhecimento dos espaços de participação social, inclusive para a manutenção das representações cognitivas que forjou a produção da PEAPO-SP. 
A PEAPO-SP é bastante ampla não apenas em seus objetivos $\left(\operatorname{artigo~} 5^{\circ}\right)$, mas também na definição das categorias que utiliza (artigo $2^{\circ}$ ), no incentivo à sua implementação com apoio da União, dos municípios, das organizações da sociedade civil e de entidades privadas (artigo $3^{\circ}$ ), diretrizes da PEAPO $\left(\operatorname{artigo~} 4^{\circ}\right.$ ), diretrizes da lei $\left(\operatorname{artigo~} 6^{\circ}\right)$, instrumentos de ação pública $\left(\operatorname{artigo~} 7^{\circ}\right)$. Aliás, uma vez promulgada, a política passa a carecer de regulamentação e planejamento capazes de dar materialidade aos seus objetivos.

\section{Os atores diretamente envolvidos na produção da PEAPO}

Nas entrevistas, fica evidente a presença de muitos atores envolvidos nas diversas fases de institucionalização da Política.

No que tange a um processo mais antigo e difuso da sociedade civil que começa a se organizar em torno da proposta de uma agricultura menos nociva no âmbito estadual é a Estância Demétria, em 1973, em Botucatu e, mais tarde, a criação do Grupo de Agricultura Alternativa (GAA) em 1979 dentro da Associação dos Engenheiros Agrônomos do estado de São Paulo (AEASP). O GAA com diversas articulações com outros atores é um dos responsáveis pela organização, em Curitiba, do $1^{\circ}$ Encontro Brasileiro de Agricultura Alternativa.

O grupo de pessoas que se forma no âmbito do GAA continua atuando no fortalecimento da causa e funda a já mecionada AAO, a qual conquista um espaço para sua sede em uma sala do Parque Municipal da Água Branca em 1990 e em seguida a realização da Feira de Produtos Orgânicos, em 1991, no mesmo parque, após articulação de uma parceria com a SAA (AAO, 2019). A AAO é um dos principais atores na discussão e defesa de agriculturas alternativas e na construção e institucionalização da PEAPO também.

Bastante citado pelos atores entrevistados com atuação mais recente em relação à AAO é o Instituto Kairós. As associações de produtores, além da AAO, que merecem ser citadas por terem uma atuação relevante são a AAZL (Associação de Agricultores da Zona Leste) e a COOPERAPAS (Cooperativa Agroecológica dos Produtores Rurais e de Água Limpa da Região Sul de São Paulo).

No âmbito do poder público estadual dois órgãos foram historicamente muito importantes, as já citadas SMA e SAA, e, em ambas secretarias a presença de funcionários de carreira muitos próximos à questão de produção agroecológica e orgânica foram condição necessária para que a pauta continuasse avançando mesmo com mudanças de secretários e de momentos políticos diferentes.

Além dos atores da sociedade civil, e das referidas secretarias acima citadas, merecem destaque tanto os espaços de governo do município de 
São Paulo quanto os atores individuais, citados pelos entrevistados a partir das narrativas sobre a construção dos diversos instrumentos de políticas de agroecologia e de agricultura orgânica que, de algum modo, são reconhecidos e potencializados pela PEAPO-SP. Trata-se, nesse caso, de burocratas, servidores públicos, com atuação em áreas específicas, como por exemplo, o gestor do programa de alimentar escolar orgânica no município de São Paulo, o gestor da Unidade de Pesquisa e Desenvolvimento (UPD) em Agricultura Ecológica localizado em São Roque, os servidores que contribuíram na produção e teste do Protocolo de Boas Práticas Agroambientais no município de São Paulo, que deu origem ao Protocolo de Transição Agroecológica (Protocolo Estadual de Boas Práticas Agroecológicas).

No âmbito do legislativo, embora também incluísse a sociedade civil e órgãos públicos, a Frente Parlamentar que atuou no município de São Paulo na construção da Lei de Alimentação Escolar Orgânica foi precursora nesse tipo de ação coletiva no âmbito legislativo. No entanto, o maior destaque com relação à PEAPO-SP é da Frente Parlamentar em Defesa da Produção Orgânica e Desenvolvimento da Agroecologia teve um protagonismo na elaboração e discussão do texto da PEAPO.

Quando se considera, entretanto, as audiências públicas regionais e a capacidade de disseminação da agroecologia e da agricultura orgânica por meio dos mais de 300 técnicos e extensionistas rurais do estado de São Paulo que tiveram acesso a cursos de formação sobre o tema, percebe-se a limitação de citação dos atores e o foco que este trabalho deu à capital paulista, aos órgãos de governo estadual, à Assembleia Legislativa e às organizações da sociedade civil com sede no município de São Paulo.

Aposta-se que o foco proposto tenha caráter de representação das diversas "agriculturas alternativas", mas se reconhece a possibilidade de expansão de escuta de outros atores, seja no interior da burocracia, do legislativo, da sociedade civil e fundamentalmente dos muitos territórios paulistas para além da capital.

A partir das entrevistas realizadas é possível iniciar um estudo sobre as diversas redes que se envolveram com a construção da PEAPO. De antemão, entretanto, podemos observar a presença de importantes mediadores de políticas públicas com presença atuação tanto no Estado quanto na sociedade civil. Para os propósitos desse trabalho, considera-se mediador um ator individual capaz de articular dois territórios com suas gramáticas específicas: o território e a gramática da política com sua lógica de partido e disputas eleitorais; e o território das políticas públicas, com suas redes de especialistas e técnicos (ABÉLÈS, 1988). Observa-se também que muitos desses mediadores alternam suas posições entre as estruturas do Estado e a sociedade civil, 
mas invariavelmente carregam consigo o tema da "agricultura orgânica e da agroecologia" a partir dos quais constroem políticas, discursos e instrumentos de acordo com as possibilidades do momento e da posição que ocupam. Finalmente, observa-se que esses mediadores articulam não apenas atores individuais, mas também atores institucionais e, também, redes específicas, seja de projetos, de temas, de comunidades de políticas públicas e redes epistêmicas (MASSARDIER, 2006).

\section{Os referenciais: agricultura, conflito territorial e suas muitas interfaces}

A produção da PEAPO-SP é fruto de muita experimentação e de muitos caminhos que se entrecruzaram. Ao retomar os olhares para um período menos recente da história, as representações cognitivas presentes na agroecologia remetem historicamente aos esforços predecessores do Movimento de Agricultura Alternativa ainda dos anos 70. Mais recentemente, a construção da PEAPO está intrinsecamente relacionada com a produção de vários instrumentos no âmbito do município de São Paulo e nem todos diretamente relacionados com a agroecologia propriamente dita.

O campo de conhecimento das "agriculturas alternativas" nasce em contraponto a agricultura convencional. No entanto, as "agriculturas alternativas" são muitas, com relevância a, pelo menos, cinco: agricultura biodinâmica; agricultura orgânica; agricultura biológica; agricultura natural; e mais recentemente agricultura agroecológica.

A chamada "agricultura alternativa" é um referencial, uma representação de mundo e tem como um de seus marcos a publicação do livro denúncia "Primavera silenciosa" de Rachel Carson em 1962. É verdade que os princípios da agricultura alternativa, integrativa, holística, estavam em voga desde o início do século XX.

A agricultura orgânica, por exemplo, ganha força, já em 1919, quando Howard propõe cultivar lavouras sem o uso de insumos químicos. Desde os anos 80, o legado científico de Howard valoriza a seguinte prática:

interação da produção animal e vegetal; uso de rações e forragens obtidas no local ou adquiridas de fornecedores orgânicos; consorciações e rotações de culturas; uso de variedades adaptadas às condições locais do clima e dos solos; adubação verde; introdução de "quebra-ventos"; uso de biofertilizantes; reciclagem dos materiais orgânicos gerados na unidade de produção agrícola; manutenção de cobertura vegetal, viva ou morta, sobre o solo (EHLERS, 2008, p. 24-25). 
A agricultura biodinâmica, por sua vez, ganha força na Alemanha, em 1934. Trata-se de uma agricultura que percebe a propriedade agrícola como uma espécie de organismo autônomo e autossuficiente e segue as seguintes práticas:

interação entre a produção animal e a produção vegetal; respeito ao calendário biodinâmico, que indica as melhores fases astrológicas para a semeadura e demais etapas do cultivo agrícola; utilização de preparados biodinâmicos para reativar as forças vitais dos solos (EHLERS, 2008, p. 41-42).

As bases da agricultura biológica, por sua vez, são lançadas pelo suíço Hans-Peter Müller, em 1930. Trata-se de uma agricultura preocupada com a autonomia dos produtores e com a comercialização direta aos consumidores. Somente em 1960, a referida agricultura ganha força, quando o alemão Hans Peter Rush, "interessado nas relações entre dieta alimentar e saúde humana, sistematizou e difundiu as propostas de Müller" (EHLERS, 2008, p. 45).

É também nos anos 30, mais propriamente em 1935, que Mokiti Okada, no Japão, lança os pilares da agricultura natural.

O movimento agroecológico é mais recente, e na verdade, deixa a impressão que integra os princípios da agricultura orgânica, aborda os circuitos curtos, preocupa-se com a questão ambiental e com a articulação com a agricultura e o meio ambiente e fundamentalmente explicita uma preocupação política e econômica relacionada com as condições de trabalho, produção, comercialização e consumo.

Cada uma das vertentes acima citadas está presente no território paulista, e todas elas expressam um referencial, uma visão de mundo específica muito embora guardem entre si pontos de convergência. Assim, os objetivos da PEAPO-SP são abrangentes suficientemente para cobrir as especificidades dessas diversas percepções sobre as "agriculturas alternativas".

A partir das entrevistas realizadas, observa-se que: não há consenso entre os atores acerca do conceito de agroecologia; agroecologia e produção orgânica, embora tenham significados diversos dependendo do ator em questão, foram utilizados de forma ampla e não hierárquica na construção da PEAPO; o peso dado às diferenças de ideias e das práticas também varia entre os diversos grupos e atores que compõem a rede.

Essas observações reafirmam a percepção relativa às diferentes representações de atores, movimentos e "agriculturas alternativas".

Além da diversidade expressa nas concepções de agricultura, há também que se considerar no caso da PEAPO-SP o fato da Frente Parlamentar que lidera a proposição da lei ser encabeçada por dois deputados, cada qual em 
partidos diferentes, e agregar ainda um conjunto inicial de 48 deputados e 60 organizações da sociedade civil.

Não é por menos que, "os objetivos enunciados nas exposições de motivos são heterogêneos, tomando forma de empilhamento de interesses a serem protegidos ou metas a serem atingidas" (LASCOUMES; LE GALÈS, 2012a, p. 93).

\section{Considerações finais}

Do ponto de vista da análise dos resultados da PEAPO-SP, como se trata de uma política recente e ainda não regulamentada não é possível analisar os resultados dela propriamente dita. Porém é pertinente reconhecer que a PEAPO é resultado de um conjunto de experimentações anteriores e instrumentos difusos no tempo e no espaço ocorridos tanto no âmbito do estado, quanto no âmbito do município e da sociedade civil.

Instrumentos são aqui entendidos à luz da ação pública como os dispositivos, ferramentas e formas institucionalizadas ou não de dar materialidade aos objetivos determinados no âmbito público (LASCOUMES; LE GALÈS, 2012b). Os instrumentos, sob essa perspectiva analítica, trarão impactos previstos e imprevistos para ação pública.

Citados anteriormente, vale a pena ressaltar a importância de alguns instrumentos que acabaram por fortalecer a agroecologia e por consequência a construção da PEAPO também, dentre os quais:

- Projeto estadual Guarapiranga Sustentável, apoiado legalmente na Lei Específica da Guarapiranga;

- Protocolo Estadual de Transição Agroecológica;

- Lei municipal de aquisição progressiva de merenda orgânica ou de base agroecológica.

A lei que cria a PEAPO-SP demonstrou ser um guarda-chuva que cobre as diversas iniciativas no campo da agroecologia e da agricultura orgânica no estado de São Paulo e procura consolidar esse campo de conhecimento e ação. Ao mesmo tempo, inspirada nas experiências de outros estados como o Rio Grande do Sul, Paraná e Minas Gerais, a PEAPO-SP busca indicar ações para a promoção e regulação do referido campo.

Ela é fruto de diversos processos dos quais participaram inúmeros atores: a sociedade civil que se articula e desenvolve a agroecologia de diversas formas, em espaços completamente diferentes em diferentes escalas, e vai aos poucos sendo reconhecida nos espaços governamentais, em suas variadas organizações. O governo estadual passa a entender como desejável a 
estruturação do setor para uma política estadual de estímulo e diálogo com esse setor, que apesar de ser plural internamente, se articula em conjunto para institucionalizar sua prática.

Pode-se dizer, então, a partir de um olhar mais recente, que a PEAPO é resultado de experimentações ambientais aliadas à produção de alimentos com algum apoio do governo estadual; da produção de projetos estaduais a partir do protagonismo de burocratas, técnicos e extensionistas; e de iniciativas legislativas tanto no âmbito da Câmara municipal de São Paulo quanto da Assembleia Legislativa do estado de São Paulo.

Da análise que realizamos neste capítulo, é relevante destacar os seguintes pontos:

- O papel central do município de São Paulo, tanto do ponto de vista da organização da sociedade civil que se mobiliza e consegue pautar a ação pública, quanto das políticas municipais que promovem o debate e novas práticas que culminam na institucionalização da política estadual, indicando que o pressuposto de que as políticas apenas descem do nível macro, no caso do nível estadual, para o nível micro (nível municipal), não se observa como regra;

- Também decorrente da importância do município, observamos o peso que a agricultura urbana exerce na PEAPO de São Paulo sobretudo pela mobilização da sociedade civil organizada em torno dessa prática, o que não se observa na mesma intensidade de outros estados analisados neste livro, como Rio Grande do Sul e Distrito Federal;

- Alguns dos atores envolvidos com a institucionalização da PEAPO-SP estão diacronicamente posicionados em lugares diferentes: ora atuam como técnicos e burocratas estáveis nas estruturas de governo; ora atuam como funcionários emprestados em gabinetes do poder executivo ou do poder legislativo; ora atuam na sociedade civil;

- A Frente Parlamentar responsável pela elaboração do texto e discussão com os envolvidos, apesar de situar-se no âmbito do legislativo, foi protagonizada e muitas vezes liderada pela sociedade civil organizada, o que teve um papel extremamente importante no amplo debate realizado e na mobilização em torno do tema que se obteve;

- A meta de tornar a merenda do município de São Paulo em 100\% orgânica ou de base agroecológica, cumpre um papel crucial na estruturação de uma demanda permanente e que incentiva a tran- 
sição agroecológica devido à atratividade do setor em termos de mercado devido ao seu tamanho

- A presença de atores diversos e de mediadores multiposicionados, capazes de articular as redes de projetos, as redes técnicas, os setores, os territórios de políticas (técnico e setorial) e de políticas públicas (organizações no interior do poder executivo e, também, o poder legislativo);

- Diferentes representações, ainda que pertencentes ao mesmo campo de conhecimento e ação e que se transfigura, na forma da lei, em objetivos amplos e diversos, na forma de "empilhamento" ainda que guardando coerência entre eles.

A configuração da PEAPO-SP, portanto, é a sedimentação de um longo processo e ponto de partida para a produção de instrumentos de políticas públicas capazes de efetivá-la e seus impactos deverão ser analisados conforme sua regulamentação for aprovada e a política for de fato implementada, sempre de forma conjunta com os outros instrumentos de ação pública que se relacionam diretamente como ela, como foi demostrado nesse capítulo. 


\section{REFERÊNCIAS}

AAO. Associação dos Agricultores Orgânicos. Quem somos. Disponível em: $<$ http://aao.org.br/aao/quem-somos.php>. Acesso em: 24 abr. 2019.

ABÉLÈS, M. Anthropologie des espaces politiques français. Revue Française de Science politique, 38e année, n. 5, p. 807-817, 1988.

ALVES, SANTOS, AZEVEDO, 2012. Disponível em: <http://orgprints. org/22814/1/Alves_Agricultura\%20orgânica.pdf>.

EHLERS, E. A agricultura alternativa: uma visão histórica. Estudos Econômicos, v. 24, n. esp., p. 231-262, 1994.

. O que é agricultura sustentável. São Paulo: Editora Brasiliense, 2008. (Coleção Primeiros Passos, 335).

INSTITUTO KAIRÓS. Institucional. Disponível em: $<$ https://institutokairos. net/kairos/>. Acesso em: 24 abr. 2019.

LASCOUMES, P.; LE GALÈS, P. A ação pública abordada pelos seus instrumentos. Revista Pós Ciências Sociais, v. 9, n. 18, p. 19-44, jul./dez. 2012 b.

. Sociologia da Ação Pública. Maceió: EDUFAL, 2012a.

LINDBLOM, C. The science of « muddling through ». Public Administration Review, Washington, D. C., v. 19, n. 2, p. 79-88, spring 1959.

MASSARDIER, G. Redes de Política Pública. In: SARAVIA, Enrique; FERRAREZI, Elisabete (Orgs.). Políticas públicas. Brasília: ENAP, 2006. (Coletânea). v. 2.

SÃO PAULO. Institui a Política Estadual de Agroecologia e Produção Orgânica - PEAPO, e dá outras providências. Disponível em: $<$ https://www.al.sp. gov.br/repositorio/legislacao/lei/2018/lei-16684-19.03.2018.html>.

Resolução Conjunta Sma/Saa-008, de 21 de dezembro de 2009. Estabelece diretrizes para incentivar as práticas de agricultura sustentável em Áreas de Proteção e Recuperação dos Mananciais da Unidade de 
Gerenciamento dos Recursos Hídricos do Alto Tietê, e dá outras providências. Disponível em: < http://www.mpsp.mp.br/portal/page/portal/cao_urbanismo_e_meio_ambiente/legislacao/leg_estadual/leg_est_resolucoes/2009_res_ est_sma_saa_conjunta_08.pdf $>$.

XAVIER, M.; FRANCO, F. Mutirões Agroflorestais: Uma estratégia para fomentar a convivência comunitária e reaproximar o Ser Humano da terra ్ㅡㄹ - Botucatu, SP Brasil, 2015. Cadernos de Agroecologia. v. 10, n. 3, 2015. Disponível em: $<$ http://revistas.aba-agroecologia.org.br/index.php/cad/article/ view/18331/13675>. Acesso em: 19 jun. 2019. 


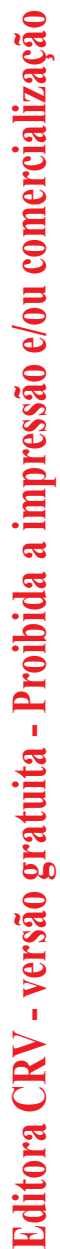




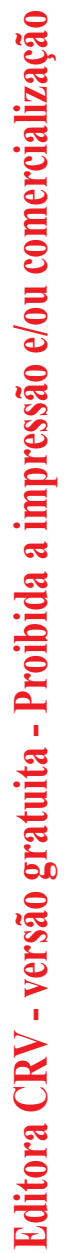

\section{REGIÃO NORTE}




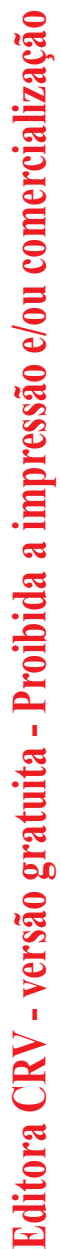




\title{
CAPÍTULO 7
}

\section{DISSONÂNCIAS NO ESTADO DO PARÁ ENTRE A INEXISTÊNCIA DA PEAPO E A TRAJETÓRIA RICA DA AGROECOLOGIA}

\author{
William Santos de Assis \\ Marc Piraux \\ Hueliton Pereira Azevedo
}

\section{Introdução}

No país, muitos estados implementaram suas Políticas Estaduais de Agroecologia e Produção Orgânica (PEAPOs) com níveis de institucionalização bastante diferentes (GUÉNEAU et al., 2019). Este texto trata da trajetória da agroecologia frente à inexistência de uma política pública específica. Em particular, queremos explicar por que, diferente de outros estados brasileiros, há um grau de institucionalização da agroecologia ainda muito frágil a nível do estado, enquanto existe um grande número de experiências em várias regiões do Pará. Mostraremos que essa situação se deve, em parte, ao não envolvimento do governo estadual na criação de instrumentos eficientes de políticas de promoção da agroecologia e da dificuldade dos movimentos sociais formarem coalizões fortes o suficiente para influenciar o conteúdo desses instrumentos.

Havia de fato forças políticas desfavoráveis ao tema da agroecologia no governo Jatene do Partido da Social Democracia Brasileira (PSDB) durante seus dois mandatos (2011 a 2018). Esses governos favoreceram a categoria empresarial, principalmente o setor das agroindústrias, a partir de políticas de fomento a grandes cadeias de produtos agrícolas, como se verifica no Programa Pará 2030. Esse programa considerou ao menos o setor da produção orgânica como um dos novos mercados interessantes visto a demanda de consumo crescente. Este fator contribuiu para a demora na criação de espaços de discussão em torno da temática agroecológica na esfera estadual. O primeiro espaço criado foi a Comissão de Produção Orgânica (CPOrg), porém sua criação foi acionada pela esfera federal e voltada especificamente para a produção orgânica. Dentre as atribuições formais da CPOrg a única que se refere explicitamente à produção agroecológica é a que estabelece que a CPOrg deve subsidiar a Comissão Nacional de Agroecologia e Produção Orgânica 
(CNAPO), Câmara Interministerial de Agroecologia e Produção Orgânica (CIAPO), Política Nacional de Agroecologia e Produção Orgânica (PNAPO) e Plano Nacional de Agroecologia e Produção Orgânica (PLANAPO).

Um segundo elemento que explica a inexistência de uma Política Estadual de Agroecologia e Produção Orgânica (PEAPO) está ligado à dificuldade de mobilização da sociedade civil no sentido de uma unidade de forma coesa em torno da pauta agroecológica, apesar de uma grande diversidade de experiências. Este processo traduz uma trajetória rica da agroecologia na sua dimensão prática e técnica, mas muito frágil do ponto de vista político. Devido à importância desta trajetória de institucionalização da agroecologia e da produção orgânica no estado, para a compreensão da situação atual, um destaque específico está sendo dado a esta análise da trajetória na primeira parte do texto, onde se procurou dar conta das especificidades dos processos neste estado e dos desdobramentos atuais na escala estadual. O texto não pretende realizar uma análise exaustiva dos processos, porém levanta os aspectos identificados como centrais para compreendê-los. A segunda parte do texto focaliza-se sobre o processo de mobilização dos atores a favor da criação da PEAPO, que começou no final de 2018, devido à realização do Seminário Regional de Agroecologia (região Amazônica) da PNAPO.

Sobre a trajetória da agroecologia no Pará, uma pesquisa de caráter qualitativo (FLICK, 2008), foi realizada entre os meses de abril e outubro de 2018, onde foram entrevistados 17 atores chaves. As entrevistas foram feitas com o uso de perguntas abertas, procurando compreender as especificidades de cada situação. Estas entrevistas compõem os dados primários utilizados na construção da análise. Além dessas entrevistas realizadas diretamente para esse texto, tivemos acesso a mais seis entrevistas sobre a história e a trajetória das ideias de agroecologia no Pará, realizadas por pesquisadores parceiros do Instituto Federal de Educação e Tecnologia do Pará, Campus de Castanhal (IFPA-Campus de Castanhal).

O uso da pesquisa documental permitiu acessar dados secundários, a partir de publicações científicas, documentos oficiais e relatórios técnicos. Foram coletados dados oficiais de natureza quantitativa sobre as políticas públicas de âmbito nacional que incidem no estado. Esses dados foram obtidos em sites oficiais de instituições como Ministério da Agricultura e Pecuária (MAPA), Companhia Nacional de Abastecimento (CONAB) e Instituto Brasileiro de Geografia e Estatística (IBGE), entre outros.

Para a análise da institucionalização da agroecologia e da proposta de uma PEAPO, foi usada a matriz de análise apresentada no capítulo introdutivo deste livro, assim como o quadro da ação pública dos autores Lascoumes e Le Galès (2012). 


\section{A riqueza da trajetória da institucionalização da agroecologia e a fragilidade da ação pública}

Nesta seção, descrevemos a trajetória estadual de institucionalização da agroecologia (IA) a partir da identificação de quatro fases situadas entre as décadas de 1980 a 2019. Procura-se com esta análise histórica revelar fatores condicionantes dos desafios enfrentados no âmbito da ação pública.

\section{O surgimento das ideias agroecológicas no estado (meados de 1980 a 1990)}

É possível reconhecer as ideias agroecológicas no Pará a partir do tema das agriculturas alternativas em meados da década de 1980. Isso mostra que estas ideias demoraram a chegar no estado, visto que emergiram há mais de uma década após seu surgimento e circulação nos debates em nível nacional. No contexto nacional, a influência teórica de profissionais críticos ao processo de modernização da agricultura teve papel importante, como foi o caso com Ana Maria Primavesi e José Antônio Lutzemberg (SILVA; GOMES, 2014). No estado do Pará, as ações de instituições eclesiásticas, universidades e representação de agricultores e técnicos foram relevantes.

No caso das instituições eclesiásticas, destacaram-se a igreja Luterana e a Católica (SILVA; GOMES, 2014). A igreja Luterana contribuiu na implementação de projetos para o plantio de culturas agrícolas consorciadas e na diversificação da produção em municípios afetados por megaprojetos de infraestrutura, como a Usina Hidrelétrica de Tucuruí (UHT). A igreja Católica contribuiu, por meio da Ação Católica (AC), na criação de espaços sociais de aprendizagem (PETERSEN, 2011) com a criação das Comunidades Eclesiais de Base (CEB's). As CEBs promoveram a formação de lideranças, sensibilização sobre as questões ambientais (ALMEIDA, 2011), emergência e fortalecimento de organizações sociais mais amplas - como os sindicatos (ASSIS, 2007) e a ressignificação de organizações conservadoras como as Colônias de Pescadores. Desta forma, a igreja Luterana contribuiu principalmente na criação de experiências de natureza técnico-produtiva e a igreja Católica em ações de natureza sociopolítica. No caso das universidades, destacou-se o Centro Agroambiental do Tocantins (CAT) criado inicialmente como um projeto vinculado à Pró-Reitoria de Extensão da Universidade Federal do Pará (UFPA). Esta experiência caracterizou-se por uma rede constituída por equipes multidisciplinares abrangendo os municípios de Marabá, Altamira e Belém (SCALABRIN; ARAGÃ̃, 2018). Suas atividades tiveram início em 1988 e perduraram até o ano 2000 (ALMEIDA, 2011). A experiência do CAT foi importante por sua inovação em articular a ação das organizações sociais com o trabalho de acadêmicos em processos organizacionais (ALMEIDA, 2011), em aspectos ecológico-produtivos, na contestação de 
intervenções modernizadoras e em novas abordagens teóricas, como a abordagem sistêmica (SILVA, Ex-integrante do CAT, 2018).

As agriculturas alternativas foram também promovidas por técnicos de instituições públicas articulados com organizações sociais em meados da década de 1980. Uma experiência relevante foi o caso da comunidade de Uraim, no município de Paragominas, onde houve incentivo ao consórcio de espécies frutíferas, seringueira e pimenta do reino por meio de um técnico da Secretaria de Agricultura do Estado (SAGRI) em articulação com o Sindicato dos Trabalhadores e Trabalhadoras Rurais (STTR) de Paragominas (SOUSA, ex-integrante do Grupo de Assessoria em Agroecologia na Amazônia-GTNA ${ }^{1}$, 2014). A experiência de Uraim foi apoiada pela cooperação internacional $^{2}$ e foi exitosa, tornando-se inspiração para outras ações em comunidades de Paragominas. A situação de instabilidade fundiária desta época implicava na preferência dos agricultores por cultivos anuais pois não havia perspectiva de permanência no lote (SILVA, ex-integrante do CAT, 2018). Por isso, na década de 1980, os arranjos com culturas perenes, a exemplo dos Sistemas Agroflorestais (SAFs), não se expandiram de forma expressiva no estado, implicando na preferência por consórcios ${ }^{3}$ (SOUSA, ex-integrante do GTNA, 2014). A atuação dos técnicos ocorreu de forma isolada no interior do estado, contribuindo com ações localizadas.

A maioria das experiências ocorreu de forma localizada, embora se observem algumas ações intermunicipais. A cooperação internacional, teve um papel importante na criação destas iniciativas por meio do apoio a projetos produtivos (SOUSA, ex-integrante do GTNA, 2014). A partir desse período essas ideias ganharam maior amplitude devido à ação das ONG's (Organizações Não Governamentais), período em que emerge no estado o uso do termo Agroecologia.

\section{O período das ONG's (1990 a 2000)}

Entre os anos de 1990 a 2000, as Organizações Não Governamentais (ONGs) mudaram de estratégia, introduziram o uso do termo agroecologia e tiveram papel relevante na disseminação das ideias agroecológicas no Pará. De fato, antes da década de 1990, havia um contexto estadual em que a agenda das

Grupo de Assessoria em Agroecologia na Amazônia. ONG que atuou na Amazônia no período entre 1993 a 2012.

A partir do exemplo de Uraim instituições internacionais aportaram apoio para atividades em Paragominas a partir de um projeto ligado ao Sindicato dos Trabalhadores e Trabalhadoras Rurais, entre elas o Fundo Canadense para Pequenos Projetos, A Fundação FORD e o Fundo Mundial para a Narureza (WWF).

3 Tecnicamente a diferença entre consórcios e SAFs é que no primeiro a complexidade é menor (em geral duas espécies) e raramente o componente arbóreo está presente. 
organizações dos agricultores estava voltada para a regularização fundiária, o acesso ao crédito e o acesso ao serviço de assistência técnica e extensão rural (SILVA, ex-integrante do CAT, 2018). As ideias agroecológicas não foram então assumidas como bandeira de luta pelos movimentos sociais (SILVA, ex-integrante do CAT, 2018). No contexto nacional ocorreu o fortalecimento das questões ambientais devido à morte de Chico Mendes em 1988 (SOUSA, ex-integrante do GTNA, 2014) e a realização da ECO-92 no Rio de Janeiro (SILVA; GOMES, 2014). A questão socioambiental começa a ganhar força e importância no debate nacional e se traduziu no estado do Para com o projeto PRORENDA ${ }^{4}$ com o apoio da German Technical Cooperation (GTZ).

Surge então o Grupo de Trabalho Novas Propostas para a Agroecologia na Amazônia (GTNA) ${ }^{5}$ no ano de 1993 (GTNA, 2004). Esta organização foi constituída a partir da uma assessoria e contribuição financeira de uma instituição alemã chamada de Pão para o Mundo (PPM) da Coordenadoria Ecumênica de Serviço (CESE) e um grupo de técnicos e técnicas atuando em vários estados da Amazônia Legal (Pará, Acre, Maranhão, Mato Grosso do Sul e Mato Grosso). Os integrantes do GTNA tinham graus variados de aproximação com as ideias das agriculturas de base ecológica (SILVA; GOMES, 2014). É provável que o termo agroecologia tenha começado a ser utilizado no estado do Pará e na Amazônia de forma geral por causa do trabalho do GTNA, representando o principal marco de surgimento destas ideias (Idem).

O GTNA foi a primeira articulação que procurou construir uma ação em rede a partir do trabalho dos assessores (BAS) ${ }^{6}$, da criação de experiências com a Rede de Informações Agroecológicas na Amazônia (RIAA) e a Rede de Mulheres Empreendedoras da Amazônia - RIMEA (GTNA, 2004). Além disso, contribuiu para uma sintonia maior das ações em andamento no estado com as ações nacionais através da mobilização para o I Encontro Nacional de Agroecologia - ENA (GTNA, 2004).

Entre os integrantes do GTNA não havia um conceito bem definido de agroecologia, por isso o trabalho desta ONG orientava-se mais por princípios agroecológicos como diversificação da produção, participação, diálogo de saberes, entre outros (SOUSA, ex-integrante do GTNA, 2018), e suas iniciativas buscavam dar visibilidade às alternativas de produção sustentável Agricultura (SAGRI) com a cooperação técnica do Governo da República Federal da Alemanha, através da GFA/GTZ, e estava vinculado ao Programa Piloto para a Proteção das Florestas Tropicais no Brasil (PPG7) (NASCIMENTO, 2009, p. 63-64).

6 Tratava-se de um banco de dados de assessores técnicos e agricultores experimentadores aptos a desenvolverem propostas de capacitação para outros técnicos e agricultores. 
com a utilização de metodologias como sistematizações de experiências (GTNA, 2004), favorecendo os processos metodológicos (SOUSA, ex-integrante do GTNA, 2018).

Além do GTNA, a Federação de Órgãos para Assistência Social e Educacional (FASE) realizou trabalhos de fortalecimento das organizações dos agricultores, criando três Centros de Tecnologias Alternativas (CTA's) no Pará (BEZERRA, FASE/PA, 2018). Mesmo com a criação destes centros, o tema das agriculturas alternativas não experimentou amplitude tão significativa no Pará, em função destes CTA's terem assumido atuação localizada. Provavelmente, isso foi motivado pela agenda das organizações dos agricultores que estava focada em regularização fundiária, acesso a crédito e ATER e as discussões sobre os arranjos produtivos não eram vistas como relevantes.

Um marco importante em toda a década de 1990 foi a sucessão dos "Gritos da Terra" realizados pelas organizações dos agricultores. As primeiras reivindicações deste repertório de ação coletiva (TILLY, 1978) eram a denúncia e a punição aos culpados pela violência no campo e a desburocratização do Fundo Constitucional do Norte (FNO). O Programa de Desenvolvimento Socioambiental da Produção Familiar Rural (PROAMBIENTE) foi conquistado através dos diversos "Gritos da Terra" realizados no estado durante a década de 1990, mas passa a ser implementado como política pública a partir do Plano Plurianual (PPA) de 2004 (HIRATA, 2006) e encerra suas operações em 2007. Para este autor, esta política foi inovadora por congregar o pagamento por serviços socioambientais, o crédito produtivo e a Assistência Técnica e Extensão Rural para apoiar a agricultura familiar. Existia também uma presença marcante das organizações sociais na implementação desta política. O Programa de Desenvolvimento Socioambiental da Produção Familiar Rural (PROAMBIENTE) foi importante pelo fato de ter representado a primeira aproximação das ideias e práticas agroecológicas nas políticas públicas no estado do Pará.

Embora se verifique a convergência na ação das organizações sociais e das ONG's para a questão ambiental, as ideias agroecológicas não estabeleceram consonância com alguns trabalhos realizados pelas organizações de base no estado do Pará no início de seu surgimento (AMARAL, ex-integrante do GTNA, 2014). Isso implicou na dificuldade de atores, como os agroextrativistas, de identificar coerência entre as ideias agroecológicas e suas lógicas produtivas. Este fato teve implicação na demora dos movimentos e demais organizações sociais do campo em assumirem a temática agroecológica em suas ações. 
A ação das ONG's de promoção da agroecologia durante a década de 1990 foi apoiada por financiamentos da cooperação internacional ${ }^{7}$ (SOUSA, ex-integrante do GTNA, 2014). Após esta década, os recursos reduziram drasticamente, implicando em um processo de crise das ONG's (SILVA; GOMES, 2014). A década de 1990 representou um período de conquista de políticas públicas com princípios alinhados às ideias agroecológicas.

\section{O surgimento de políticas públicas de promoção da agroecologia no Pará (2000 a 2010)}

Um marco importante no avanço das ideias agroecológicas no contexto estadual tem a ver com o momento em que a sociedade civil e os movimentos sociais do estado internalizam o conceito de agroecologia em suas ações. As ideias agroecológicas foram incorporadas pelos movimentos principalmente no início da década de 2000 (SOUSA, ex-integrante do GTNA, 2018). Esta "emergência tardia" (SILVA; GOMES, 2014) é um dos fenômenos que dificultou um movimento político no sentido de pressionar o estado para a implementação de uma política pública estadual de agroecologia. Neste período (2000-2010), além do fortalecimento das ideias agroecológicas nas organizações sociais, observa-se sua internalização em ações de pesquisa, ensino, programas governamentais federais como PAA (Programa de Aquisição de Alimentos) e o PNAE (Programa Nacional de Alimentação Escolar), políticas territoriais e políticas de assistência técnica e extensão rural (ATER).

No âmbito das organizações sociais, a partir do final da década de 1990, vem ocorrendo uma aproximação gradativa entre um número cada vez mais amplo de atores em relação às ideias agroecológicas. Além do II Encontro Nacional de Agroecologia (ENA) realizado em Recife no ano de 2002, outros fatores influenciaram na incorporação das ideias agroecológicas pelas organizações sociais. Nesse sentido, o ambiente agrário no período pós-massacre de Eldorado dos Carajás (que ocorreu em 1996) exigiu a construção de ações voltadas para a complexificação dos sistemas de produção devido à mudança do projeto de vida das famílias para a permanência no lote. Além disso, o enfrentamento ao modelo produtivista de agricultura passou a ser visto pelos movimentos sociais paraenses como uma bandeira de luta (SILVA; GOMES, 2014).

Somado a estes fatores, também tiveram importante influência o aumento crescente do debate sobre alimentação saudável, a existência de

7 Apesar do apoio de outras instituições o maior volume de recursos veio da Brot für die Welt (Pão Para o Mundo), de origem alemã. 
experiências produtivas convencionais malsucedidas em assentamentos e a influência dos debates nacionais sobre Agroecologia (SOUSA, ex-integrante do GTNA, 2018). Nesse contexto, alguns movimentos que tinham distanciamento em relação às ideias agroecológicas (por terem dificuldades de estabelecer consonância entre o conceito de Agroecologia em suas ações) passaram a assumir o tema da Agroecologia, como é o caso do Conselho Nacional dos Seringueiros - CNS (SILVA; GOMES, 2014). Estes fatores, no seu conjunto criaram as condições para a incorporação das ideias agroecológicas no âmbito de diversas organizações sociais do campo no estado do Pará.

A partir dos anos 2000, as ideias agroecológicas avançaram no âmbito das instituições de pesquisa e extensão. De fato, a implementação da Política Nacional de Assistência Técnica e Extensão Rural (PNATER) no ano de 2003, contribuiu na institucionalização do tema da Agroecologia nas instituições de pesquisa. A Embrapa recebeu forte influência por ter ficado responsável pela implementação de vários itens desta política (SÁ, pesquisadora da Embrapa, 2018). Além das ações da PNATER, as principais iniciativas dentro da Embrapa foram: a elaboração do Marco Referencial em Agroecologia (que possibilitou a abertura para a institucionalização das ideias agroecológicas), a formulação do projeto Tipitamba (voltado para a construção de alternativas ao uso do fogo) e o projeto "Transição Agroecológica: construção participativa do conhecimento para a sustentabilidade" que busca apoiar processos de transição para agricultura sustentável (KATO, Embrapa, 2014).

Além das instituições de pesquisa, as ideias agroecológicas foram fortalecidas nas instituições de ensino. O movimento da Educação do Campo teve um papel importante (SILVA, NEA-UFPA Belém, 2018). Entre as experiências concretas estão as Casas Familiares Rurais (CFR's), que ampliaram os cursos de Agroecologia principalmente no final da década de 2000 (VASCONCELOS, 2018). No período de 2000 a 2018 foram criados quatorze cursos completos (aqueles que possuem o nome de Agroecologia), cinco disciplinas (em cursos técnicos, de graduação e de Pós-Graduação), seis cursos com as ideias agroecológicas transversais aos eixos norteadores do currículo, dois cursos de Formação Inicial e Continuada (FIC) e uma linha de pesquisa em nível de mestrado. Isso mostra que as ideias agroecológicas estão presentes desde níveis de ensino de Formação Inicial e Continuada (FIC) até cursos de Pós-Graduação e uma dinâmica de crescente incorporação nas instituições de ensino.

Entre os anos de 2004 e 2006, surgiu a primeira ação governamental de promoção da Agroecologia de abrangência estadual. A ação foi coordenada por Gilberta Souto, a partir de um convite do governo do estado para assumir a Diretoria Técnica da EMATER-PA. Durante este período foram realizadas ações de formação, intercâmbios no interior do estado e em experiências de outras unidades federativas, seminários estaduais, entre outras iniciativas 
(SOUTO, ex-diretora técnica, 2018). A principal estratégia era qualificar os quadros da instituição e favorecer relações mais horizontais com os agricultores, assim como discutir sobre sistemas sustentáveis de produção com base nos referenciais da Agroecologia (SOUTO, ex-diretora técnica, 2018).

As ações foram principalmente influenciadas pela relação construída com o Ministério do Desenvolvimento Agrário (MDA). Foi a ação de formação mais ampla já realizada pela EMATER no estado envolvendo todas as suas regionais (RIBEIRO; EMATER, 2018), mas não se institucionalizou.

Entre os anos de 2007 e 2010, durante o mandato da governadora Ana Júlia Carepa, surgiram políticas estaduais de promoção da Agroecologia e de fortalecimento da produção orgânica. Neste período, o Estado apoiou o fortalecimento da política territorial, favorecendo as ideias agroecológicas. No estado do Pará foram criados oito territórios e construídos os Planos Territoriais de Desenvolvimento Sustentável (PTDRS). Em todos estes planos verifica-se a referência explícita ou implícita às ideias agroecológicas (RODRIGUES, 2019). As ideias agroecológicas são amplas, envolvendo aspectos ecológico-produtivos, educacionais, tecnológicos, entre outros e sua mobilização diferencia-se em cada território de acordo com as particularidades da dinâmica das mesorregiões.

A entrada das ideias agroecológicas nos planos e nos debates que ocorreram, mostra que elas orientaram um conjunto de iniciativas no âmbito da política territorial no estado do Pará; esta foi, portanto, uma política que favoreceu a agroecologia no estado do Pará. Esse conjunto de políticas cessaram após o início do mandato do governador Simão Jatene a partir do ano de 2011. Além da política dos territórios, o Programa de Assistência Técnica e Extensão Rural Pública do estado do Pará (PROATER) favoreceu as ideias agroecológicas no estado. Sua proposta tinha como objetivo integrar as ações de ATER estaduais com a Política Nacional (PNATER) e assumia os princípios agroecológicos como orientação conceitual transversal às ações propostas (PROATER, 2005). O papel educativo da extensão rural, o princípio da participação e as práticas endógenas são ideias que aparecem com destaque na formulação deste programa. Durante o governo Ana Júlia (2006-2010) ganhou relevância a percepção de que a EMATER-PA estava atuando demasiadamente na aplicação do crédito bancário e as ações de extensão rural tinham ficado em um segundo plano (LIMA, ex-presidente da EMATER, 2018). Por isso, foram fortalecidas ações de construção participativa da ação dos Escritórios Locais (ESLOC) em cada município e de melhorias de infraestrutura e equipamentos (idem). Porém, as ações demoraram a ocorrer e não tiveram resultados significativos (RIBEIRO; EMATER, 2018).

Com o fim do governo Ana Julia, no fim de 2010, o apoio do governo estadual aos territórios e às políticas de apoio à agricultura familiar cessaram. Esta realidade pode ser verificada por fatores como o fortalecimento de 
cadeias produtivas longas de comercialização previstas no programa Pará 2030 (PEREIRA, ex-secretário de agricultura, 2018) e pelo favorecimento de lógicas agroindustriais de produção (OLIVEIRA, ex-integrante do Pará Rural, 2018). Portanto, o fim do mandato de Ana Julia representou o fim de um ciclo de políticas a favor da Agroecologia no Pará.

\section{A influência fortalecedora de políticas nacionais na política do estado do Pará (2010 a 2019)}

Verificou-se que nos três volumes do Plano Plurianual (PPA) do estado, referente ao período de 2016 a 2019, não foi feita nenhuma menção ao termo Agroecologia. Outro indicador importante é a atual ausência de políticas estruturantes para a agricultura familiar. $\mathrm{O}$ apoio à agricultura familiar ocorre apenas de forma pontual (RODRIGUES, SEDAP/PA, 2018). Essa situação revela que, embora a temática agroecológica tenha incidido em políticas públicas no Pará, não houve institucionalização suficiente e o cenário atual é de esvaziamento de políticas de promoção. Por outro lado, as políticas nacionais de promoção da agroecologia tiveram um papel importante na disseminação das ideias agroecológicas no estado a partir do ano de 2010. Neste ano ocorreu a constituição dos primeiros Núcleos de Estudos em Agroecologia - NEA's (SOUSA, NEA Castanhal, 2018).

No ano de 2012 surge a Política Nacional de Agroecologia (PNAPO). No ano seguinte é formulado o primeiro Plano Nacional de Agroecologia (PLANAPO) para implementação de 2013 a 2015. A partir do ano de 2016 é elaborado/atualizado o segundo PLANAPO para implementação de 2016 a 2019. Além deste contexto de emergências de políticas nacionais de Agroecologia e produção orgânica, novos temas ligados à Agroecologia ganharam relevância no estado, como é o caso da luta contra os agrotóxicos.

Os Núcleos de Estudos em Agroecologia (NEA's) surgiram no estado a partir de uma carta convite do Ministério do Desenvolvimento Agrário MDA e se ampliaram por meio de novos editais. Estes núcleos realizam uma diversidade de ações envolvendo cursos, intercâmbios, palestras, entre outros. Uma de suas principais contribuições tem sido a capacidade de articular as ações de ensino, pesquisa e extensão (SOUSA, NEA Castanhal, 2018). Atualmente existem 24 grupos de pesquisa, porém a partir de 2016, no período pós-impeachment da presidenta Dilma Rousseff, houve redução na criação de novos grupos de pesquisa em agroecologia, devido às dificuldades de recursos estruturantes para fortalecimento das experiências já existentes e para a criação de novos grupos. Algumas experiências voltaram para uma situação de isolamento, vivenciadas em décadas anteriores, no interior de suas instituições (SÁ, Pesquisadora da Embrapa, 2018). 
Entre as políticas nacionais de promoção da agroecologia presentes no Pará estão as linhas de crédito do Programa Nacional de Fortalecimento da Agricultura Familiar (PRONAF), nas modalidades PRONAF Agroecologia, o PRONAF Florestas e o PRONAF Eco. O PRONAF Agroecologia foi criado na safra de 2003-2004 com a finalidade de apoiar iniciativas agroecológicas e agricultores em transição (BASA, 2018). Foram realizados apenas dois contratos entre os anos de 2013 e 2018 e começam a partir do ano de 2016, mais de dez anos após seu surgimento a nível nacional (BCB, 2018). A linha de crédito do PRONAF Eco foi criada em 2007 com a finalidade de apoiar energia renovável e sustentabilidade ambiental (BASA, 2018). Foram realizados 309 contratos entre os anos de 2003 e 2018 (BCB, 2018). O PRONAF Floresta foi criado em 2002 (BASA, 2018). Foram realizados 4.815 contratos entre os anos de 2015 e 2018 . O maior volume de contratos percebidos nesta linha de financiamento resulta do avanço dos sistemas agroflorestais no estado. Na implementação de todas estas linhas de crédito verificam-se duas regularidades. A primeira é o fato das operações de crédito no Pará começarem sempre anos depois de já estarem em curso no âmbito nacional, sugerindo desfavorecimento do estado em relação ao acesso a políticas públicas nacionais a favor da Agroecologia (SILVA, ex-integrante do CAT, 2018). A segunda é a tendência de redução do volume de investimentos em todas as linhas de créditos analisadas. Isso resulta do contexto nacional de redução dos investimentos após a entrada do governo de Michel Temer.

O Programa ECOFORTE de apoio as redes de gestão de conhecimento agroecológico, contribuiu no financiamento de um projeto territorial de uma rede de Agroecologia e de um projeto no nível municipal. De acordo com da Associação dos Meliponicultores de Curuçá (ASMELC) no ano de 2014, por meio do edital ECOFORTE Extrativismo. As experiências de acesso ao Programa ECOFORTE são positivas em termos de resultados alcançados pelos projetos apoiados. Porém, a quantidade de experiências contempladas no estado ainda é pequena, já que foram apenas duas até hoje.

Outra política pública nacional importante no Pará é aquela dos mercados institucionais, que funcionou por meio do Programa Nacional de Alimentação Escolar (PNAE) e do Programa de Aquisição de Alimentos (PAA). Os investimentos do PNAE passaram por estabilização no ano de 2010 e seguiram em queda crescente nos anos seguintes. Mesmo com a redução das operações, este programa promoveu efeitos agroecológicos (GARRIDO, 2011) como a diversificação da produção (NAVEGANTES, pesquisadora do PNAE na 
UFPa, Informação pessoal, 2018). Desta forma, embora não sejam praticados preços diferenciados para produtos agroecológicos ou orgânicos, esta política possui efeitos alinhados à perspectiva agroecológica de produção. O Programa de Aquisição de Alimentos (PAA) realiza também operações de compra de alimentos, mas os investimentos possuem tendência de redução resultante dos cortes feitos pelo governo de Michel Temer, após o ano de 2016. O PAA tem papel importante no fortalecimento da agricultura orgânica no Pará pelo fato dos produtos orgânicos possuírem valor diferenciado na tabela de preços deste programa (GUSMÃO, ex-integrante da CPORg, 2018). Esta é a única política identificada nesta pesquisa que possui ação de promoção da agricultura orgânica, que se dá através da diferenciação de preços. As demais políticas existentes são voltadas para a regulamentação.

Do ponto de vista da sociedade civil, em 2015, ocorreu o IX Congresso Brasileiro de Agroecologia (CBA) na cidade de Belém e que tinha como um de seus principais objetivos o favorecimento de maior articulação das organizações estaduais em torno da temática agroecológica (ASSIS, ABA Agroecologia, 2014). Além do CBA, foi realizado o IV Encontro Regional de Agroecologia (ERA) no município de Abaetetuba no ano de 2018, com um conjunto de objetivos, entre os quais figurava a articulação estadual entre as organizações. Portanto, embora não se observe atualmente uma articulação efetiva das organizações no nível estadual, em relação a temática agroecológica, já ocorreram iniciativas com este propósito.

O tema da alimentação saudável ganhou relevância no Pará nos últimos anos, em particular com relação ao uso dos agrotóxicos. Existem dois espaços de discussão sobre esta problemática. O primeiro é o Fórum Estadual de Combate aos Impactos Causados pelos Agrotóxicos, que surgiu em 2014 (BEZERRA, FASE/PA, 2018) e o segundo é o Comitê Paraense da Campanha Permanente contra os Agrotóxicos e pela Vida, que no estado do Pará, iniciou suas atividades no ano de 2017 (BEZERRA, FASE/PA, 2018). No fórum foi instalada uma Câmara Temática de Agroecologia e Produção orgânica com participação do Ministério Público do Pará (MP-PA), de organizações da sociedade civil e empresariais (idem). Este fórum tem contribuído na organização de audiências públicas, verificação de denúncias das comunidades, entre outros. No comitê participam estudantes, professores, pesquisadores e representantes de ONG's.

Em que pese a semelhança temática, estes espaços de discussão diferem em suas proposições. O fórum tem o objetivo de combater os impactos dos agrotóxicos, sem necessariamente eliminar seu uso, já o comitê visa fazer campanha contra os agrotóxicos, com a finalidade de informar a sociedade 
sobre seus riscos e defender a Agroecologia como alternativa (BEZERRA, FASE/PA, 2018). O comitê surgiu no Pará, como um espaço paralelo ao fórum estadual, devido à constatação das organizações da sociedade civil de que o fórum estava desempenhando papel de legitimação de ações favoráveis a permanência do uso de agrotóxicos. Como resultado destes espaços de discussão foi formulado e aprovado um projeto de lei estadual, apresentado pelo deputado Carlos Bordalo (PT), que instituiu a última semana do mês de abril de 2019 (denominada semana verde) para a promoção da saúde e segurança do trabalhador, com atenção privilegiada aos trabalhadores rurais expostos a agrotóxicos (ALEPA, 2019). Embora já tenha sido aprovada, a lei ainda não foi sancionada pelo governador.

Assim, e apesar dessas propostas, podemos afirmar que no estado do Pará prevalece a situação de fragilidade da ação pública de promoção da Agroecologia. Nos últimos anos da trajetória de incorporação das ideias agroecológicas não ocorreu abertura de uma janela de oportunidade (KINGDON, 2003) que possibilitasse a entrada do tema da Agroecologia na agenda governamental de forma mais permanente. As políticas de agroecologia presentes no estado são originadas diretamente do âmbito nacional. Isso não significa a ausência de numerosas experiências locais mais ou menos institucionalizadas segundo o caso.

\section{Agricultura orgânica e agroecologia: ausência de uma PEAPO no Pará}

Existem duas trajetórias de produção ecológica no estado do Pará. A primeira de produção orgânica, caracteriza-se pela produção via a substituição de insumos, realizadas por agricultores vinculados as organizações de controle Social (OCS) que são vistoriadas e apoiadas pela Comissão da Produção Orgânica do Pará - CPOrg-PA. Nas OCS's, o trabalho principal é a construção de feiras orgânicas e grupos de consumo para a venda direta, concentradas principalmente na região metropolitana do estado (GUSMÃO, Ex-integrante da CPORG, 2018). A segunda trajetória de produção ecológica é a atividade extrativista das comunidades tradicionais onde os produtos orgânicos são mobilizados por cadeias longas de comercialização voltadas principalmente para o mercado internacional da indústria de cosméticos e certificados por empresas que controlam a produção (GUSMÃO, Ex-integrante da CPORG, 2018). O estado do Pará destaca-se com a segunda maior extensão de área de produção orgânica do País e concentra a maioria absoluta de produtores orgânicos certificados (KATO, Pesquisador da Embrapa, 2018). Como as políticas existentes são voltadas quase que totalmente para a regulamentação 
da comercialização e essas são muito exigentes, os agricultores familiares enfrentam muitas barreiras para inserir seus produtos em determinados mercados. Soma-se a isto a escassez de incentivos como, por exemplo, linhas de crédito específicas para a produção orgânica (GUSMÃO, Ex-integrante da CPORG, 2018). A CPOrg iniciou assim suas ações estimulando a produção e comercialização de orgânicos com implicações positivas no avanço das organizações de produtores orgânicos.

Os atores envolvidos com a produção orgânica diferem em alguns aspectos daqueles envolvidos com a proposta agroecológica. Podem ser também observadas tensões decorrentes destas diferenças. Nesse sentido, a produção orgânica é mais promovida por ação governamental enquanto a agroecologia é mais alinhada aos movimentos sociais e com visão mais integrada aos processos socioecológicos. Além disso, a produção orgânica é mais programática devido à mobilização de repertórios padronizados e empreendedores. As tensões ocorrem na forma de relação destes atores com os mercados, visto que na agroecologia defendem-se sistemas agroalimentares alternativos fundados na produção e distribuição de alimentos saudáveis acessíveis para toda sociedade, distanciando-se da agricultura orgânica que defende alimentos saudáveis, sem forte preocupação em estar acessível para toda a sociedade, vinculando-se desta forma a nichos específicos de mercado limitados a setores capazes de pagar mais pelo alimento orgânico.

O principal espaço de discussão entre governo e sociedade civil para agroecologia foi o seminário regional de agroecologia (Região Amazônica) da Política Nacional de Agroecologia e Produção Orgânica - PNAPO e do Plano Nacional de Agroecologia e Produção Orgânica - PLANAPO. Este evento foi promovido pela Secretaria Nacional de Articulação Social, do Governo Federal, em parceria com o Governo do Pará, por meio da Secretaria de Estado de Desenvolvimento Agropecuário e da Pesca (SEDAP). Ele aconteceu no mês de dezembro de 2017. Os encaminhamentos mais importantes deste seminário foram as propostas de formulação de Política Estadual de Agroecologia e Produção Orgânica (PEAPO) e a criação de uma câmara técnica de agroecologia e produção no conselho estadual de desenvolvimento rural sustentável (KNEZ et al., 2018).

O Instituto Amazônico de Agriculturas Familiares (INEAF) da Universidade Federal do Pará (UFPA) e Empresa Brasileira de Pesquisa Agropecuária Amazônia Oriental (Embrapa-Amazônia Oriental), com apoio do Núcleo de Estudos em Agroecologia (NEA) do Instituto de Federal do Pará Campus Castanhal (IFPA-Castanhal) e da Federação dos Trabalhadores e Trabalhadoras da Agricultura do Pará (FETAGRI-Pará) criaram um grupo de trabalho para dinamizar o processo de formulação de uma proposta de política estadual 
(SOUSA, NEA Castanhal, 2018). Além disso, foi proposto um conjunto de iniciativas de promoção da agroecologia e produção orgânica envolvendo processos de formação, campanhas de conscientização, formas de geração de energia limpa, entre outras. Porém, como vimos antes, estes grupos de interesse estão desarticulados ao nível estadual, realizando ações isoladas, com incidência ainda fraca na reivindicação de políticas públicas estaduais. É o caso de Rede Jirau de Agroecologia, da Rede Bragantina de Economia Solidária e dos NEA's. Então, até meados de junho de 2019, a iniciativa de construção da política estadual não avançou.

No espaço recentemente institucionalizado para discutir agroecologia e produção orgânica se verifica distinção entre grupos com interesses diferenciados, assim como de mediadores. O espaço de discussão identificado é a Câmara Técnica da Agroecologia, Produtos Orgânicos, Comercialização e da Sociobiodiversidade - CTAPOS, criada em 2018. Esta câmara é constituída pelas seguintes instituições: Embrapa, UFPA, CNS, Fetagri, Movimento dos Trabalhadores Rurais Sem Terra (MST), Coordenação das Associações das Comunidades Remanescentes de Quilombos do Pará (MALUNGU), rede ATER, Empresa de Assistência Técnica e Extensão Rural (EMATER), Central de Abastecimento do Estado do Pará (CEASA), Serviço Nacional de Aprendizagem do Cooperativismo do Estado do Pará (OCB-PA), Conab, Sedap, Delegacia Federal de Agricultura do Pará (DFDA-PA) e CPORG. Há também a possibilidade de serem convidadas instituições da sociedade civil como: ONG FASE, Comissão Pastoral da Terra (CPT), Movimento Camponês Popular (MCP) e rede Jirau. Os grupos de interesse podem ser diferenciados entre a agroecologia tipo "ecologização" do agronegócio, de um lado, e da agroecologia mais política dos movimentos sociais, de outro. A composição desses dois grupos é a seguinte: i) o grupo ecologização do agronegócio é constituído por CEASA, OCB-PA, Conab, Sedap, DF-PA, CPOrg e; ii) o grupo da agroecologia mais política é composto por Embrapa, UFPA, CNS, Fetagri, MST, Malungu, rede ATER e EMATER. Existem intermediários entre os dois grupos como a EMATER, a Sedap e pessoas específicas do CEDRS. Devido ao período curto de sua institucionalização os resultados deste espaço ainda não são percebidos. Pelo menos, até junho de 2019, esta divergência se faz pelo menos sem oposição forte entre os grupos.

Como não houve institucionalização da política pública de agroecologia e produção orgânica a delimitação da análise não incorporou alguns elementos da matriz interpretativa comum deste livro. Nesse sentido, não foram analisados os atores-chaves na implementação da PEAPO (pós-institucionalização), o modelo de governança/gestão da política e os instrumentos desenvolvidos. 
Portanto, essa delimitação resulta da aplicação coerente da matriz interpretativa com as particularidades da trajetória de institucionalização da agroecologia e produção orgânica no estado Pará.

\section{Considerações finais}

No Pará, a trajetória de institucionalização da agroecologia e produção orgânica se traduziu no atual contraste entre a riqueza de experiências históricas e atuais em relação à fragilidade no âmbito da ação pública. As ideias agroecológicas surgem no estado, em meados de 1980, por meio das agriculturas alternativas, uma década depois de estar em circulação no nível nacional. A ação das ONGs na década de 1990 influenciou na entrada de pessoas alinhadas à agroecologia em instituições como a EMATER, a UFPA, nos atuais IF's e a Embrapa. Na década de 2000 os movimentos sociais assumem a agroecologia como temática estratégica, emergindo de forma tardia em relação aos estados do Sul do País, principalmente em função de alguns movimentos encontrarem pouca consonância com a agroecologia. Destacamos assim, ao longo da sua trajetória no estado, a fraqueza da ação pública, apesar de momentos políticos específicos, como foi o caso no governo Julia (2006-2010). No período de 2010 a 2016, a conjuntura nacional de ampliação das políticas de promoção da agroecologia implicou em um movimento de acesso das organizações estaduais (públicas e da sociedade civil) para estas políticas. Por isso, as ações de reivindicação de políticas públicas estaduais não foram priorizadas.

Entre os desafios para o avanço das ideias agroecológicas no estado figura como relevante a necessidade de ação articulada em nível estadual entre as organizações alinhadas à agroecologia. Este aspecto é relevante por representar um fator limitador na reivindicação de políticas estaduais de agroecologia. Esse é um desafio que as organizações estão procurando enfrentar desde o ano de 2015 a partir da realização de eventos como congressos e seminários. A maior articulação das organizações também enfrenta dificuldades como a extensão do estado e as condições logísticas desafiadoras. Além disso, a diferenças regionais internas implicam em dinâmicas específicas e demandas diferenciadas.

Embora seja possível identificar avanços em termos de ação conjunta (como no caso da criação de redes territoriais), permanece a situação de distanciamento entre as organizações no nível estadual. Nesse sentido, existem grupos que realizam ações de promoção da agroecologia e agricultura orgânica no estado e têm interesse na construção de políticas estaduais de agroecologia e produção orgânica. Porém, estes grupos de interesse estão desarticulados no 
nível estadual, realizando ações isoladas, com pouca incidência na reivindicação de políticas públicas.

Como resultado da trajetória histórica da institucionalização no Pará, a PEAPO ainda não está em construção em função de três fatores: 1) o frágil envolvimento/disposição do governo estadual do Jatene com esta temática; 2) a incipiente mobilização da sociedade civil; 3) instituições, como a CPOrg, que tinham legitimidade para propor, não animou nenhum processo de construção do plano. Além disso, identificam-se visões contrastantes entre a produção orgânica, mais movida pela ação governamental com um conteúdo programático caracterizado por repertórios padronizados e empreendedores, enquanto a agroecologia é mais alinhada aos movimentos sociais e com uma visão integrada. Observa-se que entre a agroecologia e a agricultura orgânica, o tipo de produção, de agricultores, de mercados e consequentemente de visões são diferentes.

O posicionamento do atual governo (2019) ainda é incerto. Porém, o contexto de primeiro mandato sugere abertura a concessões para permanecer no poder, indicando maior sensibilidade do atual governo à construção da PEAPO em relação ao anterior. Além disso, o atual governador (MDB) possui uma trajetória populista, sugerindo postura mais flexível que a gestão passada. Essa postura se traduz em primeiro lugar pela manutenção do Conselho Estadual de Desenvolvimento Rural Sustentável e pela criação da CTAPOS. A elaboração da Política Estadual para Agroecologia e Produção Orgânica e da Sociobiodiversidade faz parte da agenda de trabalho da CTAPOS. No momento da finalização desse texto foi convocada uma reunião dessa comissão (Ofício Circ. $\mathrm{N}^{\circ}$ 08/2019 - CEDRS/PA/SEDAP) para elaboração da referida política. Além deste cenário interno do estado, a nova conjuntura de fragilização das políticas nacionais de agroecologia indica também o surgimento de um novo cenário, com movimentos tanto de acesso quanto de reivindicação na esfera estadual. Este processo mudaria o tipo de ação pública. De fato, quando ela funcionou nos ciclos políticos favoráveis, ela foi muito mais dirigida pelo estado com injunções fortes, por exemplo, no caso dos territórios da cidadania. A atuação forte dos movimentos sociais e a sua capacidade de atuar conjuntamente ao nível estadual prefiguraria uma ação pública realmente híbrida onde os movimentos sociais sejam capazes de intervir diretamente na construção de uma agenda política em favor da agroecologia. 


\section{REFERÊNCIAS}

ALEPA, Assembleia Legislativa Paraense. Deputado aprova projeto de lei para saúde e segurança do trabalhador. Disponível em: $<$ http://www.alepa. pa.gov.br/Noticia/193145/deputado-aprova-projeto-de-lei-para-saude-e-seguranca-do-trabalhador>. Acesso em: 10 jun. 2019.

ALMEIDA, L. L. Sindicalistas e pesquisadores na região de marabá: uma análise do centro agroambiental do Tocantins (CAT). 2011. Dissertação (mestrado) - Universidade Federal Rural do Rio de Janeiro, Instituto de Ciências Humanas e Sociais, 2011.

ASSIS, W. S. A construção da representação dos trabalhadores rurais do sudeste paraense. 2007. Tese (Doutorado) - CPDA/UFRRJ, Rio de Janeiro, 2007.

BASA. PRONAF - Agroecologia. Disponível em: <http://www.bancoamazonia.com.br/index.php/financiamentos 1/agroecologia $>$. Acesso em: 20 ago. 2018.

FBB. Fundação Banco do Brasil. Disponível em: < https://fbb.org.br/pt-br/ component/k2/tag/ecoforte\%20extrativismo>. Acesso em: 25 fev. 2019.

FLICK, Uwe. Introdução à pesquisa qualitativa-3. Artmed editora, 2008.

GARRIDO, F. G. Ecología política y agroecología: Marcos cognitivos y diseño institucional. Agroecología, v. 6, p. 21-28, 2011.

GTNA, Grupo de Assessoria em Agroecologia na Amazônia. 10 anos trabalhando pela Agroecologia. BELÉM, 2004.

GUÉNEAU, S. et al. A construção das políticas estaduais de agroecologia e produção orgânica no Brasil. Revista Brasileira de Agroecologia, v. 14, n. 1, 2019, sob prelo.

HIRATA, M. F. Proambiente: um programa inovador de desenvolvimento rural. Agriculturas, v. 3, n. 1, abr. 2006.

IDEFLOR-BIO. Programa Pro-Saf. Disponível em: <http://ideflorbio.pa.gov. br/blog/project/projeto-prosaf-acara/>. Acesso em: 15 jul. 2018. 
KINGDON, J. W. Agendas, alternativas and public policies. 2. ed. Ann Arbor: University of Michigan, 2003.

KNEZ, S.; SOUSA, S.; PENNA, T. Relatório do Seminário Regional de Agroecologia e Produção Orgânica. Secretaria Nacional de Articulação Social. jun. de 2018.

LASCOUMES P.; LE GALES, P. Sociologia da ação pública, Maceió, Edufal, 2012.

NASCIMENTO, H. F. do. Transição agroecológica: sonho ou realidade? Uma reflexão do Pólo Rio Capim do PROAMBIENTE. 2009. Tese (Dissertação de Mestrado) - INEFA/UFPA, 2009.

NETO, P. S. F; SILVA, R. C. Processo de construção da sustentabilidade em São Félix do Xingu-PA. Belém: Instituto Internacional de Educação do Brasil - IEB, 2014.

NOVAES, H. T. Qual autogestão? Revista da Sociedade Brasileira de Economia Política, v. 18, p. 70-95, 2008.

PETERSEN, P. F. Metamorfosis agroecológica: Un ensayo sobre agroecología política. 2011. Tese (Master en Agroecología: un enfoque para la sustentabilidad rural) - Universidad Internacional de Andalucía, 2011.

PROATER. Programa de Assistência Técnica e Extensão Rural Pública do Estado do Pará. Governo do Estado do Pará. Empresa Estadual de Assistência Técnica e Extensão Rural do Estado do Pará (EMATER-PA). Fevereiro de 2005.

RODRIGUEZ V. da C. Ideias, Interesses e Institucionalizações: Propostas de fortalecimento da Agroecologia nos Territórios da Cidadania no Estado do Pará. 2019. Dissertação (Mestrado) -Programa de Pós-Graduação em Agriculturas Amazônicas, Instituto Amazônico de Agriculturas Familiares, Universidade Federal do Pará, Belém, 2019.

SCALABRIN, R.; ARAGÃO, A. L. A. Curso de agronomia do campus universitário de marabá: diálogo na construção do conhecimento. Terceira Margem Amazônia. Disponível em: $<$ https://scholar.google.com.br/scholar?hl=pt-BR\&as_sdt $=0 \% 2 \mathrm{C} 5 \& \mathrm{q}=\mathrm{CURSO}+\mathrm{DE}+\mathrm{AGRONOMIA}+\mathrm{DO}+\mathrm{CAMPUS}+\mathrm{U}-$ NIVERSIT $\%$ C3\%81RIO+DE+MARAB $\%$ C3\%81\%3A+DI\%C3\%81LOGO+-

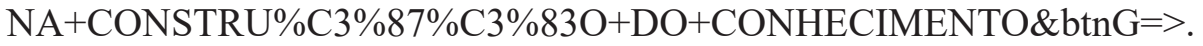
Acesso em: 30 ago. 2018. 
SILVA, F. S.; GOMES, R. C. A construção social da agroecologia na Amazônia: um olhar sobre a realidade paraense. 2014. Trabalho Acadêmico de Conclusão de Curso (TACC de Agronomia) - IFPA, Campus Castanhal, 2014.

TILLY, C. From mobilization to revolution. Boston: Wesley Publishing Co., 1978.

VASCONCELOS, T. Conselho de educação recebe casas familiares rurais. Disponível em: <http://www.cee.pa.gov.br/?q=node/482>. Acesso em: 20 jul. 2018. 


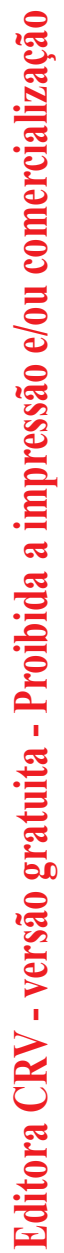

\section{REGIÃO NORDESTE}




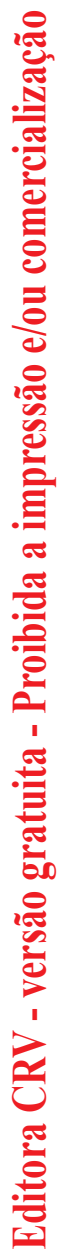




\title{
CAPÍTULO 8 \\ POLÍTICA DE AGROECOLOGIA \\ NA BAHIA: o diálogo na \\ construção da ação pública
}

\author{
Mario Lucio de Avila \\ Carlos Eduardo de Souza Leite
}

\section{Introdução}

A proposição de uma Política Estadual de Agroecologia e Produção Orgânica (Peapo) na Bahia está sedimentada numa estratégia ampla de enfrentamento e de desafios, a qual mobiliza diferentes setores da sociedade civil, movimentos produtivos e organizações populares. A presença de uma coalizão com forte componente técnico e político, pautada na segurança e soberania alimentar, na convivência com o semiárido e na resiliência dos sistemas agrícolas, na territorialização do desenvolvimento e na manutenção de direitos, associado ao maior número de agricultores familiares no país, é importante para assegurar uma estratégia política na condução das tratativas visando a consolidação legal da proposta.

A agenda em construção da política baiana de agroecologia e produção orgânica é, ao mesmo tempo, conquista e resultado de um conjunto de esforços das organizações e movimentos sociais e produtivos, das interfaces entre ações públicas na esfera federal e estadual, de articulações envolvendo agricultores e agricultoras familiares, povos e comunidades tradicionais, legislativo e executivo estadual e federal, universidades e institutos de ensino, organismos internacionais e consumidores.

Esse conjunto de atores, partilha ideias e interesses que, por diferentes caminhos, produzem as representações sobre o tema e traduzem diferentes esforços na tentativa de consolidar uma política estadual capaz de abarcar as regras do jogo político e fortalecer as estratégias para a promoção da agroecologia. E, também, enfrentar ou ao menos, minimizar os impactos do avanço das atividades de baixa resiliência e sustentabilidade agrícola, mas que contam com amplo apoio do Estado nacional, representados pela bancada ruralista que advoga a favor de latifundiários, grileiros, empresários e setores progressistas e conservadores do agronegócio brasileiro indiscriminadamente.

O Projeto de Lei (PL) n $\left.{ }^{\circ} 21.916 / 2016\right)$ contém a proposta de uma Lei de Agroecologia e Produção Orgânica que tramita na Assembleia Legislativa da Bahia com apoio forte da bancada do Partido dos Trabalhadores (PT) e alguns 
outros deputados favoráveis ao tema. Não há, por sua vez, um esforço contrário de outras bancadas em inviabilizar o PL, mas ainda não houve adesão ampla para sua aprovação. O governo estadual também do PT, em seu segundo mandato demonstrou interesse em apresentar a proposição pela via do executivo, mas até o momento não o fez.

Este contexto de construção de agenda política como resposta aos anseios sociais é o objeto deste capítulo que busca compreender a construção da Peapo no estado da Bahia e como a ação pública se constitui.

O texto conta com cinco seções além dessa introdução. Inicia com um breve histórico da agricultura familiar e da territorialização do desenvolvimento estadual; em seguida, apresenta-se os atores chaves na promoção da agroecologia no estado e a trajetória da agroecologia na Bahia; traz ainda seções sobre as concepções da agroecologia e as instituições, instrumentos e representações identificadas na pesquisa e breves considerações finais.

Do ponto de vista analítico, para entender as dinâmicas e os processos de institucionalização da agroecologia ao nível estadual, optou-se por adaptar um quadro de análise conhecido como o pentágono da ação pública (LASCOUMES; LE GALÈS, 2012), o qual inclui cinco variáveis: atores, instituições, ideias, processos e resultados.

A abordagem da ação pública rompe com os modelos tradicionais de análise de política pública à medida que a ação pública demonstra não existir: i) sucessão necessária e suficiente entre alterações de leis e transformação da política; ii) unicidade do Estado, já que ele é permeado por diversos grupos com capacidade de bloquear reformas; iii) imparcialidade nas decisões do Estado, já que ele é permeado por diversos grupos e atores, inclusive atores ocultos, os quais atuam com diversas estratégias que podem bloquear ou modificar as políticas públicas de acordo com seus interesses.

Uma matriz comum de análise foi utilizada como ferramenta para harmonizar a pesquisa e permitir a comparação dos achados com outras unidades da federação. No caso baiano, optou-se por manter a análise na categoria dos atores, instituições e das representações, uma vez que a lei ainda não foi aprovada.

A pesquisa foi realizada a partir de informações coletadas por meio de análise documental e de entrevistas semiestruturadas com atores e gestores, além da contribuição direta de informantes que dedicaram esforços na reflexão e escrita do texto. As entrevistas foram realizadas durante o mês de dezembro de 2018 e completadas durante o mês de março de 2019.

É importante ressaltar que a semelhança de outras unidades da federação, na Bahia a promoção da agroecologia se dá majoritariamente por vias não governamentais, mas que alcançam espaços e repercussões nos espaços governamentais. 
Desta forma, destaca-se um conjunto de atores que consolidaram estratégias de redes para fortalecer ações e empreender esforços na agenda política visando institucionalizar a questão agroecológica, angariaram apoio no espaço acadêmico e alcançaram eco na agenda política. O movimento agroecológico da Bahia possui uma articulação estruturada e incide de maneira muito forte na agenda política criando condições favoráveis para o surgimento da Peapo.

Embora ainda não se tenha uma Política Estadual de Agroecologia e Produção Orgânica, a Bahia tramitou o projeto de Lei $n^{\circ}$ 20.114/2012 de autoria do Deputado estadual Paulo Azi e mais recente o projeto de Lei $\mathrm{n}^{\circ}$ 21.916/2016 de autoria do Deputado estadual Marcelino Gallo que institui a Peapo. No dia mundial do Meio Ambiente (05/06/19) diversas organizações, redes, articulações e movimentos sociais se reuniram em Salvador, capital do estado pedindo a aprovação do PL.

No âmbito do executivo, o Partido dos Trabalhadores governa o estado desde o ano de 2007 e tem nas suas instâncias legais, como a Secretaria de Desenvolvimento Rural (SDR), a Superintendência Baiana de Assistência Técnica e Extensão Rural (Bahiater) e a Companhia de Desenvolvimento e Ação Regional (CAR), organizações ligadas a extensão e assistência técnica e execução de ações no espaço rural que contemplam a agroecologia em seus domínios de conhecimento.

\section{Um breve histórico da Agricultura familiar e agroecologia na Bahia: território e desenvolvimento}

A Bahia é diversa e tipicamente rural, possui o maior número de agricultores/as familiares do país, tendo mais de 760 mil agricultoras e agricultores familiares (IBGE, 2017), além disso 90\% dos municípios baianos possuem características rurais, podendo ser considerados municípios rurais. Esse contingente correspondendo a $87 \%$ dos estabelecimentos agrícolas do estado. O valor bruto da produção dessas famílias ultrapassa $\mathrm{R} \$ 3,7$ bilhões. Os principais alimentos fornecidos por esses trabalhadores são feijão (83\%), carne suína (76\%) e milho (44\%). Ainda, sabe-se que $90 \%$ do cacau produzido no estado advém da agricultura familiar e $70 \%$ do cacau brasileiro provem da Bahia.

Dados do IBGE (2017) apontam que 373 dos 417 municípios do estado realizam algum tipo de ação ou programas de apoio à agricultura familiar em 2017. O governo do estado atualmente oferta, para mais de 140 mil famílias de comunidades rurais do estado da Bahia, o serviço de assistência técnica e extensão rural (Ater).

Grande parte do incentivo a agricultura familiar na Bahia vem do reconhecimento das diferenças regionais que o estado apresenta. Borges e 
Serpa (2012, p. 35) escrevem que "a nova regionalização institucional implementada pelo governo do Estado da Bahia, a partir do ano de 2007, baseia-se em uma nova divisão regional para o espaço baiano, sustentada na ideia de “territórios de identidade". Conforme Perafán e Oliveira (2013, p. 17):

Desde 2007, o Governo da Bahia trabalha com a abordagem territorial e busca "identificar prioridades temáticas definidas a partir da realidade local, possibilitando o desenvolvimento equilibrado e sustentável entre as regiões". Na Bahia existem, atualmente, 27 Territórios de Identidade, constituídos a partir da especificidade de cada região. Com base numa consulta popular as comunidades, a partir de seu sentimento de pertencimento e representações sociais, identificaram tais territórios, que são unidades de planejamento das políticas públicas do Estado (PERAFÁN; OLIVEIRA, 2013, p. 17).

Assim, o território passa a ser concebido como unidade de planejamento e execução das políticas públicas levando em consideração a participação dos atores sociais e suas demandas. Neste caso, a agricultura familiar e a agroecologia ganham voz e vez.

\section{Atores chaves na promoção da agroecologia e produção orgânica na Bahia}

A construção da agroecologia no estado da Bahia remonta aos anos 80, com os movimentos de agricultura, agricultores, agrônomos, estudantes e distintas organizações que se envolviam com a produção agrícola como forma alternativa de produção e vida. Estão nesta lista sobretudo profissionais e organizações ligadas a igreja e aos movimentos populares, as organizações de estudantes de agronomia, os profissionais heterodoxos das agências de assistência técnica e extensão rural oficial e pesquisadores com experiências internacionais.

Embora estes atores sejam listados como figuras chaves no processo, muitos outros grupos e forças se alinharam e atuam na trajetória de defesa dos seus interesses e do campo da agroecologia e produção orgânica usando temas que se misturam, como as sementes crioulas, as feiras da agricultura familiar, os territórios rurais, as pautas da segurança e soberania alimentar e temáticas socioambientais, entre elas a água, a caatinga, o cerrado, a mata atlântica e o semiárido. Os trabalhadores e trabalhadoras rurais em seus movimentos como Movimento dos Sem Terra (MST), Confederação Nacional dos Trabalhadores na Agricultura (Contag) e afins também adotaram perspectivas agroecológicas em suas pautas e reforçam os esforços. 


\section{A trajetória da agroecologia na Bahia}

A trajetória de construção da Agroecologia na Bahia tem seu marco temporal no início dos anos 80, com o I Encontro Estadual de Agricultura Alternativa, em 1985. Ali se buscava reunir um conjunto de experiências dispersas nas diferentes regiões do estado da Bahia e seus respectivos biomas (Caatinga e Mata Atlântica, principalmente). Esta iniciativa foi organizada pelo Projeto Tecnologias Alternativas (PTA), ligado à Federação de Órgãos para Assistência Social e Educacional (Fase) Nacional, neste período, na Bahia, vinculado ao Movimento de Organização Comunitária (MOC), em Feira de Santana.

Com a reestruturação da Rede PTA Nacional, em 1988, a equipe do PTA FASE na Bahia passa a constituir o Serviço de Assessoria a Organizações Populares Rurais (Sasop). Recém fundado, o Sasop passa a priorizar a estratégia de identificação de experiências locais com potencial de expansão em diferentes regiões do estado, particularmente, na região de Irecê, onde é criado o Centro de Assessoria do Assuruá (CAA) e o Grupo de Apoio e Resistência Rural e Ambiental (Garra). No Extremo Sul, é criado o Terra Viva - Centro de Desenvolvimento Agroecológico. O Sasop passa a atuar nos Territórios do Sertão do São Francisco e no Baixo Sul da Bahia.

O processo de fortalecimento de novos atores locais de promoção da Agroecologia nos anos 90, deu início a criação da Rede de Intercâmbio em Agroecologia (RIA) que dinamizou, nesta década, os intercâmbios de experiências, processos de experimentação participativa e a ação em rede. Neste mesmo período é criado o Instituto da Pequena Agropecuária Apropriada, em Juazeiro-BA.

As organizações vinculadas a Articulação Semiárido (ASA Bahia) possuem aproximação mais recente com o tema, no entanto, suas estratégias de convivência com o semiárido são expressões da Agroecologia. Destacam-se a Cooperativa de Assistência à Agricultura Familiar (Cofaspi), o Centro de Convivência e Desenvolvimento Agroecológico do Sudoeste da Bahia (Cedasb), a Associação do Semi-Árido da Microrregião de Livramento (Asamil) e o Centro de Agroecologia no Semiárido (Casa), além do Irpaa, MOC, Sasop e outras.

Com a criação de um conjunto de organizações de assessoria à agricultura familiar no Semiárido e na Mata Atlântica, adotando o enfoque agroecológico, há uma expansão da proposta para além das experiências locais. Na primeira, década dos anos 2000, no plano nacional, ocorreu o surgimento da ANA (Articulação Nacional de Agroecologia). Sua principal estratégia inicial foi a valorização das experiências locais de promoção da agroecologia sob o protagonismo de agricultores e agricultoras experimentadores. Neste sentido, há uma sinergia entre as dinâmicas nacionais e as dinâmicas territoriais e estaduais. No Nordeste, a ASA passa a ser o espaço articulador dos momentos de mobilização para os Encontros Nacionais de Agroecologia, os ENAs, e na Bahia, não é diferente: a ASA 
mobilizou as organizações e agricultores experimentadores para participação no II ENA, em Recife-PE no ano de 2006.

Com a expansão das experiências nos territórios da Mata Atlântica, para além da região Semiárida baiana, e a necessidade de aprimorar a construção de conhecimentos no campo da agroecologia, assim como promover uma incidência no campo das políticas públicas, um conjunto de organizações decide pela criação da Articulação de Agroecologia na Bahia (AABA), em 2012. Esta articulação surge com o foco principal de dar visibilidade aos desafios de construção de ações, programas e de uma política voltada para a promoção da agroecologia no estado.

Com o surgimento da Aaba, outros espaços de construção de agroecologia vão se visibilizando como a "Teia dos Povos" e, mais recentemente, a Rede Povos da Mata de Agroecologia. Ambas iniciaram sua ação na Mata Atlântica baiana. A força do campo agroecológico se intensifica com redes e articulações de diferentes origens, que vão construindo objetivos e estratégias comuns.

O ápice deste processo se deu no II Encontro Estadual de Agroecologia, em maio de 2018, com o tema "Diálogo entre Biomas", neste momento congregando diferentes redes, articulações e movimentos sociais.

Outra vertente importante de construção da agroecologia na Bahia se dá por meio da interação entre o ensino, a pesquisa e as experiências de promoção da Agroecologia. Surgem na Bahia os Núcleos de Estudos em Agroecologia (NEAs) e muitos destes apoiados pela Rede Nordestina de NEAs (Renda). Inicia-se uma nova etapa de construção de conhecimentos e aproximação do mundo acadêmico e dos saberes práticos. Outras inciativas do campo acadêmico são os Congressos Baianos de Agroecologia.

A trajetória recente dos eventos e movimentos em favor da agroecologia na Bahia possuem um aspecto ampliado, estratégia de fortalecimento em múltiplas vias de ação que se fortalecem no tempo. A figura 01 ilustra os principais momentos que constituem a ação pública.

$\mathrm{O}$ aspecto mais importante da construção agroecológica da Bahia resulta da construção de diferentes ações no plano político de um conjunto de iniciativas que reforçam o tema. Do lado da sociedade civil, foram realizados distintos eventos e ações como os Encontros Estaduais de Agroecologia, os Seminários estaduais de agroecologia e produção orgânica, as Jornadas de Agroecologia da Bahia promovidas pela Teia Agroecológica dos Povos da Cabruca e Mata Atlântica, Encontros de Sementes e Mudas Crioulas e Atos públicos como o realizado em 2015 em Juazeiro (BA) e Petrolina (SE) cuja pauta era "Semiárido Vivo, nenhum direito a menos!".

$\mathrm{Na}$ esteira dessas iniciativas, foram constituídas a Articulação de Agroecologia da Bahia em 2012, a Rede de Agroecologia Povos da Mata no ano de 2015 e no ano de 2018 um encontro dessas expressões da agroecologia no II Encontro Estadual de Agroecologia com o título de "Diálogo entre Biomas". 
De maneira esquemática, apresentamos a seguir as ações ocorridas no âmbito público, das políticas e ações do Estado, ciente, no entanto, do papel fundamental desempenhado pela sociedade organizada para o avanço e consolidação dessas inciativas. O encontro do Fórum Baiano de Agricultura Familiar em 2010 culminou com a aprovação da Política Estadual de Assistência Técnica e Extensão Rural em 2012. A criação da Secretaria de Desenvolvimento Rural em 2014 e a constituição dos Serviços Territoriais de Apoio à Agricultura Familiar (Setaf) em 27 territórios rurais da Bahia e a aprovação da Lei Estadual de Convivência com o Semiárido no ano de 2016 e mais recentemente as iniciativas voltadas para as sementes e mudas crioulas cuja política está em construção no estado.

Observa-se que as ações do estado da Bahia são construções basilares para o fortalecimento da agroecologia enquanto ciência, política e arranjo produtivo. As iniciativas em relação a convivência com o semiárido propostas pelo Fórum de Convivência com o Semiárido, as ações do Fórum de Agricultura Familiar e as da Articulação de agroecologia são construções que tecem uma teia de sustentação para a futura Peapo.

\section{Figura 1 - Eventos mais importantes para a agroecologia na Bahia nos anos recentes}

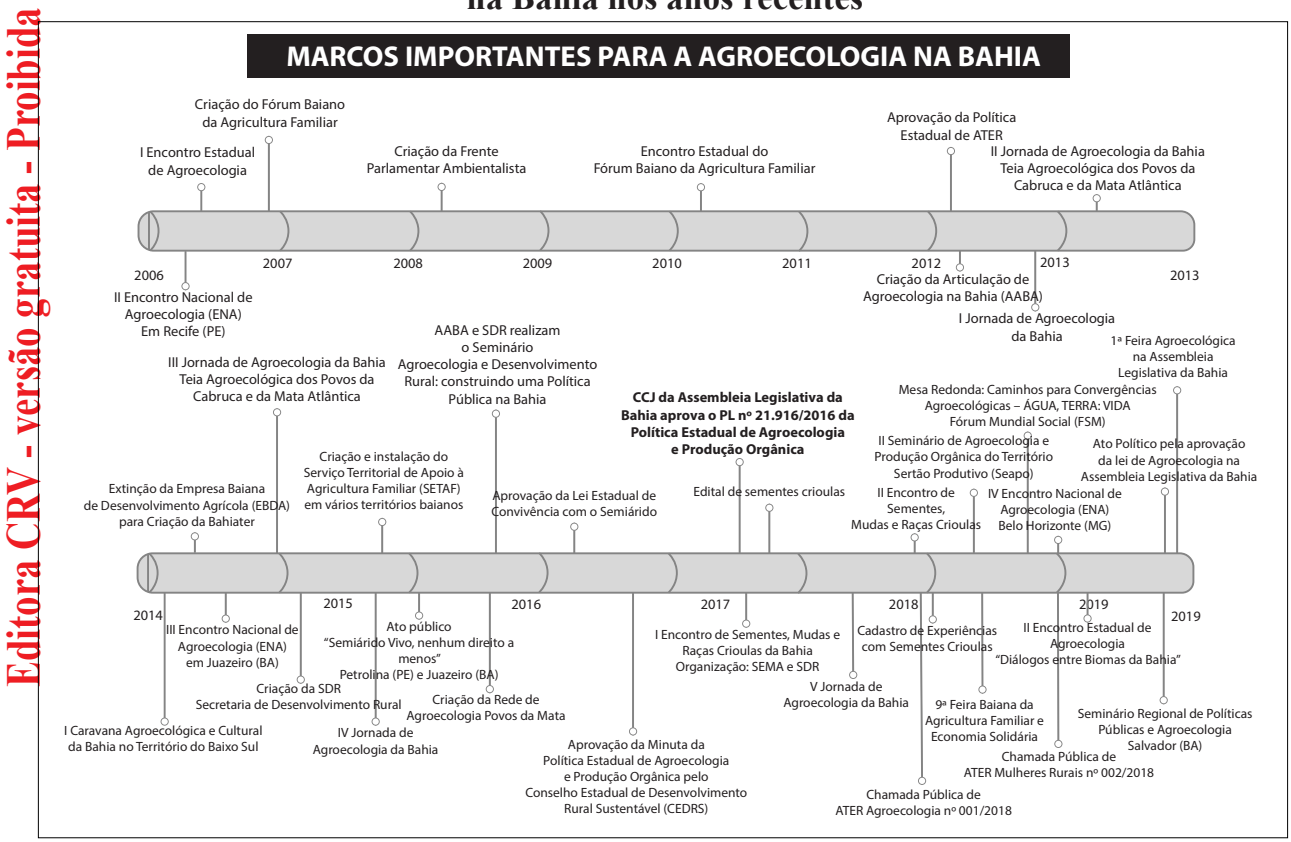

\section{Concepções da agroecologia prevista na Pleapo}

Assim como ocorreu no restante do Brasil, as nomenclaturas reconhecidas em relação ao tema eram divergentes, tais como agricultura ou agricultores 
orgânicos ou biológicos, agricultura alternativa ou sistêmica, mas o mais importante é que a noção de agroecologia que hoje se consolida se tornou uma espécie de plataforma comum para a crítica e construção de alternativa aos modelos de agricultura convencional.

Se no âmbito dos atores sociais a unanimidade do conceito ainda é objeto de disputa, sobretudo entre setores da academia e organizações e movimentos sociais, no espaço legal a influência da Política Nacional de Agroecologia e Produção Orgânica (Pnapo) é evidente.

O conceito de agroecologia proposto no PL em tramitação defende que agroecologia é "ciência ou campo do conhecimento transdisciplinar que estuda os agroecossistemas, fundamentada em conceitos, princípios e metodologias, visando o desenvolvimento das relações entre capacidade produtiva, equilíbrio ecológico, equidade social e uso e conservação da biodiversidade e dos demais bens naturais por meio da articulação entre conhecimento técnico-cientifico, saberes e fazeres ancestrais e culturas populares e tradicionais com foco na sustentabilidade".

Ainda que a concepção exposta no preâmbulo do PL evidencie apenas duas vertentes do conceito: a dimensão técnico-produtiva e a articulação entre ciência e prática, a estratégia das articulações da Peapo assume que esta possui papel de articuladora e promotora de desenvolvimento nas diretrizes e nos instrumentos estabelecidos com um arranjo de governança ampliado e participativo.

A concepção da Peapo baiana traz alguns temas que inovam quando colocada em perspectiva a outras unidades da federação. Dentre as diretrizes, o reconhecimento da diversidade étnica e a valorização das comunidades tradicionais, a sócio e a agrobiodiversidade, além da perspectiva das raças crioulas. Ainda, ressalta-se que as diversas abordagens sociais (economia solidária, organizações sociais, cooperativas e associações) são contempladas neste desenho, abrigando, portanto, número amplo de beneficiários diretos e indiretos da respectiva Política.

Alguns temas contidos nos debates da sociedade civil e do governo estão presentes na proposição. No entanto, alguns são mais permeáveis na agenda política como as compras públicas, a territorialização das políticas e a assistência técnica. Outros, como os agrotóxicos e as questões fundiárias mobilizam reações mais fortes de setores do legislativo e são mais difíceis de serem absorvidos na Peapo.

A territorialização das políticas públicas já é uma conquista do povo baiano desde 2003 e recebeu grande contribuição nos estudos do economista Vitor de Athayde Couto Filho estudada nos anos de 2007 (Couto Filho, 2007). Em sua obra, o autor apontava a agroecologia como aspecto importante das inovações no rural baiano: 
Os princípios agroecológicos representam, na realidade, um avanço da chamada agricultura alternativa, que surgiu como reação à agricultura convencional. É alternativa no sentido de oposição à agricultura baseada na química e na mecânica dos "pacotes tecnológicos" (COUTO FILHO, 2007, p. 42).

Para Couto Filho (2007, p. 42), “os sistemas produtivos agroecológicos partem da realidade de cada comunidade e das pessoas aí inseridas". Neste sentido, a territorialização é o princípio básico para o desenvolvimento rural do estado e aí reside a maior diferença da construção agroecológica da Bahia em relação ao demais entes federativos.

Em face desta perspectiva, surgem os demais temas que a Peapo contempla como inovadores: o recaatingamento, a convivência com o semiárido e a incorporação de raças tradicionais de gado e pequenos ruminantes como patrimônio genético a ser mantido, da mesma forma que previsto para sementes e mudas e diálogo e o reconhecimento das diferenças dos povos e dos biomas como a maior expressão da agroecologia baiana.

\section{Instituições, instrumentos representações e resultados}

As instituições são as instituições propriamente ditas e também normas, regulamentos, procedimentos, sequências de ações padronizadas e coordenadas entre si que medeiam ou enquadram as interações na ação pública. Isso porque a ação pública tem necessidade de regras para as atuações e representações que vão permitir aos atores posicionar-se, coordenar-se, e agir de forma previsível. São também instituições as formas que estabilizam o modo de cooperação entre os atores.

Dessa ótica, a Articulação Nacional da Agroecologia (ANA) desempenha um papel preponderante no campo político e sua articulação ao construir os significados e ações que as diferentes redes, organizações e movimentos em nível estadual desempenham.

As representações por sua vez, são as ideias, interesses, espaços cognitivos e normativos que dão sentido às ações dos atores, as condicionam e as refletem e ainda, consideram as estratégias dos atores para se apropriarem das regras, trabalhar com elas ou as evitar. A noção compartilhada entre sociedade civil organizada e setores do legislativo e executivo do governo estadual quanto a importância de uma Peapo é a representação do esforço coordenado pela ANA com importantes contribuições de outros arranjos como a ASA, o Fórum Baiano de Agricultura Familiar, as ações em favor das sementes, raças e mudas crioulas e demais esforços com importante articulação feita pelo 
Sasop. Esta representação se institucionaliza como a Articulação de Agroecologia na Bahia.

Por fim, quanto aos instrumentos previstos, na promoção do tema, o estado da Bahia poderá usar instrumentos econômicos, fiscais ou tributários que favoreçam a agroecologia fortaleça estas iniciativas. Apontam-se caminhos, mas não há segurança que eles serão trilhados.

Embora exista ainda possibilidade de alterações legais do Projeto em tramitação, sobretudo se o governo resolver apresentar novo texto por via do executivo, a expectativa é que haja poucas mudanças no conteúdo do texto. Dentre os instrumentos previstos estão aqui listados os principais com suas temáticas.

- Gestão do conhecimento agroecológico: pesquisa, treinamento, assistência técnica e extensão rural, atuação das NEAs, fortalecimento de organizações e redes (Programa Ecoforte);

- Financiamento, principalmente programas de crédito ao produtor, algumas ferramentas para subsídios a organizações e serviços técnicos de extensão (Ater);

- Comercialização: mercados e feiras, programas de compras públicas, valorização dos produtos e informações ao consumidor;

- Instrumentos regulatórios: certificação, leis de sementes locais e crioulas, condicionalidades ambientais, espaços de negociação (conselhos e colegiado territoriais), leis e políticas fundiárias (terras indígenas, quilombolas etc.).

No tocante as inovações, a Bahia traz no bojo de seu Projeto de Lei alguns instrumentos importantes. A especificidade regional já executada pela ação da assistência técnica estadual pelos Setafs prevê a regionalização do desenvolvimento no estado. Vale ressaltar que a Bahia possui cinco biomas diferentes: Cerrado, Caatinga, Mata Atlântica, Zona Costeira e Marinha, fazendo do estado um mosaico de experimentação e diversidade que a Peapo procura reconhecer e considerar.

O alcance e ação dos instrumentos da Peapo prevê a programação paritária e articulação nos conselhos municipais de desenvolvimento rural sustentáveis, colegiados territoriais e fóruns da ASA; leis de sementes locais, recuperação das áreas degradadas caatinga (BA) e o fomento ao desenvolvimento de iniciativas de máxima resiliência nos biomas.

A valorização dos produtos da sociobiodiversidade e defesa de direitos dos povos tradicionais está contemplada tanto nas ações dos movimentos e organizações sociais quanto na previsão legal. 


\section{Considerações finais}

Embora os atores que articulam a criação da Peapo possuam espaços de diálogos, disputas e convivência no processo de definição da agenda, vale ressaltar que, oficialmente não se estabeleceram espaços desta natureza pois o modelo de governança proposto no PL possui certa distância desse arranjo que apontamos anteriormente. Significa dizer que os atores e a representações podem se (re)conformar conforme as definições institucionais se acomodarem no marco jurídico.

As instituições previstas na concepção do Peapo sugerem espaços com estas características, visando a promoção, valorização, reconhecimento e fortalecimento da participação. No tocante a coordenação com outras ações, o Plano (Pleapo), um dos principais instrumentos da Peapo sugere a intersetorialidade com os diferentes planos estaduais que possuem interface com o tema, no entanto não cita quais são esses planos.

Do diálogo entre as diferentes expressões da agroecologia no campo e na sociedade civil, emerge, com forte apoio da experiência nacional da Articulação Nacional de Agroecologia (ANA) e da Pnapo, a proposta de uma Peapo na Bahia. Essa proposta analisada aqui de forma preliminar, enquanto a lei não é sancionada, é importante pois em grande medida, ela (Peapo) será responsável por avançar na consolidação e assegurar espaços de disputas por orçamento, reconhecimento e engajamento da Bahia com a agricultura familiar e a agroecologia como ações de Estado e não apenas do governo atual. 


\section{REFERÊNCIAS}

BAHIA. Assembleia Legislativa. Projeto de Lei PL 21.916/2016. Institui Política Estadual de Agroecologia e Produção Orgânica Disponível em: <https:// www.al.ba.gov.br/fserver/:docs:Proposicoes2016:PL_21_916_2016_1.rtf $>$. Acesso em: 7 mar. 2018. Texto Original.

COUTO FILHO, V. de A. Agricultura familiar e desenvolvimento territorial: um olhar da Bahia sobre o meio rural brasileiro. Editora Garamond, 2007. v. 9.

LASCOUMES, P.; LE GALÈS, P. Sociologia da ação pública. Editora da Universidade Federal de Alagoas, 2012.

PERAFÁN, M. E. V.; OLIVEIRA, H. Território e identidade. Secretaria de Cultura do Estado da Bahia. P55 Edições: Salvador, BA, 2013. (Coleção Política e Gestão Culturais).

SERPA, A.; BORGES, S. O papel dos agentes públicos e da sociedade civil na implementação de políticas de desenvolvimento territorial no Estado da Bahia: uma análise preliminar. Geografares, n. 11, p. 31-59, 2012. 


\title{
CAPÍTULO 9
}

\section{QUANDO O MOVIMENTO TECE O \\ ESTADO: as ações públicas em Sergipe na construção de uma agricultura do "plantar, colher e comer sem agredir a natureza"}

\author{
Flaviane Canavesi \\ Edson Diogo Tavares \\ Mario Lucio de Avila
}

\section{Introdução}

A agricultura familiar (AF) em Sergipe conta com cerca de 100 mil estabelecimentos agrícolas, ocupando $26 \%$ da área agrícola e representando $90 \%$ das unidades de produção. Assim como em todo o nordeste brasileiro, esse sistema é o maior responsável pela produção de alimentos e pela ocupação de postos de trabalho no campo (TAVARES; SIQUEIRA; SILVA, 2008).

Um grande desafio que se apresenta à $\mathrm{AF}$ é como produzir, com inclusão social e utilizando de forma sustentável os recursos naturais, em especial o solo, os recursos hídricos e a agrobiodiversidade. Nesse contexto é preciso refletir sobre as possíveis definições de sustentabilidade na agricultura considerando a viabilidade de longo prazo, o suprimento das necessidades humanas de alimentos e de matérias primas e a garantia de renda dos agricultores familiares. Sem dúvida, essa agricultura só terá futuro se for parceira da natureza e responsável por um desenvolvimento local que gerencie os recursos naturais no longo prazo (TAVARES; SIQUEIRA; SILVA; 2008).

Apesar de características próprias, a AF em Sergipe revela a diversidade de modos de vida, de formas de ocupação do território e de organização social que, convivem e resistem, em suas formas próprias de viver, produzir e resistir. São camponeses, povos indígenas, quilombolas, pescadores, ribeirinhos, extrativistas, assentados da reforma agrária, citricultores, rizicultores, policultores, produtores de culturas alimentares (mandioca, feijão, milho, fruteiras) e de pequenos animais, em busca de formas de produção e gestão dos recursos que possam garantir suas vidas e as de suas famílias. Nesse processo de resistência se evidencia a luta histórica pela reforma agrária e as estratégias sociais e familiares, dentre as quais se destacam a organização social, a pluriatividade 
das famílias agricultoras e a necessidade de construção de alternativas de agricultura sustentável (SIQUEIRA; SILVA, 2008; LOPES, 2009).

Para além da produção e da ciência, é fundamental que a agenda política também reflita o anseio social por uma agricultura socialmente justa, em harmonia com a natureza, enraizada nas peculiaridades regionais e saudável para os consumidores. A agroecologia e a produção orgânica conquistaram na agenda nacional com a Política Nacional de Agroecologia e Produção Orgânica (Pnapo) em 2012 este reconhecimento que agora emerge com força nos estados brasileiros.

Este trabalho tem, portanto, o objetivo de apresentar a agenda política de agroecologia que se formou em nível subnacional, no estado de Sergipe, nordeste brasileiro. Pretendemos apresentar o contexto histórico político, as coalizões de atores e as formas de implementação para analisar um conjunto de dinâmicas de ação pública na institucionalização da Política Estadual de Agroecologia e Produção Orgânica (Peapo). Para isto discute basicamente o marco legal e aponta para os desafios nos mecanismos de gestão, uma vez que, somente recentemente inicia-se o trabalho da Comissão Estadual de Agroecologia e Produção Orgânica (Ceapo).

A ação pública em Sergipe caracteriza-se por um processo gradual ascendente de conquistas no marco legal, fruto da organização da sociedade civil, que se retroalimenta no processo de mobilizações, fortalece os sujeitos políticos e permite a integralização de agendas por parte do Estado. Esta realidade distingue-se se comparada às políticas e ações relativas à AF e meio ambiente no nível nacional que passam, a partir de 2016, por um desmonte sistemático (GUÉNEAU et al., 2019).

Em 29 de maio de 2018, o Decreto $n^{\circ} 40.051$ regulamenta a Lei $n^{\circ} 7.270$, de 17 de novembro de 2011, que dispõe sobre os incentivos à implantação de Sistemas de Produção Agroecológica pelos agricultores familiares do Estado de Sergipe, instituindo a Peapo e dando outras providências correlatas.

Este estudo volta-se para as políticas e programas estaduais visando entender quais são os atores, as conceituações da agroecologia e os principais processos de mobilização e coalizão por meio dos quais as ideias agroecológicas são incorporadas pela ação pública.

Pretende reunir as principais observações do processo de articulação e mobilização social que vai conformando a agenda de agroecologia no estado. $\mathrm{O}$ artigo retrata as perspectivas do estado de Sergipe no contexto atual considerando a efetividade de execução da Peapo, uma vez que o tema perde relevância nas políticas públicas federais.

A pesquisa foi realizada a partir de levantamento bibliográfico e documental e também por meio de dez entrevistas semiestruturadas com informantes chaves em novembro de 2018 nos municípios de Aracaju e São Cristóvão, estado de Sergipe. As entrevistas foram realizadas conforme termos de 
consentimento livre e esclarecido (TCLE) de posse da autora e dos autores. O roteiro possibilitou reunir informações com um conjunto amplo de sujeitos no âmbito dos grupos coletivos, movimentos sociais, redes sociotécnicas, conselhos, instituições de pesquisa, de ensino e órgãos governamentais. Foram ouvidos analistas, pesquisadores, extensionistas, docentes e lideranças buscando abarcar o máximo de percepções e histórico de atuação na implementação da Peapo.

As análises desta pesquisa visam captar a representação dos sujeitos com relação aos instrumentos de políticas públicas diante de uma problematização considerando que, segundo Lascoumes e Le Galès (2012), os instrumentos não são neutros e revelam singularidades históricas na estruturação de relações entre governantes e governados.

A figura seguinte apresenta os principais marcos temporais relativos ao tema no estado. É certo que diversas outras ações foram realizadas, mas não estão aqui representadas por limitações dos autores. Nos apêndices do capítulo há um quadro detalhado das atividades.

Figura 1 - Linha do tempo da ação pública em Agroecologia no estado de Sergipe

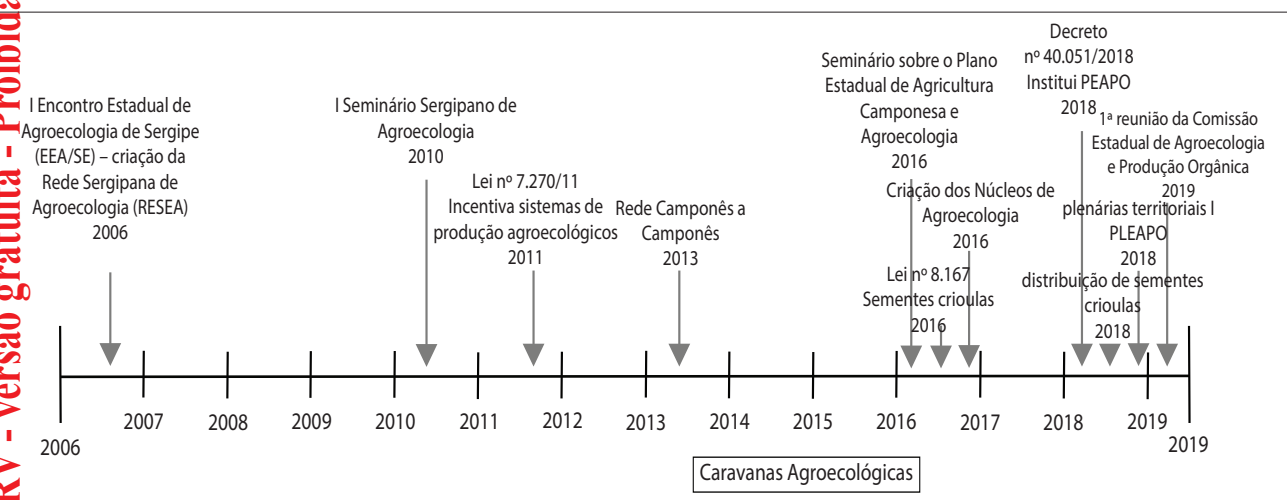

\section{A construção da Política Estadual de Agroecologia e Produção Orgânica no contexto das elaborações nacionais}

A Peapo surge em Sergipe tendo como referência o que vinha acontecendo no nível nacional que culmina com o Decreto $n^{\circ} 7.794$, de 20 de agosto de 2012, que instituiu a Pnapo. A efervescência das discussões no nível nacional, protagonizada por movimentos sociais nos quais as representações de Sergipe se fizeram atuantes, coloca a agroecologia na agenda o estado. Consequentemente, se formam as bases para o processo de elaboração da Lei de Agroecologia estadual. Apresentado como Projeto de Lei intitulado 
Projeto de Agroecologia para o estado de Sergipe pelo então deputado estadual João Daniel (PT) tornou-se a Lei n ${ }^{\circ} 7.270$ em 17/11/2011, sancionada pelo governador à época Marcelo Déda (PT).

Ainda que Sergipe tenha se inspirado no cenário nacional, o movimento agroecológico consegue sancionar a Lei subnacional em 2011, mesmo antes de ser sancionada uma lei no nível nacional, o que acontece somente no ano subsequente, em 2012.

Desta forma, tanto o processo de discussão sobretudo nos movimentos sociais sobre uma Pnapo foi tida como referência para encaminhar um projeto de lei no nível subnacional em Sergipe como também outras experiências influenciaram.

É exemplo o Decreto ${ }^{\circ} 12.431$ de 23/10/2014 que institui o Programa Paraná Agroecológico, com o objetivo de promover e apoiar ações integradas para implantação, consolidação e ampliação de sistemas de produção e consumo com base em princípios da agroecologia no Paraná.

Tiveram seus reflexos nas discussões que se seguiram. Ainda que a Lei em Sergipe tenha sido sancionada antes mesmo que a Lei nacional, que a inspirou, foram necessários 7 anos para que a mesma fosse regulamentada. É neste sentido que a experiência no Decreto paranaense, bem como a discussão em torno da Lei de sementes crioulas (Lei n ${ }^{\circ} 8.167$ de 01/12/2016) em Sergipe, vão preenchendo ou alimentando proposições dos passos subsequentes, no vão que fica entre a sanção da Lei de Agroecologia e suas regulamentação.

Neste período, os movimentos sociais em Sergipe constroem, desde as suas práticas, uma perspectiva agroecológica que vai aos poucos sendo institucionalizada num conjunto contínuo de ações que, a exemplo do nível nacional - cujo I Plano reúne e articula ações estatais antes pulverizadas em diferentes programas e projetos - vai tecendo no cenário estadual, ao longo da última década, iniciativas celulares e setoriais que vão compondo um contexto favorável à implementação e gestão com participação social de uma política estadual de agroecologia.

Há, portanto, uma inter-relação entre Estado e sociedade na construção das políticas de promoção da agroecologia em Sergipe cujo cenário de constante construção vai demarcando o acúmulo de ações empreendidas pelos movimentos sociais como: encontros estaduais, realização de caravanas, discussão e apresentação de projetos de lei como o de sementes crioulas, para citar alguns exemplos. Uma linha do tempo pode ser observada na figura 1 e mais detalhadamente no apêndice deste texto. Contribuíram para este acúmulo o cenário favorável vivido pela agricultura familiar por meio das 
políticas públicas no período de 2003 a 2015 estabelecidas e ou fortalecidas pelo governo federal.

Importante relembrar que houve em Sergipe um processo longo de mobilização até que a Lei aprovada pudesse ser regulamentada, sete anos depois.

Reforçando o argumento do espelhamento do processo de construção da Peapo-SE no processo nacional de construção da Pnapo, principalmente com relação aos processos nacionais de mobilização da sociedade civil que esteve fortemente representada nos espaços onde foi construída a política, considera-se como relevante a ação mobilizatória organizada, principalmente, pelos movimentos que compõem a Articulação Nacional e Agroecologia (ANA) que demandava o processo criador do III Encontro Nacional de Agroecologia (III ENA) que se realizou em Juazeiro-BA no ano de 2014.

Foi a partir da sistematização de experiências que agricultores e agricultoras passam a ter maior visibilidade e as Caravanas Agroecológicas, preparatórias ao referido encontro, fortalecem o grupo pois preconizam um fluxo significativo de trocas entre agricultores e agricultoras.

Os Encontros Nacionais de Agroecologia podem ser entendidos como catalisadores da agroecologia como movimento, uma vez que, sendo propósito metodológico, ele não se resume apenas aos dias de realização mas gera uma dinâmica mobilizatória relevante para a formação dos atores que empreendem, no processo preparatório, uma série de ações locais significativas para o acúmulo desejável para a ação pública.

Isto faz com que Sergipe se alinhe a uma onda nacional que pretende: colocar na agenda de governo ideias agroecológicas, fazer o movimento agroecológico se fortalecer, articulá-lo a estratégia nacional fomentada sobretudo pela rede de movimentos sociais que compõem a Articulação Nacional de Agroecologia.

Do ponto de vista legal, ainda que a Lei tenha sido sancionada em 2011 ela somente é regulamentada em 2018, o que justifica constantes mobilizações para que tal regulamentação tenha sido feita. Uma das justificativas para tal letargia pode derivar da capilaridade que as ações públicas nacionais empreendiam sobre os territórios. Não existiu, até o momento, um monitoramento e uma avaliação da política nacional, contudo, percebe-se que, ainda que a existência da Lei em Sergipe esteja ligada ao contexto nacional; é somente num cenário de crise política e de perda de relevância das políticas nacionais que o nível subnacional passa a ter uma maior responsabilidade sobre a ação pública a favor da agroecologia.

$\mathrm{O}$ fato de existir uma articulação constante dos movimentos sociais e das redes onde atuam faz com que eles possam avançar no marco legal criando 
leis e regulamentações tanto em agroecologia e produção orgânica como em áreas afins como se deu com a Lei de sementes. Contudo, a política parece ser mais uma resposta a situação de crise do que a expressão de motivações concretas para apoio a uma transição agroecológica. Este argumento se sustenta na constatação de que não houve recursos significativos para ações concretas na Lei de Orçamento Anual (LOA) de 2018, tampouco firmaram-se acordos para que fossem garantidos programas para o orçamento de 2019.

O esforço das diferentes iniciativas se consolidou com a proposição do estado em sediar o Congresso Brasileiro de Agroecologia (CBA) no ano de 2019. Emendas parlamentares foram mobilizadas e esgotadas para viabilizar o XI CBA que Sergipe sediará.

A Ceapo hoje se estrutura com a missão de legitimar um Plano Estadual de Agroecologia e Produção Orgânica (Pleapo) e de vincular a ele os recursos intersetoriais no estado sergipano.

Nos anos que antecederam a regulamentação da Lei de Agroecologia e Produção Orgânica várias cobranças foram feitas pelos movimentos sociais em fóruns e eventos. Foram realizadas oficinas de concertação para que se estabelecesse um plano de inovação que acabou não sendo construído; contudo, esta ação possibilitou ampliar o público que vinha sendo articulado como quilombolas, mulheres e marisqueiras.

Foi também no período que antecede a regulamentação que se sancionou a Lei do Governo do Estado de Sergipe - Lei n ${ }^{\circ} 8.167$ de 01/12/2016 que institui o conceito de sementes crioulas e o incentivo à conservação da agrobiodiversidade. As sementes crioulas em Sergipe foram batizadas pelos agricultores como "Sementes da Liberdade", batismo que ocorreu durante a realização do II Encontro Estadual de Agroecologia, no município de Estância, em dezembro de 2015.

Ainda no mesmo período, foi realizado em 2016 um evento que possibilitou os devidos acordos para uma discussão ampliada entre movimentos da sociedade civil, para a concertação de ações no contexto da agricultura familiar camponesa e da agroecologia. As caravanas agroecológicas tiveram início em 2014, antecedendo a realização do II ENA, e vêm sendo realizadas periodicamente. Estes encontros têm servido para dar visibilidade para a

No período que compreendeu a sanção da Lei da Agroecologia em 2011 e sua regulamentação em 2018, ocorreram importantes ações em torno das sementes crioulas. Foi realizado um Seminário Estadual de Legislação de Sementes Crioulas em 2015 com troca de experiências em estágios mais avançados no Nordeste como foi o caso da Assessoria de Serviços a Projetos de Agricultura Alternativa (AS-PTA) na Paraiba e a Cooperativa de Pequenos Produtores Agrícolas dos Bancos Comunitários de Sementes (Coppabacs) de Alagoas. A partir daí teve início um processo que culminou com a Lei $n^{\circ} 8.167$ de 01/12/2016 que institui o conceito de sementes crioulas e o incentivo à conservação da agrobiodiversidade no estado de Sergipe. 
agroecologia e motivar as agricultoras e os agricultores a continuarem com suas práticas, mas não a ponto de colocá-la na agenda de governo.

Todas essas ações foram coordenadas a partir da Rede Sergipana de Agroecologia (Resea) conforme veremos a seguir.

\section{A formação de sujeitos políticos na ação pública}

O histórico de formação dos movimentos sociais do campo em Sergipe, ao longo das últimas décadas, denota a constante relação entre a sociedade civil e o Estado na organização de agendas governamentais. Por tanto, deve ser entendido para além do espaço temporal entre a sanção da Lei de Agroecologia e o início do funcionamento da Ceapo.

Há uma diversidade de atores, sobretudo coletivos, que atuam no meio rural, urbano, em inter-relação e que estão envolvidos nos processos de construção da ação pública de agroecologia. Cada categoria de atores envolvidos pode ser caracterizada pelos seus recursos, graus de autonomia, interesses simbólicos e materiais que guiam suas estratégias e escolhas.

Para fins deste estudo consideraremos a principal rede que articula a promoção da agroecologia, entre movimentos sociais, organizações não governamentais, outras redes, associações, cooperativas e federações, no campo da sociedade civil, além de instituições de ensino, pesquisa, extensão e executoras de determinadas ações ou setores de Estado.

Ainda que possamos trazer a experiência dessa articulação, a Rede Sergipana de Agroecologia (Resea), é importante considerar que ela parte de um acúmulo da história do movimento agroecológico em Sergipe, e mesmo de experiências que antes não se articulavam. Como veremos a seguir, um processo metodológico constante afirma, fortalece e mantém essa rede.

A Resea ${ }^{2}$ é uma articulação que surgiu em 2006 com objetivo de fortalecer a dinâmica agroecológica em Sergipe a partir da construção participativa de conhecimentos. Organiza-se em grupos de trabalhos, plenárias e núcleo operativo. Fazem parte do núcleo operativo um representante de cada uma das seguintes organizações: Articulação no Semiárido Brasileiro (ASA); 
Empresa Brasileira de Pesquisa Agropecuária (Embrapa), representada pelo Núcleo de Agroecologia da Embrapa Tabuleiros Costeiros; Universidade Federal de Sergipe (UFS) pelo seu Núcleo de Estudos e Vivências Agroecológicas (Neva); Federação dos Trabalhadores na Agricultura do Estado de Sergipe (Fetase); Movimento dos Trabalhadores Rurais Sem Terra (MST) com representantes do Centro de Formação em Agropecuária Dom José Brandão de Castro (CFAC); Movimento dos Pequenos Agricultores (MPA); Movimento Camponês Popular (MCP); Núcleo de Estudos em Desenvolvimento Territorial (Nedet), Instituto Tecnológico Federal de Sergipe (IFS) com representação de seu Núcleo de Agroecologia; Sociedade de Apoio Socioambientalista e Cultural (Sasac), Centro Dom José Brandão de Castro (CDJBC); coletivo Cantinho da Roça-Produção Agroecológica, coletivo Camponês a Camponês e Instituto Pangea.

Conforme explicita um dos entrevistados: "a Resea é uma grande convergência e construção de afinidades e quem imaginou que poderia ter um resultado mais sólido está ali dentro interagindo" (entrevista realizada em novembro de 2018 com um extensionista, assessor da Secretaria de Agricultura do Estado de Sergipe).

A Resea surgiu a partir do I Encontro Estadual de Agroecologia de Sergipe (EEA/SE), ocorrido entre os dias 19 e 20 de maio de 2006 e tornou-se um campo de articulação e fortaleceu-se enquanto grupo de interesse na ação pública a favor da agroecologia.

Segundo informações do portal eletrônico ${ }^{3}$ que mantêm, a Resea tem como objetivos: estimular o protagonismo do campesinato sergipano; fomentar um espaço de troca de saberes agroecológicos; dar visibilidade aos povos tradicionais do estado; intensificar e fortalecer o debate agroecológico; elencar os desafios do campesinato no estado; fomentar um espaço para discussão e proposição de soluções aos desafios do campesinato; estimular o debate de gênero e de juventude no campo; traçar um panorama dos territórios da cidadania do estado; e fortalecer a Resea.

Há uma forma de comunicação e metodologia empregadas que permite à Resea, composta por diversas dinâmicas sociais nos territórios, fortalecer-se como uma rede de negociação com o Estado que vem do mapeamento, reconhecimento e sistematização das práticas (JARA, 1998) caracterizando um processo alicerçado de baixo para cima que permite capilaridade nas agendas discutidas ao mesmo tempo que estas experiências subsidiam as frentes prioritárias de ação em rede. A Resea mantém essa forma continua 
de comunicar e sistematizar fazendo-se movimento na construção de trocas de experiências, de caravanas agroecológicas, de implementação da metodologia camponês a camponês como tratado por Holt-Giménez (2008).

Reforça-se que a Resea possui importante papel no fortalecimento da agroecologia, contribuindo na construção do conhecimento agroecológico, como pode se depreende da afirmação seguinte:

Tendo a educação popular como base norteadora, a Rede tem debatido metodologia e ações que fortaleçam a participação. Dentre os princípios que dão movimento à Resea, destacamos os da horizontalidade, construção coletiva, respeito à cultura e conhecimento camponês que sintetizam a visão de sua responsabilidade pedagógica na construção dos processos (DE OLIVEIRA, 2017, p. 2).

Para tal, uma ação pública que fortaleceu os processos de mobilização diz respeito a atuação de redes de técnicos na interação com camponeses que resultou num maior envolvimento em rede.

A partir do ano de 2013, quando se incorporaram princípios e atividades da Rede Camponês a Camponês aos serviços da Assessoria Técnica Social e Ambiental nas áreas de Reforma Agrária (ATES), observou-se um significativo apoio logístico e profissional que evidenciaram avanços na formação da Rede. Tratava-se de potencializar a identificação, sistematização e intercâmbio de experiências, ademais da possibilidade de impressão de cartilhas, a construção de um Programa de Formação Continuado em Agroecologia (PFA) (RABANAL, 2015, p. 68).

Além dos atores locais, Sergipe tem forte articulação com movimentos regionais e nacionais. Nas entrevistas foi citada a participação efetiva de representantes da Resea em espaços de discussão nacional, principalmente com influências da ABA e da ANA.

No tocante à participação das mulheres na Resea, há uma articulação a partir de experiências por elas protagonizadas como é o caso do Movimento de Mulheres Camponesas (MMC) do território Baixo São Francisco, Associação de Mulheres Resgatando sua História do município de Porto da Folha, no território do Alto Sertão Sergipano, coletivos de gênero do MST e do MPA, Movimento de Mulheres Trabalhadoras Rurais (MMTR) do território Sul Sergipano e sistematização de saberes femininos, contudo, a pesquisa para a construção deste trabalho não aprofundou o levantamento de dados e informações sobre a participação das mulheres na Resea, algo que pode ser levantado em pesquisas futuras. 
A participação da juventude se dá basicamente pela integração das ações difusas de cada movimento e da participação da única escola família agrícola do estado, a Associação Mantenedora da Escola Família Agrícola de Ladeirinhas (Amefal) e um grupo cultural a Associação Cultural Raízes Nordestinas (Acrane). A juventude também se faz presente com a participação de estudantes de graduação dos Núcleos de Agroecologia da UFS e do IFS.

Identifica-se a ausência na Resea de atores com atuação mais expressiva no acesso às políticas de compras públicas da $\mathrm{AF}$, como é o caso das cooperativas ligadas à União Nacional das Cooperativas da Agricultura Familiar e Economia Solidária (Unicafes). As experiências de execução do Programa de Aquisição de Alimentos (PAA) e do Programa Nacional de Alimentação Escolar (PNAE) já demonstraram ser capazes de apoiar a transição agroecológica, contudo, representantes que têm como objetivo ampliar esse acesso no Estado, não fazem parte sistemática da Resea, ficando assim uma contradição entre a construção de um Plano de Agroecologia no estado que dê conta do conjunto de políticas públicas enquanto o acesso pontual à políticas já existentes se dá de forma desarticulada ao movimento que vem sendo construído.

Nas palavras de um dos entrevistados aparece a seguinte afirmação,

[...] toda entidade que fazia parte da rede [de construção do projeto Ecoforte edital [...] não conseguia acessar as políticas [já existentes no nível nacional]. Em dado momento, observou-se que, dentre 16 entidades, nenhuma tinha acessado PAA ou PNAE (entrevista realizada em novembro2018 com um extensionista, assessor da Secretaria de Agricultura do Estado de Sergipe).

Algumas ausências de atores são identificadas e, por se tratar de uma ação em curso, novos atores são mobilizados, como é o caso de instituições que trabalham no campo da economia solidaria e do cooperativismo, basicamente cooperativas filiadas à Unicafes além de buscar uma participação mais efetiva do Movimento dos Trabalhadores Rurais Sem Terra (MST).

Recentemente também passou a reunir comunidades tradicionais quilombolas, marisqueiras, pescadores através do Programa de Educação Ambiental com Comunidades Costeiras (Peac), o qual tem o apoio da Petrobras.

A Resea tem sido, a partir da reunião em rede destes atores, a principal articuladora do Plano Estadual de Agroecologia e Produção Orgânica do Estado de Sergipe.

\section{Processos: mobilizações e coalizões}

A Resea foi a principal força articulada a favor da agroecologia como política pública no estado de Sergipe. 
Esta rede é articulada a partir de experiências de vários atores e reuniu em julho de 2016 movimentos sociais, agricultores e pesquisadores, em uma frente coletiva, para refletir sobre o fortalecimento da agricultura familiar em sua diversidade identitária e agroecológica em Sergipe para a construção do Plano Estadual de Agricultura Camponesa e Agroecologia. Foi a principal força articulada a favor da agroecologia como política pública no estado de Sergipe.

Há uma relação do movimento agroecológico em Sergipe com o movimento nacional como a ANA ou movimentos regionais como é o caso da relação com os estados da Paraíba, principalmente o Polo da Borborema e de Alagoas e também a Rede de Núcleos de Agroecologia do Nordeste (Renda) com sede em Pernambuco. Além disso, há reflexos de experiências práticas sobre o processo de construção da Peapo, mostrando que o conjunto de estratégias de articulação de diferentes escalas tem uma importância que recai sobre a ação articulada para que os estados sejam pautados pela necessidade de uma agenda da agroecologia.

Assim, a Rede de Agroecologia em Sergipe além de articular diversos atores, articula também escalas que vai desde processos locais, regionais, até nacionais.

Para a articulação territorial, como metodologia de mobilização, foram realizadas Caravanas Agroecológicas ${ }^{4}$ ao longo de 2014 e 2015 nos territórios sergipanos sendo que a Caravana de 2014 se constituiu como processo preparatório para o III ENA (DE OLIVEIRA, 2017).

Todo esse processo de mobilização como relatado acima, reúne hoje um conjunto de atores para a elaboração do Pleapo, instrumento que deriva da regulamentação da Peapo, que vem sendo elaborado pela sociedade civil sergipana para desenvolver a políticas de agroecologia e produção orgânica com o apoio institucional da Secretaria de Estado da Agricultura, Desenvolvimento Agrário e Pesca.

O momento atual, iniciado em 2018, após o decreto que regulamentou a Peapo, é de construção do I Pleapo, iniciado em 2018, após o decreto que regulamentou a Peapo, participam desta elaboração, 28 organizações por representação da sociedade civil como: Associação dos produtores orgânicos

4 A Caravana Agroecológica e Cultural de Sergipe é uma realização da Resea (Rede Sergipana de Agroecologia). Representa uma estratégia para promover a interação entre camponeses, técnicos, estudantes e pesquisadores, fomentando momentos de aprendizado e o protagonismo dos sujeitos do campo na produção de alimentos saudáveis. A partir do intercâmbio, as experiências camponesas são postas em evidência suscitando a reflexão sobre a realidades, os desafios e as potencialidades de cada local visitado. Desta forma são criados espaços de diagnóstico da realidade e construção do conhecimento agroecológico com base no saber camponês. 
da Agreste (Aspoagre), Movimento dos Trabalhadores Urbanos (Motu), Federação dos Trabalhadores e das Trabalhadoras Rurais de Sergipe (Fetase), Movimento Camponês Popular (MCP), Pastoral da Juventude Rural (PJR), Movimento dos Pequenos Agricultores (MPA), Cooperativa de Produção da Agricultura Familiar e Economia Solidária do Município de Simão Dias (Cooperafes), Associação Jatobá, Sociedade de Apoio Socioambientalista e Cultural (Sasac), Agroecológicos de Salgado, Cáritas de Estância, Cooperativa de Produção, Comercialização e Prestação de Serviços dos Agricultores Familiares de Indiaroba e Região (Cooperafir), Movimento dos Trabalhadores Rurais Sem Terra (MST), Cooperativa da Produção Sustentável Familiar de Sergipe (Coopersus), Articulação Semiárido Brasileiro (ASA), Centro Dom José Brandão de Castro (CDJBC), representantes da Feira Agroecológica da Colônia 13, Coordenação Nacional de Articulação das Comunidades Negras Rurais Quilombolas (Conaq), Fórum de Religiões de Matriz Africana.

Algumas instituições do Estado também estiveram presentes, contudo, há uma forte presença de técnicos, pesquisadores, extensionistas e docentes envolvidos com a dinâmica do movimento agroecológico em Sergipe cujo compromisso e protagonismo da participação atribui-lhes além de uma representação institucional também uma prospecção de demandas que deverão servir para uma atuação profissional e orientação institucional nos ambientes onde atuam. Nesta categoria podemos considerar a Universidade Federal de Sergipe (UFS), A Empresa de Desenvolvimento Agropecuário de Sergipe (Emdagro), a Empresa Brasileira de Pesquisa Agropecuária (Embrapa Tabuleiros Costeiros) e o Instituto Federal de Sergipe (IFS).

Assim como no nível nacional, o nível subnacional também reúne e articula diversas políticas de promoção da agroecologia em uma agenda de discussão do I Pleapo. Assim, é possível observar que cada rede ou movimento ou experiência que participam da Resea, tenham acúmulo na execução de várias políticas associadas ao I Planapo.

A ASA tem um histórico de elaboração, execução e monitoramento de políticas públicas ${ }^{5}$ como é o caso do Programa um milhão de Cisternas do Ministério do Desenvolvimento Social, uma tecnologia social reconhecida pela Fundação Banco do Brasil. Também atuou no Programa de Formação e Mobilização Social para a Convivência com o Semiárido: Manejo da Agrobiodiversidade - Sementes do Semiárido que, a partir da autorganização comunitária, preserva o patrimônio genético. Existem áreas de implantação de unidade de recuperação de áreas degradadas desenvolvida com cooperação internacional Instituto Interamericano de Agricultura (Iica) e Programa das

5 Há, no entanto, desde 2016, a desconstrução das políticas de apoio à agricultura familiar (DE MATTOS, 2017; MATTEI, 2018; SABOURIN, 2018). 
Nações Unidas para o Desenvolvimento (Pnud), uma das metas do I Planapo e outras iniciativas que não foram aqui listadas pela ausência de sistematização mais ampliada.

$\mathrm{Na}$ área de comercialização ressalta-se o apoio às feiras municipais. Há um avanço identificado pelos informantes desta pesquisa com relação às políticas de mercado institucional, mas há uma observação já citada com relação ao baixo acesso dos grupos participantes da Resea ao PAA e ao PNAE. Também é registrado, por sua vez, o baixo número de agricultores cadastrados como produtores orgânicos no Ministério de Agricultura, Pecuária e Abastecimento (Mapa). Esta evidência, feita por membros da Resea, levou ao questionamento da devida inserção da sua base de agricultores nas políticas públicas já existentes. De 16 entidades participantes da Resea em 2017, nenhuma tinha acessado PAA e PNAE e apenas 2 tinham cadastro de orgânicos. Tal fato demonstra a contradição entre a efetiva mobilização de atores para a construção de uma política estadual que não se expressava no acesso às políticas públicas constituintes do I Planapo.

Houve um impacto forte na finalização do Programa de Assessoria Técnica, Social e Ambiental (Ates) em 2016 que trouxe como inovação o trabalho a partir da metodologia camponês a camponês.

Outras políticas consideradas como relevantes, citadas pelos entrevistados nesta pesquisa foram: expansão das universidades para regiões do sertão, Programa Nacional de Educação nas Áreas de Reforma Agrária (Pronera), Política de Desenvolvimento Territorial, Política de Assistência Técnica e Extensão Rural, Programa de Diversificação da Agricultura Familiar. Além destas foram apontadas as ações por meio de cooperação internacional, Sebrae como no caso do Produção Agroecológica Integrada e Sustentável (PAIS), editais da Petrobras e ainda as emendas parlamentares.

Um momento importante da interface da Resea com políticas públicas foi a elaboração do projeto para Edital de Seleção Pública no 2017/030 Redes Ecoforte. O projeto intitulado "Fortalecimento da Rede Sergipana de Agroecologia" não foi aprovado, mas segundo seus idealizadores foi uma experiência de muita articulação e que, de fato, fortaleceu a rede.

Nesta proposta os principais movimentos envolvidos propuseram uma integração de ações a partir do que já vinha acontecendo em suas bases, assim, juntou-se a experiência do arroz agroecológico, a sistematização de experiências que a Embrapa/Neva vinha realizando, a experiência na Unidade de Produção Camponesa (UPC) do MPA, o MCP com os bancos de sementes e as redes de intercâmbio de experiências na metodologia Camponês a Camponês.

Segundo informações da proposta, o projeto que integrava vários movimentos propunha-se ações de Rede de Guardiãs e Guardiões das Sementes da Liberdade; beneficiamento e comercialização da farinha de cuscuz crioulo e 
seus derivados; intercâmbio e sistematização de experiências agroecológicas; beneficiamento e comercialização do arroz agroecológico e seus derivados; potencialização de arranjos produtivos na Escola Família Agrícola de Ladeirinhas; unidades de processamento mínimo da produção agrícola; fortalecimento de redes de comercialização solidárias; desenvolvimento de ações de convivência com o semiárido; disseminação de tecnologias sociais; Caravana Agroecológica e Cultural de Sergipe e a Feira Cultural Sergipana. O extrato de texto seguinte reforça esse papel que o edital trouxe para a Resea:

A proposta da Resea para o Ecoforte 2017 pretende apoiar as iniciativas de produção de sementes crioulas e processamento da farinha de cuscuz do Movimento Camponês Popular (MCP); Auxiliar a dinâmica metodológica de intercâmbios e sistematização de experiências agroecológicas do coletivo Camponês a Camponês; Instruir uma unidade de processamento mínimo da produção agrícola, adaptado para agricultura camponesa na base do Centro Comunitário de Formação em Agropecuária D. José Brandão de Castro; Munir de condições estruturais o processo de registro cultural das comunidades por parte do coletivo Catingarte; Apoiar a produção e consolidação do coletivo de produção do arroz agroecológico do Movimento dos Pequenos Agricultores (MPA); Dotar de condições estruturais a Rede de Guardiões de Sementes da Liberdade nos territórios sergipanos; Apoiar a Associação de Mulheres "Resgatando sua História" no desenvolvimento das Tecnologias sociais e de convivência com o semiárido (RESEA, 2017).

As principais temáticas trazidas na discussão do Pleapo até então identificadas dizem respeito a produção agroecológica, transporte solidário, comercialização de produtos agroecológicos, ampla oferta de insumos e beneficiamento, soberania alimentar, genética, hídrica, energética e territorial, transição agroecológica da rizicultura no território Baixo São Francisco, uso e conservação da biodiversidade e valorização da sociobiodiversidade principalmente da mangaba, do umbu e do murici, fortalecimento dos quintais agroecológicos, tecnologia social para agricultura camponesa e implantação de um Sistema Participativo de Garantia (SPG).

\section{Ideias e concepções de agroecologia}

O movimento agroecológico em Sergipe, articulado na Resea, tem como identidade de coalizão, a contraposição à agricultura fruto da modernização do campo brasileiro que hoje se constitui em um ator político hegemônico no mundo agrícola, o agronegócio. Segundo Mendonça (2006) a noção do que hoje denominamos agronegócio organizou e instrumentalizou um poderoso 
complexo comercial e financeiro que lhe atribui importância financeira, mas, sobretudo, política.

$\mathrm{Na}$ contra hegemonia, a Resea propõe um processo de transição agroecológica que distancie o desenvolvimento rural dos marcos do padrão hegemônico da agricultura, o qual, por exemplo, afeta a produção de milho crioulo no estado. Segundo dados levantados por esta pesquisa, a partir de entrevistas realizadas com movimentos e o Instituto Federal que realizam monitoramento de sementes, foram encontradas sementes de milho crioulo contaminadas devido aos cultivos crescentes que se utilizam de sementes transgênicas no estado.

Esse problema é também demonstrado, por meio de um estudo participativo sobre os guardiões de sementes crioulas de Sergipe. Dalmora et al. (2017) mostram a importância do diagnóstico de agricultores tradicionais que preservam as sementes crioulas livres de adversidade como o da erosão genética ocasionada pelo agronegócio e aponta que o avanço do mesmo no Alto Sertão, onde se realizou a pesquisa, interfere diretamente na perda da agrobiodiversidade.

A problemática da contaminação das sementes crioulas é trazida para demonstrar como a concepção da agroecologia passa, consideravelmente, por uma denúncia a um modelo de agricultura que limita a expansão de experiências agroecológicas e coloca em risco as estratégias de reprodução devido a erosão genética que é identificada. Desta forma, não só as ideias agroecológicas devem ser entendidas na ação pública em Sergipe, mas também como sofre uma limitação pela expressão do agronegócio que faz com que se fortaleçam os sujeitos coletivos na sua denúncia e ação contra hegemônica. Há, portanto, ao se construir a ação pública em favor da agroecologia, uma reação pública à promoção do Estado ao agronegócio.

O I Pleapo debatido em 2018 e 2019, trabalha num campo de coalizões entre sociedade civil e setores do Estado que promovem a agroecologia e a produção orgânica. Desta forma, conecta diferentes concepções com interesses comuns e defende uma visão ampliada do conceito de Agroecologia, considerando as dimensões ambiental, econômica, cultural, social e política. Considera ações urbanas e periurbanas além das rurais, com participação popular. Pretende estabelecer frentes intersetoriais entre saúde, educação, meio ambiente, segurança alimentar e nutricional nas estratégias de criar territórios agroecológicos. Ainda que um conceito de agroecologia possa reunir diferentes dimensões, na Peapo promulgada em 2018 ele não demonstra tal tendência, ao contrário, restringe-se mais a uma normativa que se aproxima do conceito de agricultura orgânica operado pela Lei de Orgânicos ${ }^{6}$. 
Segundo a Lei $n^{\circ}$ 7.270/2011 que institui a Peapo em Sergipe "considera-se sistema de produção agroecológica a proposta de agricultura que seja socialmente justa, economicamente viável, ecologicamente sustentável e que englobe formas de produção orgânica, biodinâmica ou outros estilos de base ecológica". O Decreto 40.051/2018, em seu Art. II, considera Sistema de Produção Agroecológico, aquele que busca otimizar a integração entre capacidade produtiva, uso e conservação da biodiversidade e dos demais recursos naturais, equilíbrio ecológico, eficiência econômica e justiça social, abrangida ou não pelos mecanismos de controle de que trata a Lei dos orgânicos e sua regulamentação.

Nota-se no escopo da concepção da Peapo do estado de Sergipe uma aproximação com a Pnapo quando busca uma aproximação com a temática dos orgânicos de forma a angariar apoio e legitimidade ampliada. Da mesma forma, evita enfrentar os problemas históricos que a Política Nacional também o fez, como o acesso à terra e água e os enfrentamentos com os agrotóxicos. Esta estratégia foi adotada em outros estados da federação visando diminuir a resistência no âmbito legislativo. O desenho do Plano realizado posteriormente recupera um conceito mais ampliado de agroecologia do que aquele mobilizado na Política.

A percepção sobre a importância da agroecologia pode ser mais tecnicista ou sociotécnica dependendo da proximidade dos processos que ocorrem a partir da Resea, conforme assinalado a seguir.

[A agroecologia] é uma vertente importante de um modo de produção agrícola, é uma demanda significativa da sociedade, por isso, é nosso dever enquanto instituição aportar recursos e direcionamento estratégico a ela assim também como atender a outras demandas de modelos ditos convencionais (Entrevista realizada em novembro de 2018 com o Chefe Adjunto de Pesquisa Embrapa Tabuleiros Costeiros).

Ressalta ainda que é necessária uma atuação

buscando redução de insumos, independência do produtor, autosuficiência, maximizar essa autosuficiência [...] Em termos de visão gerencial é necessário ir além das trocas de experiências buscando uma atuação mais sólida em termos de gerar tecnologias agroecológicas para a realidade. Mais que conscientizar ou buscar disseminar conhecimento existente, de resgate de conhecimento, é preciso gerar conhecimento também, adaptado às condições locais. É necessário gerar ativos (Entrevista realizada em novembro de 2018 com o Chefe Adjunto de Pesquisa Embrapa Tabuleiros Costeiros). 
Ainda que exista um reconhecimento por parte da instituição de pesquisa, esse se dá pela forma da agroecologia enquanto "demanda significativa da sociedade" onde pode-se entender, dos movimentos pela agroecologia que empreendem várias ações no estado como tratado anteriormente. Percebe-se ainda que há uma tendência a tratar a agroecologia apenas como tecnologia, "um modo de produção agrícola" o que difere do que vem sendo tratado pelo Pleapo em um contexto mais ampliado e que se aproxima da definição da Lei.

Já para pesquisadores envolvidos mais diretamente com as ações em prol da agroecologia, há uma noção mais ampla do que pode ser entendido por agroecologia onde dá uma importância maior ao conceito de território e as distintas dinâmicas que nele ocorrem,

não precisa conceito [de agroecologia], construir o conceito marca o fim da gente porque a realidade abarca mais do que abarcamos no conceito. $\mathrm{O}$ conceito de agroecologia está sempre em construção, nunca vai parar de estar em construção (Entrevista realizada em novembro de 2018 com um Pesquisador da Embrapa Tabuleiros Costeiros, representante da Resea, participante do Núcleo de Agroecologia e coordenador pela Embrapa do Projeto Campesino a Campesino).

Demarcando uma atuação metodológica de construção coletiva do conhecimento em Sergipe, os movimentos de trocas partem do que conceituam os agricultores participantes do Movimento Camponês a Camponês levado a cabo de 2013 a 2016 sobre a agroecologia. Segundo Rabanal (2015) ao definir, em uma pesquisa participante, o conceito de agroecologia, o conceito construído coletivamente no $1^{\circ}$ Intercâmbio de Experiências Camponesas da Rede Camponês a Camponês, foi "plantar, colher e comer sem agredir a natureza" (RABANAL, 2015, p. 74).

\section{Considerações finais}

Em grande medida, a pauta agroecológica no ambiente político do estado de Sergipe está sendo construída mobilizando diferentes atores individuais e coletivos. Ela encontrou um ambiente favorável graças ao papel da Resea e aos diferentes arranjos que se constituem em um movimento fortemente ancorado nas estratégias nacionais da ANA e no apoio de parlamentares envolvidos com as questões de segurança alimentar, desenvolvimento rural, assistência técnica e temas ambientais.

A agroecologia é um conceito que permite analisar uma ampla diversidade de dimensões da realidade da $\mathrm{AF}$ (ou das $\mathrm{AFs}$ ), em grande medida relacionadas com o desenvolvimento rural, com a produção de alimentos sem agrotóxicos, 
mas também de uma agricultura urbana e das relações de produção, comercialização e consumo. Nesse sentido o debate empreendido pela Resea proporciona uma ampla reflexão sobre a realidade do desenvolvimento rural no estado de Sergipe.

Tendo a Pnapo como inspiração o movimento de reinvindicação de uma política estadual de agroecologia e a efetivação da sua aprovação demonstram uma articulação da Resea a partir do que tinha sido proposto na escala nacional. Dessa forma avanços e recuos na esfera nacional influenciam também o que ocorre na esfera do estado.

A identidade comum do campo agroecológico, refletida na contraposição ao agronegócio, as pautas comuns e o reconhecimento das diferenças regionais permitem também que as ações sejam articuladas na perspectiva regional, com interlocução com outras redes com atuação política como a ASA e a ANA.

A constituição da Resea como uma rede que reúne movimentos sociais, organizações de trabalhadores, Organizações Não governamentais (ONGs), instituições públicas de pesquisa e ensino revela uma dinâmica que aproxima diferentes atores em um mesmo fórum e em ações coordenadas pela própria Rede; Dessa forma se constitui numa inovação organizacional que pode facilitar a implementação da própria política de agroecologia ou outras a ela relacionadas, como é o caso da Política de Agrobiodiversidade (Lei no 8.167 de 01/12/2016) que institui o conceito de sementes crioulas e o incentivo à conservação da agrobiodiversidade no Estado de Sergipe.

Em janeiro de 2019 houve a primeira reunião da Ceapo, dessa forma o governo do estado, pela Secretaria de Agricultura demonstra a intenção de apoiar a implementação da política, nesse sentido o acompanhamento pela Resea dessa ação pode ser fundamental para resultados efetivos da política.

Enquanto lei, a agroecologia sergipana pode se fortalecer com a realização do CBA em 2019 que, por certo, garantirá o reconhecimento nacional e internacional do estado na vanguarda do tema. No entanto, a pesquisa identificou que o acesso as principais políticas públicas (PAA e PNAE) são gargalos importantes a serem superados no estado para que a Peapo alcance objetivamente os seus beneficiários finais. 


\section{REFERÊNCIAS}

DALMORA, E. et al. Diagnóstico participativo dos guardiões de sementes crioulas de Sergipe: intercâmbios, multiplicação e trocas de sementes e saberes Cadernos de Agroecologia. In: VI CLAA, X CBA e V SEMDF, v. 13, n. 1, jul. 2018. Anais... jul. 2018.

DE OLIVEIRA, L. C. L. et al. RESEA em movimento: as caravanas agroecológicas e culturais de Sergipe construindo o conhecimento agroecológico. Cadernos de Agroecologia, [S.1.], v. 12, n. 1, jul. 2017. ISSN 2236-7934. Disponível em: <http://revistas.aba-agroecologia.org.br/index.php/cad/article/ view/22380>. Acesso em: 6 jun. 2019.

FONTES, M.; RABANAL, J, E. M.; RAMOS FILHO, E. S. A roça do futuro: a construção da metodologia De Camponês a Camponês no sul de Sergipe. GEONORDESTE, Ano XXIV, n. 1, p. 102 a 127, 2013.

GUÉNEAU, S. et al. A Construção das políticas estaduais de agroecologia e produção orgânica no Brasil. Revista Brasileira de Agroecologia, n. 14, 2019.

HOLT-GIMÉNEZ, E. Campesino a Campesino: Voces de Latino América, movimento campesino a campesino para la agricultura sustentable. Managua, 2008.

JARA, O. Para sistematizar experiências. San José, Costa Rica: ALFORJA, 1998.

LASCOUMES, P.; LE GALÈS, P. A ação pública abordada pelos seus instrumentos. R. Pós Ciências Sociais, v. 9, n. 18, p. 19-44, jul./dez. 2012.

LOPES, E. S. A. A pluriatividade na agricultura familiar do estado de Sergipe. In: LOPES, Eliano. S. A.; COSTA, José. E. (Orgs.). Territórios rurais e agricultura familiar no nordeste. São Cristóvão: Editora UFS, 2009. p. 103-185.

MOTA, D. M. et al. As Catadoras de mangaba - problemas e reivindicações. Belém, PA: Embrapa Amazônia Oriental, 2007.

PARANÁ (Estado). Decreto No 12.431, de 23/10/2014. Institui o Programa Paraná Agroecológico, 2014. 
RABANAL, J. A experiência da metodologia camponês a camponês em territórios de identidade rural no Nordeste do Brasil, ALASRU, 2014. Disponível em: <https://ainfo.cnptia.embrapa.br/digital/bitstream/item/112440/1/ Resumo-Expandido-Pedro-ALASRU-2014-1.pdf> . Acesso em: 6 de fev. 2019.

Campesinato, território e assentamentos de reforma agrária: tecendo redes de conhecimento agroecológico. 2015. Dissertação (Mestrado em Geografia) - Universidade Federal de Sergipe, 2015.

RESEA. Fortalecimento da Rede Sergipana de Agroecologia. Edital de Seleção Pública nº 2017/030 - Redes ECOFORTE, 2017.

SERGIPE (Estado). Lei ${ }^{\circ}$ 8.167, de 1 dez. 2016. Institui o conceito de sementes crioulas e o incentivo à conservação da Agrobiodiversidade no Estado de Sergipe. Publicado no DOE em 20 dez. 2016.

. Lei n 8.354, de 20 dez. 2017. Lei orçamentária anual 2018.

SERGIPE. Plano estadual de agroecologia e produção orgânica PLAEAPO (Versão preliminar). Aracaju, SE, dezembro de 2018.

SIQUEIRA, E. R.; SILVA, M. A. de. Proposta de um estilo de agricultura familiar para os assentamentos rurais de Sergipe. In: CURADO, Fernando. F.; LOPES, Eliano S.; SANTANA, M. (Orgs.). Do plural ao singular: dimensões da reforma agrária e assentamentos rurais em Sergipe. Aracaju: Embrapa Tabuleiros Costeiros, 2008. p. 51-70.

TAVARES, E. D.; SIQUEIRA, E. R.; SILVA, M. A. de. Agricultura e uso sustentável dos recursos naturais. In: ALBUQUERQUE, A. C. S.; SILVA, Al. G. (Eds). Agricultura tropical: quatro décadas de inovações tecnológicas, institucionais e políticas. Brasília: Embrapa Informação Tecnológica, 2008. p. 23-62. 


\section{Apêndice}

\section{Linha do tempo das ações públicas em Sergipe}

2006 - I Encontro Estadual de Agroecologia de Sergipe (EEA/SE) criação da Rede Sergipana de Agroecologia (Resea).

2010 - I Seminário Sergipano de Agroecologia

2011 - Lei $\mathrm{n}^{\mathrm{0}}$ 7.270/11, sancionada pelo então governador Marcelo Déda. Dispõe sobre os incentivos à implantação de Sistema de Produção Agroecológica pelos agricultores familiares no Estado de Sergipe e dá outras providências.

2013 - Rede Camponês a Camponês/Serviços da Assessoria Técnica Social e Ambiental nas áreas de Reforma Agrária (Ates)

2016 - 27 e 28/07 - Seminário sobre o Plano Estadual de Agricultura Camponesa e Agroecologia.

2016 - Governo do Estado de Sergipe - Lei n 8167 DE 01/12/2016 - Institui o conceito de sementes crioulas e o incentivo à conservação da Agrobiodiversidade no Estado de Sergipe.

2016 - Criação dos Núcleos de Agroecologia na Embrapa, IFS e UFS.

2018 - Decreto n ${ }^{\circ} 40.051 / 2018$, assinado pelo governador Belivaldo Chagas. Em 29 de maio de 2018, o Decreto n ${ }^{\circ} 40.051$ regulamenta a Lei no 7.270 , de 17 de novembro de 2011, que dispõe sobre os incentivos à implantação de Sistemas de Produção Agroecológica pelos agricultores familiares do Estado de Sergipe, instituindo a Política Estadual de Agroecologia e de Produção Orgânica e dando outras providências correlatas.

2018 - Atendimento a reivindicação de distribuição de sementes: 337 toneladas de sementes de milho das variedades BR-106, Caatingueiro e Crioula são distribuídas pelo governo do estado.

2018 - Realização de 5 plenárias territoriais para construção participativa do I Pleapo (setembro a novembro).

2019 - Acontece a primeira reunião da Comissão Estadual de Agroecologia e Produção Orgânica. 


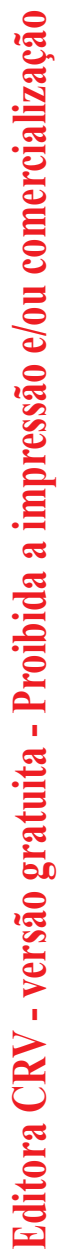




\title{
CAPÍTULO 10
}

\section{O PROCESSO DE CONSTRUÇÃO DA POLÍTICA DE AGROECOLOGIA E PRODUÇÃO ORGÂNICA DO ESTADO DO MARANHÃO - PEAPOMA}

\author{
Stéphane Guéneau \\ Evaristo José de Lima Neto \\ Camila Lago Braga
}

\section{Introdução}

O estado do Maranhão está marcado por um contexto de mudanças rápidas em sua economia agrícola, em particular através da expansão do agronegócio na mesorregião Sul do estado. No período de 2009-2017 a área de soja plantada no estado dobrou (IBGE, 2018a). Esse avanço da fronteira do agronegócio, a partir de um modelo agrícola mecanizado baseado no uso de insumos químicos, gera degradações ambientais e desmatamentos elevados (MMA, 2015, 2018), poucos benefícios econômicos e sociais para as populações rurais maranhenses economicamente pobres ${ }^{1}$ (RODRIGUES, 2010; ROCHA, 2015) e conflitos socioambientais (RODRIGUES; TERRA, 2018; SODRÉ et al., 2019).

É nesse contexto que no final do ano de 2018, o governo do estado do Maranhão institui oficialmente a Política Estadual de Agroecologia e Produção Orgânica do Maranhão (PEAPOMA), por meio da Lei ordinária nº 10.986 de 24 de dezembro de 2018 (Maranhão, 2018). A institucionalização desta política estadual coincide com a agenda de paralização e desmantelamento da política nacional a partir do ano de 2016, uma decorrência da reorientação política do executivo federal, resultado do impeachment da presidenta Dilma Rousseff durante seu segundo mandato (MATTEI, 2018).

Para completar esse contexto, vale notar também que a PEAPOMA sanciona mais de vinte anos de atuação do movimento político em prol da agroecologia no Maranhão, em particular da Rede Agroecológica do Maranhão (RAMA) (LOCH et al., 2018).

1 Segundo o Instituto Brasileiro de Geografia e Estatística (IBGE), o Maranhão é o estado da União que apresentava o menor PIB/habitantes em 2016, com um valor de $\mathrm{R} \$ 12.264,28$ por pessoa (IBGE, 2018b). 
O que examinaremos neste capítulo será o processo de elaboração desta política, destacando o seu contexto de formulação, principais atores, instituições, estratégias de ação, representações sobre o modo de produção agroecológica e orgânica acionadas e, finalmente, os resultados alcançados neste processo. Levando em conta os elementos contextuais apresentados anteriormente e trabalhos publicados sobre a institucionalização da política de agroecologia em nível federal (NIEDERLE et al., 2019; SAMBUICHI et al., 2017; SCHMIDT et al., 2017), nossa hipótese é que a institucionalização da PEAPOMA no Brasil decorre do ativismo dos movimentos agroecológicos, da necessidade de fortalecer alianças entre movimentos sociais para resistir ao avanço do agronegócio no Maranhão, e da abertura de uma janela de oportunidade política (KINGDON, 2003) relacionada à posse do governo Flávio Dino em 2014.

Como nos demais trabalhos desta coletânea, o estudo de caso da PEAPOMA foi orientado por uma matriz teórico-metodológica baseada na proposta de análise da dinâmica da ação pública de Lascoumes e Le Galès (2012). Para tanto, utilizamos como instrumentos de construção de dados os seguintes procedimentos: a leitura de documentos, a participação em eventos - em particular os Encontros Maranhenses de Agroecologia (EMA) -, observações participativas durante as reuniões de trabalho coordenadas pela Secretaria da Agricultura Familiar (SAF) do estado do Maranhão sobre a elaboração da PEAPOMA, a realização de entrevistas com atores-chave e a visita a instituições públicas e organizações sociais de destaque no que poderíamos chamar de "cena agroecológica" no estado do Maranhão. Institucionalmente, os atores interpelados nesta pesquisa ficaram circunscritos a duas categorias de entidades da sociedade civil (seis) e órgãos estatais (nove), tendo sido entrevistados um total de quinze agentes, distribuídos entre estas instituições.

Além desta introdução e da conclusão que sintetiza os principais resultados dessa pesquisa, este capítulo conta ainda com mais quatro seções. $\mathrm{Na}$ primeira apresentamos os aspectos gerais da construção da cena agroecológica no Maranhão, até o momento em que seus principais atores se voltam para a construção da PEAPOMA; na segunda, buscamos situar os principais protagonistas do processo em análise, tomando como parâmetro os tipos de representações que emanam das concepções sobre agroecologia identificadas durante a investigação; na terceira, descreveremos as estratégias de ação dando destaque às formas de mobilização dos atores, os espaços de debate e a formação de alianças e coalizões; e, por fim, serão apontados os resultados mais expressivos do processo de construção da PEAPOMA obtidos até o momento, as expectativas futuras e as preocupações dos envolvidos no processo de institucionalização dessa política. 


\section{A construção da cena agroecológica no estado do Maranhão}

De modo semelhante ao que ocorreu em outros estados da Federação (SAMBUICHI et al., 2017), a cena agroecológica no Maranhão começa a se desenhar nos idos da década de 1980, a partir dos movimentos de "agricultura alternativa" 2 . Estes movimentos se colocavam para as comunidades rurais àquela época, como uma alternativa técnica, política, econômica e cultural ao modelo de modernização da agricultura baseado na Revolução Verde, que trouxe consigo um intenso e conflituoso processo de expropriação das comunidades camponesas, indígenas e quilombolas (SANTOS; TAVARES, 2016).

Mesmo nos casos das comunidades rurais que lograram resistir ao processo de expropriação fundiária, por meio da regularização de suas posses através de projetos de assentamento, titulação de terras indígenas, territórios quilombolas e reservas extrativistas, os termos pelos quais se realizava o modelo da Revolução Verde, dificultavam e, até mesmo, inviabilizavam sua reprodução social, econômica e cultural, o que ressaltou a necessidade de se buscar modelos produtivos alternativos.

Neste contexto, o tema da "agricultura alternativa" foi introduzido no estado a partir de ONGs e entidades confessionais como, por exemplo, a Cáritas-MA e a Sociedade Maranhense de Defesa dos Direitos Humanos (SMDDH), que foram as pioneiras no estabelecimento de parcerias para implementação de experiências no âmbito do Projeto de Tecnologias Alternativas (PTA), vinculado institucionalmente à Federação de Órgãos de Assistência Social e Educacional (FASE), uma organização de atuação nacional.

A partir desta iniciativa, o ideário de agricultura alternativa vai adquirindo espaço no arcabouço político e técnico de organizações envolvidas nos trabalhos de assessoria, assistência e representação de comunidades rurais maranhenses. A agricultura alternativa chegou a ser uma referência de ação tanto entre as organizações já existentes como, por exemplo, a Animação Comunitária de Educação em Saúde e Agricultura (ACESA), e alguns sindicatos de trabalhadores rurais, quanto entre organizações que viriam a surgir animadas, entre outras coisas, por este ideário, a exemplo da Associação em Áreas de Assentamento do Estado do Maranhão (ASSEMA), e da Associação Agroecológica Tijupá, ambas fundadas no ano de 1989.

No ato de sua constituição, a ASSEMA estruturou operacionalmente suas ações a partir de cinco programas de trabalho, entre eles estava o Programa

2 Destaca-se na década de 1980 o trabalho das Comunidades Eclesiais de Base, que encamparam a discussão de um modelo de agricultura mais sustentável e adequando do ponto de vista dos trabalhadores rurais. Estas ações têm sido consideradas o embrião do desenvolvimento do movimento agroecológico entre os trabalhadores rurais e entidades de base. 
de Produção Agroextrativista, orientado pela perspectiva da agricultura alternativa. Inicialmente foram desenvolvidos dois projetos experimentais neste sentido, os "ensaios agroextrativistas" no município de Coroatá e as "roças orgânicas" no município de Lago do Junco (LIMA NETO, 2007). Por sua vez, a Associação Agroecológica Tijupá já incorpora em sua própria denominação o termo "agroecologia". Estes aspectos semânticos nos indicam já se encontravam em curso um movimento de incorporação do paradigma agroecológico entre as organizações da sociedade civil no Maranhão.

O final dos anos 1990 denota a consolidação da institucionalização deste paradigma no estado. Tal fato se revela a partir da criação de dois importantes espaços, que se mostraram bastante profícuos para a disseminação e legitimação de modelos de produção de base agroecológica. O primeiro, em 1996, consiste na implementação do Programa de Pós-Graduação em Agroecologia (PPGA), vinculado à Universidade Estadual do Maranhão (UEMA), o primeiro do Brasil com a denominação Agroecologia. O segundo fato, do ano de 1998, diz respeito à criação da Rede Agroecológica do Maranhão (RAMA), como resultado das discussões e encaminhamentos realizados por ocasião do I Seminário de Agricultura Sustentável do Maranhão.

Esta rede viria a se tornar o principal ator da cena agroecológica maranhense, por aglutinar as organizações mais expressivas do estado, lhe conferindo destacado protagonismo ${ }^{3}$. Contudo, ainda que tenha sido o Estado o primeiro a institucionalizar espaço de abrangência estadual para o fomento e disseminação do paradigma da agroecologia, com a criação do PPGA/ UEMA, nota-se que ao longo da construção da cena agroecológica no Maranhão, as organizações da sociedade civil se mostraram mais atuantes que as organizações estatais. O próprio caso do PPGA/UEMA é bastante ilustrativo deste quadro.

Este programa inicia sua atividade em 1996 com um curso de mestrado, e no ano de 2013 abre a sua primeira turma de doutorado. Atualmente possui nota 4,0 no sistema de avaliação da Coordenação de Aperfeiçoamento de Pessoal de Nível Superior (CAPES), órgão do Ministério da Educação responsável

Foram sócias-fundadoras da RAMA as seguintes organizações: Associação Agroecológica TIJUPÁ, Associação em Áreas de Assentamento no Estado do Maranhão (ASSEMA), Associação Comunitária de Educação em Saúde e Agricultura (ACESA), Instituto do Homem, Protejo de Assistência Técnica (PAT), Cáritas-MA, Cooperativa dos Pequenos Produtores Agroextrativistas de Viana (COOPAV), Sociedade Maranhense de Direitos Humanos (SMDH), Sindicatos de Trabalhadores e Trabalhadoras Rurais de várias partes do Estado, Associação Vencer Juntos em Economia Solidária (AVESOL), Movimento Interestadual de Quebradeiras de Coco Babaçu (MIQCB) Regional MA, Federação dos Trabalhadores e Trabalhadoras na Agricultura do Estado do Maranhão (FETAEMA), Cooperativa de Serviços Pesquisa e Assessoria Técnica (COOSPAT), Fórum Carajás, Comissão Pastoral da Terra (CPT), Movimento dos Trabalhadores Rurais Sem Terra (MST), Instituto Sociedade, População e Natureza (ISPN), Universidade Estadual do Maranhão, Federação dos Estudantes de Agronomia do Brasil (FEAB). 
pelo reconhecimento e a avaliação de cursos de Pós-Graduação stricto-sensu. Contudo, tem sido recorrente entre os diversos atores interpelados durante o trabalho de pesquisa, que o PPGA/UEMA apresenta duas fases, que se distinguem a partir das concepções e representações sobre a própria noção de agroecologia que orientaria a formação de seus discentes.

A primeira fase pode ser caracterizada por se alicerçar em uma concepção que privilegia uma abordagem holística dos processos produtivos, pela qual as dimensões sociais, culturais, políticas, ambientais, técnicas, tecnológicas e econômicas seriam indissociáveis. Esta perspectiva como princípio orientador, se refletia principalmente no corpo docente do programa, que naquele contexto, era formado por profissionais das áreas de Ciências Humanas e Ciências Agronômicas, o que lhe conferia um caráter interdisciplinar. Os debates sobre a questão agrária, a dicotomia entre a agricultura de base familiar e a de base patronal e, os elementos (materiais e imateriais) admissíveis nos processos de transição agroecológica, temas de grande importância no programa, estimulavam a criação de identidades entre ciência e sociedade.

Porém, a partir do ano de 2005, ocorreu uma inflexão nos conteúdos programáticos do PPGA/UEMA. Com a retirada das disciplinas da área de Ciências Humanas e Sociais, bem como, o consequente afastamento dos docentes desta área, houve uma concentração pronunciada nas disciplinas da área de Ciências Agronômicas. E de modo a consolidar esta personalidade de pronúncia mais "técnica" e menos "social", o programa migra de área no âmbito da CAPES, desvinculando-se do comitê de avaliação interdisciplinar, para vincular-se ao comitê de ciências agrárias. Com estas alterações a noção de agroecologia prevalecente no programa, se dissocia fortemente das dimensões política e social, para estar mais centrada nas dimensões técnicas (agronômicas) stricto sensu.

Mesmo dentro da área agronômica, houve também mudanças de perspectiva no que diz respeito às práticas de formação, manejo e conservação dos sistemas produtivos agrícolas, que seguiam em uma linha distinta da fase interdisciplinar, por flexibilizar a presença de insumos inorgânicos e mecânicos no sistema. Neste contexto, a identificação do PPGA/UEMA com o movimento agroecológico, no que se refere à sua dimensão política e social, se desfaz.

Nós como programa de Pós-Graduação temos que obedecer à política do MEC [Ministério da Educação] e da CAPES, que são quem de fato, avaliam e mantem o programa em funcionamento. O que nos obriga a um comportamento mais heterodoxo, do que os militantes da agroecologia queriam. Isso faz com que o programa não seja tão fundamentalista quanto as ONGs queiram. Mas isso também não significa que o programa não tenha absolutamente nenhuma perspectiva social. Meus trabalhos atendem 
totalmente aos critérios técnicos agroecológicos, mas eu não vou pra Brasília para discutir a política agroecológica nacional, para isso teria que ter uma melhor divisão do trabalho (Docente do PPGA/UEMA, entrevista concedida aos autores, 2018).

Ressalte-se que em seu contexto inicial (na sua fase interdisciplinar), o PPGA/UEMA funcionou como um espaço importante para a inserção da agroecologia na agenda pública, ao estimular uma interlocução mais estreita entre a sociedade civil e o Estado. Alguns egressos das turmas formadas durante esta primeira fase, vieram a ocupar, além dos quadros das organizações da sociedade civil (ampliando a qualificação técnica destas organizações), também os quadros técnicos e administrativos de algumas agências estatais. Seriam estes egressos, as principais vozes dentro da estrutura do Estado, a defender a incorporação do tema da agroecologia.

Contudo, apesar dos esforços empreendidos, as vozes que falavam em nome da perspectiva agroecológica, tiveram muitas dificuldades em se fazer ouvir. Nos primeiros 19 anos que sucederam à criação do PPGA/UEMA, seus egressos seriam vozes dissonantes dentro das agências estatais responsáveis pelas políticas rurais e agrárias no estado. Estas agências se mostraram muito refratárias às abordagens alternativas ao modelo da Revolução Verde, paradigma dominante no ideário do Estado.

Desse modo, em termos efetivos, foram escassos os espaços para formulação e implementação de políticas públicas (planos, programas, projetos) de orientação agroecológica e que tivessem um caráter abrangente, integrado e estruturante. As poucas ações realizadas se limitaram a projetos experimentais de caráter pontual e intermitentes. Como se pode depreender na fala de um técnico da Agência Estadual de Pesquisa Agropecuária e de Extensão Rural do Maranhão (AGERP):

Eu e X somos da primeira turma do mestrado em agroecologia, éramos 12 pessoas. Eu já era técnico da EMAPA [Empresa Maranhense de Pesquisa Agropecuária], que no final da década de 1990, foi extinta junto com a EMATER [Empresa de Assistência Técnica e Extensão Rural] durante o primeiro governo Roseana, e hoje se tornou uma coisa só, a AGERP. Ao longo desses anos houve muita dificuldade de se trabalhar com qualquer tipo de prática diferente do modelo hegemônico da revolução verde, seja lá o nome que tivesse: alternativa, orgânica, agroecológica. Os recursos sempre foram muito escassos e havia muita resistência não somente entre os técnicos do Estado como um todo, mas também de grande parte dos produtores. O que tivemos em termos práticos, foram praticamente projetos individuais dos colegas (Pesquisador da AGERP, entrevista concedida aos autores, 2018). 
Dentro do executivo estadual, este quadro somente viria a se transformar em favor da agroecologia a partir do ano de 2015, com a eleição de Flávio Dino (PC do B) para governador do estado. Logo no início da sua gestão, o governador instituiu a Secretaria Estadual de Agricultura Familiar (SAF), atendendo a uma demanda dos movimentos sociais do campo. Com esta medida, as pautas e reivindicações dos trabalhadores rurais, extrativistas, quilombolas, indígenas, que até então eram encaminhadas pela Secretaria Estadual de Agricultura (SAGRIMA), sendo na maioria das vezes diluídas ou subsumidas pelas pautas e reivindicações da agricultura patronal e de grande porte, passam a ter lugar próprio na SAF. Neste ponto cabe uma digressão, para que voltemos a tratar especificamente da atuação da sociedade civil. Até então, conforme já mencionado, as organizações da sociedade civil, devido a sua atuação mais abrangente, enfática e perene, vêm assumindo o protagonismo da cena agroecológica maranhense. Viu-se desde os primeiros momentos, que estas organizações buscaram fazer sua atuação junto às comunidades vulneráveis, se debruçando sobre várias temáticas que incidem no processo de reprodução material e imaterial destas.

Tratando especificamente da temática relativa ao paradigma agroecológico, o trabalho prático de execução de políticas, programas e projetos, nestas organizações, estavam marcados pelas idiossincrasias político-sociais de cada uma delas e também pelas características socioambientais de suas áreas de atuação geográfica. Este último aspecto, por sinal, alcançou praticamente todas as regiões do estado, sendo assim, a título de exemplo parte das organizações que viriam a se tornar sócias fundadoras da RAMA, apresentam a seguinte distribuição: Tijupá (norte maranhense), ASSEMA, ACESA e AVESOL (centro maranhense), MST, MIQCB, FETAEMA e CARITAS (todas as regiões).

\section{As representações da agroecologia}

Assim como tem ocorrido em outros lugares, a diversidade organizações e de contextos (sociais, econômicos, culturais e ambientais) de atuação, nos/ pelos quais foi erigida a cena agroecológica maranhense, terminou por lhe conferir um caráter polissêmico, dado os múltiplos significados que foram atribuídos à noção de agroecologia. A este respeito Norder et al. (2015) ressaltam a importância de

Reconhecermos as especificidades, das prerrogativas e da autonomia de cada campo, ator ou instituição na construção de um conceito próprio de agroecologia, tanto para fins analíticos como político/programáticos, bem como para estabelecer vinculações e parcerias com atores de outros campos (NORDER et al., 2015, p. 81). 
Nesta perspectiva, os autores percebem a mobilização de distintas noções de agroecologia que sobressaem em quatro campos sociais: o científico, o dos movimentos sociais, o governamental e o educacional. No entanto, estes campos não se apresentam como blocos monolíticos, visto que, é notável a coexistência e interação entre as diferentes acepções, discursos e delimitações sobre a noção de agroecologia, diferenças estas que, por sua vez, podem ser categorizadas a partir de três sentidos possíveis, o da agroecologia como prática, como ciência e como movimento social (NORDER et al., 2015).

Dado as peculiaridades das organizações e seus contextos de atuação, o que pudemos depreender da observação da cena agroecológica foi a existência de três vertentes de ideias que até então vêm orientando os debates e práticas agroecológicas no estado. Nota-se ainda, que a filiação a determinada vertente, não se estabelece pela identificação imediata de determinado ator a um dos campos sociais elencados por Norder et al. (2015). Neste sentido, observamos que atores pertencentes a campos distintos, podem em dado momento, compartilhar as ideias vinculadas a uma vertente específica.

A primeira vertente seria aquela que identificamos como "alternativa" que vem se desenvolvendo no bojo das primeiras experiências de PTAs no Maranhão. Prevê uma indissociabilidade entre as dimensões culturais, políticas, ambientais, técnicas, tecnológicas e econômicas, figuram entre os temas de maior relevância, o acesso à terra, segurança alimentar, equidade de gênero, combate aos organismos geneticamente modificados, agrotóxicos, eliminação de insumos agroquímicos, restrições à mecanização pesada, economia solidária, circuitos curtos, mercados de proximidade, educação popular contextualizada, entre outros. Esta vertente é manifesta principalmente por atores « pioneiros » como ACESA, ASSEMA, Tijupá, ISPN, egressos das turmas da primeira fase do PPGA, bem como atores de emergência mais recente como o Laboratório de Extensão Rural (LABEX), da UEMA, e os Núcleos de Estudos em Agroecologia (NEA), vinculados à UFMA e ao IFMA. Para este conjunto de atores, a agroecologia não seria simplesmente uma conduta técnica e tecnológica, mas antes de tudo, "modo de vida", como "modelo de produção alternativo ao agronegócio".

A segunda vertente pode ser identificada como aquela que visa promover uma "Agricultura familiar de base ecológica competitiva". Apesar de compartilhar com a vertente "Alternativa" o reconhecimento da importância da indissociabilidade entre as dimensões culturais, políticas, ambientais, técnicas, tecnológicas e econômicas, e ter em seu repertório léxico, muitos temas tidos como irrenunciáveis para as vertentes alternativas (o acesso à terra, segurança alimentar, equidade de gênero, combate aos organismos geneticamente modificados, agrotóxicos, economia solidária), a vertente da "Agricultura familiar de base ecológica competitiva" vêm a se diferenciar, principalmente por ser mais tolerante à incorporação de certos insumos agroquímicos e determinados 
níveis de mecanização. Esta "flexibilização" ao nível das técnicas e tecnologias, é justificada pelos adeptos desta vertente, a partir das condições edafoclimáticas presentes no Maranhão.

Ao proferirem suas justificativas, os entrevistados nesta pesquisa deram destaque especial aos tipos de solo: "Os solos maranhenses são muito ácidos! Como vamos ter boa produtividade sem recorrer ao calcário?”; suas implicações para adoção de práticas de manejo: "se não tivermos técnicas que reduzam a penosidade do trabalho, não teremos agricultores dispostos a aderir. Não podemos ter restrições com a mecanização"; e sua relação com os aspectos culturais que ensejaram práticas consideradas tradicionais, entre os camponeses maranhenses, em especial aquelas voltadas para o preparo do solo (sistema de corte e queima): "O discurso da agroecologia mais radical, no Maranhão, tem um limite. Não dá para baixar uma capoeira usando um porrete. Para ter condições de mudar práticas de gerações, temos que apresentar bons resultados”. Comungam desta visão organizações como o MST, a FETAEMA (que representa o movimento sindical) e certos quadros das agências governamentais, com a AGERP. Nesta perspectiva, busca-se ressaltar o potencial "verde" da agricultura familiar, em oposição ao potencial "predatório" do agronegócio.

A terceira vertente, identificada como "científica", emana do campo científico, representado pela academia, mas que, também tem sido comungada por atores dos demais campos sociais, em especial o governamental (NORDER et al., 2015). Aqui a agroecologia é um ramo das ciências agronômicas strito $\operatorname{sen} \mathrm{s} u$, no qual prevalece uma visão despolitizada da agroecologia. Esta preza pelo rigor técnico-científico nos procedimentos de investigação, desconsiderando o potencial dos conhecimentos tradicionais das comunidades rurais. Seu foco de interesse primordial é a produtividade da agricultura maranhense, num contexto de solos coesos ${ }^{4}$. Como o "pacote tecnológico" baseado na química não se aplica neste tipo de solo, a representação da agroecologia dessa vertente "cientifica" é uma ciência agronômica que se adapta ao contexto ecológico específico do Maranhão.

A denominação "agroecológica", institucionalizada através o PPGA/ UEMA, é apenas uma referência para expressar uma corrente de pensamento das ciências agronômicas, desvinculada dos contextos histórico-sociais nos quais se inserem. Na cena agroecológica maranhense, esta vertente tem agregado especialmente membros da academia (grupos hegemônicos no PPGA/ UEMA, Cursos de ciências agrárias dos IFMAs, da UFMA e da UEMA), técnicos governamentais (AGERP, SAGRIMA, SEMA ${ }^{5}$ ) e agências como o 
SEBRAE. A fala de um professor do corpo docente do PPGA/UEMA entrevistado ilustra a vontade desses atores de se afastar da agroecologia política: “nem sei se é agroecologia. É agricultura biológica". Os pesquisadores e professores que se situam nesta corrente de pensamento não participam dos eventos científicos organizados pela Associação Brasileira de Agroecologia (ABA) nem publicam na Revista Brasileira de Agroecologia. Essa vertente tem sido objeto de crítica do campo dos movimentos sociais.

Contudo, a coexistência desta polissemia no interior da cena agroecológica maranhense, não impediu a construção de uma articulação de caráter sistemático e perene, em torno da pauta agroecológica em seu sentido amplo. Contando com expressivo apoio (financeiro, político e técnico) de entidades de cooperação internacional ${ }^{6}$, as organizações maranhenses puderam desenvolver experiências próprias de inspiração agroecológica. Ao longo de suas trajetórias, estas organizações foram construindo uma identidade coletiva, que tinha na agroecologia política forte elemento aglutinador, que desembocaria na constituição da RAMA, no ano de 1998. A instituição da RAMA, veio significar, não apenas um espaço de congregação e troca de experiência, mas principalmente uma entidade de referência ideológica e empoderamento do movimento agroecológico do Maranhão, em especial frente ao Estado.

\section{O processo de construção da PEAPOMA}

Os movimentos sociais maranhenses em favor da agroecologia se mobilizaram no final da década de 1990 por meio da organização de reuniões que tinham como objetivo a troca de experiências agroecológicas e a construção de um plano de ação comum. Em 1998, três organizações (ACESA, Caritas/ MA e MST) decidiram organizar o "I Seminário de Agricultura Sustentável do Maranhão”. É nessa ocasião que a RAMA foi criada (LOCH et al., 2018).

Depois dessa data, outros Seminários de Agricultura Sustentável e Encontros Maranhenses de Agroecologia (EMA) foram organizados (ver Figura 1), na maioria dos casos em cidades do interior do estado em áreas rurais. Estes eventos eram locais de debate decentralizados sobre as ideias agroecológicas e, ao mesmo tempo, espaços de mobilização da sociedade civil, o que levou gradualmente a elaborar um projeto político em favor da agroecologia. Outros seminários temáticos - sobre sementes caboclas, por exemplo - foram organizados para tratar de assuntos e problemáticas de relevância maior.

Para aprofundar o debate sobre certas questões específicas da agroecologia política, como o papel das mulheres, da juventude e das comunidades tradicionais na implementação do projeto agroecológico, ou a importância da

6 Para citar alguns exemplos, temos: Grassroots, Action-Aid, OXFAM, Misereor, Terre des hommes, DED, Chistian-Aid. 
agroecologia para a segurança alimentar e nutricional, a RAMA iniciou uma série de caravanas agroecológicas itinerantes. Campanhas complementaram essas ações, a fim de destacar o ativismo político da RAMA em favor de uma sociedade baseada nos princípios da agroecologia.

\section{Figura 1 - Principais momentos chaves de mobilização e ação da RAMA em favor da agroecologia}

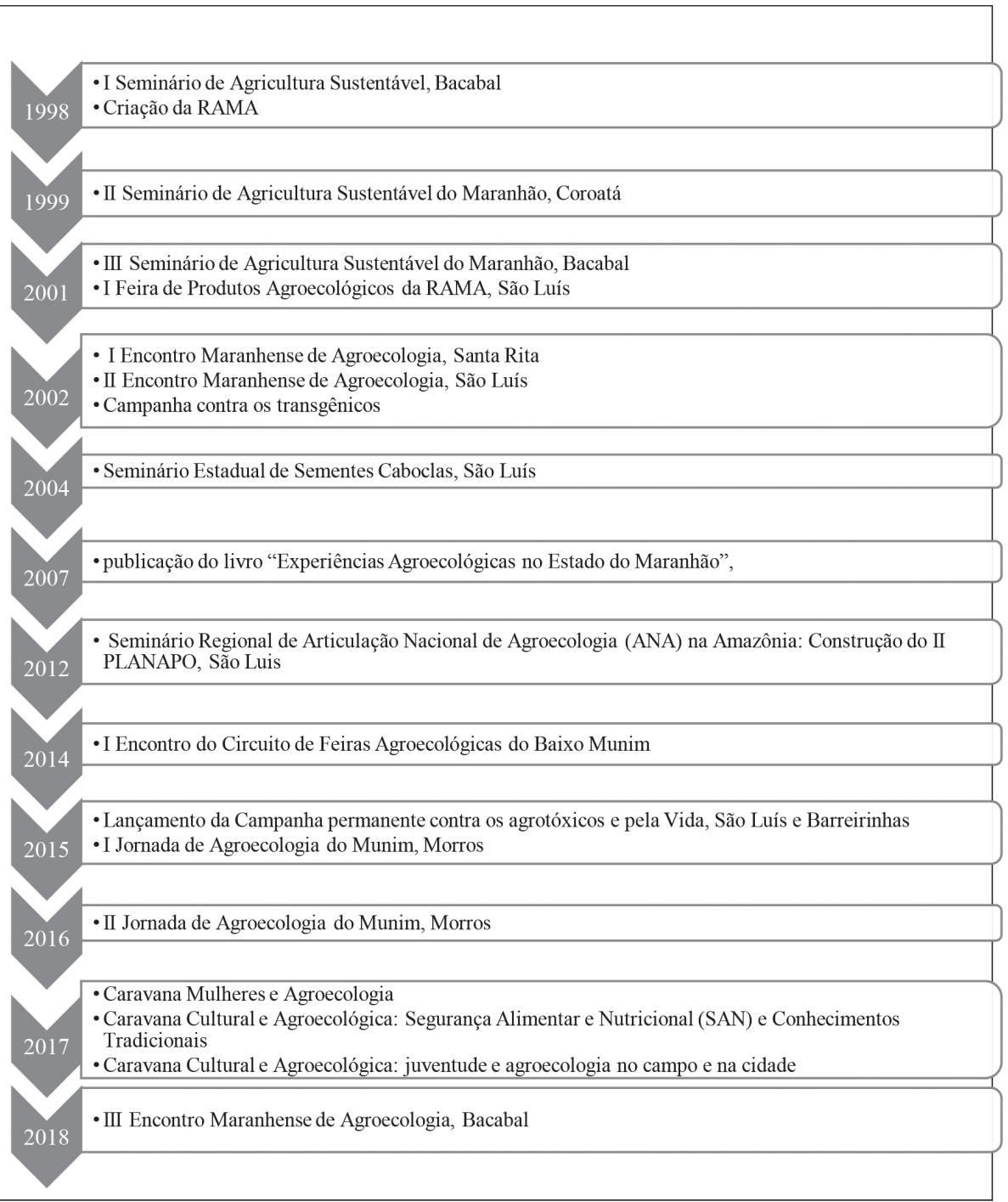


Em 2007, a publicação do livro "Experiências Agroecológicas no Estado do Maranhão" foi um marco fundamental da legitimidade da RAMA como ator central da institucionalização da agroecologia no Maranhão. O livro é uma coletânea de dez experiências que foram apresentadas no II Encontro Nacional de Agroecologia, em 2006. Ele é uma referência citada no Plano Estadual de Segurança Alimentar e Nutricional do Maranhão (PLANESAN). Esse reconhecimento confirma a importância da agroecologia como ferramenta relevante pela conservação, o manejo e o uso da agrobiodiversidade, e, principalmente, para atingir a Segurança Alimentar e Nutricional da população maranhense.

A implementação de um circuito de feiras agroecológica é outro processo importante de institucionalização da agroecologia, sendo que as feiras não são apenas um espaço de compra e venda de produtos, mas também espaços de expressão política e de divulgação dos valores do projeto da agroecologia política. Assim, as questões relativas à economia circular ou a importância do equilíbrio de gênero são regularmente divulgadas durante as feiras através de mensagens políticas que os clientes podem observar nos banners colocados por trás das arquibancadas ou nas próprias camisas dos agricultores. A expressão das mensagens políticas é identificada também, através das falas dos organizadores das feiras ou dos agricultores mais comprometidos na implementação do projeto agroecológico.

Devido à demanda para apoiar a comercialização dos produtos, o estado do Maranhão começou a organizar um roteiro de feiras estaduais. O governo disponibiliza "kits feiras" para os agricultores. Todavia, apesar do sucesso desta iniciativa, ela foi bastante criticada pelos movimentos da agroecologia política, os quais implementaram uma rede automonitorada que evita a venda de produtos convencionais nas feiras que participam, enquanto que naquelas organizadas pelo estado, os agricultores participantes comercializam produtos não agroecológicos.

A garantia científica do projeto de agroecologia política foi possível através da participação de ex-alunos do mestrado de agroecologia da UEMA na coalizão formada pela RAMA. Esses membros da RAMA trabalham como assessores técnicos na AGERP ou nas ONGs que implementam os projetos de agroecologia no Maranhão. Recentemente, essa base científica foi consolidada após a aproximação entre a RAMA e os núcleos de estudos em agroecologia (NEAs) coordenados pelos Institutos Federais de Educação, Ciência e Tecnologia do Maranhão (IFMA).

Fomentados por meio de chamadas públicas do Conselho Nacional de Desenvolvimento Científico e Tecnológico (CNPq), esses NEAs "procuram

7 Contendo barracas, Equipamentos de Proteção Individual (EPI's), gaiolas plásticas vasadas, caixas de isopor com válvula e balanças eletrônicas digitais com capacidade de $20 \mathrm{~kg}$. 
garantir espaços de diálogo e o exercício da indissociabilidade entre pesquisa-ensino-extensão, em constante e permanente interação com a sociedade" (SOUZA et al., 2017). Por exemplo, o NEA do IFMA, Campus Monte Castelo, que reúne agricultores, estudantes, docentes e técnicos, realizou entre 2013 e 2017 várias atividades de pesquisa, ensino e extensão, como trocas de experiências entre o saber local e o científico, oficinas, e intercâmbios para promover o conhecimento agroecológico no campo e na academia (MARQUES et al., 2018).

Com o fortalecimento das atividades de formação e extensão em agroecologia implementadas no Maranhão, o tema entrou na agenda de educação ambiental da Secretaria de Estado da Educação (SEDUC). Assim, o Plano Estadual de Educação Ambiental do Maranhão que foi aprovado em 2017, visa a "capacitar os agricultores na perspectiva da agroecologia", ao "fortalecimento dos sistemas agroecológicos de plantio integrado" e a apoiar "ações educativas para agricultores familiares sobre uso de técnicas agroecológicas utilizando materiais didáticos (cartilhas e vídeos)". A agroecologia entrou no ensino fundamental e na educação do campo depois de demandas das famílias, e a SEDUC resolveu fomentar projetos e atividades dos Institutos de Educação, Ciência e Tecnologia do Maranhão (IEMAs) voltados a agroecologia.

Outro marco importante que contribuiu na institucionalização da agroecologia foi a alternância política que ocorreu em 2014 com a eleição do governador Flávio Dino (PC do B). Apoiado pelos movimentos sociais em favor da agricultura familiar, o Governo Dino estabeleceu uma Secretaria da Agricultura Familiar (SAF) em 2015. A aproximação entre a Secretária Adjunta de Extrativismo, Povos e Comunidades Tradicionais da SAF e os membros mais ativos da RAMA consolidou a coalizão da agroecologia. Um espaço de debate foi institucionalizado dentro do Conselho Estadual de Desenvolvimento Rural Sustentável e Solidário (CEDRUS). Embora a agroecologia fosse um assunto de discussão novo no CEDRUS, já existia uma proposta concreta de plano de ação em favor da agroecologia preparada pela RAMA. A Secretaria adjunta passou a considerar essa proposta, e os serviços técnicos e jurídicos da SAF transformaram esse texto em projeto de lei.

Assim, a eleição do governo Dino criou uma janela de oportunidade política (KINGDON, 1995). Este conceito se refere à formação de três fluxos que, combinados, levam a inserção de questões sociais na agenda governamental, de modo a garantir que as mesmas sejam discutidas e transformadas em políticas públicas.

Kingdon (1995) fala de "fluxo de problemas", ou seja, os problemas que se tornam objeto de atenção dos tomadores de decisão. No caso do Maranhão, os problemas são bastante documentados com indicadores relevantes: pobreza 
no meio rural; conflitos sociais no campo; impacto ambiental e social do avanço do agronegócio, em particular na área do MATOPIBA ${ }^{8}$; e a necessidade de promover um modelo agrícola alternativo e sustentável. O segundo fluxo do modelo de Kingdon (1995) é o "fluxo de políticas" (ou fluxo de solução), que tem como pressuposto a existência atores que já elaboraram soluções viáveis que podem ser transformadas em políticas públicas. No que tange a PEAPOMA, este fluxo de política é representado pelo próprio plano de ação estratégico construído pelos atores da RAMA. O terceiro fluxo é o "fluxo político" que corresponde ao ambiente político do momento, ou seja, uma fase de adequação de valores entre os governos e os governados, que muitas vezes ocorre no momento de mudanças políticas, em particular quando o governo é eleito com uma base eleitoral forte. Esse fluxo político se materializou em 2015 quando foi criada a SAF pelo governador do Maranhão recém-eleito. Assim, a combinação desses três fluxos criou uma janela de oportunidade para incorporar a questão da agroecologia na agenda governamental.

\section{Resultados, perspectivas e preocupações dos atores}

A PEAPOMA foi aprovada por lei no dia 21 de dezembro 2018, com alguns vetos relacionados a questões de constitucionalidade. Um novo projeto de lei está em discussão para superar os vetos e estabelecer uma comissão paritária de gestão da lei contando com a participação de oito representantes do governo e oito membros da sociedade civil vinculados à RAMA. Essa nova organização formaria a Comissão Estadual de Agroecologia e Produção Orgânica do Maranhão (CEAPOMA). Os grandes eixos de debates atuais focam na questão do enquadramento da PEAPOMA e as condições para o recebimento de recursos financeiros do Fundo Especial do Meio Ambiente (FEMA) e do Fundo Maranhense de Combate à Pobreza (FUMACOP).

É importante destacar que, apesar de ter a sua lei regulamentada, até o presente momento, não foram formulados no estado do Maranhão nenhum Decreto de implementação da PEAPOMA, nem o Plano Estadual de Agroecologia e Produção Orgânica (PLEAPOMA). Contudo, na lei, se destaca, entre outras, as diretrizes e instrumentos seguintes:

- Estruturação dos circuitos de produção dando preferência aos mercados locais, regionais e institucionais; certificações socioparticipativas e sistemas de garantias;

8 O Decreto $n^{0} 8.447$, de 6 de maio de 2015 dispõe sobre o Plano de Desenvolvimento Agropecuário do MATOPIBA (região definida pelos acrônimos dos estados do Maranhão, Tocantins, Piauí e Bahia) e a criação de seu Comitê Gestor. 
- Internalização da perspectiva agroecológica nas instituições de ensino, pesquisa e extensão;

- Valorização da agrobiodiversidade e dos produtos da sociobiodiversidade;

- Criação de territórios livres de transgênicos.

Além disso, os entrevistados sinalizam questões que eles consideram como prioritárias, particularmente na perspectiva da formulação do PLEAPOMA. Um dos maiores problemas da transição agroecológica no Maranhão é a formação e a apropriação das técnicas agroecológicas pelos agricultores familiares. Neste sentido, dar visibilidade a experiências exitosas, através de intercâmbios e trocas de experiências, deve constituir um assunto chave de implementação da PEAPOMA. A capacitação dos funcionários de ATER em agroecologia é considerada como uma outra necessidade prioritária, sendo que a ATER pode ter um papel fundamental de difusão das técnicas agroecológicas no estado.

Uma das questões que a PEAPO precisa resolver é a do acesso ao mercado para produtos da agroecologia. Geralmente a venda dos produtos agroecológicos se realiza no mercado convencional, sem possibilidade de diferenciar os atributos e a qualidade desses produtos. A lei gera expectativas de levar recursos para melhorar o acesso ao mercado através de cursos sobre empreendedorismo, implementação de sistemas de diferenciação dos produtos agroecológicos como os sistemas participativas de garantia (SPG), ou apoio a organização das cadeias produtivas.

Finalmente, o acesso às linhas de financiamento da produção agroecológica, em particular através do PRONAF-AE (Programa Nacional de Fortalecimento da Agricultura Familiar - Agroecologia), ainda é uma questão prioritária, já que no período atual, esse programa não funciona. Muitas organizações esperam que a PEAPOMA facilite a relação entre os agricultores familiares engajados na agroecologia e os bancos. Contudo, as organizações que apoiam o projeto de agroecologia no Maranhão ficam preocupadas com a falta de apoio das organizações do estado, com exceção da SAF. As questões de regularização fundiárias ainda precisam ser resolvidas para implementar o projeto de agroecologia no estado, mas essas questões dependem de outras instituições como a Secretaria de Estado da Agricultura, Pecuária e Pesca (SAGRIMA) e o Instituto de Colonização e Terras do Maranhão (ITERMA), que possuem gestores com outra visão a respeito do desenvolvimento agrícola no Maranhão. 


\section{Conclusão}

Instituída no final de 2018, a PEAPOMA caracteriza-se por nascer das reivindicações e ações da sociedade civil organizada, em torno da pauta agroecológica no Maranhão. A institucionalização da PEAPOMA beneficiou-se de uma "janela de oportunidade política" aberta no Poder executivo estadual, com a criação da Secretaria da Agricultura Familiar. Essa política tinha sido construída de forma participativa, através da atuação de uma coalizão ampla formada por organizações sociais diversas representadas pela RAMA e funcionários do Estado aliados aos movimentos da agricultura familiar.

Contudo, apesar do sucesso óbvio, a coalizão ampliada em favor da agroecologia apresenta algumas fragilidades, em particular porque os atores da coalizão não compartilham exatamente a mesma visão da agroecologia. Os atores que se situam na corrente de ideias "alternativa" juntam-se com os movimentos que representam a agroecologia como uma agricultura familiar de base ecológica competitiva, gerando uma tensão latente. Essa tensão se exprime com maior intensidade em relação ao orçamento destinado à agroecologia, quando o mesmo entra em competição com o orçamento destinado à agricultura familiar. A consolidação da agroecologia no Maranhão precisa superar essas tensões.

\section{Agradecimentos}

Esse artigo é resultado de uma pesquisa realizada no marco dos projetos IDAE (ANR-15-CE21-0006), ODYSSEA (UE H2020, Marie Skłodowska-Curie grant agreement 691053). Contou com o apoio da Agence Nationale de la Recherche (ANR), da União europeia, e da Fundação de Amparo à Pesquisa e ao Desenvolvimento Científico e Tecnológico do Maranhão (FAPEMA) no âmbito do programa Ignácio Rangel. Os autores agradecem o apoio dessas instituições. Os autores agradecem à Luana da Silva Rocha, discente do curso de Licenciatura em Ciências Humanas da UFMA-Bacabal, que colaborou com assistente de pesquisa neste projeto. 


\section{REFERÊNCIAS}

IBGE. Produção Agrícola - Lavoura Temporária. Soja / Área plantada / Maranhão. 2018a. Disponível em: <https://cidades.ibge.gov.br/brasil/ma/pesquisa/14/10366?tipo=grafico\&indicador=10370>. Acesso em: 22 jun. 2019 .

. Sistema de Contas Regionais: Brasil 2016. 2018b. Disponivel em: <https://biblioteca.ibge.gov.br/visualizacao/livros/liv101619_informativo.pdf>. Acesso em: 22 jun. 2019.

KINGDON, J. W. Agendas, alternatives, and public policies. 2. ed. New-York: Harper Collins, 1995.

LASCOUMES, P.; LE GALÈS, P. Sociologia da Ação Pública. Maceió, EDUFAL, 2012.

LIMA NETO, E. O associativismo em áreas de babaçuais: a experiência das organizações de trabalhadores rurais do Município de Lago do Junco-MA associadas à ASSEMA. 2014. Dissertação (Mestrado) - CPDA / Universidade Federal Rural do Rio de Janeiro, Instituto de Ciências Humanas e Sociais, 2014.

LOCH, V. D. C. et al. Os 19 Anos da Rede Agroecológica do Maranhão: contribuições e desafios. Cadernos de Agroecologia, v. 13, n. 1, 2018.

MARANHÃO (Estado). Lei ordinária no 10.986 de 24 de dezembro de 2018. Institui a Política Estadual de Agroecologia e Produção Orgânica do Maranhão (Peapoma). Diário Oficial [do Estado do Maranhão], ANO CXII Nº 241 São Luís, segunda-feira, 24 de dezembro de 2018.

MARQUES, G. E. et al. Vivências, saberes e experiências para a construção do conhecimento agroecológico. Revista Brasileira de Agroecologia, v. 13, n. esp, p. 143-152, 2018.

MATTEI, L. A política agrária e os retrocessos do governo Temer. OKARA: Geografia em debate 12, p. 293-307, 2018.

MMA. Mapeamento do uso e cobertura do Cerrado: projeto TerraClass Cerrado. Ministério do Meio Ambiente. Brasilia, 2015. 
Plano de Ação para Prevenção e Controle do Desmatamento e das Queimadas no Cerrado. $4^{\mathrm{a}}$ Fase (2016-2020). Ministério do Meio Ambiente. Brasília: 2018

NIEDERLE, P. A. et al. A trajetória brasileira de construção de políticas públicas para a agroecologia. Redes, v. 24, n. 1, p. 270-291, 2019.

NORDER, L. A.; LAMINE, C.; BELLON, S. Agroecologia: Polissemia, pluralismo e controvérsias. In: BRANDENBURG, Alfio; BILLAUD, Jean-Paul; LAMINE, Claire. Redes de agroecologias: experiências no Brasil e na França. Curitiba: Kirós Edições, 2015.

ROCHA, R. G. O processo de ocupação do Sul do Maranhão: dinamismo econômico e des (re)ordenamento territorial. InterEspaço: Revista de Geografia e Interdisciplinaridade, v. 1, n. 1, p. 5-26, 2015.

RODRIGUES, S. J. D. Organização camponesa em Balsas/MA e a expansão do agronegócio da soja: implicações e resistências no sul do Maranhão. 2010. Dissertação Mestrado (Desenvolvimento e Meio Ambiente) - UFC, Fortaleza, 2010.

RODRIGUES, V. V.; TERRA, A. O drama camponês no Cerrado Sul Maranhense: conflitos socioterritoriais no campo em Balsas-MA. Revista de geografia agrária, v. 13, n. 31, p. 191-207, 2018.

SAMBUICHI, R. H. R. et al. Análise da construção da política nacional de agroecologia e produção orgânica no brasil. Brasilia: IPEA, 2017.

SANTOS, F. B. dos; TAVARES, J. C. Questão Agrária e violência no Maranhão: grilagem, colonização dirigida e a luta dos trabalhadores Revista de Políticas Públicas, São Luís, v. 20, n. 1, p. 361-382, jan./jun. 2016.

SCHMITT, C. et al. La experiencia brasileña de construcción de políticas públicas en favor de la Agroecología. In: POLÍTICAS públicas a favor de la agroecología en América Latina y El Caribe. Porto Alegre: Criação Humana/Red PP-AL/FAO, 2017. p. 73-122.

SODRÉ, R. B. et al. As faces do agronegócio maranhense: uma análise da expansão agrícola e do aumento da violência no campo. Geosul, v. 34, n. 71, p. 599-622, 2019. 
SOUZA, N. A. et al. Os Núcleos de Agroecologia: Caminhos e desafios na indissociabilidade entre ensino, pesquisa e extensão. In: SAMBUICHI, R. H. R. et al. (Eds.). A política nacional de agroecologia e produção orgânica no Brasil. Uma trajetória de luta pelo desenvolvimento rural sustentável. Brasília: IPEA, 2017. p. 403-431. 


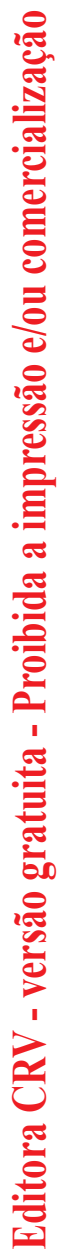




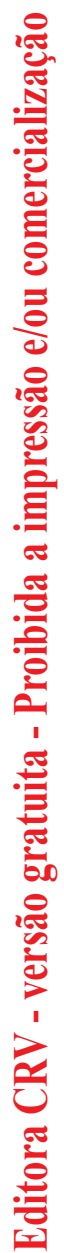

\section{REGIÃO CENTRO-OESTE}




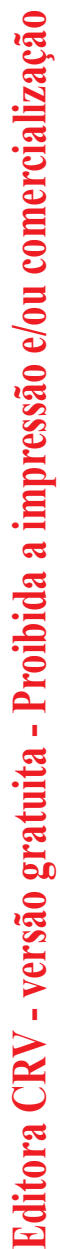




\title{
CAPÍTULO 11
}

\section{A REDE DE AÇÃO PÚBLICA EM TORNO DA AGROECOLOGIA E PRODUÇÃO ORGÂNICA NO DISTRITO FEDERAL}

\author{
Eric Sabourin \\ Luiz Raimundo Tadeu da Silva \\ Mario Lucio de Avila
}

\section{Introdução}

Desde 2013, o Brasil conta com uma Política Nacional de Agroecologia e Produção Orgânica (PNAPO) que reúne mais de 120 ações de dez ministérios sob a coordenação da Secretaria da Presidência da República. As ações foram conduzidas a nível federal de acordo com o I Plano Nacional de Agroecologia e Produção Orgânica, o PLANAPO 1, para o período de 2012 a 2015 (SCHMITT et al., 2017). Alguns estados federados passaram a adotar e construir esse tipo de política em paralelo ou depois da promulgação da PNAPO, em diálogo com a sociedade civil mediante câmaras ou comissões estaduais de agroecologia e produção orgânica (GUÉNEAU et al., 2019). O artigo apresenta uma análise da recém-criada Política Distrital de Agroecologia e Produção Orgânica do Distrito Federal (PDAPO-DF), promulgada em janeiro de 2017. Essa política, sendo muito recente, não pode ainda ser avaliada, no entanto, foi precedida por uma série de iniciativas, instrumentos, programas que contribuíram para a sua formulação (TADEU DA SILVA, 2019). É, mais especificamente, o exame dessa trajetória, dos seus atores e processos que caracteriza o presente estudo. O referencial teórico para a abordagem da PDAPO e dos dispositivos e instrumentos que a antecederam bas,eia-se no referencial conceitual e metodológico da sociologia da ação pública (LAGROYE et al., 2006; LASCOUMES; LE GALES, 2012), Lagroye et al. (2002) definem a ação pública como o "conjunto de efeitos, não necessariamente previsíveis e coerentes, resultantes de interações entre instituições interdependentes, entre os agentes dessas instituições e uma quantidade de atores sociais interessados pelas decisões políticas" (LAGROYE et al., 2002, p. 501).

A noção de rede de ação pública completa o enfoque em torno das relações entre os atores que promovem as políticas. Mobilizamos esse conceito, porque se adéqua melhor a realidade institucional fragmentada da agroecologia 
no DF que ainda não constitui um verdadeiro movimento social estruturado e estabilizado. Segundo Rhodes (2008)

As redes de políticas públicas são conjuntos de ligações institucionais formais e informais entre agentes governamentais e outros atores estruturados em torno de crenças e interesses compartilhados, negociados de forma permanente, na formulação e implementação de políticas públicas (RHODES, 2008, p. 426).

Nossa principal hipótese é que os diversos instrumentos e programas a favor da agroecologia implementados no DF, e, finalmente, a PDAPO-DF, foram promovidos por uma coalizão reunindo agroecologia e produção orgânica em torno de dois principais grupos de interesse. O grupo de interesse é uma entidade organizada que procura influenciar os poderes políticos numa direção favorável a seu próprio interesse (SAURRUGER, 2014). Uma segunda hipótese considera que esses grupos de interesse, embora defendam em primeiro lugar suas próprias causas, conseguiram interagir ou se unir, constituindo uma rede de ação pública a favor da agroecologia e da produção orgânica, mais ou menos estruturada e mais ou menos forte segundo nos diversos momentos de sua trajetória desde os anos 1980 até hoje (TADEU DA SILVA, 2019).

A metodologia combina a análise de documentos e arquivos com entrevistas de 17 atores-chaves, gestores, políticos, técnicos, acadêmicos e representantes das organizações de agricultores. Foi aplicado um arcabouço analítico comum a outros estudos sobre as políticas estaduais de agroecologia e produção orgânica no Brasil realizados no marco dos trabalhos da Rede "Políticas Públicas e Desenvolvimento Rural na América Latina" (SABOURIN et al., 2018; GUENEAU et al., 2019). O artigo está dividido em quatro partes. A primeira apresenta os atores e instituições-chaves no processo de construção da PDAPO-DF; a segunda introduz as suas representações e a terceira os processos e coalizões; finalmente a quarta parte trata da governança e dos instrumentos.

\section{Os atores-chaves e a sua trajetória na promoção da agroecologia e da produção orgânica no DF}

\section{Os pioneiros: um grupo de elite programática}

A maioria das ações de promoção da agroecologia e da produção orgânica no DF passa por um pequeno grupo de agrônomos militantes da agricultura alternativa que promoveu iniciativas individuais e integrou o movimento social da agricultura alternativa no DF desde o final dos anos de 1980. Eles se 
tornaram líderes de movimentos sociais, por exemplo, na Federação de Agrônomos do Brasil, e criaram, em 1989 em Brasília, a Associação de Agricultura Ecológica (AGE). A partir das décadas de 1980 a 1990, passaram a ocupar espaços públicos e privados e a atuar a favor da agricultura ecológica. Por exemplo, dentre os entrevistados e entrevistadas, uma foi produtora e é, hoje, Presidente da AGE; um foi técnico e logo responsável da produção orgânica e agroecológica na Empresa de Assistência Técnica e Extensão Rural do DF (EMATER-DF); outro foi responsável pela produção orgânica e logo agroecológica no Ministério de Agricultura Pecuária e Abastecimento (MAPA), outro se tornou dono da maior empresa de orgânicos do DF. Este último foi deputado distrital, Secretário de Ciência e Tecnologia do DF e até Presidente da EMATER e promoveu a criação da AGE e do Sindicato dos Produtores de Orgânicos do DF (Sindiorgânicos).

Outros membros desse grupo ocuparam cargos na área de ensino e pesquisa e extensão como professores e pesquisadores na Universidade de Brasília (UnB), no Instituto Federal de Brasília (IFB), na Empresa Brasileira de Pesquisa Agropecuária (EMBRAPA) e na EMATER-DF. Podemos reconhecer nesses pioneiros um grupo de "elites programáticas" de vários instrumentos e dispositivos de agroecologia no DF e até da gênese da atual PDAPO-DF. De acordo com Genieys (2007), as elites programáticas se caracterizam por trajetórias setoriais na alta administração do Estado, onde combinam habilmente uma aprendizagem profissional específica que coincide com o contorno atual das políticas públicas. Pudemos verificar isso com as carreiras de quatro desses pioneiros na esfera federal (MAPA, EMBRAPA e UnB) e distrital (Deputado, Direção da EMATER, da Secretaria de Ciência e Tecnologia). Eles desenvolveram estratégias de carreira ancoradas em torno de um tema privilegiado e setor público específico: aqui a agroecologia e a produção orgânica. O seu poder se manifesta por uma alta concentração de capacidade em torno de um programa de ação pública singular resultando na formação de um sentido forte de identidade do grupo.

\section{Uma trajetória de "transição agroecológica institucional"}

A noção de Agroecologia emerge como novo conceito da agricultura alternativa nos anos 2000 (LUZZI, 2007). Mas segundo os técnicos da EMATER-DF, foi difícil mudar o rumo das instituições de ciência e tecnologia e da Secretaria de Agricultura. Nos anos 1990 existia, segundo o seu então Presidente, "uma atividade dispersa da EMATER-DF a favor da agricultura mais comercial". Em 1999, a Secretaria de Estado da Agricultura, Abastecimento e Desenvolvimento Rural do Distrito Federal (SEAGRI-DF) financiou um 
incentivo à produção orgânica no âmbito do Plano de Desenvolvimento Rural do Distrito Federal (ProRural), um programa de apoio às cadeias produtivas. Na continuidade das ações da AGE e da EMATER-DF, a Comissão da Produção Orgânica (CPORG) do DF é criada em 1999 e o Sindiorgânicos, em 2002.

Segundo a então coordenadora de agroecologia, na EMATER-DF houve um processo de "transição agroecológica institucional". Foi também determinante a força dos movimentos sociais para trazer a agroecologia aos assentamentos de reforma agrária do DF. O Ministério do Desenvolvimento Agrário (MDA) financiou a assistência técnica agroecológica (ATER Agroecológica) a partir da Política Nacional de Assistência Técnica e Extensão Rural (PNATER) de 2004 e a comercialização com preços diferenciados para produtos orgânicos, mediante o Programa de Aquisição de Alimentos da agricultura familiar (PAA). Em 2005, um Arranjo Produtivo Local (APL) centrado na produção orgânica foi lançado pelo governo do DF com o objetivo de reforçar os laços e intercâmbios de conhecimentos entre os atores. Hoje a EMATER-DF conta com extensionistas capacitados em agroecologia e produção orgânica.

Os responsáveis da EMATER reconhecem que a agroecologia no DF, concretamente, tem progredido muito pela influência dos movimentos sociais de luta pela terra. A produção agroecológica familiar do DF está na sua grande maioria restrita aos assentamentos. Não foi por acaso que a CNAPO, para o PLANAPO II exigiu mais esforço de reforma agrária ou fundiária (mais acesso à terra) para promover a agroecologia.

A trajetória das ações, eventos e instrumentos a favor da agroecologia e produção orgânica no DF é marcada por três fases:

- 1980 a 1998: da agricultura alternativa à agricultura ecológica, marcada pela AGE;

- 1999 a 2008: a consolidação da produção orgânica em 2008, após a criação da CPORG e do Sindiorgânicos, com a instalação do Mercado Orgânico na Central de Abastecimento do Distrito Federal (CEASA-DF);

- de 2008 até hoje, com a emergência de instrumentos para a agroecologia, o florescimento das feiras agroecológicas, com a criação da Articulação Brasiliense de Agroecologia (ABRAA) em 2008 (na base de funcionários da Embrapa, EMATER-DF, UnB e IFB), da PNAPO em 2012, da PDAPO-DF em 2017 e a realização do Congresso Brasileiro de Agroecologia em Brasília no mesmo ano. 


\section{Representações: as concepções da agroecologia na PDAPO}

O texto da PDAPO-DF oferece várias definições dos conceitos utilizados. Elas retomam os termos utilizados no texto da PNAPO. No entanto, não diferencia claramente a agroecologia (termo genérico, mas amplo para uma "agricultura ecológica ampliada a justiça social”) e a produção orgânica é qualificada como "um dos sistemas de produção para chegar à agroecologia, ao lado dos sistemas de produção de base agroecológica" (DISTRITO FEDERAL, 2017, p. 2).

Segundo a então coordenadora do programa de agroecologia e produção orgânica da EMATER-DF, foi preciso sensibilizar os produtores para alternativa de transição para agroecologia por meio das práticas concretas e não do discurso e da ideologia. Para ela, "a produção orgânica é diferente da agroecologia; é mais uma substituição de insumos que de práticas e de concepção, mas as duas têm a ligação comum de responder a uma demanda crescente do mercado dos consumidores do DF". Ainda considera que "agroecologia permite responder a uma diversidade de demandas e de situação, mas sem pretensão a gerar automaticamente uma conversão" (Entrevista, 2018).

Os membros da Articulação Brasiliense de Agroecologia (ABRAA) adotam a definição da ecologia política e da ecologia "como ciência" (ALTIERI, 1995). Um fundador da AGE que foi responsável pela primeira Coordenação da produção Orgânica no MAPA, relata que "quando a gente escreveu a Lei nacional da agricultura orgânica, e depois quando a gente construiu o regulamento, o decreto, em 2007, usamos como princípios da agricultura orgânica os princípios da agroecologia. Então se você pega o começo da lei, o que se considera e quais são os objetivos da agricultura orgânica são os princípios da agroecologia" (Entrevista, 2018).

Para a presidente da AGE, no DF agroecologia e produção orgânica são irmãs gêmeas, "filhas da agricultura alternativa da década de 1980, pois gravitam em torno do mesmo eixo composto pelo tripé: não uso de fertilizante químico, não uso de agrotóxico e preservação do ambiente" (Entrevista, 2018). Além disso, a agroecologia para a AGE, é um movimento contra hegemônico, uma forma de produzir alimentos, recompondo e mantendo a paisagem natural do terreno. Significa produzir alimentos paralelamente a um trabalho de recomposição ou manutenção do ecossistema em função da paisagem natural.

Por fim, entendem que na produção orgânica pode-se modificar toda a paisagem natural e plantar diversos hectares de um mesmo produto. Tanto é que a certificação é direcionada para o produto e não para a propriedade. Então pode ter um produto orgânico que não é oriundo de uma produção 
agroecológica. Porém, segundo a perspectiva da agricultura alternativa, agroecologia e produção orgânica são formas de atuação diferentes, mas não antagônicas. Gliessman (2014) reconhece que a produção orgânica é um dos caminhos da transição agroecológica. O mesmo ocorre com lideranças entrevistadas "o meu produto é orgânico e sua produção é agroecológica, por isso minha órbita dentro do sistema é mais que produzir alimentos saudáveis... Vou dizer que a minha produção é agroecológica e a certificação garante que o produto é orgânico" (Entrevista, 2018).

Para vários membros da ABRAA, essa preocupação não é nova e deve ser recolocada no espectro das forças e das etapas numa trajetória para fortalecer uma coalizão a fim de promover a agroecologia. Reconhecer a produção orgânica e associar o movimento social da agricultura biológica ou orgânica ao movimento da agroecologia era essencial é indispensável, conforme expressa uma liderança entrevistada:

porque a gente optou por agricultura orgânica nos anos 90? Foi um consenso, tínhamos a Federação Internacional dos Movimentos de Agricultura Orgânica (IFOAM) que tinha essa visão, tínhamos os EUA com a sua Lei dos orgânicos, entendíamos, naquele momento, que a sociedade estava mais preparada para uniformizar o sentido em termos de agricultura orgânica (Entrevista, 2018).

No entanto, segundo animadores do Núcleo de Estudos de Agroecologia (NEA) da UnB, essa proximidade "pragmática" entre agroecologia e produção orgânica termina mantendo nas instituições e nas políticas públicas do DF uma visão reduzida da agroecologia, uma versão mais tecnológica quando não tecnocrática.

\section{Os processos: grupos de interesse e coalizões políticas}

O grupo de interesse dos produtos orgânicos e o da agroecologia têm a mesma origem: os pioneiros dos anos 1980. No entanto, segundo os temas e os momentos, estes grupos vão defender propostas comuns ou propostas próprias a interesses específicos.

O grupo dos servidores do DF e do governo federal compartilha ações e apoia, de forma alternada, os dois grupos de interesse: o de produtores agroecológicos e o de empresários orgânicos. Esses três grupos de interesse formam uma coalizão ampla que promoveu políticas públicas de agroecologia e produção orgânica e compete por recursos públicos com a coalizão da agricultura familiar produtiva (público do PRONAF) e com a coalizão do agronegócio. Não analisaremos aqui as relações entre essas três coalizões da agricultura 
no DF. Apenas vamos examinar os atores, componentes, propostas e ações defendidas por cada um desses grupos de interesse que configuram a coalizão da agroecologia e da produção orgânica (ver Quadro 1). O importante é notar que, no caso específico do DF, esses três grupos de interesses foram capazes de se unir, apesar das diferenças, para avançar em uma proposta de apoio público a uma agricultura mais ecológica e a produtos orgânicos certificados.

\section{O grupo de interesse da produção orgânica}

O grupo de interesse da produção orgânica se fortalece quando é necessário um processo de certificação para distinguir produtos realmente agroecológicos e orgânicos de outros produtos nas feiras e outros pontos de venda de Brasília. Este grupo foi determinante na criação da CPORG e na certificação dos produtos. É conduzido por produtores cuja manutenção depende da venda da sua produção, tendo sido progressivamente liderado por produtores maiores (médios e empresários) como a Malunga, o sitio Corujinha, a AGE.

Não tinha nada que desse mais raiva para gente quando começamos com a nossa feirinha da Asa Norte, na Messiânica, que uns caras que montaram uma feira do outro lado da rua, com a faixa de produto orgânico, mas compravam na CEASA e por isso tinham muito mais itens que nós. Assim a gente não podia fazer nada, porque não tinha legislação que punisse o que eles estavam fazendo. Qualquer um podia se denominar produtor orgânico porque não tinha nada que impedisse. Então, para mim era muito claro que ter uma legislação era parte do processo (Entrevista, 2018).

Segundo os produtores pioneiros entrevistados, eles "conseguiram, no primeiro momento, sobreviver e não falir porque agregaram valor econômico ao produto e tiraram alguns atravessadores". No ano de 1995, organizaram o $1^{\circ}$ Seminário de Agricultura Alternativa do Distrito Federal. Em 1999 criam a CPORG do DF e em 2002 eles tiveram acesso à certificação por meio do Sindiorgânicos. Para os produtores isso foi essencial: "Agora não precisa mais o produtor falar com o consumidor de que seus produtos são saudáveis e preservam o meio ambiente. Tem uma instância que certifica isso" (Entrevista, 2018).

Depois da criação do Sindiorgânicos, com o apoio da Fundação Mokiti Okada, do Serviço e Apoio às Micro e Pequenas Empresas do DF (SEBRAE-DF), da ECOCERT Brasil, os esforços dos produtores orgânicos grandes e médios do DF (Malunga, AGE e outros) se concentraram na obtenção de um espaço de comercialização na CEASA-DF (ver Quadro 1). Para isto, teceram alianças mais amplas para obter apoio do MDA, da SEAGRI-DF e até da Confederação Nacional dos Trabalhadores na Agricultura (CONTAG) que 
apoiava um projeto de comercialização da Região Integrada de Desenvolvimento do Distrito Federal e Entorno (RIDE-DF) na CEASA, justificando o envolvimento de 80 agricultores familiares do DF. Para isso foi criada a Associação do Mercado Orgânico do DF, dirigida por um núcleo de pequenos empresários. Em 2004, um financiamento do MDA foi obtido para a construção do mercado através do Território da Cidadania Águas Emendadas. No entanto, o projeto teve que esperar até 2008 para ser concretizado com um cofinanciamento da SEAGRI-DF e um complemento da Secretaria de Ciência e Tecnologia do DF.

Os integrantes desse grupo de interesse, e em particular suas lideranças, têm uma visão empresarial e comercial da produção orgânica e agroecológica. Essa estratégia convém bastante para uma demanda urbana como a de Brasília, para venda em supermercados, restaurantes, lojas orgânicas e feiras. No entanto, para poder escoar quantidades importantes, esse grupo precisava também de um espaço comercial estrategicamente situado na CEASA-DF. Depois de experiências de venda improvisada no estacionamento da CEASA, mas sem nenhuma infraestrutura, o grupo se consolidou e, ao mesmo tempo se fechou de certo modo, com o projeto do Mercado Orgânico do DF. Nessa empreitada o grupo contou com o apoio de instituições que compartilham essa visão empresarial como o SEBRAE, o Sindicato dos Orgânicos e a Ecocert Brasil. A aliança provisória com a Agência Regional de Comercialização para Agricultura familiar da RIDE-DF (ARCO) criada por iniciativa da CONTAG, foi mais estratégica para obter o financiamento do Mercado Orgânico por meio MDA, no marco do Território Águas Emendadas (LANDEL, 2009).

A trajetória do projeto do Mercado Orgânico mostra a habilidade e a atuação estratégica de verdadeiros "empreendedores de política pública". Para Kingdon (1984) são pessoas dispostas a investir seus recursos - tempo, energia, reputação e dinheiro para promover uma posição em troca de um ganho futuro antecipado na forma de benefícios materiais, propositais ou solidários. Massardier define assim esse perfil:

Eles têm três qualidades i) a capacidade de ouvir os outros e de falar em seu nome, ocupando uma posição de decisão; ii) a capacidade de ser reconhecidos pelo seu capital social, por seus recursos em termos de rede e competências de negociador; ii) pela sua persistência e tenacidade na ação. Estes empreendedores de políticas públicas procuram seus próprios benefícios na promoção de uma concepção de política pública que tentam impor na agenda política (MASSARDIER, 2008, p. 36).

Uma das características dos empreendedores de políticas públicas é exercer o papel de mediadores que podem traduzir as reivindicações vinculadas aos problemas em "dossiês" aceitáveis pelas administrações, tanto para sugerir 
textos jurídicos como instrumentos de ação pública. Neste sentido, sua atuação vai além daquela dos grupos de pressão ou de interesse.

Landel (2009) mostra, em particular, a evolução das alianças construídas para obter apoio público para o Mercado Orgânico. O projeto inicial contava apenas com pequenos empresários. Em 2005, para obter o financiamento do MDA, justifica-se o ingresso de 80 agricultores familiares. Em 2009, a associação de produtores é substituída por uma cooperativa que requer um mínimo de 20 sócios, assim foram mantidos apenas dois ou três agricultores familiares a título simbólico.

\section{O grupo de interesse da agroecologia}

Esse grupo de interesse reúne os intelectuais e técnicos reunidos na ABRAA e algumas lideranças da produção familiar agroecológica do DF, basicamente de assentamentos da reforma agrária que seguiram os cursos promovidos pelo IFB, a UnB, a EMATER-DF ou a EMBRAPA Hortaliças. O grupo se consolidou em torno da expressão local e principalmente dos membros do movimento social brasileiro da agroecologia, a Articulação Nacional da Agroecologia (ANA) e a Associação Brasileira de Agroecologia (ABA). Segundo um dos coordenadores regionais da ABA,

A terminologia agricultura orgânica já vinha se consolidando e a colocação do Altieri é que a agroecologia era a base científica. Isto foi fundamental para responder às críticas e brigas na Federação de Associações de agrônomos onde nos diziam anti-ciência e que nós estávamos indo contra a ciência moderna da agricultura que embasava a revolução verde. E que nós éramos contra esses avanços tecnológicos da revolução, e então nós estávamos indo contra a ciência" (Entrevista, 2018).

Esta coalizão se fortaleceu a partir de 2008, com a organização bianual do seminário de agroecologia do DF. A criação da ABRAA aconteceu no processo de organização dos seminários de agroecologia do DF que integraram o sistema de organização do Congresso Brasileiro de Agroecologia (CBA) com encontros regionais a cada dois anos. Não sendo formalizada juridicamente, a ABRAA se caracteriza como uma rede de ação pública, visando debates e difusão do conhecimento agroecológico no DF e região e a implementação de políticas públicas de promoção da agroecologia. Dois tipos de atores integram esta articulação: os indivíduos (pessoas) militantes da Agroecologia e Produção Orgânica e as organizações públicas em que esses indivíduos atuam (ver Quadro 1). Seu objetivo principal é organizar os Seminários de Agroecologia e Produção Orgânica do Distrito Federal. Os seminários não eram elementos de implementação das políticas públicas de desenvolvimento 
rural. Tal articulação de atores, assim como os seminários, influenciaram as instituições públicas na mobilização em favor da agroecologia. Com isso, nasceu em 2012 a ABRAA, cujos membros eram, na sua grande maioria, servidores públicos e estudantes universitários, professores, pesquisadores da EMBRAPA, técnicos da EMATER e de ONGs.

Os seminários são um dos dispositivos que impulsionam o desenvolvimento da agroecologia, tanto nas práticas agrícolas quanto na co-construção de conhecimentos e saberes. Seus resultados reverberam politicamente na ação pública do DF. De fato, os seminários do DF surgiram tanto das ações individuais quanto institucionais, para apresentação dos resultados dos projetos de agroecologia e produção orgânica em curso e das reflexões do movimento. Nesses seminários acontece também a retroalimentação de ideias, reconhecimentos de parceiros e sensibilização de gestores de órgãos governamentais. Assim, os seminários são a estrutura de sentido (o objetivo maior) da ABRAA. Por meio deles se percebe a vontade de construção de uma rede de ação pública dedicada à defesa e ao aprimoramento da PDAPO-DF, bem como ao apoio à gestão local do conhecimento agroecológico. Ela se articula em três níveis: i) no nível pessoal/individual, para ganhar força em suas instituições; ii) no nível institucional; e iii) no nível de ação pública distrital pela união dessas instituições a favor da agroecologia.

A coalizão atuou na difusão do conhecimento agroecológico, e a ABRAA também conseguiu apoio para realizar os eventos, construir agendas, dialogar com deputados e gestores de políticas públicas. A Figura 1 ilustra a trajetória dessa coalizão de ação pública do DF. Os principais resultados da coalizão da agroecologia do DF que perpassam outros espaços além do conhecimento foram capitaneados pela ABRAA. Observou-se, de forma geral, um aumento da circulação de ideias e conhecimentos de temas sobre a agroecologia.

Figura 1 - Linha do tempo das ações da ABRAA e da coalizão da agroecologia no DF

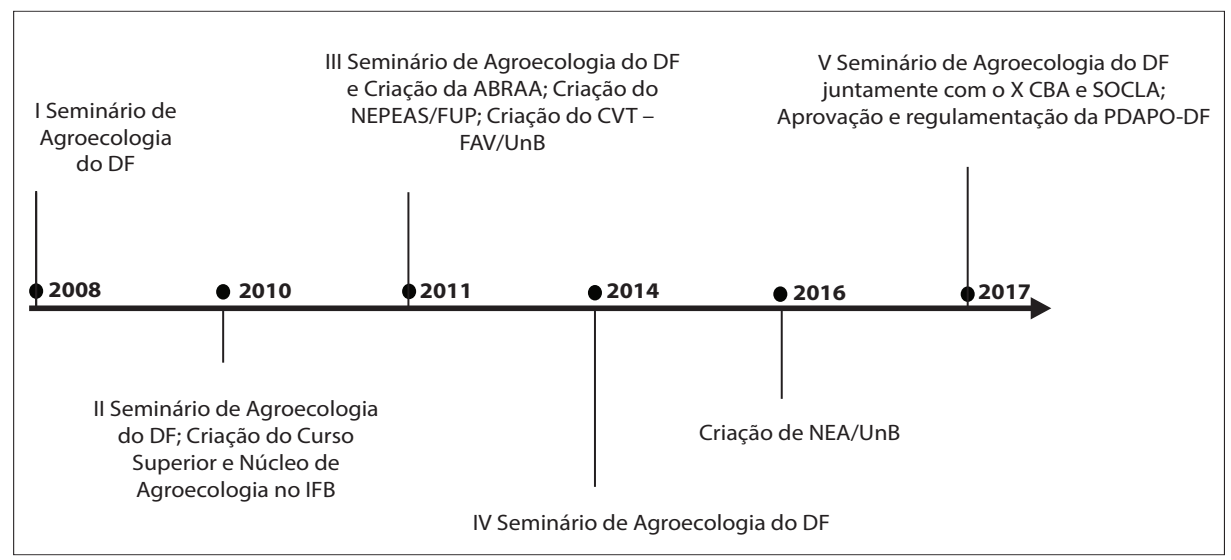


Finalmente, a proposta, a tramitação e a aprovação da PDAPO-DF foram a última conquista dessa rede que colocou seus atores-chaves na Câmara de Agroecologia e Produção Orgânica do DF (CAO). Os grupos dos orgânicos e da agroecologia tiveram enfrentamentos e diferenças internas, inclusive dentro da AGE, quando as preocupações eram contraditórias ou exclusivamente voltadas para a comercialização. Isso levou à saída de vários membros fundadores da AGE, segundo um deles:

\begin{abstract}
Um dos motivos porque eu saí da AGE e outros dos fundadores foi porque ela acabou se transformando numa associação para viabilizar feiras. Então toda reunião da AGE era para discutir os pontos de vendas, quem vai produzir. Não conseguíamos que a AGE fosse o que tinha sido proposto na sua criação, ser um espaço de discussão de como a agricultura alternativa poderia crescer e encapar ações (Entrevista, 2018).
\end{abstract}

De fato, na época das tensões na AGE quem se definia apenas como produtor agroecológico e não dependia apenas das vendas para viver (porque produzia também para o autoconsumo), como os agricultores dos assentamentos de Reforma Agrária do DF, não compartilhava a mesma necessidade de certificação externa e de multiplicar pontos de venda.

No início, os produtores do Assentamento Colônia 1 de Brazlândia, antes da existência da certificação participativa, não eram certificados. Produziam segundo os princípios da agroecologia e vendiam os produtos na base da confiança e da reputação, na Universidade de Brasília, em frente à EMATER-DF ou ao Ministério de Meio Ambiente ou até em baixo do prédio do Sindicato Rural. Eles saíram da AGE em 2009 e em 2012, porque não aceitavam ter a obrigação de passar mais tempo, duas vezes por semana, e sobretudo os sábados, para vender muitos produtos e até conservas, uvas e cogumelos dos produtores empresariais como da Fazenda Malunga, entre outros, quando eles traziam poucos produtos próprios.

\title{
O papel de mediadores e gestores do setor público
}

Historicamente no DF, indivíduos do setor público ligados a um ou aos dois grupos de interesse, assumem alternativamente um papel de mediador, de empresário promotor de políticas ou até de gestor de políticas públicas. São funcionários públicos da UnB, IFB, Embrapa, MAPA, MDA e EMATER-DF (ver Quadro 1). No caso da UnB, existem dois núcleos de agroecologia que associam aos professores vários estudantes. Seus membros apresentam, todos, um nível de educação superior, experiência 
profissional na agricultura (muitos são engenheiros agrônomos) e, portanto, são dotados de vários recursos políticos individuais e coletivos. $\mathrm{O}$ Centro Vocacional Tecnológico em Agroecologia e Agricultura Orgânica da UnB (CVT-UnB) embora não se inscreva na categoria dos Núcleos de Estudos da Agroecologia (NEAs), existe desde 2014. Focaliza sua ação na produção orgânica e na formação de produtores e extensionistas para esse setor. Tem parceria com EMATER, EMBRAPA e IFB.

Desenvolve atividades experimentais na Fazenda Água Limpa e em propriedades nas regiões de Brazlândia, Planaltina e São Sebastião denominadas de "vitrines agroecológicas". Pelo seu perfil, é frequentemente envolvido em ações de capacitação, pesquisa ou extensão, mas também de assessoria política, formação de agricultores, técnicos e para formulação de recomendações em matéria de instrumentos de políticas públicas de agroecologia, produção orgânica, certificação, comercialização, compras públicas, crédito e extensão rural agroecológica. Por causa dessa expertise, os atores são chamados a ocupar cargos de confiança em órgãos da administração pública no setor da agricultura a nível distrital ou federal, acumulando experiência, capital social, típicos deste tipo de "ator multiposicionado" (MASSARDIER, 2008). Tais atores apoiaram tanto as iniciativas a favor da estruturação da produção orgânica (CPORG, certificação inclusive participativa, Mercado dos Orgânicos) como da agroecologia (feiras agroecológicas, NEAs e seminários e eventos em Brasília). A EMATER-DF, a CEASA-DF e em menor grau a UnB e a Embrapa têm apoiado a construção do Mercado Orgânico, mas também a implementação da feira da agricultura familiar e da agroecologia no espaço da CEASA.

Uma característica central desses funcionários é o fato de defendem a agroecologia e a produção orgânica no seio de instituições federais e distritais. Primeiro, alguns trabalham em ministérios ou instituições federais (MAPA, MDA, EMBRAPA, UnB e IFB) e ao mesmo tempo assumem funções e liderança no movimento social da agroecologia (ABA e ANA). Isso significa que antes de promover a PDAPO no DF, eles tinham experiência adquirida na elaboração da Política de Produção Orgânica e logo da própria PNAPO. Em segundo lugar, os membros da academia mantêm laços com os produtores agroecológicos familiares dos assentamentos de reforma agrária do DF, mediante cursos e reuniões, visitas e unidades demonstrativas. Terceiro, em termos de preparação de instrumentos de política pública, além da sua trajetória militante e dos seus recursos (capital social, conhecimentos temáticos, capital educativo) eles conseguem 
certa eficiência graças à sua situação de multiposição entre setor público, movimentos sociais e produtores.

Eles adotaram uma estratégia pragmática de considerar a produção orgânica como uma possível etapa na transição para a agroecologia. Por isso, sempre apoiaram também instrumentos a favor da produção orgânica. Esse comportamento faz que esse grupo seja a favor dos dois sistemas. Esse grupo de interesse associa membros da academia e funcionários técnicos que têm um perfil mais pragmático, pela sua função de assistência técnica a todos os tipos de agricultores do DF (do empresário médio produtor de soja com plantio direto até os assentados agroecológicos, passando por agricultores familiares, pecuaristas, e pequenos empresários dos orgânicos). Os extensionistas da EMATER-DF, que estão em contato permanente com os agricultores, seguem o perfil de "burocratas de nível de rua" (LIPSKY, 1980). Eles têm uma visão mais técnica da agroecologia (conservação do solo, luta biológica, uso de bioinsumos etc.). Este é também o caso dos funcionários da CEASA-DF. No outro espectro, na academia, docentes e estudantes membros dos NEAs, têm um perfil mais militante e ideológico. Defendem a proposta de Altieri (1995) de uma agroecologia política, na medida em que promove, antes de tudo, um sistema agroalimentar alternativo ao domínio do modelo produtivista convencional do agronegócio (SABOURIN et al., 2018, p. 2). São extremamente ativos tanto na organização de eventos quanto no acompanhamento de ações nos assentamentos de reforma agrária do DF. Os líderes desse grupo correspondem praticamente ao núcleo fundador da ABRAA, multiposicionados, bem informados e detentores de um alto nível de recursos políticos, em particular de uma bagagem técnico-científica e de uma rede de relações pessoais como institucionais. Aproveitando-se também da experiência acumulada numa trajetória militante e profissional, foram determinantes para a criação da PDAPO-DF.

\section{Uma rede de ação pública para agroecologia e produção orgânica}

O conjunto desses três grupos de interesse configura uma coalizão ampla de política pública de agroecologia e produção orgânica na escala do DF, cujos principais elementos constitutivos e características de acordo com Sabatier e Jenkins (1993): membros componentes, crenças e valores, recursos políticos, arenas e espaços específicos e modalidade de interação, estão resumidos no Quadro 1 a seguir. 


\section{Quadro 1 - Elementos constitutivos dos dois de interesse da} coalizão da agroecologia e produção orgânica no DF

\begin{tabular}{|c|c|c|c|}
\hline $\begin{array}{l}\text { Grupo de } \\
\text { Interesse }\end{array}$ & $\begin{array}{l}\text { Grupo da } \\
\text { produção } \\
\text { Orgânica }\end{array}$ & $\begin{array}{l}\text { Grupo da } \\
\text { Agroecologia }\end{array}$ & $\begin{array}{l}\text { Mediadores e promo- } \\
\text { tores no setor publico }\end{array}$ \\
\hline Principais membros & $\begin{array}{l}\text { Principais membros } \\
\text { Associação dos Agrônomos } \\
\text { do DF, AGE } \\
\text { CPORG-DF } \\
\text { Sindicato dos Orgânicos } \\
\text { Fundação M. Okada } \\
\text { Ecocert Brasil } \\
\text { SEBRAE-DF e INDEC } \\
\text { CEASA-DF } \\
\text { CONTAG-ARCO-TAE } \\
\text { CVT-UnB } \\
\text { Coope Mercado Orgânico } \\
\text { Agro-Orgânica } \\
\text { Ass Mista dos A F Orgâni- } \\
\text { cos e Produtores Rurais do } \\
\text { DF Ass dos Prod de Horti- } \\
\text { granjeiros do DF } \\
\text { Empresas: Malunga, Sitio } \\
\text { Corujinha, Kapra, Desifrut, } \\
\text { D'ro, Videiras do lago, } \\
\text { MamaGé, Cogu, Hatidori }\end{array}$ & $\begin{array}{c}\text { AGE, ABRAA } \\
\text { Assent. Colonia 1. P } \\
\text { Bernardo } \\
\text { Aprospera/ S Barto- } \\
\text { lomeu } \\
\text { Ass. Ass. Chapadinha } \\
\text { Ass. Prod. Agroecológi- } \\
\text { cos Lago Oeste } \\
\text { Ass. Prod. Agroecológi- } \\
\text { cos São Sebastião } \\
\text { Ass. dos Prod Rurais do } \\
\text { INCRA 09 } \\
\text { Ass dos Prod Rurais e } \\
\text { Agric Fam do INCRA IX } \\
\text { Ass dos Prod do P.A. } \\
\text { Contagem } \\
\text { Ass do Grupo de Mu- } \\
\text { Iheres Prod do Assent } \\
\text { Contagem } \\
\text { Ass dos Prod Rurais de } \\
\text { Alexandre Gusmão } \\
\text { Asso dos Prod Fam } \\
\text { Agroecológicos DF e } \\
\text { entorno } \\
\text { Ass dos Trab Rurais do } \\
\text { Assent Três Conquistas } \\
\text { NEPAS -FUP, NEA } \\
\text {-UnB }\end{array}$ & $\begin{array}{c}\text { Universidade de Brasí- } \\
\text { lia: FAV, CDS, FUP-NE- } \\
\text { PEAS, NEA } \\
\text { Instituto Federal Agrí- } \\
\text { cola DF } \\
\text { Embrapa (Hortaliças, } \\
\text { Cerrado e Cenargen) } \\
\text { MAPA - Coord AE e PO } \\
\text { MDA-SDT } \\
\text { EMATER-DF } \\
\text { CAO } \\
\text { CEASA-DF }\end{array}$ \\
\hline Crenças & $\begin{array}{l}\text { Visão empresarial e comer- } \\
\text { cial; alimentação saudável }\end{array}$ & $\begin{array}{l}\text { Visão mais radical na } \\
\text { transformação dos sis- } \\
\text { temas agroalimentares }\end{array}$ & $\begin{array}{l}\text { Visão pragmática de } \\
\text { serviço aos produtores } \\
\text { e consumidores }\end{array}$ \\
\hline Recursos & $\begin{array}{l}\text { Políticos, capital financeiro, } \\
\text { empresariais }\end{array}$ & $\begin{array}{l}\text { Capital social e educa- } \\
\text { tivo, acesso a redes de } \\
\text { Mov. Sociais }\end{array}$ & $\begin{array}{l}\text { Poder federal ou dis- } \\
\text { trital, capital social e } \\
\text { educativo }\end{array}$ \\
\hline Arenas e espaços & $\begin{array}{l}\text { AL DF, CEASA, FAPE-DF- } \\
\text {-Sindiorganicos, SEAGRI }\end{array}$ & $\begin{array}{l}\text { Seminários e eventos, } \\
\text { academia, AL DF }\end{array}$ & $\begin{array}{c}\text { Administração distrital } \\
\text { e federal }\end{array}$ \\
\hline Interações & $\begin{array}{c}\text { Mediante AGE e algumas } \\
\text { feiras }\end{array}$ & $\begin{array}{c}\text { AGE e UnB agem como } \\
\text { pontes }\end{array}$ & $\begin{array}{c}\text { EMATER DF e UnB } \\
\text { são pontes, Embrapa } \\
\text { e MAPA }\end{array}$ \\
\hline
\end{tabular}


O conjunto das interações e articulações dessa rede de ação pública é representado na Figura 2. No entanto, a subcoalizão da agroecologia tem desenvolvido na última década uma forma particular de articulação em rede. AABRAA é um dos resultados desse trabalho de abertura de variadas frentes e de ocupação de espaços em prol da agroecologia, para além do mercado, da produção e da legislação.

Os membros dessa rede entendem que é possível haver uma convivência entre promotores da Agroecologia e da Produção Orgânica. Um fator que contribuiu na sinergia observada entre os atores da ABRAA é o fato deles já se conhecer antes da formação da rede e de compartilhar o mesmo mundo do serviço público, da pesquisa e do ensino. Todos são pesquisadores, professores, agentes de assistência técnica rural ou estudantes.

Figura 2 - Esquema da rede de ação pública da agroecologia e produção orgânica no DF

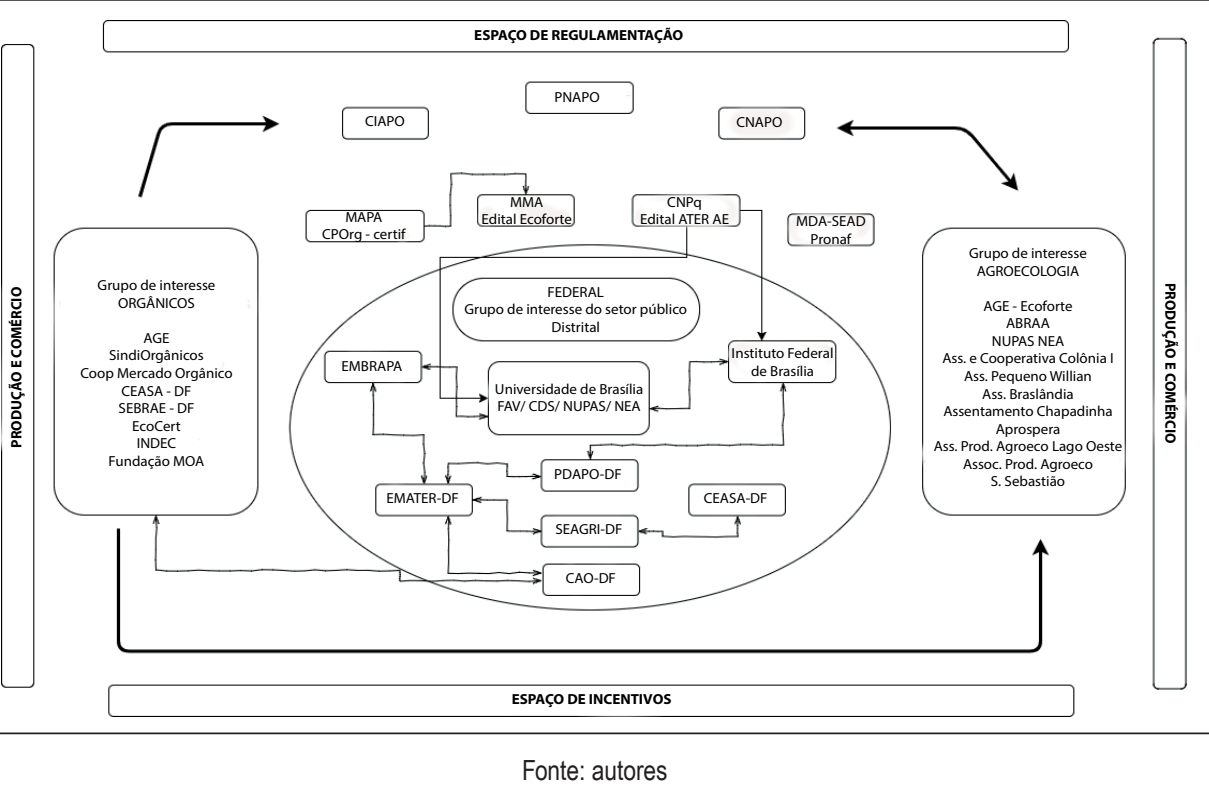

Marsh e Rhodes (1992) distinguem cinco tipos de redes de ação pública: i) a rede temática, ii) a rede de produtores (de ideias), iii) a rede intergovernamental, iv) a rede profissional (ou setorial) e v) a comunidade de políticas públicas. Estes autores propõem enfatizar as redes temáticas e a comunidade de política pública. No caso da PDAPO-DF, as redes temáticas correspondem aos grupos de interesse dos orgânicos e da agroecologia, a rede intergovernamental corresponde às instituições do setor público federal e distrital e a comunidade de política pública corresponde ao conjunto dos atores mobilizados na rede de ação pública da agroecologia e produção orgânica. 
A identificação de atores multiposicionados nos indica relações dinâmicas entre as subredes temáticas ou grupos de interesses e permite evidenciar o papel de intermediário ou de mediador que assumem entidades como a AGE, a EMATER-DF ou a UnB. De fato, as redes de ação pública produzem sentido e conhecimentos, portanto, se constituem a partir de uma matriz cognitiva comum. Isto é particularmente evidente no caso da subrede da agroecologia e da preocupação dos seus membros em manter uma identidade e uma dinâmica de gestão do conhecimento agroecológico. Desta forma, a coalizão da agroecologia se identifica também como uma comunidade epistêmica. $\mathrm{O}$ conceito de comunidade epistêmica se refere à influência dos "peritos técnicos e acadêmicos" que a configuram. Hass as define como "redes de profissionais com experiência e perícia reconhecidas em um campo particular que possam demonstrar conhecimento relevante sobre políticas públicas nesse campo" (HAAS, 1992, p. 3). Le Galès e Tatcher (1995) associam a rede de ação pública a processos de governança. Eles definem a governança como um processo de coordenação de atores, de grupos sociais, de instituições para atingir metas próprias, discutidas e definidas coletivamente em ambientes fragmentados e incertos (LE GALÈS; TATCHER, 1995).

Essa definição traduz bem a fragmentação e a incerteza que envolvem a realidade como o futuro das políticas para agroecologia no Brasil e no DF.

\section{Resultados: a implementação de uma governança e a integração dos instrumentos existentes}

No caso da PDAPO-DF, a CPORG tendo perdido importância, nos limitaremos a tratar da Câmara Setorial de Agroecologia e Produção Orgânica do DF (CAO) que constitui o novo espaço de governança entre os representantes dos três grupos de interesse.

A execução da PDAPO-DF é confiada à SEAGRI e para a orientação, acompanhamento e avaliação da PDAPO foi criada a CAO.

A CAO foi criada pelo Decreto ${ }^{\circ} 38.618 / 2017$ (DISTRITO FEDERAL, 2017) para ser a instância de gestão da PDAPO-DF. É um órgão consultivo do Governo do Distrito Federal, vinculado à SEAGRI-DF, com o objetivo de debater e acompanhar ações e apresentar proposições relacionadas ao desenvolvimento da agroecologia e da produção orgânica no Distrito Federal. Compete à CAO, junto ao PDAPO-DF: 1) a proposição das diretrizes, dos objetivos, dos instrumentos e das prioridades da PDAPO, 2) a interação das instâncias governamentais e não governamentais relacionadas a agroecologia e produção orgânica; 3) o acompanhamento da execução das ações da 
PDAPO-DF; 4) a coordenação, a mobilização e o monitoramento das ações e dos processos que contribuam para o cumprimento da PDAPO-DF; 5) os projetos e as ações e a previsão dos recursos financeiros; 6) as responsabilidades e os indicadores de monitoramento e avaliação; 7) as ações de fomento à agroecologia e a produção orgânica do Distrito Federal.

A CAO é composta de forma paritária por sete representantes titulares e suplentes do governo: SEAGRI-DF; Secretaria de Estado do Meio Ambiente do DF, Secretaria de Trabalho, Desenvolvimento Social, Mulheres, Igualdade Racial e Direitos Humanos do DF, EMATER/DF, MAPA, EMBRAPA e, também, por sete representantes da agroecologia e da produção orgânica da sociedade civil: Federação dos Trabalhadores na Agricultura Familiar (FETRAF-DF), Sindiorgânicos, COOPERORG, AGRORGÂNICA, SEBRAE/ DF; IFB; Cooperativa de Trabalho e Desenvolvimento da Agricultura Camponesa (CODESTAC). A CAO já tem regimento interno aprovado e realizou uma oficina no final do ano 2018 para a preparação do Plano Distrital de Agroecologia e Produção Orgânica (PLADAPO) a ser elaborado em 2019. Até fevereiro de 2019, os rumos da PDAPO-DF não parecem ser alterados com a posse do novo governo. No entanto, a CAO foi desestruturada: representantes de entidades com cargo de livre exoneração (da SEAGRI, EMATER-DF e das organizações de produtores) saíram em dezembro de 2018 no fim do governo Rollemberg.

Quanto aos instrumentos que constituem ao mesmo tempo o resultado e a operacionalização do processo de ação pública, no caso da PDAPO-DF, eles incorporam os programas preexistentes dentro da SEAGRI e EMATER-DF, antes de serem completados por novas ferramentas ou propostas no marco do plano em elaboração.

A EMATER-DF identifica três fontes de financiamento: i) os instrumentos da política federal: ATER agroecologia (capacitação, campos demonstrativos, visitas dos técnicos), contratos de Assistência técnica para DF e entorno; linhas de crédito federal e distrital, Programa PROSPERA/FUNGEP; PRONAF Agroecologia e compras públicas de alimentos (Programa de Aquisição de Alimentos - PAA e Programa Nacional de Alimentação Escolar - PNAE); ii) recursos da PDAPO-DF: Programa de Aquisição da Produção da Agricultura (PAPA-DF) com R \$ 2,5 milhões para agroecologia e produção orgânica, incentivos a Pesquisa e ATER com redes de financiamento de crédito; iii) emendas parlamentares: em 2018, por intermédio de um deputado federal foi conseguida uma emenda de $\mathrm{R} \$ 600.000,00$ para apoio a 630 agricultores familiares da reforma agrária para receberem o programa de Sistema Agroflorestal 
(SAF) de produção de morangos, irrigação, Transição Agroecológica (TAE) e comercialização em TAE.

A EMATER-DF operacionaliza os seguintes programas de crédito rural: Fundo de Desenvolvimento Rural (FDR-DF), PRONAF, Fundo Constitucional do Centro-Oeste (FCO) e PROSPERA. O Fundo Programa de Microcrédito Produtivo Orientado (PROSPERA), criado pela Lei Complementar $\mathrm{N}^{\mathrm{0}} 005 / 1995$ (FUNSOL) destina crédito para agricultores familiares e assentados da reforma agrária ${ }^{1}$.

Segundo a então coordenação de Agroecologia da EMATER-DF, as linhas Agroecológica e Eco do PRONAF e do DF são pouco acessadas por falta de divulgação mais do que por resistência do banco (embora os bancos prefiram os créditos para produtores patronais com juros mais elevados) como os do FCO. Por isso a capacitação dos técnicos do banco sempre é necessária porque, quem executa crédito rural nos bancos tem pouco conhecimento sobre questões agrícolas, sobretudo no que se refere à agroecologia e à produção orgânica. De acordo com os responsáveis da EMATER-DF, o PRONAF deixou de ser uma linha "a fundo perdido" ou com juros muito baixos. O seu acesso pelos agricultores familiares do DF é dificultado pela falta de regularização fundiária e de acesso à Declaração de Aptidão ao PRONAF (DAP). Segundo a EMATER-DF, muitos assentados da reforma agrária não têm perfil ou tradição para acessar crédito com sucesso. Porém, pelo que observamos, os agricultores que produzem em sistemas agroecológicos e comercializam nas feiras, na CEASA e nos restaurantes, mostram capacidades de gestão que deveriam lhes garantir o acesso ao crédito. Muitos fazendeiros da região não chegam aos mesmos níveis de produtividade e qualidade destes produtores. No DF, segundo a então coordenadora de agroecologia da EMATER, só se tem conhecimento de um contrato de PRONAF Agroecologia.

\section{Instrumentos que dialogam com a PNAPO ou com efeitos mais relevantes}

A PDAPO-DF foi normatizada em novembro de 2017. Para a EMATER-DF, existe uma boa articulação entre a PNAPO (se ela for mantida) e a PDAPO-DF. Primeiro, é preciso articular orçamentos entre a programação federal (4 anos) e a do DF (anual). Mas já são implementadas atividades de capacitação e fomento com previsão de criação de centros de referência

1 O Prospera - DF é um programa de concessão de empréstimo orientado para pequenos empreendedores informais e microempresas sem acesso ao sistema financeiro tradicional, principalmente por não terem como oferecer garantias reais. Não é específico para agricultores. 
para agroecologia e produção orgânica no DF com apoio da PNAPO. Cinco instrumentos são principalmente objeto de interações e coordenações entre a PNAPO e a PDAPO-DF: o crédito como já indicado, a Assistência Técnica Rural (ATER), a comercialização, a certificação, e o apoio a organização de redes.

No DF o principal instrumento para agroecologia que dialoga com a PNAPO é a ATER agroecológica, associada às evoluções da PNATER desde 2004 e a criação da PNAPO. Segundo a então coordenadora de agroecologia da EMATER-DF, todos os escritórios locais teriam agora competência em agroecologia e produção orgânica. De maneira geral, a ATER se divide entre apoio técnico à produção e apoio à certificação. A maioria do trabalho do extensionista para agroecologia e produção orgânica constitui em sensibilização e capacitação, não se restringindo apenas a trabalho de campo. $\mathrm{O}$ apoio à produção passa por visitas sistemáticas, unidades demonstrativas e a elaboração de projetos de crédito. Em 2017, 1.714 agricultores e agricultoras receberam ações de ATER para o desenvolvimento da agroecologia e agricultura orgânica. Essas ações culminaram no aumento da produção certificada, fazendo com que a EMATER-DF negociasse a sua inserção mediante programas de compras públicas de alimentos orgânicos junto ao programa distrital (PAPA-DF) ou aos programas federais (PAA e PNAE), no total foram 134 produtores familiares beneficiados com esses programas de governo. Com a ampliação das formas de certificação para produção orgânica e agroecológica foi possível aplicar preços melhores (15 a 30\% superiores) para produtos agroecológicos e orgânicos nas compras públicas da agricultura familiar que têm estimulado a produção orgânica e agroecologia. O governo do DF tem apoiado contratos de compras públicas de alimentos com agricultores da reforma agrária. Por exemplo, o programa PAPA-DF mobiliza R\$ 13 milhões/ ano, dos quais $10 \%$ para a produção agroecológica. Uma linha do PAPA-DF chama se "Cesta verde" para produção orgânica e representou em 2017, um total de R\$1.800.000,00 para 30 a 40 agricultores familiares certificados. Eram 50 produtores certificados em 2010, 200 em 2015, 272 em 2018, o que demonstra um crescimento do setor. A criação de Organizações Participativas de Avaliação da Conformidade (OPAC) no marco da AGE e do Sindiorgânicos ofereceu alternativas a certificação por auditoria externa via Ecocert ou MOA que custavam até mil reais por ano aos produtores. As OPAC e Organizações de Controle Social (OCS) que são bem baratas ou até gratuitas (OCS) permitiram uma adesão maior de produtores agroecológicos que não podiam financiar uma certificação por auditoria externa, sobretudo nas áreas de assentamentos: Paranoá, São Sebastião, Brazlândia e Planaltina.

O Programa Ecoforte representou uma das principais inovações da PNAPO. Trata-se de um programa de fortalecimento institucional e capacitação 
para redes de gestão de conhecimento agroecológico descentralizadas. O programa contava em 2014 com um orçamento de $\mathrm{R} \$ 34,6$ milhões de investimento social da Fundação Banco do Brasil e de Fundo Amazônia, gerido pelo Banco Nacional do Desenvolvimento Econômico e Social (BNDES) e em 2017 com R\$ 25 milhões para o último edital. Na região Centro-Oeste, a AGE é responsável pela execução da Rede Agroecológica Planalto Central, uma das 28 redes habilitadas pelo edital Ecoforte Redes, voltado a projetos de produção agroecológica e agroextrativista sustentável. Esse projeto envolve diretamente 3.216 produtores do DF e mais três municípios: Cidade Ocidental e Padre Bernardo, em Goiás, e Unaí, em Minas Gerais. Os produtores passam por capacitação, compartilham equipamentos e veículos adquiridos no projeto, trocam experiências e juntam forças na logística de comercialização e distribuição dos produtos em feiras livres. A EMATER-DF, a UnB e a Embrapa participam do apoio dentro dessa rede.

\section{Conclusões}

A PDAPO-DF objetiva ampliar o enfoque agroecológico nas propostas de desenvolvimento rural, contemplando novas bases metodológicas, técnicas e científicas. Visa promover estratégias e ações objetivas para iniciação e progresso pelos caminhos da transição agroecológica e contribuir para o aumento da produção de alimentos saudáveis pela construção de sistemas de base ecológica. É uma política muito recente, com implementação a partir de 2019, portanto, é muito cedo para avaliar resultados ou impactos. No entanto, ela tem um longo histórico e foi precedida pela aplicação de outros instrumentos distritais ou federais, que permitem analisar as bases de interação entre o nível distrital e o nível federal, hoje, através da PNAPO.

Em termos de ensinamentos da análise da construção da PDAPO-DF, podemos reter três elementos centrais: Primeiro, a reivindicação e promoção dessa política são frutos dos esforços de uma coalizão criada em torno de pioneiros da agricultura alternativa desde os anos 1980. Esses pioneiros têm todas as características de um núcleo próximo e solidário de elites programáticas com capacidade de atuar e mostrar influência nas mais altas esferas da política, dos ministérios, da administração distrital, da pesquisa federal e da UnB, assim como entre os produtores. Os produtores do setor dos orgânicos, se caracterizam pela sua capacidade empresarial, atuando como verdadeiros empreendedores de política pública, principalmente na estruturação da comercialização (mercados, cooperativa) e na certificação (inclusive participativa) dos orgânicos. A articulação da agroecologia reúne os intelectuais orgânicos (academia e alta administração) e poucos agricultores agroecológicos dos assentamentos de reforma agrária. Não tem ainda as características de um movimento social da agroecologia integrando produtores e consumidores. A 
ABRAA atua no apoio à gestão do conhecimento agroecológico e na promoção de seminários. A reunião de entidades dos três grupos de interesse na Rede de Agroecologia do Planalto Central, mais centrada nessa função de compartilhamento do conhecimento, poderia constituir uma base regional indo além da especificidade do DF, dos seus consumidores e produtores. No entanto, a não renovação de chamadas do programa Ecoforte pode comprometer essa iniciativa atualmente fragilizada. $\mathrm{O}$ conjunto destes três grupos de interesse se caracteriza como uma potencial rede de ação pública a favor da agroecologia e da produção orgânica no DF que têm conseguido, em torno de um grupo de uma dezena de indivíduos centrais e multiposicionados, manter uma pressão para a elaboração de instrumentos de política pública que culminaram em 2017 na promulgação da PDAPO-DF.

Em segundo lugar, cada subcoalizão (agroecologia e produção orgânica), tem mais aproximação com um determinado perfil de produtores: o principal público do apoio da EMATER, assim como dos dois NEAs da UnB é a produção agroecológica e orgânica em assentamentos. Por outro lado, a produção orgânica que tem se fortalecido em torno dos restaurantes e do Mercado Orgânico na CEASA, envolve pequenos e médios empresários, aposentados do serviço público e de profissões liberais detentores de terras ou de chácaras.

Em terceiro lugar, a proposta da PDAPO integrou uma visão ampla da agroecologia e da produção orgânica: ações de combate à pobreza, inclusão social e produtiva, promoção da segurança e soberania alimentar, da equidade, justiça e cidadania no campo também são alvos estratégicos dessa política. No entanto, até hoje, o programa de Agroecologia e Produção Orgânica da EMATER-DF tem sido mais centrado na tecnologia de produção. De fato, na PDAPO-DF estão incluídas diversas e novas ações sociais amplas, como a capacitação e organização social dos agricultores visando à transição agroecológica e o acesso aos mercados diferenciados, mas essas atividades precisam encontrar recursos e estruturas. Isto deveria ser o objeto da realização do Plano Distrital de Agroecologia e Produção Orgânica do DF a cargo da CAO. Ainda é prematuro analisar resultados e efeitos. No entanto, nos trabalhos de campo, elementos significativos têm sido observados, como a menor dependência externa de insumos caros e não renováveis, as melhorias sociais e econômicas, o protagonismo das mulheres na produção ecológica e o acesso a mercados diferenciados, o que é bem característico do DF. Ainda que a EMATER-DF disponha de extensionistas capacitados em agroecologia e de um programa de compras públicas (PAPA-DF), a maioria das ações importantes de apoio estrutural dependem de financiamentos federais. Os desafios residem essencialmente na consolidação das organizações tanto de produtores agroecológicos quanto de consumidores. 


\section{REFERÊNCIAS}

ALTIERI, M. Agroecology: The Science of Sustainable Agriculture. CRC Press, 1995.

DISTRITO FEDERAL. Decreto 38.618, de 16/11/2017. Regulamenta a Lei $\mathrm{n}^{\mathrm{o}}$ 5.801, de 10 de janeiro de 2017. Política Distrital de Agroecologia e Produção Orgânica - PDAPO.

GENIEYS, W. L'émergence d'élite(s) programmatique(s) face à la mutation de l'État français. Barcelona Institut de Ciències Polítiques i Socials. CNRS, WP n. 261, 2007.

GLIESSMAN, S. Agroecology: The Ecology of Sustainable Food Systems. CRC Press, 2014.

GUENEAU, S. et al. Construção de políticas públicas de agroecologia nos Estados Federados do Brasil. Revista Brasileira de Agroecologia, n. 14, (2), 2019.

HAAS, P. M. Introduction: Epistemic Communities and International Policy Coordination. International Organization, Knowledge, Power, and International Policy Coordination, v. 46, n. 1, p. 1-35, 1992.

KINGDON, J. Agendas, alternatives and public policies. Boston, MA: Little, Brown, 1984.

LAGROYE, J.; BASTIEN, F.; SAWICKI F. Sociologie politique. Paris: Dalloz-Sirey, 2006.

LANDEL, P. Sociogenèse d'un projet de développement rural territorialisé - Le cas du Marché Organique à Brasilia, dans le Territoire Aguas Emendadas au Brésil. 2009. Dissertação (Master 1 - Sciences Politiques) - Lyon, Université Lumière Lyon II, 2009.

LASCOUMES P.; LE GALES P. Sociologia da ação pública, Maceió: Edufal, 2012. In: LE GALÈS, P.; THATCHER, M. (Orgs.). Le Réseaux de politique publique. Debaut autor des policy networks. Paris: Ed. L'Harmattan, 1995. 
LIPSKY, M. Street-level Bureaucracy: dilemmas of the individual in public services. New York: Russell Sage Foundation, 1980.

LUZZI, Nilza. O debate agroecológico no Brasil: uma construção a partir de diferentes atores sociais. 2007. Tese (Doutorado) - Instituto de Ciências Humanas e Sociais da Universidade Federal Rural do Rio Janeiro, 2007.

MARSH, D.; RHODES, R.A.W. Policy networks in British government. Oxford /New York: Clarendon Press Oxford University Press, 1992.

MASSARDIER, G. Politiques et actions publiques. Paris: Armand Colin, 2008.

PAL, L. Public Policy Analysis: An Introduction. Toronto: Nelson, 1992.

RHODES, R. Policy network analysis. In: MORAN, M.; REIN, M.; GOODIN, R. E. (Eds.). The Oxford handbook of public policy. Oxford: University Press, 2008. p. 425-443.

SABATIER, P.; JENKINS-SMITH, H. (Eds.) Policy Change and Learning: An Advocacy Coalition Approach. Boulder, CO: Westview Press, 1993.

SABOURIN E. et al. Public policies to support agroecology in Latin America and the Caribbean. Perspective 45, Montpellier: CIRAD, 2018.

SAURRUGER, S.; GROSSMAN E. Les groupes d'intérêt. Action collective et stratégies de représentation. Paris: Armand Colin, Collection U, 2012

SCHMITT, C. et al. La experiencia brasileña de construcción de políticas públicas a favor de la agroecología. In: SABOURIN, E. et al. (Orgs.). Políticas públicas a favor de la agroecología en América Latina y EI Caribe. Porto Alegre: Criação Humana/Red PP-AL, 2017. p. 73-122.

TADEU DA SILVA, L. A construção da Agroecologia no Distrito Federal através de uma rede de ação pública. 2019. Tese (Dissertação de Mestrado) - Programa de Pós-Graduação em Meio Ambiente e Desenvolvimento Rural (PPG/MADER), Universidade de Brasília, 2019. 


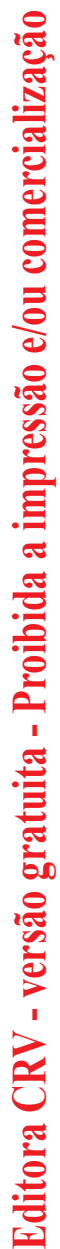




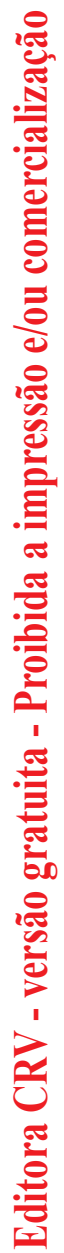

\section{ANÁLISE TRANSVERSAL DOS ESTUDOS DE CASO}




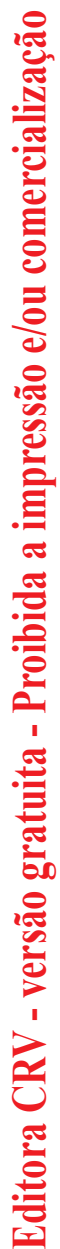




\section{CAPÍTULO 12}

\section{RUMOS, ENSINAMENTOS E PERSPECTIVAS PARA AS POLÍTICAS ESTADUAIS DE AGROECOLOGIA E PRODUÇÃO ORGÂNICA}

Stéphane Guéneau

Eric Sabourin

Julianna Colonna

Luiz Raimundo Tadeu da Silva

Paulo Niederle

Mario Lucio de Avila

Marc Piraux

\section{Introdução}

Esse capítulo apresenta a título de síntese, uma análise transversal, mais que estritamente comparativa dos estudos nos onze estados federados, o que não deixa de contribuir para um retrato da configuração da construção das Políticas Estaduais de Agroecologia e Produção Orgânica (PEAPOs) na escala nacional.

As principais seções desse capítulo final retomam os elementos do quadro teórico-metodológico de Lascoumes e Le Gales (2012) e as categorias de análise introduzidas no capitulo inicial desse livro.

Pela natureza e o caractere recente das PEAPOs estudadas, é claro que existem mais elementos de informação sobre a trajetória dos atores, as suas concepções e coalizões ou sobre o processo de institucionalização da agroecologia, por meio de instrumentos e espaços de ação pública do que sobre os resultados em termos de instrumentos e da sua aplicação. Apenas podemos avançar em algumas tendências quanto aos modos de governança dessas políticas estaduais.

Na maior parte dos dez estados estudados, as PEAPOs instituídas por instrumentos jurídicos específicos, como leis e decretos, foram elaboradas de 2010 até hoje, ou pelo menos foram objeto de projetos de leis atualmente em discussão nas assembleias legislativas estaduais. Essa institucionalização progressiva ocorreu em vários ciclos, podemos por exemplo, considerar alguns estados como "pioneiros" na medida que elaboraram Programas 
Agroecológicos antes da criação da Política Nacional de Agroecologia e Produção Orgânica (PNAPO).

No caso do Paraná, se o Programa Agroecológico foi elaborado em 2011 e adotado em 2014, a discussão ainda está em andamento para estabelecer uma nova política de agroecologia e produção orgânica, o que lhe conferiria maior segurança jurídica. A nova lei foi elaborada por conta de duras críticas formuladas por movimentos sociais quanto a falta de participação das entidades agroecológicas no processo de formulação do Programa de 2015 e a sua fragilidade no entendimento dos processos de produção locais.

No caso do Rio Grande do Sul, a construção de um referencial de ação pública em favor da agroecologia foi discutida a partir dos anos 1990, o que levou a aprovação da lei que instituiu a PEAPO-RS em 2014.

No estado do Minas Gerais, a PEAPO adotada em 2014 tem como referência original o Projeto de Lei ${ }^{\circ} 2.547 / 2011$. Essa política é o resultado de um processo de maturação iniciado nos anos 2000 com vários marcos regulatórios e políticas públicas de âmbito estadual como, entre outros, a Política Estadual de Apoio à Agricultura Urbana (2006).

Em três estados (DF, MA e SP), embora o ativismo a favor da incorporação da agroecologia na agenda política tenha iniciado ainda nos anos 1990, os projetos de leis foram escritos e debatidos nos últimos anos e as leis foram promulgadas entre 2017 e 2018 . Por fim, nos três outros estados existem apenas projetos de lei para instituir uma PEAPO (RJ e BA) ou os atores ainda estão discutindo a oportunidade de elaborar tal legislação, como é o caso do estado do Pará (PA).

Em maio de 2019, quinze estados federados disponham de uma legislação específica que estabeleceu suas políticas estaduais de agroecologia: Minas Gerais (MG); Paraná (PR); Rio Grande do Sul (RS); Sergipe (SE); Distrito Federal (DF); Goiás (GO); Maranhão (MA); Rio Grande do Norte (RN); Alagoas (AL); Amazonas (AM); Espírito Santo (ES); Mato Grosso do Sul (MS); Pernambuco (PE); Rondônia (RO); e São Paulo (SP). Destes, os oito primeiros (MG; PR; RS; SE; DF; GO; MA e RN) tiveram suas leis regulamentadas; e os quatro primeiros (MG; PR; RS e SE), além da regulamentação, tiveram também seus Planos estaduais instituídos.

\section{Os atores da construção das PEAPOS e suas configurações}

A construção das PEAPOs foi marcada pela forte atuação das organizações da sociedade civil. O movimento de agroecologia começou em algumas grandes cidades como em São Paulo, onde as primeiras redes de agricultura alternativa nasceram no final dos anos 1970, principalmente pela contribuição de agrônomos gaúchos emblemáticos como José Lutzemberger. Em 1989, o Grupo de Agricultura Alternativa da Associação dos Engenheiros Agrônomos 
do Estado de São Paulo fundou a Associação de Agricultura Orgânica (AAO), com a adesão de produtores, agrônomos, técnicos e consumidores de seis estados brasileiros. A AAO esteve envolvida em ações com o movimento agroecológico do Brasil e da América Latina, mas ela tinha, também, uma atuação local expressiva no estado de São Paulo, o que levou à criação da Comissão Técnica de Agricultura Ecológica da Secretaria de Agricultura e Abastecimento do Estado de São Paulo (COSTA, 2019). Nos outros estados, se destacam, entre outros, a Rede de Agroecologia do Maranhão (RAMA), que tem mais de vinte anos de existência (LOCH et al., 2018), o Grupo de Trabalho Novas Propostas para a Agroecologia na Amazônia que foi criado no Pará em 1993 - hoje conhecido como Grupo de Assessoria em Agroecologia na Amazônia (GTNA) (ASSIS; PIRAUX; AZEVEDO, 2019, nesse livro), a Associação de Agricultura Ecológica do DF (AGE), criada em 1989 e a Articulação Brasiliense de Agroecologia - ABRAA (SABOURIN et al., 2019a). Ademais, vale mencionar o papel da Rede Ecovida de Agroecologia na Região Sul do país, a qual foi formada oficialmente em 1998 e atualmente congrega, aproximadamente, 340 grupos de agricultores e 20 ONGs (NIEDERLE et al., 2019, nesse livro).

Geralmente, a composição dessas redes inclui indivíduos (muitas vezes pesquisadores e/ou professores e estudantes das universidades ou institutos federais e estaduais de educação), inúmeras associações (organizações de produtores agroecológicos e orgânicos, ONGs ambientais e de promoção da agroecologia, associações de consumidores de produtos orgânicos) e representantes locais de movimentos sociais e sindicatos rurais (Movimento dos Trabalhadores Rurais Sem Terra - MST, Federações de Trabalhadores Rurais). No Distrito Federal, por exemplo, militantes da agricultura alternativa tiveram um papel determinante na institucionalização da agroecologia, em particular ex-estudantes de agronomia que foram líderes de organizações estudantis e profissionais, como a Federação dos Estudantes de Agronomia do Brasil (FEAB) e a Federação das Associações de Engenheiros Agrônomos do Brasil (FAEAB), os quais criaram, em Brasília, uma das primeiras Associações de Agricultura Ecológica do Brasil (AGE), em 1989. Na região sudeste (casos de SP e RJ), destaca-se, também, o ativismo dos movimentos de apoio à agricultura urbana. No Maranhão, associações como a Tijupá e a Associação em Áreas de Assentamento do Estado do Maranhão (ASSEMA) foram muito ativas na organização da RAMA. No estado do Pará, durante os anos 1990, o GTNA promoveu intercâmbios e difundiu noções de agroecologia em meio a técnicos que atuavam diretamente com organizações de trabalhadores rurais (CARNEIRO; HÖHN; CALORIO, 2004).

O processo de construção das PEAPOs beneficiou-se da criação de novas entidades estaduais vinculadas à agricultura familiar como a Secretaria de Estado de Desenvolvimento Agrário (SEDA) em Minas Gerais, a Secretaria 
Estadual de Desenvolvimento Rural (SDR), no Rio Grande do Sul, e a Secretaria de Agricultura Familiar (SAF) no Maranhão. Esses atores estão geralmente em contato relativamente próximo com as redes da agroecologia (Figura 1) e têm tido um papel importante para atender às reinvindicações dos movimentos agroecológicos, bem como ajudar a colocar o tema na agenda política.

Muitas vezes, os atores-chave da agroecologia na esfera pública são agrônomos sensíveis à causa da agricultura familiar e da agroecologia, que conseguiram ocupar cargos nas administrações estaduais. Estes atores são geralmente apoiados por técnicos das empresas estaduais de assistência técnica, professores das universidades e pesquisadores da Empresa Brasileira de Pesquisa Agropecuária (Embrapa).

Os atores das administrações estaduais possuem, por um lado, os recursos jurídicos internos para preparar os projetos de lei de agroecologia e, por outro lado, as conexões políticas necessárias para encontrar aliados nas assembleias locais. Por exemplo, no estado de São Paulo, o projeto de lei foi apoiado pela Frente Parlamentar em Defesa da Produção Orgânica e Desenvolvimento da Agroecologia, fruto de uma iniciativa criada em março de 2013, a qual envolveu cerca de 50 parlamentares de diferentes correntes ideológicas e 60 organizações da academia e sociedade civil para debater caminhos para institucionalizar a política estadual.

Figura 1 - Configuração dos atores na construção das PEAPOs

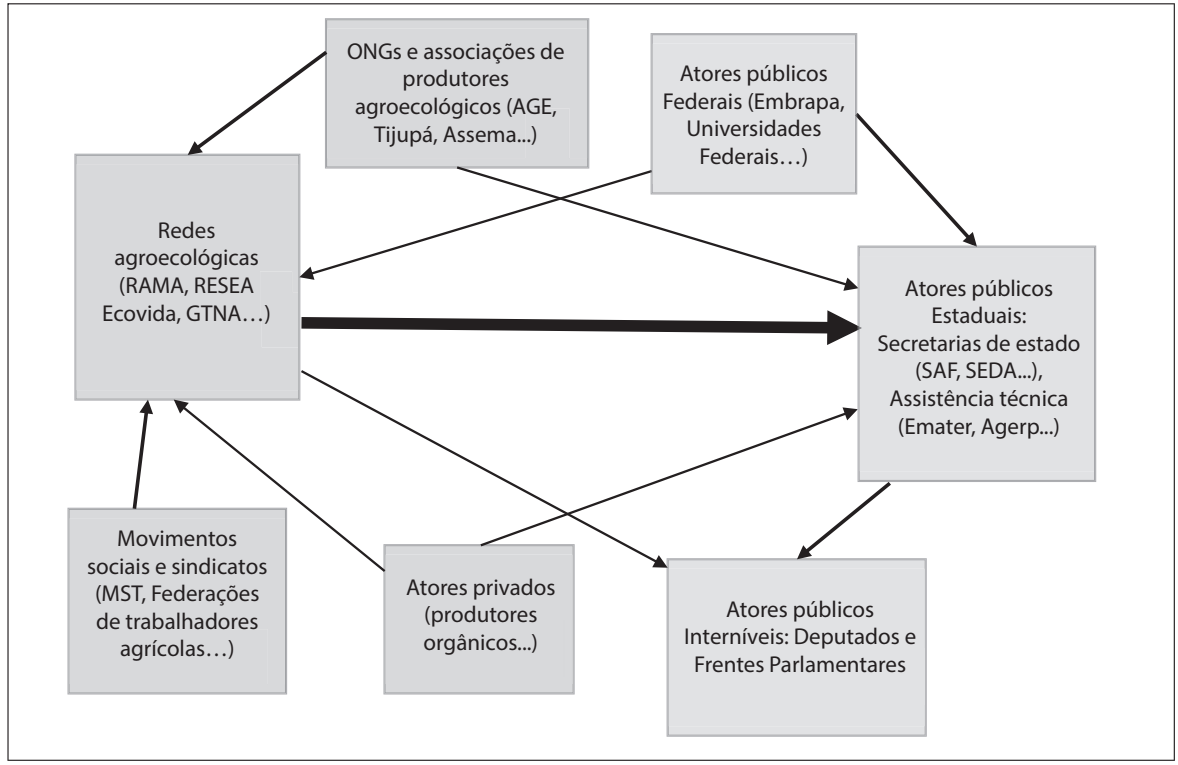

Fonte: autores. 


\section{Quais representações da agroecologia?}

Assim como ocorreu na PNAPO, as definições de agroecologia incorporadas pela maioria das PEAPOs também revelam a opção por um conceito abrangente, no qual predomina a ideia de agroecologia como ciência ou campo do conhecimento. Ao incorporar uma definição tão ampla, a maioria das PEAPOs sugere um processo de construção que busca incorporar as demandas e particularidades de cada grupo social, evitando conflitos latentes. Assim, por um lado, do ponto de vista da capacidade de orientação da ação pública, este tipo de definição se mostra pouco operacional e não reflete as divergências de representação do objeto agroecologia. Por outro lado, ela permite ajustes e adaptações no sentido de destacar segmentos e práticas sociais específicos à realidade do estado.

Analisando as principais ideias que os atores individuais e coletivos defendem em cada estado, podemos tipificar as representações da agroecologia em quatro grandes categorias:

- Uma perspectiva técnico-produtiva associada à produção orgânica. Essa representação focaliza os modelos técnicos oriundos das ciências agronômicas modernas, cujo objetivo é a busca da produtividade agrícola sem recorrer ao pacote tecnológico baseado em produtos químicos e organismos geneticamente modificados (OGM). Ela pode ser baseada na estratégia da promoção dos Sistemas Agroflorestais (SAFs), consórcios de espécies produtivas e exóticas, ou outras técnicas agronômicas. Essa visão é compartilhada por alguns engenheiros agrônomos, pesquisadores da Embrapa e universitários que se consideram do mundo da agroecologia. Por exemplo, o Programa de Pós-Graduação em Agroecologia da Universidade Estadual do Maranhão (UEMA) - pioneiro da institucionalização científica da agroecologia no Brasil por ser o primeiro reconhecido pelo Ministério da Educação, em 2002, com a nomenclatura "Agroecologia" - conta com uma boa parte de seu corpo docente que se situa nessa perspectiva técnico-produtiva.

- Uma concepção de agroecologia política baseada em outra maneira de pensar as relações sociais e econômicas, bem como as relações com a natureza, conforme as ideias agroecológicas desenvolvidas no âmbito das redes de agroecologia. Esta corrente se situa em contraposição à agricultura convencional e representa boa parte dos movimentos da agroecologia política que reivindicam a promoção 
de sistemas agroalimentares sustentáveis como alternativas ao modelo dominante. A concepção da agroecologia é direcionada tanto por princípios agroecológicos técnicos (equilíbrio ecológico, métodos culturais biológicos, manutenção do solo, etc.) quanto por princípios socioculturais (incorporação do conhecimento e das culturas tradicionais; autoconsumo, segurança alimentar e nutricional; igualdade de gênero e respeito às diferenças).

- Uma concepção próxima à visão da agroecologia política, mas que privilegia a transição agroecológica da agricultura familiar, uma concepção que considera os aspectos produtivos, incluindo, também, as questões de desigualdades e de inclusão social, entre outras. Neste caso, a agroecologia é considerada como um sistema de produção da agricultura familiar com baixo impacto na natureza, que permite destacar o "lado sustentável" da agricultura familiar em oposição à "dimensão degradante" do agronegócio. A diferença entre essa concepção da agroecologia e as ideias defendidas pelas redes históricas de agroecologia é tênue, porém relevante, pois vários atores dos movimentos sociais e da assistência técnica envolvidos nos debates sobre agroecologia às vezes definem como excessivamente "ideológica", "radical" ou "dogmática" a corrente de pensamento histórica da agroecologia política. Concretamente, as divergências dizem respeito, por exemplo, aos aspectos técnicos (autorização do uso de calcário ou da mecanização) ou relativos à comercialização (possibilidade de venda de produtos não orgânicos em feiras agroecológicas).

- Uma perspectiva que se aproxima da agricultura empresarial, privilegiando as práticas sustentáveis dos agricultores convencionais, inclusive aquelas vinculadas à certificação orgânica e/ou participativa. Com essa perspectiva, a agroecologia, que antigamente era exclusivamente uma referência conceitual vinculada aos movimentos sociais camponeses, comunidades tradicionais e indígenas, é apropriada pelos movimentos da agricultura familiar empresarial, tornando o conceito o vetor principal de acomodação ecológica da agricultura convencional. Na PEAPO-MG, por exemplo, a transição agroecológica é compreendida como uma transformação nas práticas e formas de manejo associadas, especificamente, aos "agro-ecossistemas convencionais", destacando, sobretudo os aspectos relacionados à produção. Essa concepção da agroecologia está mais alinhada com o sistema econômico capitalista, em particular no que 
tange ao objetivo de expansão da oferta de produtos certificados e dos mercados, inclusive mercados convencionais (supermercados e lojas de orgânicos).

Essas representações diferenciadas criam tensões entre os grupos de atores na definição das políticas e ações prioritárias, as quais se expressam em questões como: a concepção técnico-produtiva associada à produção orgânica versus a perspectiva da agroecologia política (em particular no DF, MA e PA); as divergências sobre o público alvo das políticas: abarcar práticas agroecológicas dos agricultores convencionais e/ou não certificados de um lado, versus atender apenas ou prioritariamente agricultores agroecológicos e/ou certificados do outro (RS, PR e SP). Contudo, apesar dessas tensões, podemos considerar que a agroecologia é vista em todos os estados como um marco de ação para facilitar a transição para sistemas agrícolas mais sustentáveis, embora a representação dominante se aproxime da concepção compartilhada de agroecologia política que foi promovida pelas redes de agroecologia em nível federal, em particular, pela Articulação Nacional de Agroecologia (ANA), ou seja, a agroecologia como alternativa sustentável aos padrões atualmente dominantes na organização do desenvolvimento rural brasileiro (NIEDERLE et al., 2019).

\section{Contextos políticos e trajetórias institucionais}

No período de 2004 a 2014, a institucionalização da agroecologia no nível estadual beneficiou-se de um contexto político favorável, o qual envolve a proximidade dos atores do poder executivo e dos serviços técnicos das administrações locais com os movimentos sociais estaduais em favor da agroecologia (SCHMITT et al., 2017). Este contexto institucional local refletia, numa certa medida, a adoção da "democracia participativa" como referencial de ação pública a partir dos anos 1990, com a abertura de espaços de diálogos entre sociedade civil e governos, dando origem a uma pluralidade de dinâmicas de institucionalização da agroecologia em diversas escalas (União, Estados federados, Municípios e Territórios). No Paraná, por exemplo, em 1998 foi criado o Conselho Estadual da Agricultura Orgânica (CEAO), "órgão normativo, deliberativo e regulador" de composição conjunta (cinco entidades governamentais e cinco ONGs). No estado de São Paulo, um órgão similar foi instituído em 2000, a Câmara Setorial de Agricultura Ecológica, responsável por diversas discussões e articulações do estado.

$\mathrm{O}$ ambiente político e institucional que favoreceu o fortalecimento das políticas de agricultura familiar durante os anos 2000 e a primeira metade 
dos anos 2010, possibilitou que a ação de diferentes setores mobilizados em torno da agroecologia adquirisse maior densidade política e coesão. Seguindo a dinâmica iniciada no nível federal, vários estados criaram espaços de governança participativa das políticas públicas. Os Conselhos de Desenvolvimento Rural e da Agricultura Familiar (CEDRAF) tiveram um papel catalizador de introdução da questão agroecológica nas agendas políticas de vários estados. Por exemplo, no Paraná, o CEDRAF teve a ideia de construir um programa de agricultura orgânica e agroecológica, que levou à criação, em 2007, de uma Câmara Setorial de Agroecologia e Agricultura Orgânica responsável pela elaboração do programa agroecológico paranaense (entre 2008 e 2011), adotado em 2014. O Rio Grande do Sul também conta com uma Câmara Técnica de Agroecologia (CTAGRO) vinculada ao Conselho Estadual de Desenvolvimento Rural Sustentável (CEDRS).

Além disso, a criação de novas secretarias de estado dedicadas ao desenvolvimento agrário e à agricultura familiar reforçaram essa dinâmica. No estado de Minas Gerais, por exemplo, foi criada a Subsecretaria da Agricultura Familiar e Regularização Fundiária em 2011 e, posteriormente, a Secretaria de Estado de Desenvolvimento Agrário (SEDA), à qual foi incorporada à Subsecretaria da Agricultura Familiar. Nesse período foram aprovados diversos marcos regulatórios favoráveis à agricultura familiar, agricultura urbana e povos e comunidades tradicionais, incluindo a PEAPO-MG. No DF, as evoluções institucionais foram marcantes no que tange à assistência técnica agroecológica a partir de 2004, conduzindo à capacitação de muitos extensionistas do DF em agroecologia e produção orgânica, o que também ocorreu no estado de São Paulo, que já formou mais de 300 técnicos desde 2013.

Em vários estados, as alternâncias no poder executivo nos anos 2010 abriram uma janela de oportunidade política para o fortalecimento da pauta agroecológica, como no caso do Maranhão, com a posse do governador Flavio Dino, do PT (Partido dos Trabalhadores) (2015-2018, reeleito). Por sua vez, a construção da PEAPO-MG foi marcada pela atuação do governo de Antônio Anastasia, filiado ao PSDB (Partido da Social Democracia Brasileira) (2010-2014). A construção da PEAPO do RS ganhou relevância no governo Tarso Genro do PT (2011-2014) e encontrou dificuldades após seu fim. Já no Pará, a ausência de mudança política durante o período 2011-2018 é um dos fatores explicativos das dificuldades de institucionalização da agroecologia, apesar de um contexto favorável no nível federal e em vários estados da União. Durante os dois mandatos do governo Jatene (PSDB), as forças políticas eram desfavoráveis à agricultura familiar e à agroecologia.

Os processos de institucionalização da agroecologia também sofreram retrocessos em vários estados (RS, MG e PR), em particular no período de 
mudanças políticas recentes. Em Minas Gerais, o novo governador recém-eleito Romeu Zema (Partido Novo), apresentou um projeto de lei visando a extinção da Secretaria Estadual de Desenvolvimento Agrário (SEDA). Este fato sinaliza um momento claro de ruptura institucional na trajetória de construção da política estadual de promoção da agroecologia neste estado. No Rio Grande do Sul, durante o Governo Sartori do então MDB (Movimento prioritário e há dúvidas sobre a continuidade da implementação dessa política a partir de 2020. A Secretaria de Desenvolvimento Rural (SDR) que abrigava as políticas para a agricultura familiar e agroecologia foi rebaixada à condição de subsecretaria no interior da Secretaria da Agricultura no novo governo. No Paraná, apesar de uma dinâmica pioneira de institucionalização da agroecologia a partir do final dos anos 2000, o governo Beto Richa do PSDB (20112018) não apoiou significativamente a agroecologia. Embora duas leis tenham sido sancionadas, os recursos financeiros para implementar as ações previstas eram quase inexistentes. Com o novo governo Ratinho Jr. (2019-2022) do PSD (Partido Social Democrático), a situação é ainda pior, sinalizando uma tendência clara de desestruturação das políticas. O governo propõe a extinção do Centro Paranaense de Referência em Agroecologia (CPRA) criado em 2004, única organização deste tipo no Brasil, reunindo pesquisadores e extensionistas. No estado de São Paulo, da gestão de João Dória (2019-2022) do PSDB, a transformação da Secretaria de Meio Ambiente (SMA) em uma subsecretaria subordinada à área de infraestrutura e a transferência de parte de suas atribuições à Secretaria de Agricultura e Abastecimento (SAA), também deixa dúvidas sobre o caminho futuro da pauta de agroecologia neste estado.

\section{Coalizões, redes e mobilizações}

Em muitos estados, a mobilização dos atores e a disseminação de ideias em favor da agroecologia no nível estadual foram, inicialmente, realizadas em espaços de debates de âmbito nacional, como os Encontros Anuais de Agroecologia (ENA) organizados desde 2002 ou os Congressos Brasileiros de Agroecologia (CBA), organizados desde 2003 no âmbito da Associação Brasileira de Agroecologia (ABA). Foi dentro desses espaços que se formaram as primeiras redes agroecológicas locais, muitas vezes ligadas à pesquisa e à extensão rural. A título de exemplos, podemos citar os marcos históricos pela institucionalização da agroecologia que foram o I Encontro Brasileiro de Agricultura Alternativa (EBAA) de $1981 \mathrm{em}$ Curitiba (PR) e o II EBAA ocorrido em 1984 em Petrópolis (RJ). 
Essa dinâmica de institucionalização da agroecologia também se fortaleceu nas grandes cidades, por meio da criação de movimentos de desenvolvimento da agricultura urbana e periurbana, como foi o caso no estado de São Paulo.

A partir da atuação política dessas redes estruturadas, várias atividades e manifestações contribuíram para disseminação mais ampla das ideias agroecológicas no nível subnacional, como por exemplo, a realização das caravanas agroecológicas, a organização de encontros estaduais de agroecologia, a sistematização e a troca de experiências agroecológicas, a criação de cursos e formações universitárias em agroecologia, a criação de feiras agroecológicas, que podem ser consideradas não apenas como espaços de vendas de produtos, mas também como espaços políticos de difusão das ideias agroecológicas, em particular nas cidades.

Posteriormente, a organização de seminários descentralizados sobre a PNAPO e o PLANAPO também teve uma função de mobilizar representantes políticos locais e, às vezes, estimulou a atividade parlamentar sobre a agroecologia, em particular a redação e/ou o apoio a projetos de lei sobre a agroecologia pelos deputados estaduais, como foi o caso no estado do Rio de Janeiro, em 2017, após o Seminário Regional de Agroecologia e Produção Orgânica da Região Sudeste.

Na maioria dos estados, houve uma transposição do processo de construção e disseminação das ideias agroecológicas em arenas institucionalizadas, onde os projetos de leis foram elaborados e/ou discutidos. Este é o caso do estado do Maranhão, no qual a minuta do projeto de lei de agroecologia foi discutida no Conselho Estadual de Desenvolvimento Rural Sustentável (CEDRUS). Em outros estados (PR, MG e RS), o CEDRAF desempenhou esse papel de construção participativa das PEAPOs. Em regra geral, as Comissões de Produção Orgânica (CPOrg), compostas por representantes de segmentos da rede de produção orgânica dos estados, não foram muito ativas na construção das PEAPOs. Todavia, em alguns casos (RS, PA, DF, PR e SP) os atores circulam entre a CPOrg e os espaços específicos dedicados à construção das PEAPOs.

A formação de "coalizões de causas" (SABATIER, 1988) em favor da agroecologia ocorreu dentro dessas arenas e três tipos de coalizões foram identificados:

- a) Coalizão ampla entre redes agroecológicas e de produção orgânica, organizações da agricultura familiar e gestores públicos (RS, PR, MG, SE, BA e SP); 
- b) Coalizãa ampla entre redes agroecológicas e de produção orgânica, organizações da agricultura familiar e gestores públicos, mas com grupos de interesses diferenciados dentro das coalizões (MA e DF). No caso do Maranhão, as ideias e valores sustentados pelas organizações ligadas à agricultura familiar (MST e sindicatos) se diferenciam daquelas do grupo de interesse histórico em favor da agroecologia representado pelo núcleo duro da RAMA, mas ambas as organizações se juntaram em uma única coalizão de causa. No $\mathrm{DF}$, as articulações a favor da agroecologia e os grupos de interesse da produção orgânica têm uma origem comum e fazem parte da mesma coalizão ampla que apoiou a PEAPO-DF, apesar de várias divergências de valores e de prioridade: os primeiros apoiam a capacitação nos assentamentos e atividades militantes de difusão das ideias agroecológicas (organização de seminários e criação de redes); os segundos privilegiam ações para a certificação e comercialização diferenciada de produtos orgânicos.

- c) Coalizões mais diferenciadas entre atores que apoiam uma representação da agroecologia que se aproxima da ecologização da agricultura convencional e até do chamado "agronegócio verde", bem como movimentos que defendem uma visão politizada da agroecologia (PA e AM). Apesar dessas visões bem diferenciadas, esses atores se reuniram em uma coalizão que enfrenta o agronegócio tradicional.

Certos estudos como aquele do DF (SABOURIN et al., 2019b nesse livro) e do Paraná (LAMINE et al., 2019 nesse livro) mobilizam uma caracterização dos atores em termos de redes de ação pública quando não existe ainda movimento social agroecológico estabilizado e estruturado. As redes dependem muito das conexões entre indivíduos, são informais, podem mostrar agilidade e eficiência para promover uma política pública como a PEAPO. Mas, precisamente porque a rede não depende de uma organização formal e as decisões de votos, a proposta final pode carecer de conteúdo renovador e amplamente debatidos com os principais atores que são os produtores e os consumidores. Isso foi o caso no DF onde a rede de ação pública atrás da formulação da PEAPO é majoritariamente composta de acadêmicos e gestores, funcionários do setor federal e distrital.

Do mesmo modo as avaliações parecem convergir no sentido de que, para a construção dos projetos de lei, as coalizões não colocavam em questão, pelo menos de uma forma aberta, temas mais delicados, relacionados aos grandes 
interesses do agronegócio e da mineração. No entanto, existem alguns fatores de desestabilização das coalizões. Três tipos de tensões foram identificados:

- a) Tensões ao respeito à comercialização. A comercialização diferenciada dos produtos é uma das questões que gera discordâncias entre os atores que querem desenvolver mercados orgânicos exclusivos (comercialização em nichos de mercados) e outros que são favoráveis a uma visão menos empresarial da comercialização, com maior foco na dimensão social e solidária das feiras. No Distrito Federal, por exemplo, foram observadas tensões entre as modalidades de comercialização no mercado orgânico, o qual foi criado dentro da Central de Abastecimento (CEASA). No Pará, um grupo de atores promove o acesso de alimentos saudáveis para toda sociedade, já outro grupo mais focado na promoção da agricultura orgânica defende uma perspectiva de produto de nicho. No Maranhão, alguns atores históricos da agroecologia criticam a iniciativa do estado, em parceria com os movimentos sociais a favor da agricultura familiar, de implementar um roteiro de feiras agroecológicas, pois alguns produtos não são agroecológicos, e as feiras são mais parecidas com feiras da agricultura familiar do que feiras "verdadeiramente" agroecológicas. Em virtude disso, encontramos outro roteiro de feiras agroecológicas no Maranhão, sustentado pela Associação Tijupá, que se fundamenta mais na economia solidária e na agroecologia.

- b) Tensões conceituais. Observam-se tensões entre dois grupos de interesses ligados à agricultura familiar sobre o conceito da agroecologia, pois o conceito tem sido apropriado por dois grupos de atores não necessariamente alinhados: de um lado, os produtores orgânicos num sistema de produção semelhante ao convencional e, de outro, um grupo representado pelos agricultores familiares que entendem a agroecologia como uma forma diferenciada de se relacionar com a terra, com a natureza e com o mundo, o que vai muito além de apenas abandonar o uso de defensivos e adubos químicos. Essa tensão se encontra de maneira mais ou menos expressiva em vários estados (AM, PA, RS e SP). As oposições e disputas pelo conceito de agroecologia observam-se, também, nas práticas agrícolas diferenciadas: por exemplo, alguns agricultores autorizam o uso do calcário e da mecanização, enquanto outros proíbem qualquer técnica associada à agricultura convencional. Essa linha de tensão também se exprime na maneira como cada grupo qualifica o outro, 
o primeiro acusando o segundo de se posicionar contra o progresso técnico e de promover uma visão radicalizada da agroecologia.

- c) Tensões de ordem orçamentária. Nos estados cuja política foi institucionalizada, isto geralmente ocorreu no período de crise das finanças públicas e de profundas transformações no campo político-institucional, que reduziram o suporte das políticas nacionais. No estado do Maranhão existe uma tensão latente com relação ao orçamento destinado a agroecologia, ainda que o governo do estado seja favorável ao tema e à agricultura familiar. No Rio Grande do Sul, a tensão entre os atores também é de ordem orçamentária, sobretudo a partir do momento em que o governo Sartori deixou de executar o repasse de recursos para as organizações de ATER da sociedade civil e cortou os recursos do fundo estadual (FEAPER) que subsidiava o Programa Estadual de Agricultura de Base Ecológica (PABE).

Apesar das características significativamente diferentes das coalizões, e da existência de vários eixos de tensões dentro delas, os pontos comuns observados nos estados estudados são a relativa estabilidade das coalizões e a ausência de coalizões abertamente contrárias à institucionalização das PEAPOs. Apenas nos estados do Pará, Paraná, Bahia e Minas Gerais, a sociedade civil, principalmente os movimentos sociais de promoção da agroecologia e da segurança alimentar e nutricional, encontraram certa oposição do governo, o qual tem fortes alianças com o agronegócio e os fornecedores de alimentação escolar.

\section{Governança e principais instrumentos das PEAPOs}

Poucos estados iniciaram as fases de formulação e de implementação de planos de ação estaduais de agroecologia (PLEAPOs), o que torna a análise da governança e dos instrumentos das políticas complexa e fragmentada. No Rio Grande do Sul, o PLEAPO-RS para o período 2016-2019 está em execução, porém possui uma dotação orçamentária insuficiente pois muitas ações provavelmente não serão finalizadas ou sequer iniciadas. Aliam-se a isso as muitas incertezas sobre a renovação do PLEAPO-RS em 2020 pelo novo governo estadual. O Programa Paraná Agroecológico contém um plano estadual anual, mas a perda de apoio político e os bloqueios na formalização de uma política estadual freiam a elaboração de um plano com metas detalhadas. Em Minas Gerais, o PLEAPO previsto na lei ainda não chegou a ser formalmente elaborado. Porém, existe um Plano de Ação da Estratégia 
Intersetorial de Redução do Uso de Agrotóxicos e Apoio à Agroecologia e à Produção Orgânica (PLANERA), em vigor no período 2018-2022. Em Sergipe, uma primeira versão do PLEAPO foi elaborada em 2018, mas o texto ainda não foi aprovado. Nos demais estados, os PLEAPOs estão em processos de discussão ou ainda não foram elaborados.

Quadro 1 - Diversas estruturas de governança das PEAPOS

\begin{tabular}{|c|c|c|c|c|c|}
\hline PR/2008 & RS/2014 & MG/2014 & SE/2018 & DF/2017 & MA/2018 \\
\hline $\begin{array}{l}\text { Câmara } \\
\text { Setorial } \\
\text { de Agroe- } \\
\text { cologia e } \\
\text { Agricultura } \\
\text { orgânica } \\
\text { dentro do } \\
\text { CEDRAF- } \\
\text {-PR }\end{array}$ & $\begin{array}{c}\text { Comitê ges- } \\
\text { tor paritário. } \\
24 \text { do } \\
\text { governo + } \\
24 \text { da socie- } \\
\text { dade civil, } \\
\text { a partir da } \\
\text { CTAGRO } \\
\text { (Câmara } \\
\text { Técnica } \\
\text { de Agroeco- } \\
\text { logia). }\end{array}$ & $\begin{array}{c}\text { Grupo } \\
\text { Temático } \\
\text { de Agroe- } \\
\text { cologia e } \\
\text { Produção } \\
\text { Orgânica } \\
\text { dentro do } \\
\text { CEDRAF- } \\
\text {-MG }\end{array}$ & $\begin{array}{c}\text { CEAPO-SE } \\
\text { (Comissão } \\
\text { Estadual de } \\
\text { Agroecolo- } \\
\text { gia e Produ- } \\
\text { ção Orgânica) } \\
\text { Participa- } \\
\text { ção pública } \\
\text { + RESEA } \\
\text { (e outros } \\
\text { movimen- } \\
\text { tos sociais, } \\
\text { economia } \\
\text { solidária, } \\
\text { produ- } \\
\text { ção orgâ- } \\
\text { nica). }\end{array}$ & $\begin{array}{c}\text { CAO-DF } \\
\text { (Câmara } \\
\text { Setorial de } \\
\text { Agroecologia } \\
\text { e Produ- } \\
\text { ção Orgâ- } \\
\text { nica). } \\
7 \text { do governo } \\
+7 \text { da socie- } \\
\text { dade civil }\end{array}$ & $\begin{array}{c}\text { Projeto de } \\
\text { Lei em Fev. } \\
\text { de } 2019 \\
\text { Para criar a } \\
\text { CEAPO-MA } \\
8 \text { do } \\
\text { governo + } 8 \\
\text { da socie- } \\
\text { dade civil }\end{array}$ \\
\hline
\end{tabular}

Fonte: autores

A respeito das estruturas de governança elaboradas para orientar, gerir e monitorar a implementação da PEAPO, nos onze estados estudados, observamos uma proximidade com o modelo federal da PNAPO construído em torno da CNAPO, com paridade entre 14 representantes da sociedade civil organizada e 14 dos poderes públicos federais. No entanto, enquanto alguns estados criaram um órgão paritário específico baseado nesse modelo, outros optaram por integrá-lo ao CEDRAF ou criar uma câmara setorial específica dentro deste conselho (Quadro 1).

A evolução da governança das PEAPOs, sobretudo após as recentes eleições em alguns estados federados, está caraterizada por diversas rupturas, com uma tendência crescente à recentralização da tomada de decisões. Em Minas Gerais, observamos uma desestruturação dos espaços de participação social. Com a extinção da SEDA, o CONDRAF-MG chegou a ser controlado pela Secretaria de Estado de Agricultura, Pecuária e Abastecimento (SEAPA-MG), formalizando uma retomada de controle da PEAPO pelas estruturas do poder público vinculadas ao agronegócio. No Paraná, em 2019, ocorreram a extinção do CPRA e uma fusão entre quatro organizações historicamente vinculadas à 
agroecologia, criando uma Agência de Desenvolvimento Rural sem garantia do tratamento da agroecologia. No Rio Grande do Sul, nota-se a retração da participação da sociedade civil, o que, em grande medida, tem a ver com a própria reestruturação do arranjo governamental, em particular a extinção de fundações e o rebaixamento institucional da SDR. Em parte, esse desmonte também se observa no estado de São Paulo, com a fusão das Secretarias de Meio Ambiente, Energia e Infraestrutura, além da mudança de atribuições e do organograma da SAA. Contudo, a discussão dentro do governo para a elaboração do texto de regulamentação da PEAPO-SP apresenta continuidade em 2019.

Em suma, nos estados onde a institucionalização das PEAPOs já era consolidada, a remoção das estruturas de governança paritárias e a colocação das PEAPOs, sob controle de um conselho ampliado desfavorável à agroecologia ou diretamente do poder executivo, sinalizam uma mudança profunda da governança. Passamos de uma governança participativa e policêntrica para um sistema mais vertical e centralizado, controlado pelos atores estatais (Figura 2).

Figura 2 - Modalidades de governança das PEAPOs pós-eleições nos estados onde já existem estruturas de governança das PEAPOs

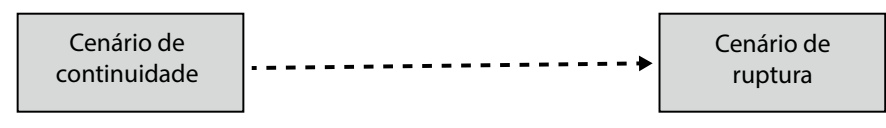

DF: CAO-DF paritária

MA: Projeto de lei para implementar CEAPO paritária

SE: CEAPO com participação ampla da Sociedade civil (além da RESEA)

PR: extinção do
CPRA e fusões de 4
organizações,
criando uma nova
Agência de
Desenvolvimento
Rural sem garantia
de priorização da
agroecologia

RS: esgotamento da participação da sociedade civil, e relativo esvaziamento do Comitê Gestor do PLEAPO
Horizontal

Público-privado

Participativo

Policêntrico
MG: extinção da SEDA e retomada de controle do CONDRAF pela Secretaria de Estado de Agricultura Pecuária e Abastecimento (SEAPA). Desestruturação dos espaços de participação social
Vertical

Público

Autoritário

Centralizado 
Com relação aos instrumentos de ação pública de promoção da agroecologia ou que dialogam com a agroecologia, a maioria foi construída no período anterior à formalização das PEAPOs, sendo, então, abrigados dentro dos PLEAPOs, mas geralmente de maneira desarticulada. Os instrumentos listados a seguir encontram-se em estágios diferentes em cada estado (discussão, planejamento ou já implementados, mesmo que em programas anteriores à criação da PEAPO). Podemos destacar quatro principais tipos de instrumentos mobilizados em todas as PEAPOs estudadas:

- a) Gestão do conhecimento agroecológico. Nessa categoria, identificamos instrumentos de pesquisa, treinamento, assistência técnica e extensão rural, com forte atuação dos Núcleos de Agroecologia (NEAs), e uma tendência ao fortalecimento de organizações e redes (Programa Ecoforte).

- b) Incentivos financeiros e fiscais. Focalizam, principalmente, programas específicos de crédito ao produtor com taxas reduzidas ou condições facilitadas, mas incluem, também, ferramentas para subsídios a organizações que prestam apoio aos agricultores agroecológicos (ONGs) e serviços técnicos de extensão (estatais e ONGs). Também existem instrumentos financeiros baseados no atendimento a condicionalidades ambientais como a Bolsa Verde ou outros Pagamentos por Serviços Ambientais (PSAs) ou Ecossistêmicos (PSEs).

- c) Comercialização. Vários instrumentos promovem a comercialização via criação de feiras específicas para facilitar a inserção dos produtos agroecológicos em mercados. Existem, ainda, os programas de compras públicas (merenda escolar, por exemplo), a valorização dos produtos com desenvolvimento de selos e informações ao consumidor, a promoção de "rodadas de negócios".

- d) Instrumentos regulatórios. Um leque bastante amplo de dispositivos regulatórios completa a lista de instrumentos de ação pública para promoção da agroecologia, haja vista, por exemplo, o enquadramento da certificação, as leis de sementes crioulas, as leis e políticas fundiárias (terras indígenas, quilombolas etc.), restrições ao uso do solo em regiões de mananciais.

Embora poucos instrumentos estejam realmente vinculados às PEAPOs, seja por causa dos gargalos na fase de implementação (RS e MG), seja porque 
as PEAPOs ainda não foram aprovadas ou estão recém-aprovadas (DF, BA, MA, PA e SP), existem vários instrumentos implementados contribuindo para institucionalizar a agroecologia no nível estadual, como os programas de capacitação de agricultores e de educação nas escolas rurais, as compras públicas para produtos agroecológicos e o apoio às feiras agroecológicas.

\section{Considerações finais}

A análise dos processos de construção das PEAPOs mostra a riqueza, a diversidade e a importância das experiências dos movimentos sociais com relação à agroecologia. Na maioria dos estados brasileiros, a atuação das redes estaduais de agroecologias levou à inclusão da questão agroecológica na agenda política, mas o nível de institucionalização varia consideravelmente em função das conjunturas políticas de cada estado.

As tensões existentes entre vários grupos dentro das coalizões em favor da agroecologia não impediram certa convergência das propostas agroecológicas com o objetivo comum de apoiar a transição para sistemas agrícolas mais sustentáveis e, na maioria dos casos, em virtude da necessidade de construir alternativas aos modelos dominantes de produção e consumo. Esses resultados ecoam outros trabalhos sobre a institucionalização da agroecologia realizados na escala federal (NIEDERLE et al., 2019a; SAMBUICHI et al., 2017).

Embora as coalizões agroecológicas não tenham encontrado forte oposição para aprovação de políticas estaduais para a agroecologia, a institucionalização destas enfrenta alguns obstáculos relacionados às mudanças recentes na trajetória política e institucional nos níveis federal e estadual. Nos estados pioneiros (PR, RS e MG), o processo de consolidação da agroecologia como categoria política é bloqueado ou revertido pela emergência de governos estaduais comprometidos com outros setores e projetos de agricultura. Por sua vez, onde a política agroecológica foi institucionalizada mais recentemente, a redução dos recursos financeiros fragiliza as coalizões e amplia as tensões latentes entre os atores dedicados à agroecologia e movimentos mais comprometidos com a agricultura familiar

Essa pesquisa na escala dos estados federados, embora exploratória, indica problemas nacionais e novas questões que mereceriam um aprofundamento e até estudos na escala dos territórios. Propomos três temas de investigação por serem, particularmente, problemáticos e característicos de tendências nacionais.

Primeiro, caberia entender melhor as dificuldades dos movimentos sociais da agroecologia e produção orgânica para conseguirem construir coalizões amplas e fortes de maneira estável. Os estudos nos estados mostram certo esgotamento ou pelo menos uma não renovação da narrativa e dos argumentos das organizações da agricultura familiar e camponesa (MATTEI, 2018; 
SABOURIN, 2018) o que, num quadro político e econômico hostil, configura uma situação pouco propícia para integrar novas dimensões e pressupostos (NIEDERLE et al., 2017). Reinventar ideário em relação ao poder do agronegócio e as políticas públicas maioritárias torna-se necessário. As narrativas das coalizões que levaram à institucionalização da PNAPO foram construídas pelos movimentos históricos vinculados à agricultura familiar a partir duma posição defensiva e de resistência contra a expansão do agronegócio. Uma pista de renovação das ideias e de constituição de coalizões amplas que nos parece interessante seria de construir uma narrativa proativa em favor da agroecologia, a partir dum sistema de valores ligados à proteção da saúde humana, à preservação do meio ambiente e na luta contra as mudanças climáticas, à inclusão social e à valorização da sociobiodiversiade. Tal renovação pressupõe uma aproximação maior com atores em favor da agroecologia que começam a se estruturar nas cidades tais como organizações de consumidores, comunidades que sustentam a agricultura (CSAs), movimentos de chefs, cozinheiros e outros atores em favor da alimentação sustentável como a organização SlowFood (GUÉNEAU et al., 2017).

Em segundo lugar trata-se de entender melhor os processos que explicam as iniciativas e resistências locais derradeiras. Pois, obviamente existem experiências inovadoras, mas elas pouco difundem e se expandem (SABOURIN; SAMPER, 2018) apesar da tese de uma mudança de escala natural e horizontal dos promotores da agroecologia (ALTIERI; NICHOLLS, 2012). Várias inovações políticas e organizacionais locais merecem ser acompanhadas e analisadas, pois elas poderiam ter um efeito de alavanca significativo sobre os processos de consolidação e continuação da institucionalização da agroecologia. A título de exemplo, podemos destacar duas inovações relevantes. A primeira trata das redes que tentam transformar a ação pública por meio do fortalecimento do vínculo direto entre o agricultor e o consumidor. Nesses últimos anos, observamos a multiplicação de iniciativas que visam o encurtamento das cadeias de distribuição de produtos de qualidade vindos da agroecologia, em particular por meio da multiplicação de CSAs nas grandes cidades brasileiras ${ }^{1}$. Essas redes, que pelo momento parecem mais iniciativas atomizadas, precisam ser estudadas para entender seu poder de difusão das ideias agroecológicas e de ampliação das coalizões de atores, incluindo um número crescente de consumidores. A segunda inovação que queremos destacar é aquela do MST que diante do desmantelamento total da política de reforma agrária, passou a auto assentar famílias transformando acampamentos em assentamentos populares (SAUER; MEZAROS, 2017; MST, 2017). Trata-se de fazer acontecer a reforma agrária legítima e necessária, como elemento 
de justiça social e de dignidade humana, sem esperar reconhecimento e apoio público. Corresponde a uma luta pela vida e pela sobrevivência, mas também pela segurança e soberania alimentar frente ao abandono público dessa categoria já extremamente precária e estigmatizada. Qual é a relação com a agroecologia? Precisamente os acampamentos e assentamentos do MST, entre outros, promovem a transição agroecológica, a partir de um intenso esforço de formação e capacitação, em escolas técnicas e centros universitários próprios, a exemplo da Escola Florestan Fernandes em Presidente Prudente (SP) ou da Escola Estadual do Campo Chico Mendes, localizada no Assentamento Vale da Conquista em Sobradinho na Bahia.

Finalmente, outro aspecto que deveria ser pesquisado de maneira aprofundada é a relação da agroecologia com a comercialização. Parte do movimento social agroecológico defende uma postura radical e purista de ruptura com o mercado capitalista. Em teoria e em condição de exercício do poder, seria certamente uma estratégia útil para a saúde e a sustentabilidade do planeta. Mas num contexto de marginalização e de hostilidade direta do sistema dominante, e atualmente de um governo predador e proto-fascista no Brasil, não pode ser a alternativa vencedora e generalizada. É necessário sair do impasse do purismo ideológico e considerar a necessidade de escoar grande quantidade de excedentes a partir de momento que uma família ou um grupo de mulheres, por exemplo, com uma horta coletiva, mesmo com uma produção modesta e vendida ao mesmo preço que os produtos convencionais, satura rapidamente os mercados "institucionais" locais (as feiras agroecológicas e as compra públicas dos governos). Isto foi demostrado pelo estudo de Pra et al. (2016) no Agreste da Borborema. Cabe avaliar melhor as reais possibilidades de venda e valorização diferenciadas, mostrando os atributos agroecológicos dos produtos a partir de sistemas de controle sociais como os Sistemas Participativos de Garantia (SPGs) (NIEDERLE; DORVILLE; LEMEILLEUR, 2019), e não se fechar apenas nas feiras e nas compras públicas do Estado. Por exemplo o acampamento Abril Vermelho, no perímetro irrigado do Salitre (Juazeiro-Bahia), com 400 famílias, se tornou o principal provedor em frutas e hortaliças irrigadas do Mercado do Produtor de Juazeiro, já que a produção empresarial é orientada em maioria para a exportação ou para as grandes capitais do Brasil (IRPAA, 2012).

Contudo, apesar dessas questões e dos obstáculos, em face dos retrocessos políticos e econômicos que se observam em âmbito nacional no que tange ao suporte à agricultura familiar e à agroecologia, é possível que alguns estados se tornem protagonistas na construção de alternativas ao desmonte federal. Ao que tudo indica nos próximos anos a institucionalização da agroecologia no Brasil dependerá cada vez mais do apoio e do comprometimento dos governos estaduais e, talvez, municipais. 


\section{REFERÊNCIAS}

ALTIERI M. A.; NICHOLLS C. I. Agroecology Scaling Up for Food Sovereignty and Resiliency. In: LICHTFOUSE, E. (Ed.). Sustainable Agriculture Reviews, Springer: Dordrecht, v. 11, 2012. doi: 10.1007/978-94-007-5449-2_1

BRASIL. Decreto $n^{0} 7.794$, de 20 de agosto de 2012. Institui a Política Nacional de Agroecologia e Produção Orgânica. Diário Oficial da República Federativa do Brasil, 2012.

CARNEIRO, M. et al. (Orgs.). 10 Anos Trabalhando pela Agroecológia. Belém: Gráfica Alves, Grupo de Assessoria em Agroecologia na Amazônia, 2004.

COSTA, M. AAO: Um pouco de história. Associação de Agricultura Orgânica. São Paulo. Disponível em: <http://aao.org.br/aao/quem-somos.php>. Acesso em: 18 maio 2019.

HASSENTEUFEL, P. Sociologie politique: 1'action publique. Paris: Armand Colin, 2011.

IRPAA. MST ocupa área da Empresa AGROVALE no Projeto Salitre em Juazeiro (BA), 2012, 17 abr. 2012. Disponível em: < https://irpaa.org/ noticias/433/mst-ocupa-area-da-empresa-agrovale-no-projeto-salitre-em-juazeiro-ba->. Acesso em: 20 maio 2019.

LAMINE, C. et al. A Evolução da Política de Agroecologia no Paraná (2008-2019): Avanços e recuos de uma trajetória pioneira, 2019, neste livro.

LASCOUMES, P.; LE GALÈS, P. Sociologia da Ação Pública. Maceió: EDUFAL, 2012a.

LOCH, V. D. C.; PACHECO, F. P. F.; LINDOSO, J. C. G.; ALVES, R. Os 19 Anos da Rede Agroecológica do Maranhão: contribuições e desafios. Cadernos de Agroecologia, v. 13, n. 1, 2018.

MATTEI, L. A política agrária e os retrocessos do governo Temer. OKARA: Geografia em debate, v. 12, n. 2, p. 293-307, 2018. 
MOVIMENTO DOS TRABALHADORESSEM TERRA- MST Resistência no semiárido: a luta pela terra nos perímetros irrigados. 2017. Disponível em: <http://www.mst.org.br/2017/10/20/resistencia-no-semiarido-a-luta-pela-terra-nos-perimetros-irrigados.html>. Acesso em: 20 maio 2019.

NIEDERLE, P. A. et al. A trajetória brasileira de construção de políticas públicas para a agroecologia. Redes, v. 24, n. 1, p. 270-291, 2019a.

NIEDERLE P. A. et al. Construção, institucionalização e implementação da política estadual de agroecologia e produção orgânica no Rio Grande do Sul, 2019b nesse livro.

NIEDERLE, P. A. et al. Narrative Disputes on Family Farming Public Policies in Brazil: Conservative Attacks and Civic Countermovements. In: CONFERENCE NEW EXTRACTIVISM PEASANTRIES AND SOCIAL DYNAMICS: CRITICAL PERSPECTIVES AND DEBATES 1:1-23. Moscow: BRICS Initiative in Critical Agrarian Studies, 2017. Acesso em 30 out. 2017.

NIEDERLE, P. A.; DORVILLE, C.; LEMEILLEUR, S. Estrutura e funcionamento dos Organismos Participativos de Avaliação da Conformidade Orgânica (OPACs) no Rio Grande do Sul. Relatório de pesquisa. CIRAD e UFRGS, 2019.

PRA, M. et al. Lógicas e estratégias de comercialização na agricultura familiar do Agreste da Paraíba. Estudos Sociedade e Agricultura, v. 24, n. 1, p. 5-27, 2016. Disponível em: <http://r1.ufrrj.br/esa/V2/ojs/index. $\mathrm{php} / \mathrm{esa} / \mathrm{article} / \mathrm{view} / 775>$. Acesso em: 20 maio 2019.

SABATIER, P. A. An advocacy coalition framework of policy change and the role of policy-oriented learning therein. Policy sciences, v. 21, n. 2-3, p. $129-168,1988$.

SABOURIN, E. Erosão, crise e desmonte de políticas para a agricultura familiar e agroecologia na América Latina. In: POLÍTICAS PÚBLICAS PARA O MEIO RURAL BRASILEIRO NO PERÍODO RECENTE: MUDANÇAS, CONTINUIDADES E RUPTURAS. Rio de Janeiro. Anais... Rio de Janeiro: UFRRJ/CPDA/OPPA, 2018. 
SABOURIN E.; SAMPER M. El escalamiento de experiencias y el rol de las políticas. In: SEMINARIO INTERNACIONAL: POLÍTICAS PÚBLICAS Y DESARROLLO RURAL EN AMÉRICA LATINA: BALANCE Y PERSPECTIVAS, Cali, Colombia, 5 -7 /09/2018, Red PP-AL \& CIAT. Disponível em: <https://www.pp-al.org/es/noticias/politicas-publicas-ydesarrollo-rural-en-america-latina-balance-y-perspectivas $>$. Acesso em: 20 maio 2019.

SABOURIN, E.; TADEU DA SILVA, L. R.; AVILA, M. L. A rede de ação pública em torno da agroecologia e produção orgânica no Distrito Federal. neste livro, 2019b.

SABOURIN, E.; TADEU DA SILVA, L. R.; AVILA, M. L. Construção da política de agroecologia e produção orgânica no Distrito Federal. Revista Brasileira de Agroecologia, 2019a. (No prelo).

SAMBUICHI, R. H. R. et al. Análise da construção da política nacional de agroecologia e produção orgânica no brasil. Brasília: IPEA, 2017.

SAUER, S.; MÉZSÁROS, G. The Political Economy of land struggle in Brazil under Workers' Party Governments. Journal of Agrarian Change, v. 17, p. 397-413, 2017.

SCHMITT, C. et al. La experiencia brasileña de construcción de políticas públicas en favor de la Agroecología. In: POLÍTICAS públicas a favor de la agroecología en América Latina y El Caribe. Porto Alegre: Criação Humana/Red PP-AL/FAO, 2017. p. 73-122. 


\section{SOBRE OS AUTORES}

\section{Alfio Brandenburg}

Professor, PPG em Sociologia, Universidade Federal do Paraná - UFPR. E-mail: alfiob@hotmail.com.br

\section{Alberto Bracagiolli Neto}

Professor do Programa de Pós-Graduação em Desenvolvimento Rural (PGDR) da Universidade Federal do Rio Grande do Sul. E-mail: abracagioli@gmail. com

\section{Camila Lago Braga}

Doutoranda do Programa de Pós-Graduação em Desenvolvimento Rural (PGDR) na Universidade Federal do Rio Grande do Sul (UFRGS), membro do Grupo de Estudos e Pesquisa Trabalho e Sociedade da Universidade Federal do Maranhão (UFMA).E-mail: camila.lago.braga@gmail.com

\section{Carlos Eduardo de Souza Leite}

Engenheiro agrônomo, Coordenador Geral do SASOP (Serviço de Assessoria a Organizações Populares Rurais). E-mail: caesleite@sasop.org

\section{Claire Lamine}

Socióloga, Institut National de la Recherche Agronomique - INRA Ecodéveloppement. E-mail: claire.lamine@inra.fr

\section{Claudia Job Schmitt}

Doutora em Sociologia, professora do Programa de Pós-Graduação de Ciências Sociais em Desenvolvimento, Agricultura e Sociedade (CPDA/UFRRJ) das Universidade Federal Rural do Rio de Janeiro (UFRRJ) e integrante da equipe do Observatório de Políticas Públicas para a Agricultura (OPPA). E-mail: claudia.js21@gmail.com

\section{Edson Diogo Tavares}

Agrônomo, Pesquisador do Centro EMBRAPA Tabuleiros costeiros. E-mail: edson.diogo@embrapa.br

\section{Eduardo de Lima Caldas}

Economista, doutor em ciência política e professor livre-docente da Universidade de São Paulo (USP). E-mail: eduardocaldas@usp.br; elcaldas@ hotmail.com 


\section{Eric Sabourin}

Sociólogo, pesquisador do CIRAD (Umr Art Dev) e professor visitante na Universidade de Brasília. E-mail: eric.sabourin@cirad.fr

\section{Evaristo José de Lima Neto}

Docente do Curso de Licenciatura em Ciências Humanas da Universidade Federal do Maranhão (UFMA)campus Bacabal, membro do Grupo de Estudos e Pesquisa Trabalho e Sociedade da UFMA. E-mail: ejlneto@gmail.com

\section{Flaviane de Carvalho Canavesi}

Professora da Faculdade de Agronomia e Medicina Veterinária da Universidade de Brasília. E-mail: flavianecanavesi@unb.br

\section{Gervásio Paulus}

Extensionista Rural da EMATER-RS/Ascar. E-mail: gpaulus@emater.tche.br

\section{Guilherme de Freitas Ewald Strauch}

Agrônomo, Superintendente da Superintendência de Desenvolvimento Sustentável/Secretaria Estadual de Agricultura do Rio de Janeiro. E-mail: gstrauch58@gmail.com

\section{Hueliton Pereira Azevedo}

Centro de Ciências Agrárias (CCA)/Universidade Federal de Santa Catarina (UFSC); Doutorando em Agroecossistemas; Pensamento sistêmico crítico aplicado ao planejamento de sistemas social-ecológicos. E-mail: huelitontuba@hotmail.com

\section{José Cleber Dias de Souza}

Fiscal Federal Agropecuário do Ministério da Agricultura, Pecuária e Abastecimento.E-mail: jose.cleber@agricultura.gov.br

\section{Julianna Colonna}

Gestora ambiental (EACH-USP) e mestranda em Ciência Ambiental (PROCAM-USP). Atua nas áreas de análise de políticas públicas, políticas de mudanças climáticas e agroecologia. E-mail: colonna.julianna@gmail.com

\section{Juliano Luís Palm}

Doutorando no Programa de Pós-Graduação de Ciências Sociais em Desenvolvimento, Agricultura e Sociedade - Universidade Federal Rural do Rio de Janeiro (CPDA/UFRRJ). E-mail: julianoluispalm@gmail.com 


\section{Luiz Raimundo Tadeu da Silva}

Universidade de Brasília (UnB) e Instituto Chico Mendes de Conservação da Biodiversidade (ICMBio). Mestre em Meio Ambiente e Desenvolvimento Rural com ênfase em Análise de Política Pública. E-mail: luizrtsilva@unb.br

\section{Marc Piraux}

Pesquisador do Cirad/UMR Tetis Montpellier, Professor na UFPA/INEAF, Belém. E-mail: marc.piraux@cirad.fr

\section{Margit Hauer}

Eng. Agrônoma, Doutora em Eng. Florestal, área de concentração Silvicultura/Agrossilvicultura, Instituto Ambiental do Paraná. E-mail: margith@iap. pr.gov.br

\section{Mario Lucio de Avila}

Doutor em Desenvolvimento Sustentável, Universidade de Brasília, PPG-Meio Ambiente e, Desenvolvimento Rural e Gestão Pública. E-mail: unbavila@, gmail.com

\section{Moacir Darolt}

Agrônomo, Instituto Agronômico do Paraná - IAPAR e Professor UFPR. E-mail: darolt@iapar.br

\section{Paulo Niederle}

Professor dos Programas de Pós-Graduação em Sociologia (PPGS) e Desenef volvimento Rural (PGDR) da Universidade Federal do Rio Grande do Sul. E-mail: pauloniederle@gmail.com

\section{Sabrina Milano Vaz}

Analista Agropecuária e Florestal da Secretaria da Agricultura, Pecuária e Desenvolvimento Rural do Rio Grande do Sul. E-mail: sabrina-vaz@seapdr. rs.gov.br

\section{Stéphane Guéneau}

Socioeconomista, Pesquisador do Cirad (UMR Moisa), Professor visitante no Programa de Pós-Graduação em Ciências Sociais (PPGCSoc) da Universidade Federal do Maranhão (UFMA) e Pesquisador Colaborador no Centro de desenvolvimento sustentável (CDS) da Universidade de Brasília (UnB-CDS). E-mail: stephane.gueneau@cirad.fr 


\section{William Santos de Assis}

Instituto Amazônico de Agricultura Familiar (INEAF)/ Universidade Federal do Pará (UFPA); Professor no INEAF/UFPA. E-mail: williamassis@ufpa.br

\section{Yamira Rodrigues de Souza Barbosa}

Engenheira agrônoma, doutoranda no Programa de Pós-Graduação de Ciências Sociais em Desenvolvimento, Agricultura e Sociedade (CPDA) da Universidade Federal Rural do Rio de Janeiro (UFRRJ).E-mail: yamira.rodrigues@ gmail.com 


$$
\mid
$$


SOBRE O LIVRO

Tiragem: 100 (Não comercializada)

Formato: $16 \times 23 \mathrm{~cm}$

Mancha: $12,3 \times 19,3 \mathrm{~cm}$

Tipologia: Times New Roman 11,5/12/16/18

Arial 7,5/8/9

Papel: Pólen $80 \mathrm{~g}$ (miolo)

Royal Supremo $250 \mathrm{~g}$ (capa) 